\title{
Experimental myocardial infarction : a proteomics point of view
}

Citation for published version (APA):

De Celle, T. (2005). Experimental myocardial infarction : a proteomics point of view. [Doctoral Thesis, Maastricht University]. Universiteit Maastricht. https://doi.org/10.26481/dis.20051207td

Document status and date:

Published: 01/01/2005

DOI:

10.26481/dis.20051207td

Document Version:

Publisher's PDF, also known as Version of record

\section{Please check the document version of this publication:}

- A submitted manuscript is the version of the article upon submission and before peer-review. There can be important differences between the submitted version and the official published version of record.

People interested in the research are advised to contact the author for the final version of the publication, or visit the DOI to the publisher's website.

- The final author version and the galley proof are versions of the publication after peer review.

- The final published version features the final layout of the paper including the volume, issue and page numbers.

Link to publication

\footnotetext{
General rights rights.

- You may freely distribute the URL identifying the publication in the public portal. please follow below link for the End User Agreement:

www.umlib.nl/taverne-license

Take down policy

If you believe that this document breaches copyright please contact us at:

repository@maastrichtuniversity.nl

providing details and we will investigate your claim.
}

Copyright and moral rights for the publications made accessible in the public portal are retained by the authors and/or other copyright owners and it is a condition of accessing publications that users recognise and abide by the legal requirements associated with these

- Users may download and print one copy of any publication from the public portal for the purpose of private study or research.

- You may not further distribute the material or use it for any profit-making activity or commercial gain

If the publication is distributed under the terms of Article $25 \mathrm{fa}$ of the Dutch Copyright Act, indicated by the "Taverne" license above, 


\section{Experimental Myocardial Infarction:}

A Proteomics Point of View 
Experimental Myocardial Infarction: A Proteomics Point of View

Thesis, Universiteit Maastricht, Maastricht, The Netherlands

ISBN-10: 90-9019992-6

ISBN-13: 9789090199924

(C) Tijl De Celle, Maastricht, 2005

Printed by Claes Printing

Cover designed by Bruno Vermeulen

No part of this book may be reproduced in any form without prior written permission from the author. 


\title{
Experimental Myocardial Infarction:
}

\author{
A Proteomics Point of View
}

\author{
PROEFSCHRIFT
}

ter verktijging van de graad van doctor aan de Universiteit Maastricht, op gezag van de Rector Magnificus, Prof. mr. G.P.M.F. Mols

volgens het besluit van het College van Decanen, in het openbaar te verdedigen

op woensdag 7 december 2005 om 16.00 uur

door

\section{Tijl De Celle}

geboren op 16 mei 1974 te Asse (Belgie) 


\section{Promotor:}

Prof. dr. J.F.M. Smits

Copromotor:

Dr. B.J.A. Janssen

Beoordelingscommissie:

Prof. dr. E.C.M. Mariman (voorzitter)

Prof. dr. W.A. Buurman

Prof. dr. H.J.G.M. Crijns

Prof. dr. M.J.A.P. Daemen

Prof. dr. D.J.G.M. Duncker (Universitair Medisch Centrum Rotterdam)

Financial support by Pfizer Belgium for the publication of this thesis is gratefully acknowledged. 


\section{Table of contents}

\section{ABBREVATIONS}

\section{CHAPTER 1}

General introduction.

CHAPTER 2

Long-term structural and functional consequences of cardiac ischaemia-reperfusion injury in viwo in mice

CHAPTER 3

Sustained protective effects of 7 -monohydroxyethylrutoside in an in wro model of cardiac ischaemia-reperfusion.

\section{CHAPTER 4}

In vwo protective effects of 7-monohydroxyethylrutoside in a mouse model of cardiac ischaemia-reperfusion are dependent on the time point of administration.

CHAPTER 5

Alterations in mouse cardiac proteome after in trino myocardial infarction: permanent ischaemia versus ischaemia-reperfusion

CHAPTER 6

Lack of effect of 7-monohydroxyethylrutoside on cardiac protein expression in an in wo mouse model of myocardial ischaemia-reperfusion as assessed by 2 -D gel electrophoresis.

CHAPTER 7

Summary and conclusions

CHAPTER 7

Samenvatting.

DANKWOORD 184

CURRICULUM VITAE \& LIST OF PUBLICATIONS 186 


\section{Abbreviations}

$A A R$ area at risk

ACE: angiotensin-converting enzyme

ADH: alcohol dehycrogenase

AK: adenylate kinase

AM(D)(T)P: adenosine mono-(di-)(tri-) phosphate

ANOVA: analysis of variance

$A W:$ anterior wall

AWTd(s): anterior wall thickness in diastole (systole)

AZAN: azocarmine anilineblue.

BPV: blood pressure variability

BrdU: 5-bromo-2-deoxyuridine

BW: body weight:

CHAPS: 3-(3-(cholamidopropyl)-dimethylammonio)-1-propanesulfonate

CID: collision-induced dissociation

COMT: catechol-O-methyltransferase

$\mathrm{C}(\mathrm{P}) \mathrm{K}$ : creatine (phospho) kinase

$C X$ : circumflex

DCM: dilated cardiomyopathy

2-DE: 2-dimensional gel electrophoresis

DIGE: 2-D difference gel electrophoresis

DMTU: dimethythiourea

DNA: deoxyribonucleic acid

DP: developed pressure

DSP: dual specificity phosphatase

D'T T: dithiothreitol

Iic: extracellular

ECG. clektrocardiogram

EDP: end diastolic pressure

ED (S) V: end diastolic (systolic) volume

EF: ejection fraction

ER: endoplasmic reticulum

ESI: electrospray ionisation

$\mathrm{FADH}_{2}$ : flavin adenine dinucleotide, reduced form

FS: fractional shortening

GAPDH: glyceraldehyde phosphate dehydrogenase

dGM(T)P: dihydroxyguanosine mono(tri)phosphate

GSH: reduced glutathione 
GSK: glycogen synthase kinase

GR: glutathione reductase

GSSG: oxidized glutathione

HIF: hypoxia inducible factor

Hint: histidine triad nucleotide binding protein

HNE: hydroxynonenal

hnRNP: heterogeneous nuclear ribonucleoprotein

HPLC: high performance liquid chromatography

HR(V): heart rate (variability)

HSA: human serum albumin

HSP: heat shock protein

ICAM: intracellular adhesion molecule

IEF: isoelectric focusing

i.m.: intramuscularly

IPG: immobilised pH gradients

i.p.: intraperitoneally

IR: ischaemia-reperfusion

IS: infarct size

ISLAND: Infarct Size Limitation: Acute $\mathrm{N}$-acetylcyteine Defense

i.v.: intravenously

JNK: jun-kinase

LA: left atrium

LAD: left anterior descending coronary artery

LC: liquid chromatography

LDH: lactate dehydrogenase

LDL: low density lipoprotein

LOX: lipoxygenase

LVAd(s): left ventricular area in diastole (systole)

LV ((E)D $(S) P)$ : left ventricle ((end) diastolic (systolic) pressure)

LVIDd(s): left ventricular internal cavity diameter in diastole (systole)

LW: lung weight

MALDI: matrix assisted laser desorption ionisation

MAP: mean arterial pressure

5-MCA-NAT: 5-methoxy-carbonylamino- $\mathrm{N}$-acetyl-tryptamine

MCP: monocyte chemoattractant protein

MDA: malondialdehyde

MHC: myosin heavy chain

MI: myocardial infarction

MIP: macrophage inflammatory protein

MLC: myosin-tegulatory light chain 
MMP: matrix metalloproteinase

monoHER: 7-monohydroxyethylrutoside

MPG: N-(2-metcaptopropionyl)-glycine

MPO: myeloperoxidase

$\mathrm{M}_{\mathrm{r}}$ : molecular weight

MS: mass spectrometry

MS/MS: tandem mass spectrometry

NAC: N-acetylcysteine

NAD(P): nicotinamide adenine dinucleoticle (phosphate)

NCBI: National Center for Biotechnology Information

$N F \circ K B$ : nuclear factor- $K B$

$(\mathrm{e}-) /(\mathrm{h}-) /(\mathrm{i}-) /(\mathrm{mt}-) /(\mathrm{n}-) \mathrm{NO}(\mathrm{S})$ : (endothelial-)/(human-) (inducible-) $/$ (mitochondrial-)

nitric oxide (synthase)

PDH: pyruvate dehydrogenase

$\mathrm{PE}(\mathrm{G})$ : polyethylene glycol

PARP: poly-(ADP-ribose) polymerase

PI: permanent ischaemia

pI: isoelectric point

PKC: protein kinase-C

PMN: polymorphonuclear neutrophils

PTCA: percutaneous transluminal coronary angioplasty

PT'M: post translational modifications

PUFA: poly unsaturated fatty acids

PW: posterior wall

PWTd(s): posterior wall thickness in diastole (systole)

(m)RNA: (messenger) ribonucleic acid

ROS: reactive oxygen species

RPP: rate pressure product

SAP: serum amyloid $\mathrm{P}$-component precursor

s.c.: subcutaneously

$\mathrm{SD}$ : standard deviation

SDS(-PAGE): sodium dodecyl sulphate (-polyacrylamide gel electrophoresis)

S.E.M.: standard error of mean

(ec-)(h-)/(r-)SOD: (extracellular-) (human-)/(recombinant-) superoxide dismutase

SV: stroke volume

TAC: transverse aortic constriction

TFA: trifluoracetate

TTMP: tissue inhibitor matrix metalloproteinase

(c) Tn: (cardiac) troponin

TOF: time of flight 
PA: tissue plasminogen activator TTC: triphenyltetrazoliumchloride

TUNEL: terminal transferase dUTP (deoxyuridine triphosphate) nick-end labeling

UCH: ubiquitin carboxyl-terminal hydrolase

VCAM: vascular cell adthesion molecule

VW: ventricular weight

Wht: Wint 
General introduction *

Chapter 1

\section{General introduction}


The gencral introduction of this thesis is divided into four separate parts. The first part discusses the structural and functional adaptations of the heart after myocardial infarction in the mouse (published in the handbook "The Physiological Genomics of the Crutically II] Mouse" [1]). In the second part the focus will be on oxidative stress and antioxidant therapy related to cardiac ischaemia and reperfusion. In the third part, the application of proteonics particularly in the field of cardiovascular research will be discussed. Finally, in the fourth part, the aims of the present thesis are outlined.

\section{Structural and functional adaptations of the heart after coronary artery ligation in the mouse}

\subsection{Introduction}

Despite advances in the treatment of myocardial infarction (MI), congestive heart failure secondary to infarction continues to be a major complication. In Western societies beart failure is becoming a pandemic disease for which the current treatment is still symptomatic rather than curative [2]. Developing an effective therapy for heart failure is a challenging assignment for many research groups. Mouse models are increasingly used in this research quest, because modification of the genome is relatively easier than in any other mammal. However, due to the small size of the mouse, many techniques had to be scaled down and refined. In the past 5 years, this process has been largely concluded. Sophisticated tools, including non-invasive echocardiography $[3-10]$ and magnetic resonance imaging $[11,12]$ are available now to cxamine the molecular mechanisms underlying heart failure in mouse models or to test the efficacy of novel interventions.

With exception of some inbred strains $[13,14]$, mouse strains do not devellop heart failure spontaneously. Murine cardiac dysfunction is usually experimentally induced by toxic or pharmacological agents $[15,16]$, viral infections [17], surgical interventions [18], and genetic modifications. In these genetic models one or more genes that are crucial for cardiac performance are distupted [19-21]. Alternatively, cardiac function is altered by overexpressing genes that are placed under control of cardiac specific promoters $[15,22]$. There is a variable degree to which these generic models retlect the pathogenesis and pathophysiological characteristics of human heat failure. Some interfere dramatically with cardiac growth and development and cause the death of the animal in wher or soon after birth. In other models the genetic modification does not lead to any obvious cardinc malfunctioning under nomal conditions. However, cardiac dysfunction becomes apparent when the heart is challenged to increase its work load $[23,24]$. Cardiac stress is often imposed by a surgical procedure in which the aortic arch between the carotid arteries is narrowed, the so-called TAC (transverse aortic constriction) procedure. The progression of left ventricular hypertrophy following TAC has been described in detail by Liao et al. [5]. However the TAC model is only to a minor extent associated with cardiac ischaemia. To mimic the predominant ischaemic nature of human heart failure, many research groups make use of the so-called MI (myocardial infarction) model. In this model 
ischaemia is induced by permanent ligation of the left anterior descending (1.AD) coronary artery of the mouse heart.

The aim of this section is to describe some general and technical aspects of the development of the mouse MI model (section 1.2.). In addition, we will summarize the structural and functional changes that occur over time after ligation of the LAD in the mouse (section 1.3. and 1.4.). Finally it is discussed to which extent this mouse MI model is suitable for studying heart fallate in humans (section 1.5.).

\subsection{General and technical aspects}

To our knowledge the mouse MI model has been clescribed first by Kogan et al in 1977 [25]. In this paper the authors describe also the TAC procedure as well as the banding of the apex of the heart to produce cardiac aneurysms. Because the paper is written in the Russian language and the mouse model was not popular at that time, this publication did not receive much attention. Ten years later Japanese researchers reported the occurrence of spontaneous infarctions in male Fl hybrid mice of the NZW $\times$ BXSB strain $[13,14]$. The incidence of spontaneous MI was $45 \%$ at the age of 24 weeks and in a few cases dilated cardiomyopathy was observed. However, in such affected animals, the infarct size was generally smaller than $10 \%$ of the ventricular area. As we will discuss later, the size of the infarcted area is probably too small to affect cardiac output and the development of obvious heatt failure. This particular mouse model proved to be lupus-prone and is currently used to study the involvement of auto-immune factors in this disease.

Paralleling developments in genomic research, the mouse MI model was rediscovered in the early nineties and in 1993 the first non-invasive echocardiographic description of murine cardiac function following MI appeared [6]. From then on the number of publications on this model has been ever increasing, rendering about 200 publications in the year 2004. (To achieve the latter number PubMed was searched using the lkeywords "myocardial ischaemia" or "myocardial infarction" and (mice or mouse)). About $2 / 3$ of the studies that make use of this model focussed on mechanisms of ischaemia-reperfusion, while about $1 / 3$ examined cardiac remodelling following permanent occlusion of the LAD.

Figure 1 depicts the in vito murine coronary vasculature after loading the blood with a fluotochrome. Both the LAD and circumflex (CX) are clearly visible. When the thoracic cavity is opened one can usually, under microscopic view, identify the LAD on the anterior epicardial side. "The branching point of the $L A D$ and $C X$ arteries, however, is not directly visible because it is mostly covered by the left atrium. In our experience mice do not survive the coronary occlusion when the ligature is placed too high and includes both the $I A D$ and $C X$. When the $\triangle A D$ is ligated below the location where the $\mathrm{CX}$ branches, the average survival rate is about $60-70 \%$.

In our experience the outcome of the surgical intervention does not depend upon the type of anaesthesia that is used. We have performed the ligation of the U.AD under pentobarbital $[18,20,26]$, ketamine/xylazine $[23,26]$, or isoflurane. 
- Chapteri: 1

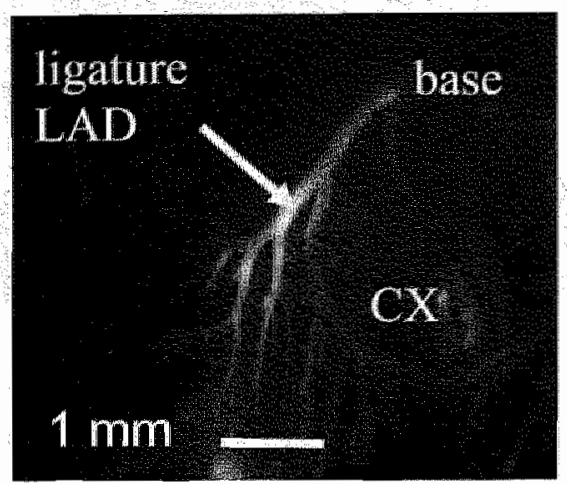

Figure 1: Photograph of the coronary arteries of a mouse heart after injection of a fluorochrome.

The left anterior descending (LAD) and circumflex (CX) are indicated. Myocardial infarction is induced by ligation of the I.AD under its branching point with the CX artery.

Following the surgical intervention under isoflurane, mice wake up within minutes after the volatile anaesthetic is withdrawn. With pentobarbital, mice may remain sedated for prolonged periods (up to 3-4 hours). Genetally, the recovery from surgery improves when the anaesthetic period is kept to a minimum. However, in this particular case, the prolonged sedative period may prevent the occurrence of cardiac arrhythmias or othet complications that may arise from this intervention. After surgery mice are kept for 24 hours in a special recovery room with the ambient temperature set at $30^{\circ} \mathrm{C}$. They are inspected regularly and positive pressure respiration is applied if necessary. When needed additional oxygen is added and a two-lead surface ECG is made for continuous inspection. In our hands, i.v. injection of local anaesthetics such as lidocaine does not seem to improve survival. Analgaesic agents such as buprenorphine should be administered with care after coronary artery ligation. In our experience, s.c. injections of buprenorphine (at recommended doses of 2 $\mathrm{mg} / \mathrm{kg}$ ) at the time the mice are still deeply anaesthetized, depresses breathing, worsens their condition and decreases survival tate. Therefore additional analgaesic treatment is started when mice begin awaking from anaesthesia.

When the $L A D$ is ligated at the indicated place about $40-60 \%$ of the left ventricular area becomes ischaemic. If reperfusion follows after 30 minutes of ischaemia, part of the area at risk (AAR) will recover spontaneously. However, about $20 \%$ of the left ventricular area is affected chronically [27]. The longer the ischaemic period, the larger the infarcted area will become, reaching up to $50 \%$ of the left ventricle following permanent ischaemia. In ischaemia-reperfusion protocols, the infarct size is not only dependent upon the architecture of the coronaty arteries and duration of the ischaemic period, but also upon many experimental factors. One of these is body temperature. If body temperature is not mantained during surgery the hypothermia may protect against ischaemic damage and remaining infarct sizes will be much smaller [28]. Besides temperature, many more factors have been described that act as a preconditioning factor and limit infarct size [29]. 


\subsection{Structural and histological aspects}

An acute occlusion of a mouse coronary artery leads to rapid apoptosis and necrosis in the infarcted part of the heart [30]. This evokes a wound healing process which starts with an early inflammatory response, in which neutrophylic granulocytes migrate into the infarcted area [27]. Hence, the inflammatory response is followed by the formation of granulation tissue, which is rich in inflammatory cells, (myo-) fibroblasts and small blood vessels [19]. This process starts at the border zone of the infarcted area as early as 3 days after MI and is associated with an increase of DNA synthesis, measured as nuclear BrdU incorporation. The enhanced DNA synthesis is mainly detected in non-myocytes $(>90 \%)$ and occurs also in non-infarcted areas [18]. During the first two weeks of the wound healing process, cells from the granulation tissue migrate into the infarcted area where necrotic debris is removed by macrophages and replaced by (myo-) fibroblasts and blood vessels. Eventually, the granulation tissue matures into a scar, a process characterized by extensive extracellular matrix deposition and significant cell loss. Enhanced collagen disposition has also been demonstrated in the non-infarcted area $[18,20]$. In contrast to the content of the final scar that develops after a dermal wound, the intriguing feature of a cardiac scar is that it still contains myofibroblasts even years after MI [31], possibly to cope with the rhythmic stretch to which the scar is subjected.

The phenotypic result of the wound healing process is depicted in figure 2. Representative sections through murine hearts are shown in comparison to a noninfarcted heart (panel A) to illustrate the gross histological remodelling of the heart at 7 (panel B) and 14 (panel C) days after MI. Note that the infarcts are transmural, located mainly antero-apically and that the septum and right ventricle are spared [18, $32]$.

A

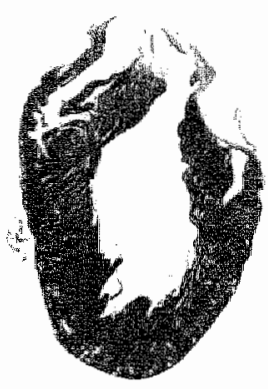

B

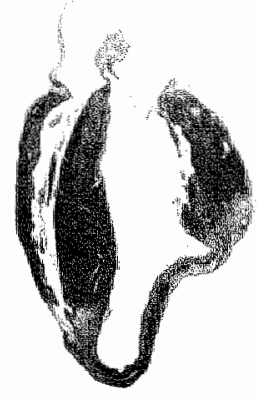

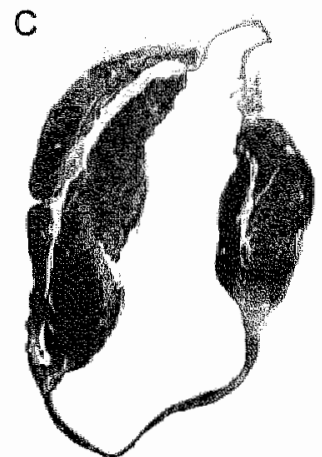

Figure 2: Histological sections of a murine hearts. Panel A shows a non-intarcted control heart. Panel B and $C$ are sections taken 7 and 14 days after ligation of the left anterior elescending coronary artery, respectively. Note that during the renodelling process the left wentricular cavity dilates progressively and the spared myocardium hypertrophies. This process is associated with remarkable thinning of the infarcted area. The histological changes are explained in more detall in the text. 


\section{- Chaprer 1}

The remodelling of the heart leads to enlargement of the left ventricular volume and thickening of the remaining healthy rissue, which is alleady visible at two weeks after MI. Septal mass was found to be linearly related to the expansion ratio defined as the length of thinned ventricular wall divided by the total endocardial surface [32]. As indicated by echocardiographic measurements the dilatation is nearly completed at 4 weeks fter MI 33,34$]$ but additional dilatation can occur at later stages [3].

The study of the process of infarct healing in animal models allows the monitoring of the effects of either genetic or pharmacological interventions. This has yielded new information regarding the role of matrix metalloproteinases (MMPs), which are involwed in the degradation of the preexisting extracellular matrix scaffold and in the migration of the cells into the area of infarction. MMPs form a large family of endoproteinases that can degrade components of the extracellular matrix. Their activity is fine-runed by endogenous inhibitors, the so-called tissue inhibitors of metalloproteinases (TTMPs). MMPs are present in the normal heart but mainly in their latent form, and are activated in pathological conditions by proteolytic cleavage. The most potent activator of MMPs is plasmin, the activated form of plasminogen. The generation of plasmin is controlled by the balance between plasminogen activators and plasminogen activator inhibitors [24].

Several studies have demonstrated the importance of the plasminogen system in infarct healing. In mice lacking the plasminogen gene, infarct healing was virtually abolished. Inflammatory cells were found to be unable to migrate into the infarcted myocardium and no dilatation of the infarct area was observed. The gelatinolytic activity of MMP-2 and MMP-9 was depressed in the plasminogen-deficient hearts, suggesting a role of MMPs in this remarkable model [35]. Impaired cardiac healing after MI was also observed in mice lacking urokinase plasminogen activator [36]. Creemers et al. found that in mice deficient for TIMP-1 infarct dilatation was augmented and associated with a pronounced hypertrophic response of the viable myocardium [20]. Together, these observations underscore the importance of a balanced activation of the MMP system during infarct healing.

Another aspect of infarct healing that so far has received little attention is the control of cell migration in both space and time, the so-called architectural control of infarct healing. We have identified members of the Wht/frizzled signal transduction system, known to be involved in the architectural control of the developing Drosophila, to be overexpressed during infarct healing. The overexpression of the Frizzled-2 turned out to be confined to the phase of infarct healing where cells migrate in the infarcted area and align parallel with the epi- and endocardial plane. In contrast, no frizzled 2 expression was observed in stationary myofibroblasts [37]. In the mean time, we have observed attenuated infarct healing in mice that were immunized with a peptide fragment of the frizzled-2 receptor [38]. Moreover, overexpression of a soluble frizzled-related protein, which can act as a scavenger for Wnt protein ligands, reduced infarct size and improved cardiac function after MI [39]. Recent data indicate that overexpression of the enzyme glycogen synthase kinase 3- $\beta$ (GSK3-B), involved in the intracellular signaling of frizzled-receptors, can inhibit the development of cardiac hypertroplyy [15]. Finally, the involvement of the $\mathrm{W} / \mathrm{nt} / \mathrm{frizzled}$ signaling 
transduction system in the neovascularization of the infarcted area has been suggested 40].

The combined findings of these studies suggest a functional role for the Wnt frizzled cascade in diverse aspects of cardiac remodelling after $\mathrm{MI}$.

\subsection{Physiological aspects}

Myocardial function has been examined at several time points after infarction using a variety of methods. The findings of these physiological measurements are largely in agreement with what would be expected on the basis of the cardiac structures as depicted in figure 2. Using myocardial contrast echocardiography, hypo- and akinetic ventricular wall segments can aiready be demonstrated at $30 \mathrm{~min}$ and $24 \mathrm{~h}$ after MI and are associated with a reduction of the fractional shortening from 45 to $24 \%[8,9]$. The magnitude of this effect (of permanent ligation) is comparable to values induced by $30 \mathrm{~min}$ of cardiac ischaemia (and $24 \mathrm{~h}$ reperfusion) [11, 41]. Scherrer-Crosbie at al. found that LV dimensions were already enlarged 24 h after MI when compared to values before surgery. End-diastolic volumes increased from 24 to $33 \mu \mathrm{l}$ and endsystolic volumes from 10 to $24 \mu \mathrm{l}[8]$. Thus, it is not surprising that derived parameters such as stroke volume, ejection fraction, and cardiac output are considerably reduced early after MI $[32,42]$. Later after MI when wound healing progresses, cardiac function may somewhat recover. Probably due to dilation of the left ventricle and hypertrophy of the remaining viable cardiomyocytes, stroke volume and cardivic inotropy may somewhat recover. In this tespect, Michael of at found that 2 woeks after MI the dectease in ejection fraction was only $25 \%$ whereas the initial decline was $47 \%$ [32]. Four weelss after MI and later, when the dilatation process is more or less completed, cardiac function assessed serially by echocardiography remains however depressed $[3,33,34]$. Values on remaining cardiac function vary considerably. Six weeks after MI or later, the observed decline in fractional shortening ranged from 30 $\%[7]$ to $50 \%$ [33] or even more. Reduction in ejection fractions up to $75 \%$ of preoperative values have been reported too [34]. As recently demonstrated part of this variation may be strain- [43] and age-dependent [44].

Functional measurements do not always parallel the histopathological observations after MII in the mouse. For instance Creemers at al. found that, despite a $42 \%$ infarct size, the ejection fraction was not reduced 2 weeks after MI [20]. Among the explanations that were given was the remark that the MI procedure may also affect the papillary muscle and lead to mitral regurgitation, which would cause a pseudonormalization of the left ventricular ejection fraction. The incidence of this phenomenon, however, is currently unknown and should be verified by ultrasound Doppler measurements. In our experience, as verified from histological sections, papillary muscles are largely preserved. In a recent paper, Nemoto et al suggested that pressute volume loops are among the most sensitive methods to document small changes in left ventricular function in mice [45]. In our lab we found that 1 and 3 weeks after MI left ventricular systolic pressure and pressure development ( $t \mathrm{dP} / \mathrm{dt}$ ) as measured under basal conditions were reduced by $20-30 \%$ |18. However, such a reduction in baseline $+\mathrm{dP} / \mathrm{dt}$ is not consistently found. In some studies that were 
conducted in our lab the difference in pressure development became discernible only during stimulation of the heart either with dobutamine or during volume loading 20 , 23]. On the one hand, these observations suggest that the mouse heart is apt to compensating large infarcts under basal conditions but fails when it is challenged to increase its working load. On the other hand variations in experimental conditions and variations in genetic background may contribute to the divergent degrees of cardiac dysfunction that are observed in mice.

Although direct left ventricular pressure and volume measurements may belong to the most sensitive techniques that are available, they have the disadvantage that they can only be performed once (teminal measurement) and require the use of anaesthetics. To overcome these hampering factors, we have pursued and validated the feasibility of chronic cardiac output measurements in conscious mice. Using electromagnetic as well as transit time flow probes, which are chronically implanted around the ascending aorta, we are able now to measure ascending aortic blood flow in conscious conditions over prolonged periods of time [26]. For skilled surgeons, the success rate of the procedure is about $70 \%$ in controj mice. After MI the success rate is lower and seems to depend more on the physical condition of the mouse rather than on technical aspects. Thus, as is applicable for any intervention after MI, the procedure is associated with some bias towards eliminating mice in which cardiac function is inferior.

Despite this we were able to demonstrate that ascending aortic blood flow was reduced after $\mathrm{MT}$ in the mouse. As excmplified in figure 3, peak aortic blood flow reached up to $100 \mathrm{ml} / \mathrm{min}$ in an adult intact mouse, but was severely depressed after MI. Neglecting cotonary blood. flow, the average basal stroke volume determined as the average aortic blood flow per beat, was significantly reduced (in sham-operated mice: $31 \pm 7 \mu l$ versus $25 \pm 4 \mu$ after $M T$, values are means $\pm S D$, see (260). Because heart rates were not altered after infarction, average diffetences in basal cardiac output paralleled those of stroke volume, being $20 \pm 4 \mathrm{ml} / \mathrm{min}$ in sham-operated and $16 \pm 3$ $\mathrm{ml} / \mathrm{min}$ in MI mice (means $\pm S D$ ). Cardiac work can be increased in conscious mice by volume loading. This is accomplished by constructing a Frank-Starling curve by rapidly infusing i.v. a wamed Ringer's solution $(2.5 \mathrm{ml} / \mathrm{min}$ during one minute), thereby doubling the blood volume of the mouse [46]. As shown in figure 3 , this results in a rise in peak and average anotic blood flow.

The average increase in stroke volume was significantly $(P=0.03)$ greater in sham operated than in $\mathrm{MI}$ mice $(10.4 \pm 4.5 \mu]$ versus $6.1 \pm 3.5 \mu \mathrm{l}$, see $[26]$ ). Surptisingly, heart tate does not increase with volume loading in mice. In the given example even a small reduction is observed, suggesting that the Bainbridge reflex does not play a dominant role in this condition. An alternative method to stimulate cardiac output in conscious mice is the i.v. infusion of dobutamine. Using this tool we observed that heart rate rather than stroke volume increased 146]. At high heart rates above 600 beats/min filling times are probably rate limiting. Georgakoupolus ot al demonstrated recently that end-diastolic volumes declined with increasing heart rates 147 . From these observations we learn that the mouse, at least in comparison to humans, who can increase cardiac output by a factor 4 , has a limited cardiac reserve $(+30 \%$ to $50 \%)$. 
Yet, whth the chronically implanted How probes, reductions in stroke rolume and cardiac output due to MI can be measured relably.

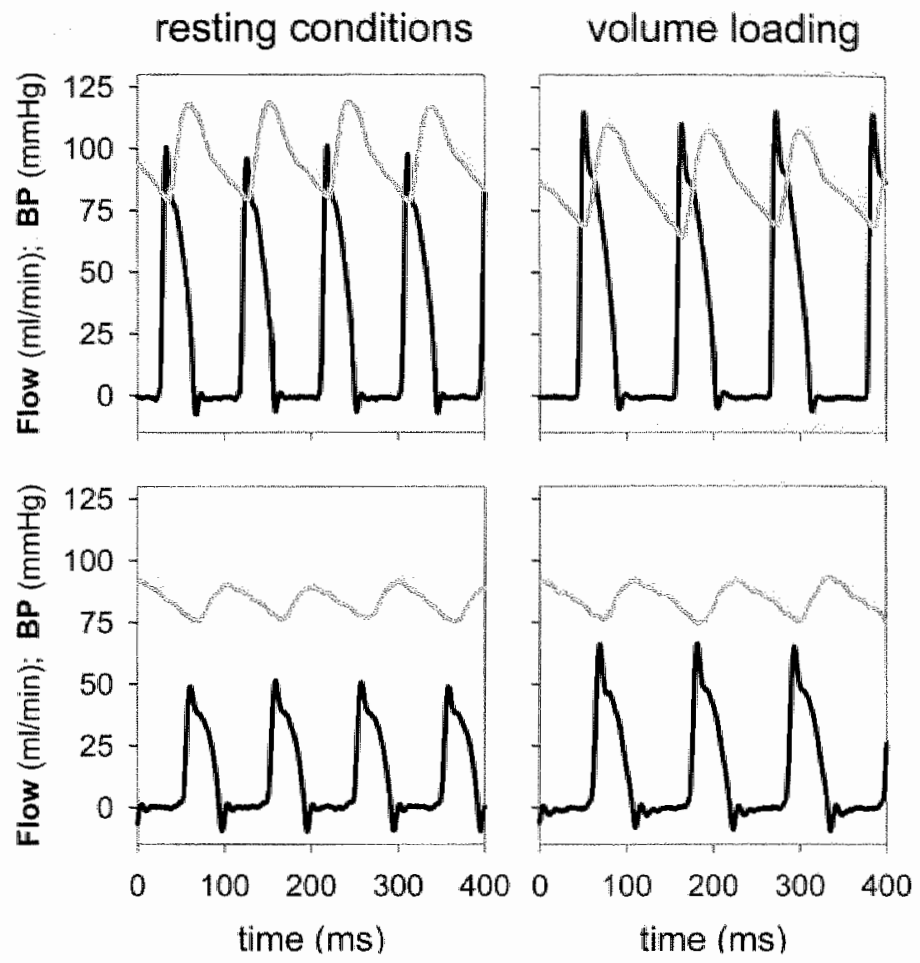

Figure 3: Original tracings of ascending aortic blood flow (thick line) and arterial blood pressure (thin line) in conscious unrestrained mice. The upper two panels show tracings obtained in a control mouse under basic (resting, not moving) as well as stimulated (volume loading) conditions. In the lower two panels the tracings are shown as obtained in a mouse, 5 weeks after M1. Note that average and peak aortic blood flows are reduced in comparison to the control mouse. More detalls atre given in the text.

\subsection{Does the mouse MI model reflect human heart failure?}

The above mentioned studies clearly demonstrate that the mouse MI model is suitable to study molecular alterations involved in cardiac remodelling and left ventricular dysfunction after ischaemic damage. But, does the MI mouse model reflect human heart failure? For this, in our view, the physiological derangement should include more than left ventricular dysfunction only. However, in our experience relevant characteristics such as congestion and cachexia are only observed occasionally after MI in the mouse and exercise intolerance is difficult to measure. In many studies lung and liver weights after MI are not given or were reported to be unaltered $[3,33,34]$. This suggests that the mouse seems to tolerate a reduced cardiac output over prolonged periods of time. One of the explanations may be that mice are able to 
reduce metabolic tate and slip into a torpor-like state to preserve energy during the day. This adaptive mechanism is evoked in mice when homeostasis is threatened by fasting or cold exposure [48] and is associated with very low heart rates $(<200 / \mathrm{min})$ and decreased oxygen consumption. It may be that after MI, mice are more prone to go into such atate of hibernation preserving energy for the remaining periods of activity. Jong-term telemetric studies are necessary to validate this hypothesis.

Recently, Gould ot al. showed that age is an important factor [44]. In most studies MI is induced in relatively young $(2-4$ months old $)$ mice. However, when coronaty artery ligation was performed in 14 months old mice, death rate during a 60 days follow-up period was dramatically higher. Only 9 out of 25 of these older mice survived this follow up period, despite the obserwation that infarct size was smaller (18 $\%$ ) than in young (28\%) mice. These observations suggest that additional factors than only left ventricular dysfunction play an important role. The extent of neurohumoral activation as judged from plasma hormones or direct sympathetic nerve measurements is positively correlated to the degree of heart failure in humans. In mice, however, due to the limited volume of blood, neutohormones can not be determined repeatedly after MI. To circumvent this problem we have examined potential alterations in blood pressure variability (BPV) and heart rate variability (HRV) after $\mathrm{MI}$ in the mouse. We and others recently validated that also in mice frequency-dependent changes in BPV and $\mathrm{HRV}$ are related to altered autonomic control $[49,50]$.
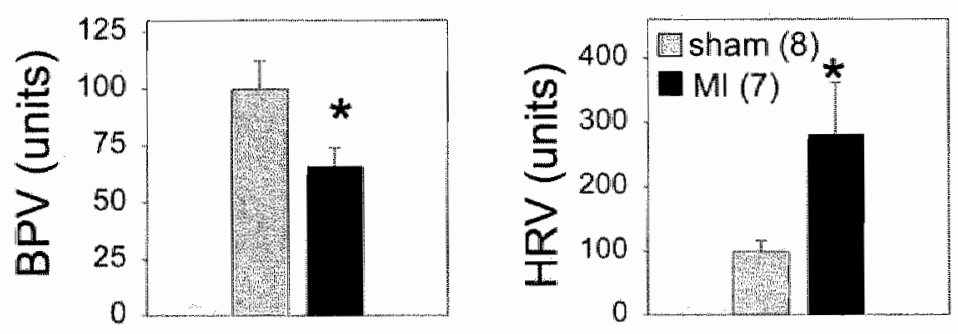

Figure 4: Comparison of indices of blood pressure variability (BPV) and heart rate variability (HRV) in sham-operated and mice 5 weeks after MI. BPV and HRV were determined as cumulative spectral density power obtained in a $0.1-1 \mathrm{~Hz}$ frequency band. For comparison, values BPV and HRV werc normalized to those obtained in sham-operated controls (100 units).

As shown in figure 4, the index of BPV was significantly lower in MI than in shamoperated mice [51]. This finding corresponds to observations made in heart failure patients. In mice and in patients, the reduction in BPV may be attributed to a declining intluence of sympathetic nerwes on blood vessel contractions [52], possibly caused by sympathetic desensitization. In contrast, the HRV index increased significantly after $\mathrm{MI}$ in the mouse. In heart failure patients, however, HRV is decreased. This apparent discrepancy can be explained by the fact that heart rate 
control in the mouse, unlike in humans, is predominandy sympathetically mediated. We have shown before that in intact mice both $\beta$-adrenergic blockade as well as ganglionic blockade increase HRV [49]. Thus the increase in HRV after MI may also point to a declining influence of sympathetic nerves on HR control. Because sympathetic desensitization is a manifestation of heart failure in humans; these findings suggest that analysis of BPV and HRV may be useful to monitor changes in autonomic control over time in the mouse after MI.

\subsection{Conclusion}

Taken together, data suggest that the MI mouse model is suitable to study the molecular aspects of wound healing evoked by cardiac ischamic damage and that the model has similar characteristics of left ventricular dysfunction and autonomic dysfunction as observed in patients with heart failure. On the other hand, despite the fact that infarct size and dilatation are more pronounced in mice than in patients, other symptoms of heart failure such as congestion, dyspnea or cachexia do not: always accompany severe left ventricular dysfunction in mice. This suggests that additional factors make men more prone to developing heart failure after MI, and that the mouse MI model may be less suitable in this respect. 
- Chapter 1

\section{Oxidative stress and antioxidant therapy in cardiac ischaemia and reperfusion}

\subsection{Introduction}

Coronaty artery occlusion, resulting from atherosclerotic plaques, plaque rupture, or vasospasms, reduces myocardial blood flow. When this is sufficiently prolonged or severe it results in myocardial cell injury, necrosis and apoptosis, ultimately leading to deterioration of cardiac function.

The treatment of coronary artery occlusion inwolves the use of thrombolytic agents (i.e., tissue plasminogen activator, streptokinase), percutaneous transluminal coronary angioplasty or coronary artery bypass surgery, in order to restore blood flow to the ischaemic myocardium. Reperfusion of an occluded human coronary artery is known to reduce infarct size, to limit deterioration of left ventricular function, and to reduce overall mortality $[53,54]$. However, it is recognized that the readmission of oxygenated blood into previously ischaemic myocardium can initiate a cascade of events that will paradoxically produce additional myocardial cell dysfunction and cell. necrosis [55-57]. This phenomenon is termed "ischaemia-reperfusion (IR) injury", and has been proposed to be caused mainly by the generation of reactive oxygen species (ROS).

Evidence supporting the role of ROS in myocardial IR injury is fourfold. First, an association has been recognized by demonstrating the generation, accumulation, and release of various ROS and simultaneous changes in the levels and/or activity of endogenous antioxidants [58-66]. Second, exposure of myocardium to exogenous ROS results in myocardial dysfunction that is comparable to that elicited by IR [67]. Third, indirect evidence is derived from studies that have demonstrated in wivo or in vitro cardioprotective effects of antioxidants following IR (section 2.6). Fourth, the role of ROS in IR injury is directly supported by genetic approaches whereby overexpression or deficiency of genes participating in the antioxidant defence alters the outcome of IR injury (section 2.6 ).

The following sections will discuss the chemistry of these ROS (section 2.2), their cellular and enzymatic sources (section 2.3), their interactions with biomolecules and the subsequent damage they cause (section 2.4). In addition, the endogenous antioxidant system and its responses to oxidative stress during cardiac IR will be discussed (section 2.5). Furthermore, we will give a detailed overview of the antioxidant interventions in experimental models of cardiac IR (section 2.6). Finally, attention will be paid on the results of antioxidant treatment in the clinical setting of catiac IR (section 2.7).

\subsection{Definition and chemistry of reactive oxygen species and free radicals}

Reactive oxygen species and oxygen free radicals, i.e. atoms or molecules with unpaired electrons in their outer orbit, are generated and degraded by all aerobic organisms. They include a number of chemically reactive molecules derived from 
oxygen. The cellular production of oxygen free radicals occurs from both enzymatic and non-enzymatic sources. In this case, any electron-transfering protein or enzymatic system can give rise to the formation of ROS as "by-products" of electron transfer reactions (see further section 23.).

The superoxide anion $\mathrm{O}_{2}{ }^{*}$ resulting from molecular oxygen $\left(\mathrm{O}_{2}\right)$ by addition of an electron is, in spite of being a free radical, not highly reactive. Catalyzed by superoxide dismutase (SOD), two molecules of $\mathrm{O}_{2}{ }^{-}$dismutate to hydrogen peroxide $\left(\mathrm{H}_{2} \mathrm{O}_{2}\right)$ and molecular oxygen (table 1).

In a reaction catalyzed by metal ions ( $\mathrm{Fe}^{2+}$ and $\mathrm{Cu}^{2+}$ ), the hydroxyl tadical $(\mathrm{OH})$ is formed from $\mathrm{H}_{2} \mathrm{O}_{2}$ (table 1 ). Hydroxyl radicals are very reactive and interact with almost all molecules found in the cell. Attack of $\mathrm{OH}^{*}$ upon biological compounds (lipids, proteins, DNA) induces the formation of carbon-centred radicals that can react with $\mathrm{O}_{2}$ to give peroxyl radicals $\left(\mathrm{RO}_{2}{ }^{\circ}\right)$. Reaction of $\mathrm{OH}^{*}$ with thiols can also produce thiyl radicals (RS).

Peroxyl radicals are the main chain-propagating species in the process of lipid peroxidation in membranes. The reactions lead to the generation of lipid hydroperoxides (LOOH) and in the presence of trace amounts of iron to alkoxyl radicals (RO') [68].

Free radicals also include nitric oxide (NO) which is synthesized enzymatically from L-arginine by nitric oxide synthase (NOS). Nitric oxide functions as an intracellular messenger stimulating guanylate cyclase, thereby relaxing smooth muscles e.g. those in blood vessels. Membrane-bound proteins are especially important tatgets for $\mathrm{NO}$ and nitrosylation of proteins is known to regulate enzymatic activity [69]. Peroxinitrite $\left(\mathrm{ONOO}^{-}\right.$), is formed by the biradical reaction between nitric oxide (NO) and superoxide anion $\mathrm{O}_{2}{ }^{\circ}$ (table 1$)$.

Table 1: Free radical formation reactions

$$
\begin{aligned}
& \mathrm{O}_{2}^{--}+\mathrm{O}_{2}^{*-}+2 \mathrm{H}^{+*} \rightarrow \mathrm{H}_{2} \mathrm{O}_{2}+\mathrm{O}_{2} \\
& \mathrm{O}_{2}{ }^{-}+\mathrm{H}_{2} \mathrm{O}_{2} \rightarrow \mathrm{O}_{2}+\mathrm{OH}^{\circ}+\mathrm{OH}^{-} \text {(Haber-Weiss reaction) } \\
& \mathrm{Fe}^{3+} / \mathrm{Cu}^{2+}+\mathrm{O}_{2}{ }^{*} \rightarrow \mathrm{O}_{2}+\mathrm{Fe}^{2+} / \mathrm{Cu}^{+} \\
& \mathrm{Fe}^{2+} / \mathrm{Cu}^{+}+\mathrm{H}_{2} \mathrm{O}_{2} \rightarrow \mathrm{Fe}^{3+} / \mathrm{Cu}^{2+}+\mathrm{OH}^{-}+\mathrm{OH}^{*} \text { (iron-catalyzed Fenton reaction) } \\
& \mathrm{O}_{2}{ }^{*}+\mathrm{NO}^{\circ} \rightarrow \mathrm{ONOO}^{-}
\end{aligned}
$$

\subsection{Sources of reactive oxygen species and free radicals}

As mentioned before, the cellular production of ROS occurs from both enzymatic and non-enzymatic sources. In this section we will give a complete overview of these sources and explain the mechanisms of ROS production.

\subsubsection{Mitochondria}

Within a cell, mitochondria largely contribute to the production of free radicals via the respiratory chain. During normal cellular metabolism the free energy necessary to generate ATP is extracted from the oxidation of $\mathrm{NADH}$ and $\mathrm{FADH}_{2}$ by the electron 


\section{- Chapter 1}

transport chain (figure 5). Normally the end product of oxygen in this process is water, when oxygen accepts 4 electrons at the cytochrome $c$ oxidase complex (complex IV) (figure 5). However, part of the oxygen is incompletely, i.e. 1 electron instead of 4 electrons, reduced to $\mathrm{O}_{2}^{--}$(figure 5).

The major sites for free radical production ate at the $\mathrm{NADH}$-coenzyme $\mathrm{Q}$ reductase (complex I) and cytochrome $c$ oxidase (complex III) components of the mitochondrial election transport chan [71-81] (figure 5).

During ischaemia when oxygen is absent to accept electrons, there is an increased ratio of reduced to oxidized components of the electron transport chain. In addition to this, declines in the activities of electron transport complexes I, III, IV, ATP synthase, and adenime nucleotide translocase have been observed during ischaemia and/or reperfusion $[82-89]$.

After reperfusion, when oxygen reaches the mitochondria, it reacts directly with the reduced complexes and consequently generation of reactive oxygen radicals is promoted.

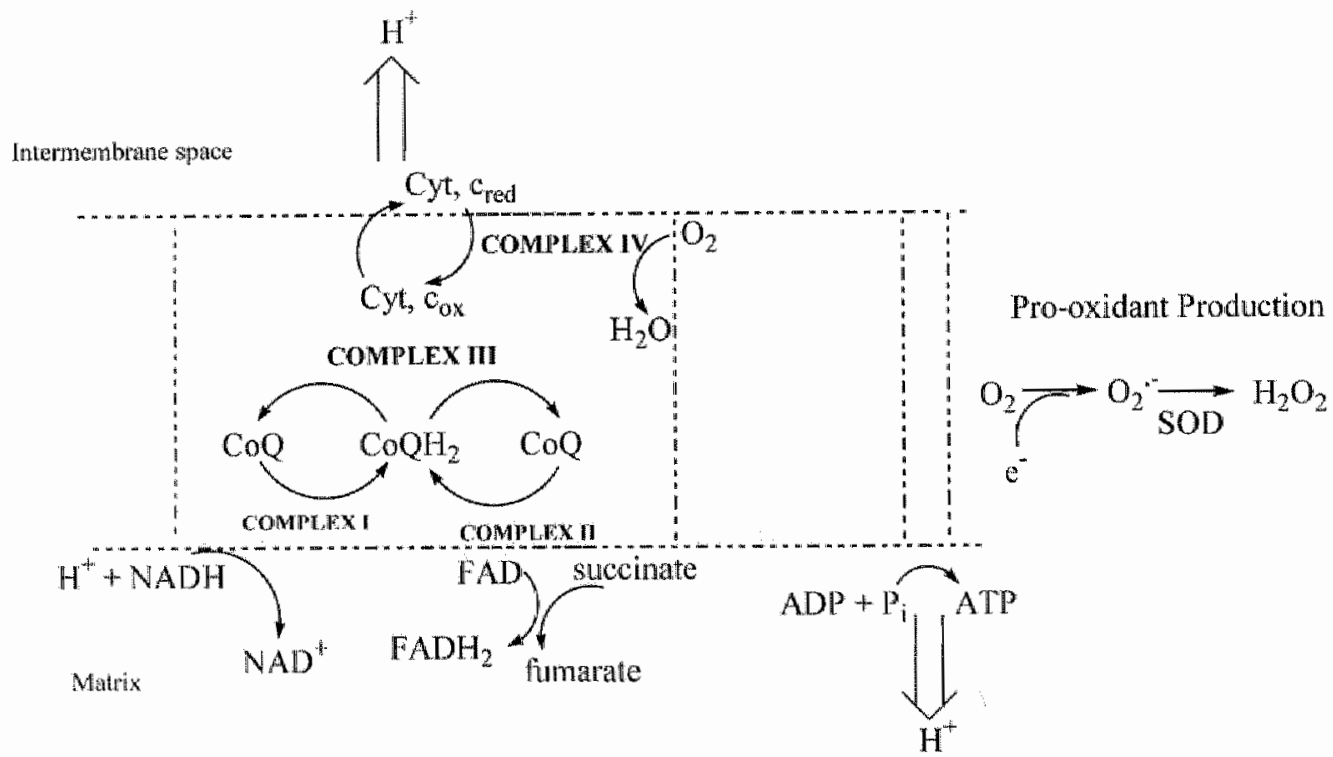

Figure 5: Mitochondrial electron transport and pro-oxidant generacion (modified from Sadele at ad. [70]). Reducing equivalents in the form of NADH and $\mathrm{FADH}_{2}$ produced through the function of the Krebs cycle enter the electron transport cham through complex I and complex II, respectively. Electrons are then tmonsferred though a series of redox couples with the final electron acceptor being $\mathrm{O}_{2}$, leading to the formation of $\mathrm{H}_{2} \mathrm{O}$. The energy that is liberated in the process of passing electrons to successively lower reduction potentials is udilized to pump protons from the mitochondrial matrix into the mitochondial intermembrane space. The proton gradient so established is then utilized by ATP synthase to convert ADP and P: to ATP. By wirtue of the redox reactions catried out during electron transport, it is not supprising that this process is a potential source of oxygen derived tadicals during nomal physiological processes and during disturbances in metabolic homeostasis such as IR. 
General Introduction -

\subsubsection{Xanthine oxidoreductase}

Xanthine oxidoreductase has two interconvertable forms. Xanthine oxidase teduces oxygen only. Xanthine dehydrogenase reduces either oxygen or $\mathrm{NAD}^{+}$, but has greater affinity for the latter. Both forms catalyse the conversion of hypoxanthine to xanthine and xanthine to uric acid, the terminal two reactions of the purine degradation pathway in humans. Tissue damage caused by xanthine-oxidoreductase generated ROS during reperfusion was first hypothesized by Granger $e t$ al as shown in figure $6[90]$.

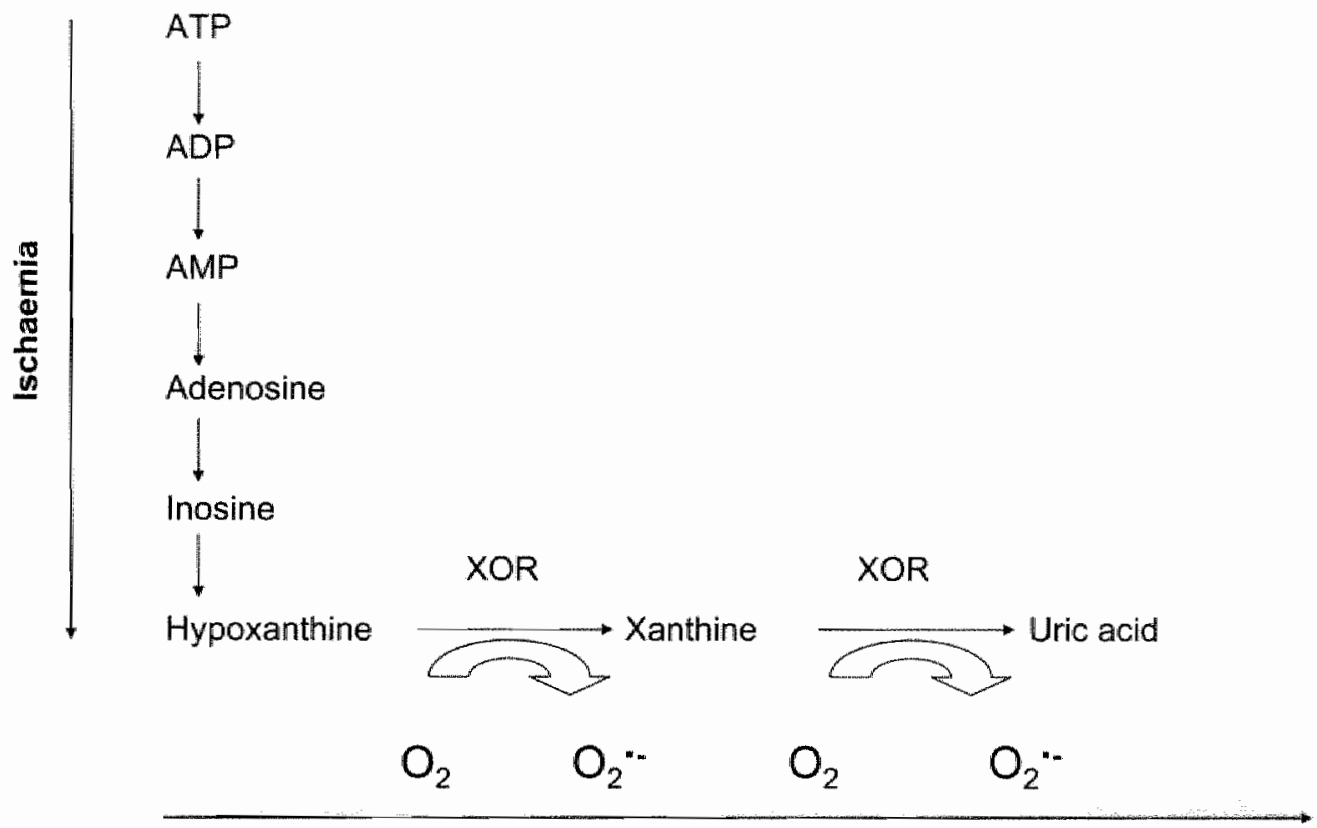

Reperfusion

Figure 6: Xanthine-oxidoteductase-generated ROS duc to ATP catabolism during ischaemia and increased electron availability on reperfusion (modifed from Berry ef at, 191 ).

Xanthine oxidoreductase activity can be found in mammalian liver and small intestine $[92]$ and in other mammalian tissues, including bovine heart $[93,94]$ and rat heart $[94$, 95]. The abundance of xanthine oxidoreductase is relatively low in human tissue, but it has been consistently identified in liver, smali intestine, endothelial cells and manmary glands [96-98]. Furthermore, most [95, 99-101] but not all [96, 102] studies have identified xanthine oxidoreductase protein and/or activity in the human heart. Subcellular localization methods have demonstrated the presence of xanthine oxidoreductase both in the cytosol and on cell membranes |103|. 


\subsubsection{NADPH oxidase}

Neutrophils are involved in the inflammatory response related to the wound healing process after IR and myocardial infarction (section 1.3.). Neutrophils are a primary source of $\operatorname{ROS}[104,105]$, including superoxide anions $\left(\mathrm{O}_{2}{ }^{\circ}\right)$, generated by the activity of the membrane-associated multisubunit NADPH oxidase [100]. The superoxide anion thus formed 1 s rapidly broken down to hydrogen peroxide $\left(\mathrm{H}_{2} \mathrm{O}_{2}\right)$ by superoxide dismutase, and then to hydroxyl radicals $\left(\mathrm{OH}^{\circ}\right)$. The NADPH oxidase system is also present in vascular smooth muscle cells, endothelial cells, and fibroblasts where it is responsive to a variety of neurohormonal stimuli, including angiotensin II, tumor necrosis factor-a, and growth factors [107].

Another source of ROS in neutrophils is the heme-containing enzyme myeloperoxidase, found in azurophilic granules. It converts $\mathrm{H}_{2} \mathrm{O}_{2}$ to hypochlorous acid (HOCl) in the presence of halides, such as chlotide. The bactericidal HOCl oxidizes various amines to toxic chloramines.

\subsubsection{Nitric oxide synthase}

Nitric oxide (NO) is synthesized endogenously by a family of enzymes called nitric oxide synthases (NOS) which exists in three major isoforms. While neuronal NOS (nNOS, NOS1) and endothelial NOS (eNOS, NOS3) are $\mathrm{Ca}^{2+} /$ calmodulin-dependent and constitutively expressed in a wide variety of cells, inducible NOS (iNOS, NOS2) is $\mathrm{Ca}^{2+}$ independent and is expressed in cells of the immune system and other cells in response to various stimuli [108].

The ability of some cells to regulate the expression of iNOS allows them to produce large amounts of nitric oxide on demand. Neuronal NOS, eNOS and iNOS are all present in the cytosol. Another NOS, mitochondrial NOS (moNOS), is exclusively present in the mitochondria $[109,110]$. Co-stimulation of superoxide production and meNOS can result in the formation of high concentrations of the highly reactive and damaging peroxinitrite (ONOO) $[111,112]$. All NOS enzymes function as homodimers. They generate nitric oxide (NO) by a two-step oxidation of the amino acid L-arginine to citrulline and NO via the intermediate compound $\mathrm{N}$-hydroxy- $\mathrm{L}$ arginine $\|13\|$.

\subsubsection{Remaining sources}

The endoplasmatic teticulum (ER) is membrane-bound intracellular organelle that is primarily involved in lipid and protein biosynthesis. Smooth ER, which is devoid of ribosomes, contains enzymes that catalyze a series of reactions to detoxify lipidsoluble drugs and other ham ful metabolic products. These include cytochrome P450 and $b_{5}$ families of enzymes that can oxidize unsaturated fatty acids and xenobiotics and reduce molecular $\mathrm{O}_{2}$ to produce $\mathrm{O}_{2}{ }^{--}$and/or $\mathrm{H}_{2} \mathrm{O}_{2}[114-116]$. Nuclear menbranes contain cytochrome oxidases and electron transport systems that resemble those of the ER [116]. It has been postulated that electrons "leaking" from these latter enzymatic systems may give tise to ROS that can damage nuclear DNA w wo [117]. 
Peroxisomes are membrane-enclosed otganelles and are an important source of total cellular $\mathrm{H}_{2} \mathrm{O}_{2}$ production [118]. They contain a number of $\mathrm{H}_{2} \mathrm{O}_{2}$-genestang enzymes including glycolate oxidase, D-amino acid reductase, urate oxidase, L $\alpha$-bydroxycid oxidase, and fatty acetyl-CoA oxidase [118]. Peroxisomal catalase utilizes $\mathrm{H}_{2} \mathrm{O}_{2}$ produced by these oxidases to oxidize a variety of other substrates in "peroxidative" reactions [119]. These types of oxidative reactions are particularly important in liver and kidney cells in which peroxisomes detoxify a variety of toxic molecules (induding ethanol) that enter the circulation.

Auto-oxidation of small molecules such as dopamine, adrenaline, havins, and hydroquinones can also be an important source of intracellular ROS production [116]. In most cases, the direct product of such autooxidation reactions is $\mathrm{O}_{2}{ }^{-}$.

Phospholipase $A_{2}$ hydrolyzes phospholipids to generate arachidonic acid which is a substrate for cycloxygenase-and lipoxygenase (LOX)-dependent synthesis of the four major classes of eicosanoids: prostaglandins, prostacyclins, thromboxanes, and leukotrienes. These synthetic pathways involve a series of oxidation steps that involve a number of free radical intermediates [116]. Arachidonic acid metabolism, particularly involving the IOX pathway, which leads to leukotriene synthesis, has been reported to generate ROS [120-123].

\subsection{Oxidative modifications of biomolecules: proteins, lipids and DNA}

As mentioned before, ROS increase in concentration upon reperfusion of ischaemic cardiac tissue [124-132]. It is well established that these reactive species can interact with and damage various cellular components, such as proteins, lipids, DNA and consequently contribute to cardiac IR injury. In this section we give an overview of these oxidative modifications and shortly illustrate them, as far as avalable, with examples in the setting of cardiac IR.

\subsubsection{Proteins}

As explained in figure 7, oxygen free radicals as for example hydroxyl radicals (OH'), induce oxidation of amino acid residue side chains.

Table 2 lists the products formed during oxidation of amino acids that are most susceptible to oxidation.

Even under mild conditions of oxidative stress, particularly induced by peroxinitrite, cysteine residues are targets for S-glutathiolation or disulfide formation and methionine residues are converted to methionine sulfoxide residues [133] (table 2). Several studies have shown oxidation of thiol groups of proteins caused by oxidative stress during cardiac IR [134-136]. For example, glyceraldahyde phosphate dehydrogenase (GAPDH) is a target for S-glutathiolation during IR [135]. GAPDH oxidation is associated with a loss in reduced cysteine status that correlates with the inactivation of this enzyme during IR [135]. 
- Chapter 1

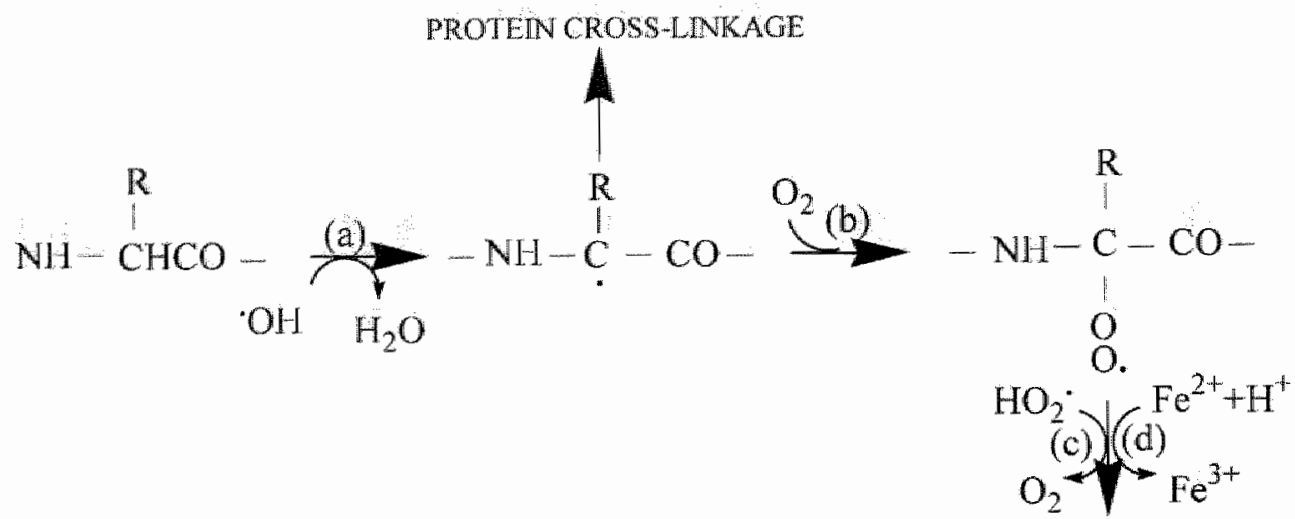

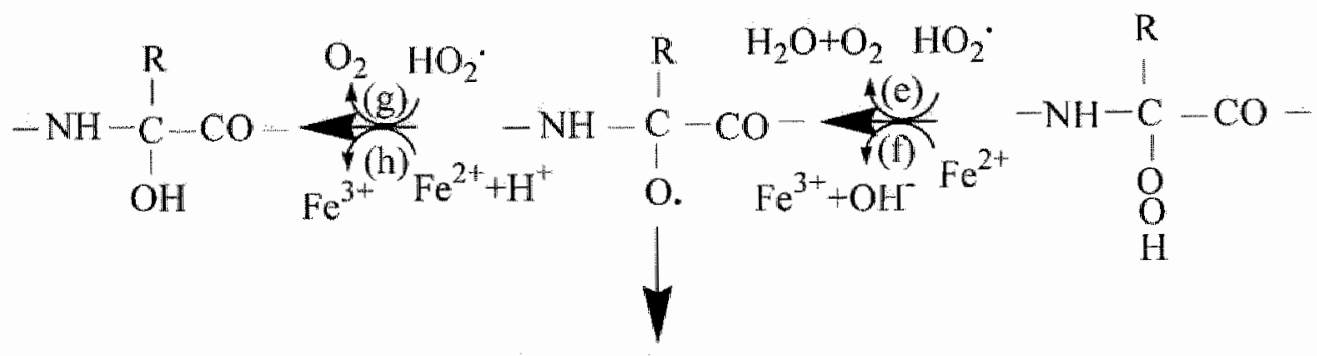

PEPTIDE BOND CLEAVAGE

Figure 7: Oxidative attack of the polypepride backbone (modified from Berlett et al.[133]). Reactions are initiated by the $\mathrm{OH}^{\circ}$-dependent abstraction of the $\alpha$-hydrogen arom of an amino acid residue to form a carbon-centered radical (reaction a). The carbon-centered radical thus formed reacts rapidly with $\mathrm{O}_{2}$ to form an alkylperoxyl radical intermediate (reaction b), which can give rise to the alkylperoxide (reaction c), followed by formation of an alkoxyl radical (reaction $\mathrm{e}$ ), which can be converted to a hydroxyl protein derivative (retction g). Nany of the steps in this pathway that are mediated by interactions with $\mathrm{HO}_{2}$ cann be catalyzed also by $\mathrm{Fe}^{2+}$ (reacrions $\mathrm{d}, \mathrm{f}, \mathrm{h}$ ) or by $\mathrm{Cu}^{2+}$ (not shown). The alkyl, alkylperoxyl, and aikoxyl madical intermediates in this pathway may undergo side reactions with other amino acid residues in the same or a different protein molecule to generate a new carbon-centered radical capable of undergoing similar reacrions. Moreover, in the absence of oxygen, when reaction b is prevented, the carbon-centered madical may rewct with another carbon-centered radical to form a protein protein cross-linked derivative. The generation of alkoxyl adicals (reactions e, 1 ) sets the stage for cleavage of the pepude bond by either the diamide or $\alpha$-amidation pathwass [133].

Furthermore, more proteins are substrates for S-thiolation during in witro reperfusion of the ischaemic rat heart. To these belong actin, HSP-27, protein-tyrosine phosphatase $1 \mathrm{~B}$, protein kinase $\mathrm{C} \alpha$, the small $\mathrm{G}$-protein ras, triose phosphate isomerase, aconitate hydratase, $\mathrm{M}$-protein nucleoside diphosphate kinase $\mathrm{B}$, and myoglobin [134-136]. Unfortunately no further implications for cardiac function were investigated in these studies [134-136]. 
Table 2: Amino acids most suscepible to oxidation (modified from Berlert at a/ (133))

\begin{tabular}{|c|c|}
\hline Amino acids & Oxidation products \\
\hline Cysteine & Disulfides, cysteic acid \\
\hline Methionine & Methionine sulfoxide, methionine sulfone \\
\hline Tryptophan & $\begin{array}{l}\text { 2-,4-,5-6 , and 7-Hydroxytryptophan, nitrotryptophan, } \\
\text { kynurenine, 3-hydroxykynurenine, formylkynurenine }\end{array}$ \\
\hline Phenylalanine & 2-,3-Dihydroxyphenylalanine, 2-,3-, and 4-hydroxyphenylalanine \\
\hline Tyrosine & $\begin{array}{l}\text { 3,4-Dihydroxyphenylalanine, tyrosine-tyrosine cross-linkages, } \\
\text { Tyt-O-Tyr, cross-linked nitrotyrosine }\end{array}$ \\
\hline Histidine & 2-oxohistidine, asparagine, aspartic acid \\
\hline Arginine & Glatamic semialdehyde \\
\hline Lysine & $\alpha$-Aminoadipic semialdehyde \\
\hline Proline & $\begin{array}{l}\text { 2-Pyrrolidone, 4-,5-hydroxyproline pyroglutamic acid, } \\
\text { glutamic semialdehyde }\end{array}$ \\
\hline Threonine & 2-Amino-3-ketobutyric acid \\
\hline Glutamyl & Oxalic acid, pyruvic acid \\
\hline
\end{tabular}

Aromatic amino acid residues are among the preferred targets for oxygen radical attack [133]. For example tryptophan residues are readily oxidized to formylkynurenine, kynurenine, and to various hydroxy derivatives; phenylatanine and tyrosine residues yield a number of hydroxy derivatives; histidine residues are converted to 2-oxohistidine, asparagines, and aspartic acid residues [133] (table 2). Additionally tyrosine and tryptophan residues are selective targets for peroxinitritedependent nitration [133].

As shown in table 2 , direct oxidation of lysine, arginine, proline, and threonine residues may also yield carbonyl derivatives [133]. In addition, carbonyl groups may be introduced into proteins by reactions with aldehydes (4-hydroxy-2nonenal or malondialdehyde) produced during lipid petoxidation (see section 2.4.2.) $[137,138]$ or with reactive carbonyl derivatives (ketoamines or ketoaldehydes) generated as a consequence of the reaction of reducing sugars or their oxidation products with lysine residues [139].

The presence of carbonyl groups in proteins has been used as a marker of ROSmediated protein oxidation. Several sensitive methods for the detection and quantitation of protein carbonyl groups have been developed 1140 . For example, it was demonstrated that the cardiac myofibrillar protein actin was oxidized during cardiac IR in an in who rat model $[141,142]$. Antioxidant treatment reduced myofibrillar protein oxidation and subsequently increased the degree of cardiac contractility recovery after IR significantly [142].

As shown in figure 7 , oxidative stress also results in the formation of proteinprotein cross-linkages. A recent study for example, reported interptotein disulfide interactions between highly abundant cardiac proteins (actin and tropomyosin) following cardiac IR [142]. 
Furthermore, oxidation of the protein backbone may result in protein fragmentation (figure 7). For example, cleavage of myosin-regulatory light chain (MLC-2) in its functionally important $\mathrm{N}$-terminal site occurred in stunned rabbit myocardium [143]. Treatment with a hydroxyl radical scavenger, $N$-(2-mercaptopropionyl) glycine, ptevented this proteolytic trancation of MLC-2 and was associated with preservation of contractile function [143]. Therefore, proteolytic damage to MLC-2, related to the presence of hydroxyl radicals during reperfusion, correlates with myocardial stunning and may contribute to impaited contractility [143].

It has been described that the accumulation of oxidized proteins depends not only on the rate of protein oxidation but also on the activity of the proteasome, a major intracellular proteolytic system which degrades oxidized forms of proteins [144]. It was shown that free radical-derived modifications of the proteasome during in wo cardiac IR inactivated this system and consequently resulted in intracellular accumulation of oxidized proteins which may further impact the outcome of IR [145].

\subsubsection{Lipids}

Polyunsaturated fatty acids (PUFA) of cell membrane lipids are highly susceptible to peroxidation by oxygen radicals [137]. Not surprisingly, increases in the level of free radicals are paralleled by elevated rates of lipid peroxidation during myocardial ischaemia [146] and reperfusion [147-153]. As shown in figure 8, peroxidation of membrane lipids results in the fragmentation of polyunsaturated fatty acids giving rise to various aldehydes, alkenals, and hydroxyalkenals such as malonaldehyde and 4 . hydroxy-2-nonenal (HNE) [137].

Many of these products are cytotoxic when introduced into cells in culture or experimental animals; effects to be mediated in large part by their reactivity towards proteins $[137]$.

HNE, a major product of lipid peroxidation, is thought to be the most reactive of these compounds and is, therefore, an important mediator of free radical damage [137]. HNE reacts with proteins at the sulfhydryl group of cysteine, the imidazole nitrogen(s) of histidine, and/or the s-amine of lysine [137, 154-157], resulting in enzyme inactivation $[137,138,158,159]$. For example, formation of HNE-modified proteins was increased by $>50$-fold after $30 \mathrm{~min}$ of ischaemia in rat heart [160]. Furthermore, the concentration of HNE in the perfusate increased upon reperfusion of rat ischaemic myocardium $\llbracket 151$.

Mitochondtia, a source of free radicals during reperfusion $[161,162]$, are likely targets of lipid peroxidation and HNE-mediated dysfunction. In an in who rat mode of cardiac IR, Lucas al demonstrated that the degree of mitochondrial dysfunction during reperfusion was positively correlated with the level of HNE-modifted proteins, and, morcover, also with the age of the animals [163]. Furthermore, treatment of intact cardiac mitochondria with HNE reduces NADH-linked respiration [164] mainly via inactivation of $\alpha$-lietoglutarate dehydrogenase [165]. In addition, adduct formation of $\mathrm{HNE}$ with cytochrome-c oxidase during cardiac reperfusion resulted in dysfunction of this respimatory enzyme [88]. Finally, HNE was also shown to contribute to the reduction of $\beta$-adrenoceptor function in the heart by oxidative stress [166]. 


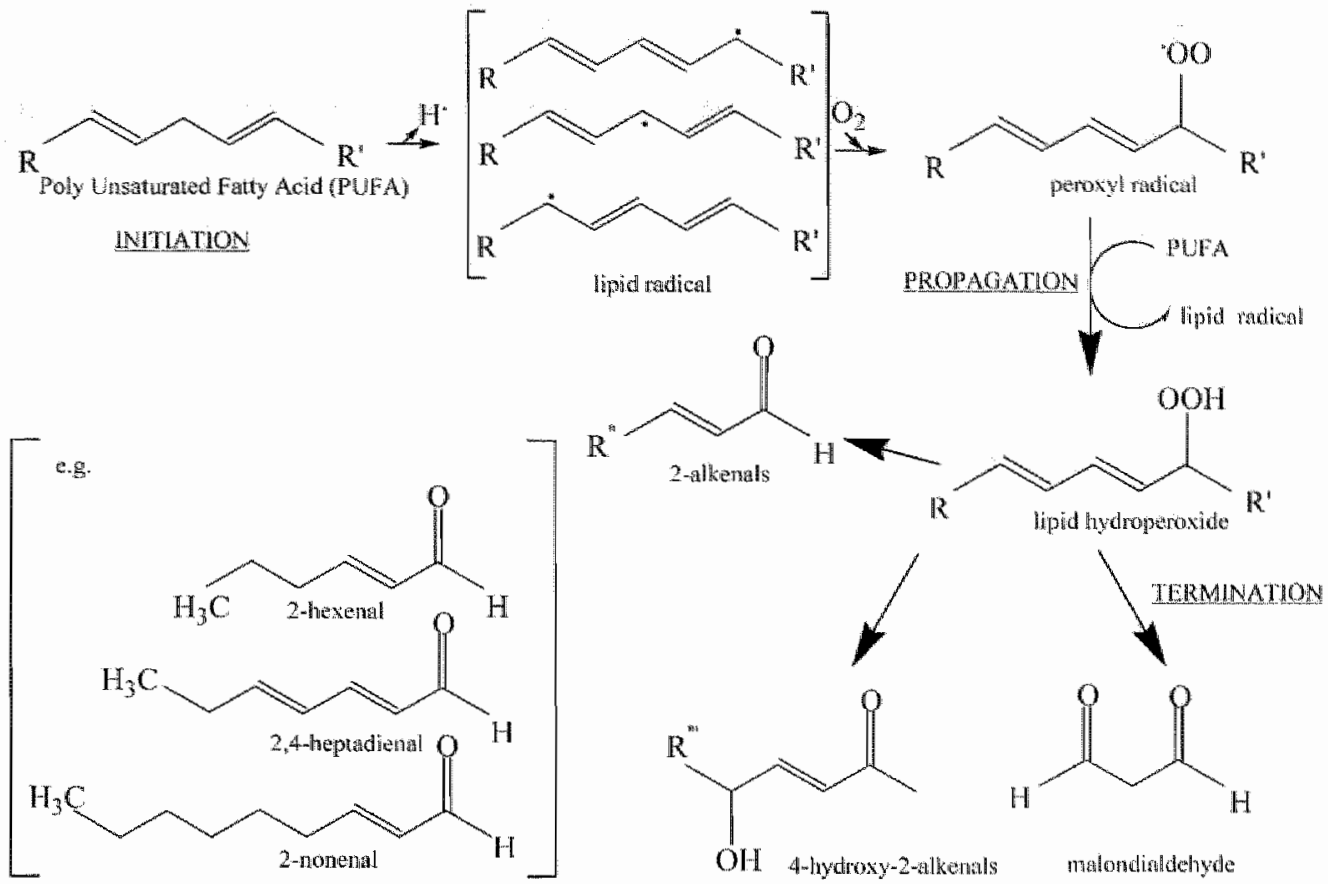

Figure 8: Process of lipid peroxidation and formation of toxic radicals (modiffed from Berlett of al. $[133])$.

\subsubsection{DNA}

Reactive oxygen species can also cause oxidative modifications of nucleotides. Specifically, ROS produce 8-oxo-7,8-dihydroxyguanosine triphosphate (8-oxo-dGTP), which modifies the bases in DNA and generates 8-0xo-7,8-dihydro-2'-deoxyguanosine (8-oxo-dG) [167]. As a result, 8-oxo dGTP is considered a potent mutagenic substrate for DNA replication [168]. Oxidative DNA damage has been detected in cancer and neurodegenerative diseases [167]. However, limited data ate available regarding heart diseases, except for an increased level of 8-oxo-dG formation in aged heart $|169|$ and in superoxide dismutase 2 mutant mice [170].

Increased generation of ROS has been associated with mitochondrial DNA damage and dysfunction in failing hearts after myocardial infarction |171|. "The incorporation of 8-oxo-dGTP into DNA is prevented by 8-oxo-dGTPase, which hydrolyzes 8-oxo-dGTP into 8-oxo-dGMP. It was shown that the level of 8-oxodGTPase was increased in the mitochondria isolated from post-MI mice hearts as oxidative stress increased. This suggests a preventive mechanism activated against ROS-induced DNA damage in failing hearts [172].

Single-strand DNA breaks, caused by ROS can allso activate the nuclear enzyme poly-(ADP-ribose) polymerase (PARP). "This initiates an energy-consuming, inefficient cellular metabolic cycle with transfer of the ADP -ribosyl moiety of NAD* to protein acceptors and subsequent depletion of $\mathrm{NAD}^{+}$and ATP pools |173-178|. 
Activation of PARP has been demonstrated in in wito and in wiw models of cardiac IR $[179,180]$. Inactivation of the enzyme significantly limited additional ROS production [181], reduced myocardial necroses and inflammation and preserved ATP pools, restoring myocardial function after IR [182-184].

\subsection{Responses of the endogenous antioxidant system during IR}

Endogenous antioxicants are present in tissues to minimize injury by ROS. This endogenous antioxidant system is composed of both, antioxidant enzymes, including superoxide dismutase (SOD), catalase and glutathione peroxidase, and non-enzymatic antioxidants including $a$-tocopherol (vitamin $\mathrm{E}$ ), ubiquinonone (coenzyme Q10), ascorbate (vitamin C), and glutathione (GSH). The major endogenous antioxidants and their sites of action in cardiomyocytes are presented in table 3 .

Table 3: The major endogenous antioxidants and their sites of action in cardiomyocytes (modified from Dhatlat at al. [185])

\begin{tabular}{|c|c|c|}
\hline Natane & Site & Accion \\
\hline Cu,ZN-SOD (SODI) & cytoplasina & \multirow{2}{*}{$\frac{\mathrm{SOD}}{2 \mathrm{O}_{2}{ }^{-m}+2 \mathrm{H}^{+} \rightarrow \mathrm{H}_{2} \mathrm{O}_{2}+\mathrm{O}_{2}}$} \\
\hline $\mathrm{Mn}-\mathrm{SOD}(\mathrm{SOD} 2)$ & mitochondria & \\
\hline Catalase & $\begin{array}{l}\text { peroxisomes and } \\
\text { mitochondrial } \\
\text { membrane }\end{array}$ & $\begin{array}{l}\text { Catalase } \\
\mathrm{H}_{2} \mathrm{O}_{2} \rightarrow 2 \mathrm{H}_{2} \mathrm{O}+\mathrm{O}_{2}\end{array}$ \\
\hline Glutathione peroxidase & cytoplasin & $\begin{array}{c}\text { Glutahione peroxidase } \\
\mathrm{H}_{2} \mathrm{O}_{2}+2 \mathrm{GSH} \rightarrow 2 \mathrm{H}_{2} \mathrm{O}+\mathrm{GSSC}\end{array}$ \\
\hline Glutathione & intracellular & cellular reductant \\
\hline $\begin{array}{l}\text { Cocnzyme Q10 } \\
\text { (ubicpunone) }\end{array}$ & cell mermbrane & redox active electron carrier \\
\hline Vitaning $(\alpha-$ tocopherol) & cytoplasm and plasma & breaks lipid peroxidation chan and LDL reaction \\
\hline$\beta$-Carotene (Jro-vitamin $A$ ) & plasima & inhibits oxidation of $\mathrm{LDL}$ \\
\hline Virtunin $C$ (ascontic acid) & cyroplasma and plasma & dirscely as an antioxidant of as a cofactor for vitamin $\mathrm{E}$ \\
\hline
\end{tabular}

In parallel to studies that have investigated the generation of ROS in ischaemic and reperfused hearts, reports have also described the time-dependent changes in levels of endogenous myocardial antioxidants following cardiac IR /1861941. However, inconsistent results were found in those studies. Upon oxidative stress, some studies reported increased activities of myocardial enzymatic antioxidants [190], while other studies reported decreased activities [186-189, 193]. In addition, both increased content of myocardial non-enzymatic antioxidants [191], and decreased content of myocardial non-enzymatic antioxidants have been reported $[149,186-188$, $190,191,194 \%$.

These contradictions may be due to differences in experimental design of these studies. Therefore, when antioxidant systems are evaluated in the same model, one may arrive at a comprehensive understanding of how the cardiac tissue endogenous antioxidant system operates as an integrated system against free radical injury.

In a series of experiments, Haramaki ef al. took an integrative approach to study systematic changes in the myocardial endogenous antioxidant defences in the 
isolated rat heart during IR [195]. They found that myocardial hydrophilic antioxidants such as ascorbate (vitamin C) and glutathione were easily oxidized to dehydroascorbate and glutathione disulfide, and were released from the myocardium. In contrast, antioxidant enzymes and lipophilic antioxidants temained unchanged under conditions of IR. At the moment of severe oxidative challenge induced by reperfusion with exogenous $\mathrm{H}_{2} \mathrm{O}_{2}$, the decrease in the hydrophilic antioxidants exacerbated further and was under these conditions also associated with a reduction of the lipophilic antioxidants. These results demonstrate that antioxidants are gradually utilized in a certain order and support the idlea that they are hiemrchically organized during cardiac IR. These observations can have therapeutic implications in that they lend support to rationalization of combined treatment with different antioxidants for conditions associated with different degrees of oxidative stress.

There is also increasing evidence for the involyement of an antioxidant network during cardiac IR in human. For instance, many studies have demonstrated oxidative modification and release of the myocardial hydrophilic antioxidants in patients undergoing coronary bypass surgery utilizing aortic cross-clamping [196-205]. Ferrari $e t$ al. were the first to report the formation and release of oxidized glutathione (GSSG) in the coronary sinus following human myocardial IR [205]. The coronary sinus concentration of GSSG was related to the duration of the ischaemic period providing evidence for consumption of GSH in humans subjected to heart surgery [205]. They also found a positive correlation between reduced glutathione levels and delay in postoperacive recovery of cardiac function [205].

Data from myocardial biopsies indicate that the cross-clamp period produces also a massive loss of myocardial glutathione [202]. Moreover, reperfusion results in oxidative damage, as evidenced by release of the oxidized form of glutathione (GSSG) in the coronary sinus [202]. These authors have described a relationship between myocardial glutathione and baseline LV function [202].

In patients, Barsacchi et al. observed a large variability in basal atrial vitamin $\mathrm{E}$ content and a reproducible and substantial decrease in vitamin $E$ content after cardiopulmonary bypass surgery [197]. This was directly related to the aorta crossclamping duration. Also the net myocardial loss of vitamin $\mathrm{E}$ in the first 5 minutes of reperfusion was positively correlated with the total cross-clamp time [199]. Similar: observations have been made in humans even following short episodes of myocardial ischaemia as for example during angioplasty [206-208].

We can conclude that in animal models as well as in various clinical settings consumption of endogenous antioxidants occurs during myocardial $I \mathbb{R}$. However, more research is needed to identify the types and time course of this consumption of endogenous antioxidants in order to optimize antioxidant treatment.

\subsection{Antioxidant interventions in experimental models of cardiac IR}

\subsubsection{Antioxidant enzyme interventions}

The evidence implicating ROS in the pathogenesis of myocardial IR injury is in part based on in vitro and in vino experiments that have examined the ability of free radical 
- Chapter 1

scavengers to alter the injury tesponse. Superoxide dismutase (SOD) and catalase have received most attention in this regard. Table 4 gives an overview of animal studies in which in wiwo and in witro (langendorf model) approaches as well as animal cardiomyocytes in culture were used to test for protective effects of antioxidant enzymes against cardiac IR injury induced by ROS. Around 40 publications were found in literature.

The first evaluation of antioxidant enzyme therapy in myocardial reperfusion injury was performed by Jolly at in an in wivo dog model [209]. This study, published in 1984, revealed that the combined administration of SOD and catalase significantly reduced infarct size after 24 hours of reperfusion. Since this report, there have been a number of stadies that have also demonstrated a beneficial effect of combined SOD and catalase treatment in experimental models of myocardial IR injury [209-212]. However, an equal amount of studies could not prove such favourable effects of combined treatment on cardiac recovery after IR [213-216].

Also mono-therapy with SOD led to conflicting results with several studies in support of protective effects $[213,217-224]$ and several studies that could not show protective effects in cardiac IR $225-230]$.

So far, only two studies have tested effects of mono-therapy with catalase. However they failed to prove protective effects [224, 230].

Two separate groups compared the effects of single therapy with SOD or catalase on cardiac IR injury together in one single study $[220,230]$. "The study of Werns et al. [220] could prove beneficial effects with SOD compared to catalase in a dog model of IR, while the study of Gallagher ef at. in the same animal model could not show an effect with either substance [230].

The reasons for the discrepancy in results with SOD and/or catalase among these studies are unclear. Among the experimental variables that have been postulated to explain these conflicting results ane: 1/ animal species; $2 /$ general features of the experimental model (e.g. anaesthetized or awake model, open or closed- chest model); $3 /$ the presence or absence of critical stenosis; 4/ duration of ischaemia; 5/ duration of reperfusion; $6 /$ pharmacokinetic considerations; $7 /$ method used to quantitate infarct size; $8 /$ inclusion or omission of measurements to control for baseline predictors of infarct size (e.g. collateral blood flow). However, up to now, there is no study available in literature that really proved that one of these factors or a combination is the cause for this discrepancy.

Several studies have tried to increase the plasma half-life of SOD by conjugation with polyethylene glycol (PEG). Also these studies revealed positive $[232$, $234]$ and negative $[233,234]$ results. In the latter studies it has been suggested that PEG-SOD may in fact be too large to gain access into cells, and therefore unable to scavenge the superoxide radicals derived from intracellular sources.

In contrast to PEG-SOD, synthetic low molecular weight SOD-mimetic molecules such as M40403 [235] and SC-52608 [236] have yielded positive results in an in wivo model and an in witro rabbit model of IR, respectively. This underscores the need to further test the protective effects of low molecular weight SOD mimetics in the setring of cardiac IR. 
Intracellular concentrations of SOD have been taised by gene therapy also. With this technique, protective effects of extracellular $50 \mathrm{D}$ and Mn-SOD were proven in an in mo rabit [237] and in miro mouse model [238], respectively These results may have significant clinical implications for the development of aovel cardioprotective strategies in the setting of cardiac IR.

Another experimental strategy that has been used to study the role of ROS in myocardial IR injury is to assess the injury response in mutant mice in which the gene encoding a specific antioxidant enzyme has been either deleted ot overexpressed. Transgenic mice in which various isofotms of SOD have been overexpressed [239$242,244]$ or deleted [243-245], as well as mice that lack or overexpress glutathione peroxidase $[248,249]$ or haeme-oxygenase $[246,247]$ and glutathone peroxidase [248] have been developed and tested in the context of cardiac IR. The relative contribution of the endogenous enzymes, i.e. cytosolic Cu, $\mathrm{Zn}$ SOD versus mitochondrial $\mathrm{Mn}$. SOD, in protecting the heart from oxidative injury after IR was tested in witw by Asimaki to al. [245]. They found that Mn-SOD ( $+/ \omega)$ mice had a deficit in postischaemic myocardial function. Cardiac tissue from these animals showed a higher level of lipicl peroxidation compared with wild type mice and $\mathrm{Cu}, \mathrm{Zn}-\mathrm{SOD}(+/-)$ mice. This implies a major role for $\mathrm{Mn}-\mathrm{SOD}$ compared to $\mathrm{Cu}, \mathrm{Zn}-\mathrm{SOD}$ in protecting the heart against in witro IR injury. However, in mitro studies in which $\mathrm{Cu}, \mathrm{Zn}-\mathrm{SOD}$ was overexpressed [241, 242] or deleted [243] showed improved or impaired functional recovery, respectively. This suggests that cytosolic $\mathrm{Cu}, \mathrm{Zn}-\mathrm{SOD}$ might also be involved in the protection against in witro cardiac IR injury. The in wo effect of mitochondrial Mn-SOD was investigated by Jones ef al [244]. They demonstrated that cytoprotection resulting from Mn-SOD overexpression in transgenic mice was associated with the preservation of cardiac output and fractional shortening at 7 days after IR. In addition, an in wo protective role for extracellular SOD (Ec-SOD) was proven by Dewald et al. who showed less inflammation, less fibrosis and no ventricular dysfunction up to 7 days after IR [240].

Both, glutathione peroxidase and heme-oxygenase protect against IR injury. Transgenic mice that overexpress glutathione peroxidase are resistant to myocardial IR injury [248], whereas glutathione peroxidase knockout mice are more susceptible to myocardial reperfusion injury compared with their wild-type counterpatts [249].

Haeme-oxygenase overexpression has a protective in witro and in wo role during reperfusion $[246,247]$. 
- Chapter 1

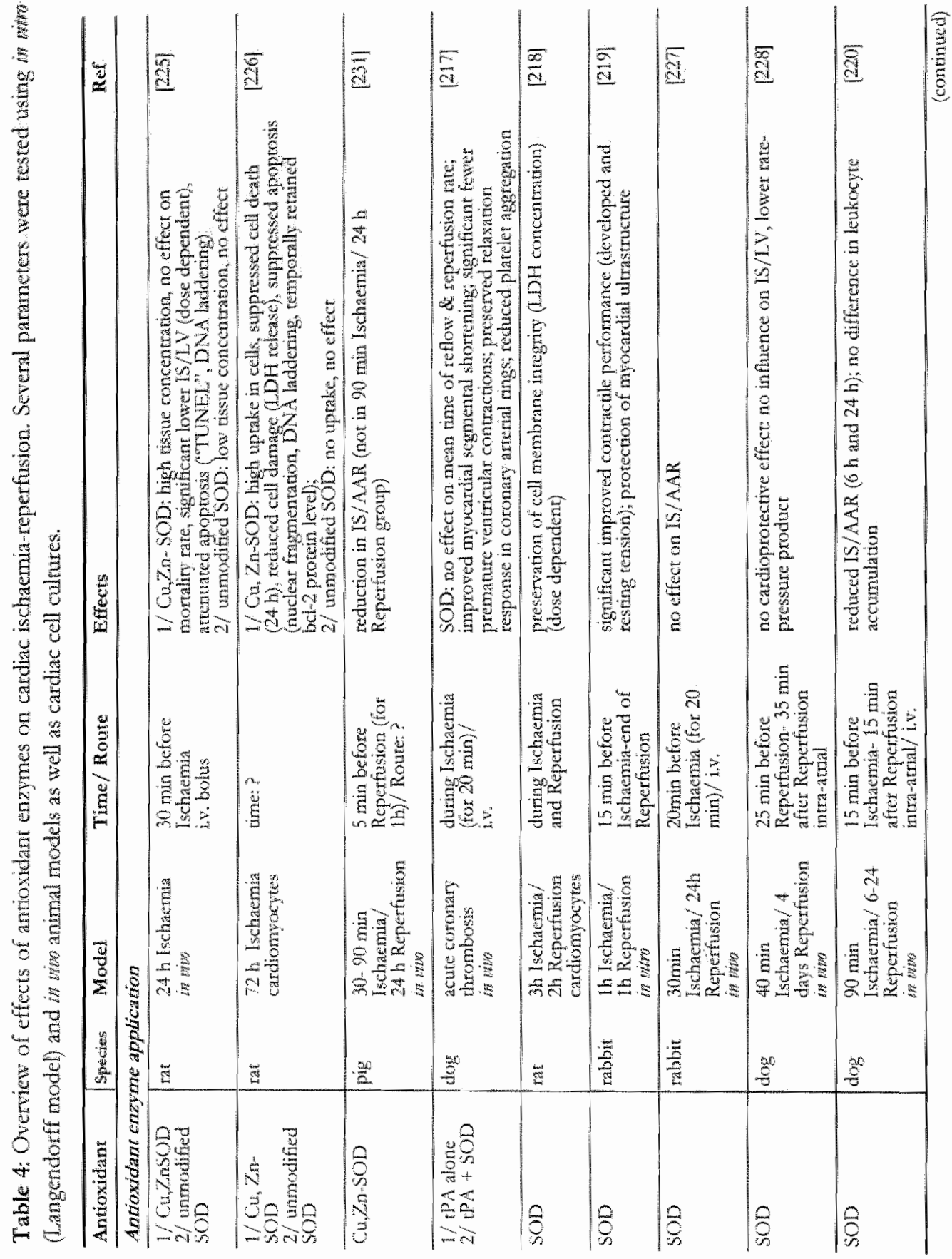


General Introduction -

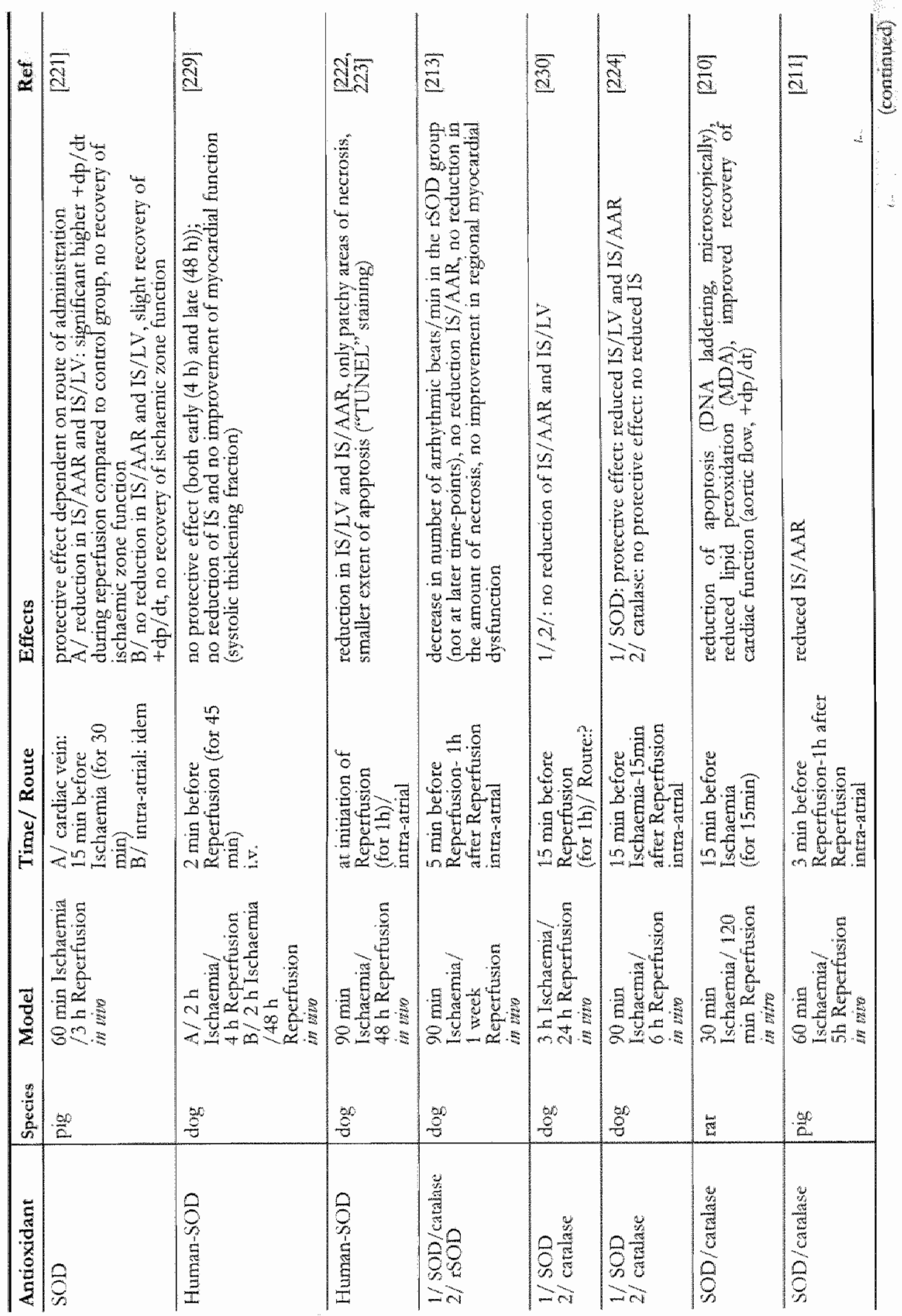


- Chapter 1

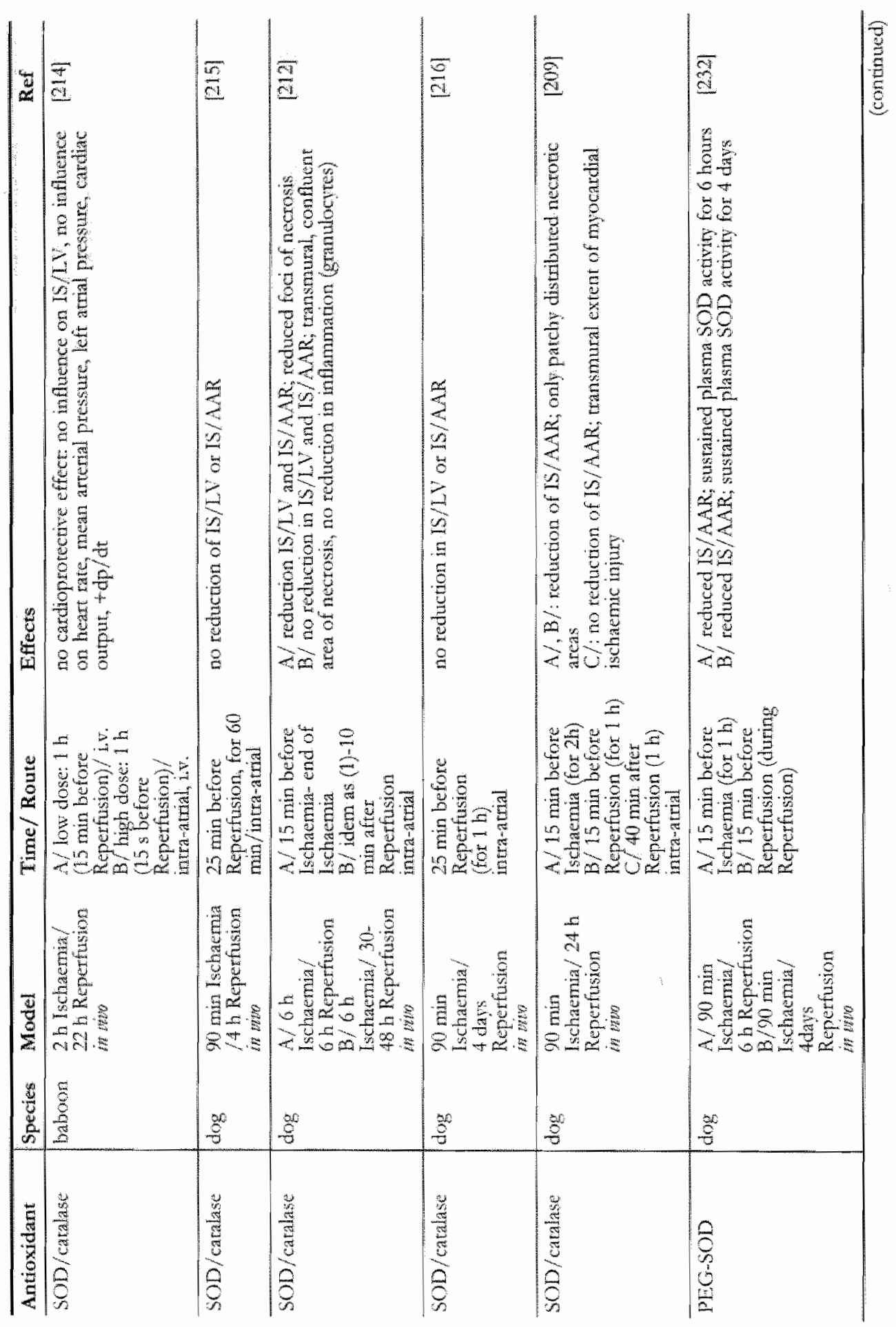


General Introduction.

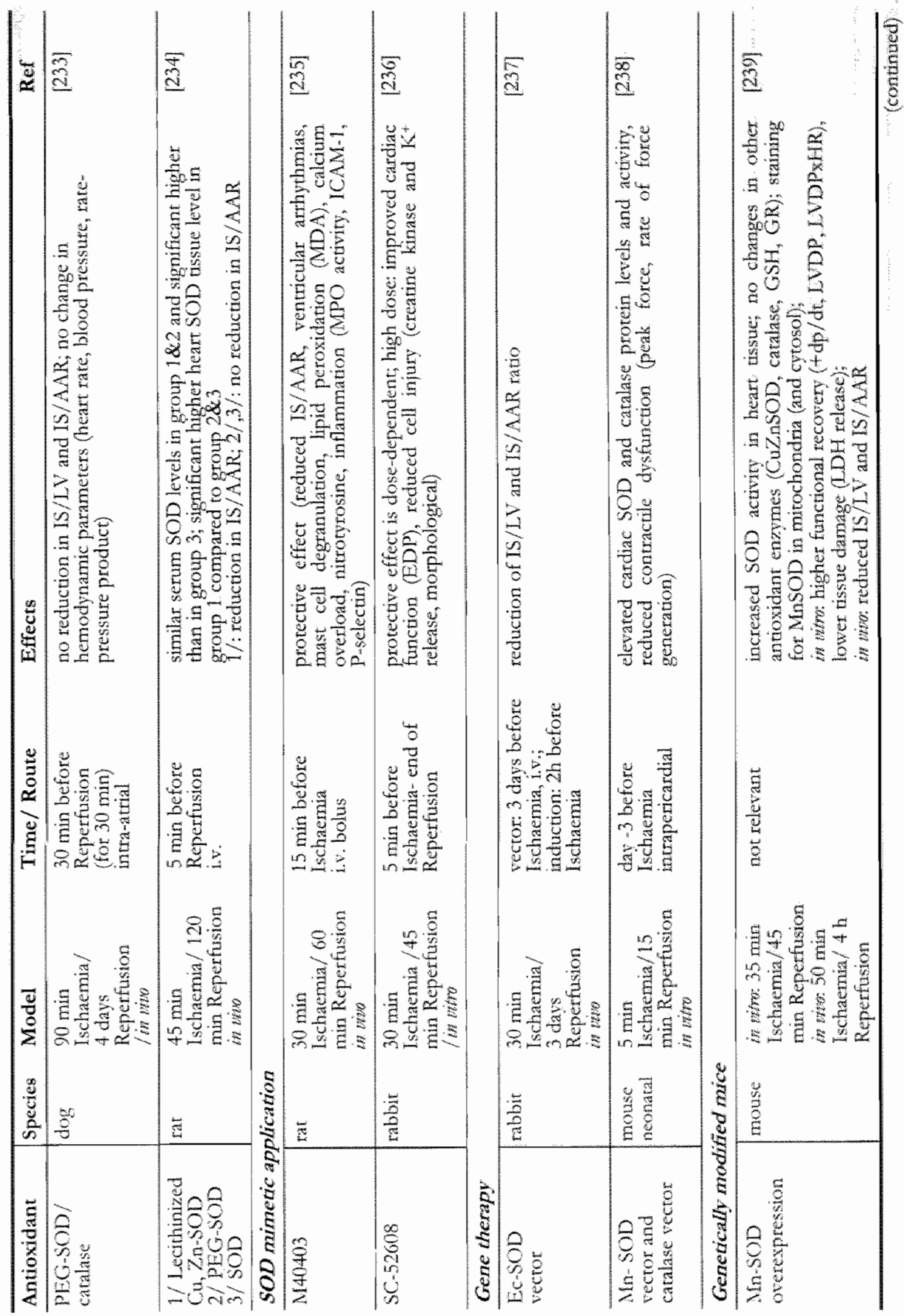




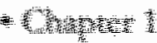

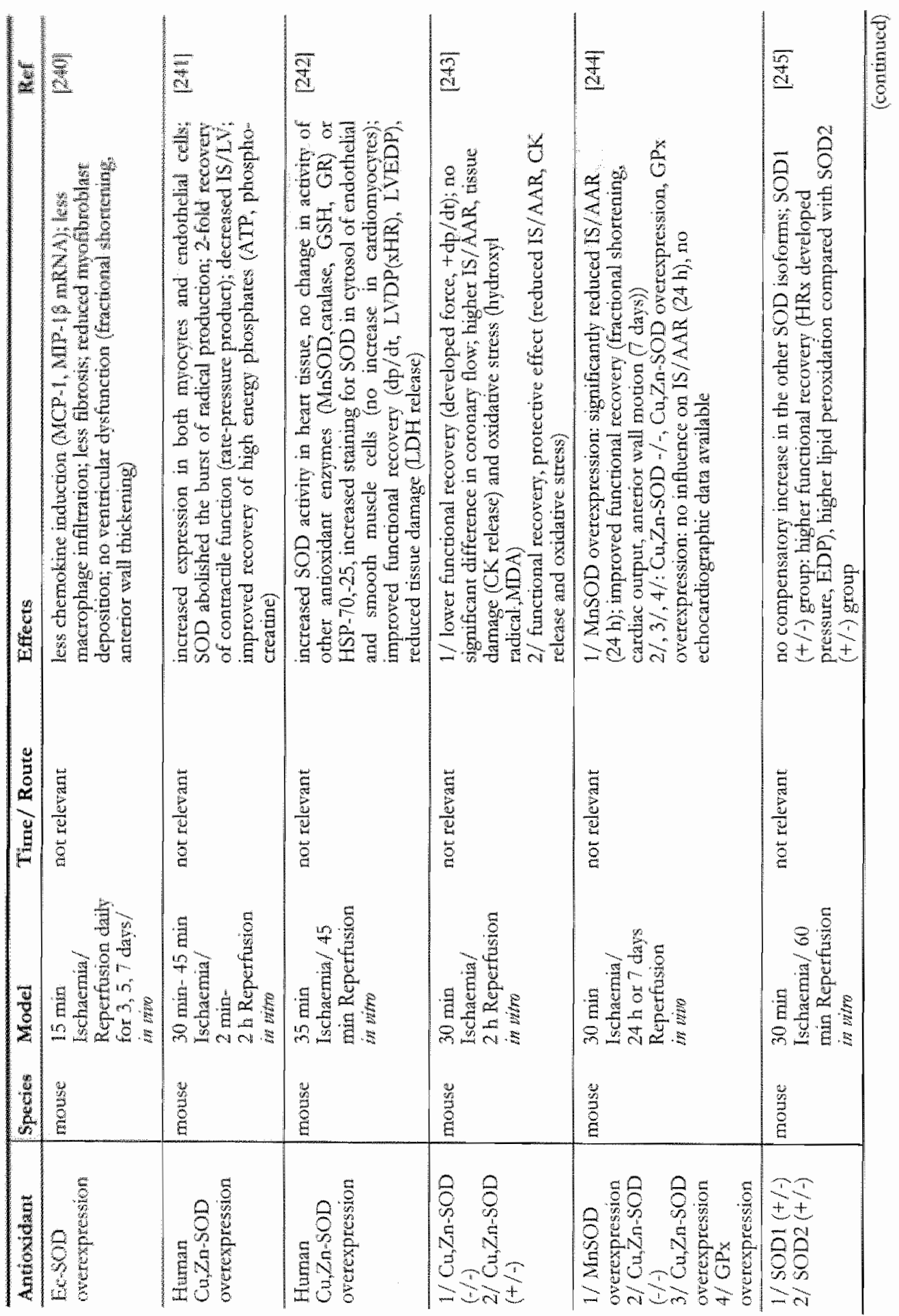


Genenal Intoduction -

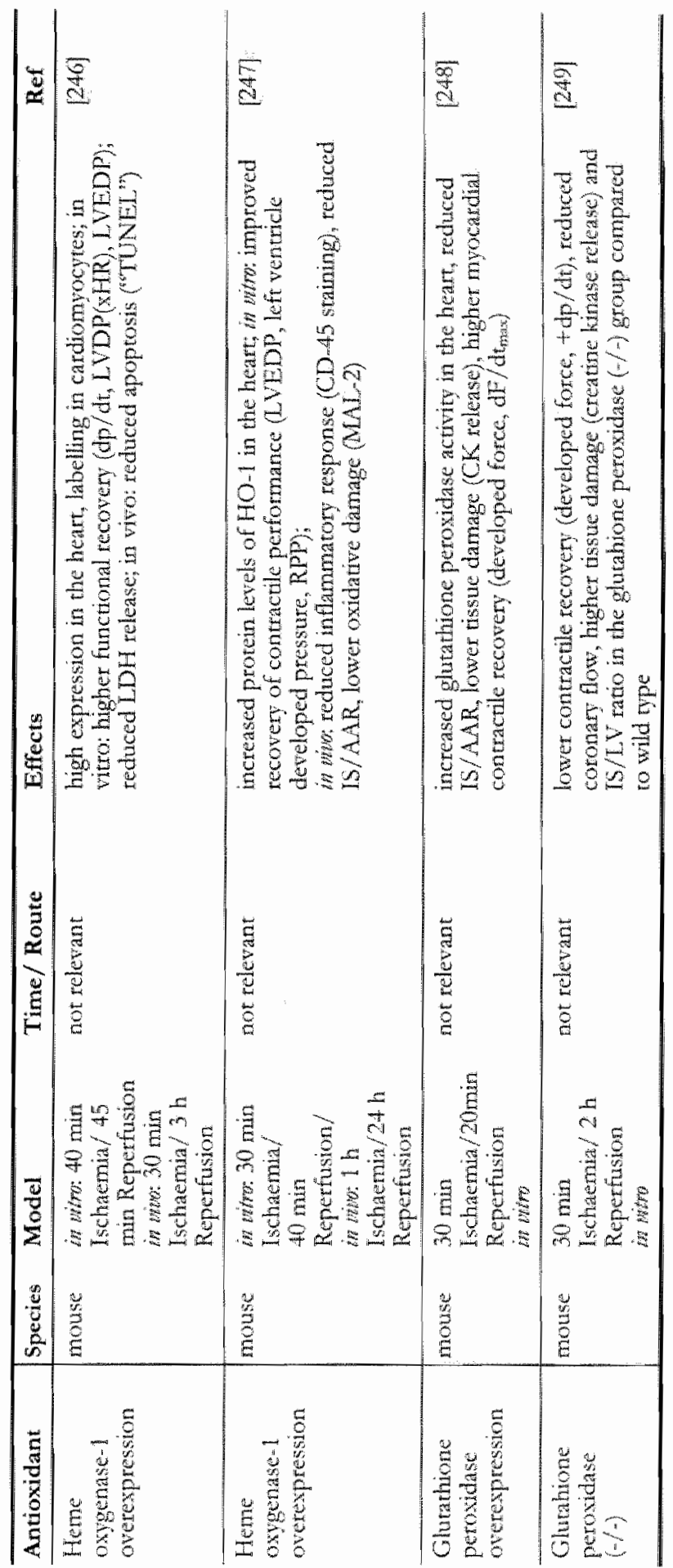


- Chapter 1

Owerall we can conclude that studies with transgenic mice in which endogenous levels of antioxidant cnzymes are altered yicld more consistent results in support of a role for ROS in myocardial IR injury than animal studies in which antioxidant enzymes were exogenously administrated. This difference may reflect a need for substantial elevations in intracellular antioxidant enzyme levels for protection aganst cardiac IR, achieved by exogenous administration of antioxidant enzymes.

\subsubsection{Interventions with antioxidant agents}

Many studies have examined the role of less specific antioxidant interventions in reducing cardiac IR injury. Around 50 publications were found in literature and are listed in table 5. "These antioxidants can be grouped into nine different classes, i.e. vitamin $\mathrm{C}$ - and E-like antioxidants; polyphenolic compounds; melatonin or structural analogues; cytochtome $P_{450}$; lipid peroxidation inhibitors; xanthine oxichase inhibitors; glutarhione analogues; derivatives of thiourea and pyruvate; and miscellaneous. "Their: effects are discussed in separate sections below.

\section{Vitamin $\mathrm{C}$ - and E-like antioxidants}

Vitamin $\mathrm{E}$ ( $\alpha$-tocopherol) is a lipid-soluble vitamin which resides in cell membranes and acts physiologically as a free radical scavenger by breaking peroxyradical chain reactions of membrane lipids [250]. Using a model of saline-perfused rabbit heart muscle, Guarnict $t$ al were the first to describe protective effects of $\alpha$-tocopherol against TR injury [251]. The protection was shown in three ways, including reduced rates of enzyme leakage, some preservation of the endogenous energy-rich phosphate reserves, and the maintenance of mitochondrial respiratory function to near control levels. These in witro protecrive effects of $\alpha$-tocopherol were confirmed by Massey ot al. [252] and Chen et al. [253].

Protective effects of $\alpha$-tocopherol were less obvious in win. One stady proved protective effects [254] while two studies could not [255, 256]. An explanation for these conflicting in wo results is not evident. The achieved myocatial vitamin $E$ levels may be different between studies and depend on the duration, dose, time point or route of administration 255$]$.

In this tegard, acute administration of a-tocopherol is not feasible due to its high lipophilicity and slow tissue incorporation [252, 257]. Consequently, vitamin E analogues such as IRFT 042 [258], MDL analogues [259-262] and Raxofelast [263], with less lipophilic character have been developed. These agents showed in win protective effects in a rat model of cardiac IR. In the case of MDT-73404, reduced infarct size and improved recovery of cardiac output wete demonstrated 8 days after repertusion $[259]$.

Vitamin $C$ was not tested as mono-therapy but only in combination with vitamin $\mathrm{E}[257]$. On this basis no conclusions can be drawn about possible protective eftects of vitamin $C$ in cardiac IR. 


\section{Polyphenolic compounds}

Epidemiological evidence indicates that the consumption of red wine is beneficial in the prevention of coronary heart disease [301, 302]. This beneficial effect has been attributed to the antioxidants present in the polyphenolic fraction of red wine which include phenolic acids, trihydroxy stilbenes, oligomeric ptoanthocyanidins, and the Alavonoids [303-305].

Polyphenols i.e flavonoids (quercetin, flavones, baicalein, purpurogallin, proanthocyanidin) and the trihydroxy-stilbenes (resveratrol and astringinim) have been tested for their ability to reduce cardiac IR injury. The polyphenolic compounds have in who $[264-266,269-271]$ as well as in vino $[267,268,272]$ cardioprotective effects.

Wu al al found in wivo protective effects of the flavonoid purpurogallin which were superior in regard to infarct size compated to the protective effects of "Trolox, a vitamin E analogue [267].

\section{Melatonin}

Melatonin (n-acetyl-5-methoxytryptamine) is a homonal product of the pineal gland with a highly lipophilic nature. It has the ability to directly scavenge free radicals and has also been reported to alter the activities of enzymes (as superoxide dismutase and nitric oxide synthase) which improve the antioxidant defence capacity of the organism $[306,307]$.

Duting cardiac IR, melatonin has proven in witw protective effects [274-276]. However, in wivo protective effects of melatonin as tested in mice and rats, were only present shortly after initiation of reperfusion ( $2 \mathrm{~h}$ ) but not at a longer term ( $6 \mathrm{~h}$ and 24 h) [273]. This may be explained by the short half-life reported for melatonin [308]. In addition, these in wiv protective effects were dose dependent and not present when melatonin was administered intraperitoneally (i.p.) during reperfusion [273].

In contrast, injection of melatonin directly into the left ventricle right before reperfusion conferred cardioprotection [273]. Therefore, to obtain a protective effect, a certain time is necessary for sufficient uptake of melatonin into the blood circulation after i.p. administration [273].

\section{Cytochtome $P_{450}$ inhibitors}

Granville of al. demonstrated in witro as well as in wo protective effects of cytochrome $P_{450}$ inhibitors $[277]$. Chloramphenicol, cimetidine and sulfaphenazole reduced superoxide production and consequently reduced infarct size after IR [277|. This suggests a role for cytochrome $P_{430}$ in the generation of oxidative stress during myocarcial IR.

\section{Lipid peroxidation inhibitors}

As described before (section 2.4.2.), lipid peroxidation importantly contributes to tissue damage during cardiac IR [309-311]. The experimental compounds $074389 \mathrm{G}$ 
and $\mathrm{UT}_{4006 \mathrm{~F}}$ are members of the group of 21 -aminosteroids lacking classical glucocotticoid or mineralocorticoid activity. These agents have been termed "lazaroids" $[312,313]$ and are known as potent in vitro inhibitors of lipid peroxidation in a manner similar to witamin $E[279,312,313]$. They act protective during $i s$ witro IR [280]. In who protective effects for $U 74389 \mathrm{G}$ during IR have been obtained in a heart transplantation model [278] but not in a model of transient coronary artery occlusion [279]. Another lipid peroxidation inhibitor, indenoindole $\mathrm{H} 290 / 51$, diminished infarct size and improved recowery after in wizo IR.

\section{Xanthine oxidase inhibitors}

As mentioned before (section 2.3), xanthine oxidase is a majot potential source of superoxide radicals and plays an important role in the genesis of IR injury. The xanthine oxidase inhibitors allopurinol and its active metabolite oxypurinol wete tested in rat and dog models of $I R$, respectively. Beneficial effects, being a reduction in cardiac tissue damage [283], improved recovery of ventricular furction [265, 283], and teduced incidence of arrhythmias were demonstrated shortly after initiation of reperfusion (10-30min). However, long-term protective effects for oxypurinol could not be demonstrated [216].

\section{Glutathione analogues}

$\mathrm{N}$-(2-mercaptopropionyl)-glycine (MPG) is a low molecular weight synthetic analogue of glutathione, an important endogenous antioxidant. Studies on potential in wivo protective effects of MPG during ischaemia and reperfusion yielded conflicting results. Mitsos et al. [104] could prove protective effects after $6 \mathrm{~h}$ of reperfusion while others did not [284, 285]. In another study only short-term (3 h) but no long-term protective effects ( $72 \mathrm{~h}$ ) [287] of MPG were found. From another set of studies it appeared that protection was dependent on the time point of drug administration $[286,288,289]$ and on the duration of the ischaemic pertiod [290]. This may suggest that MPG has only a shott duration of action [290]. 
General Introduction -

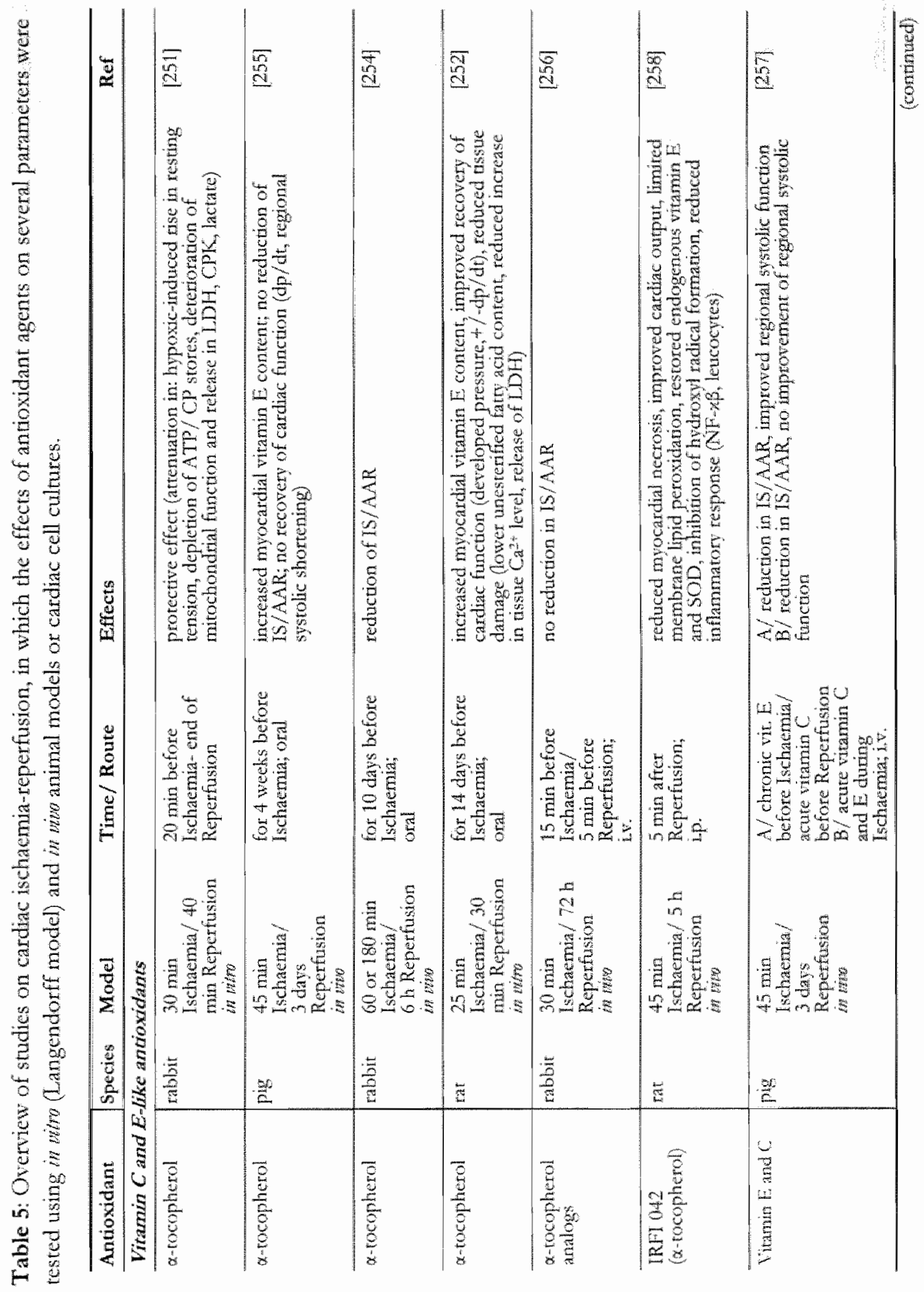


- Chapter 1

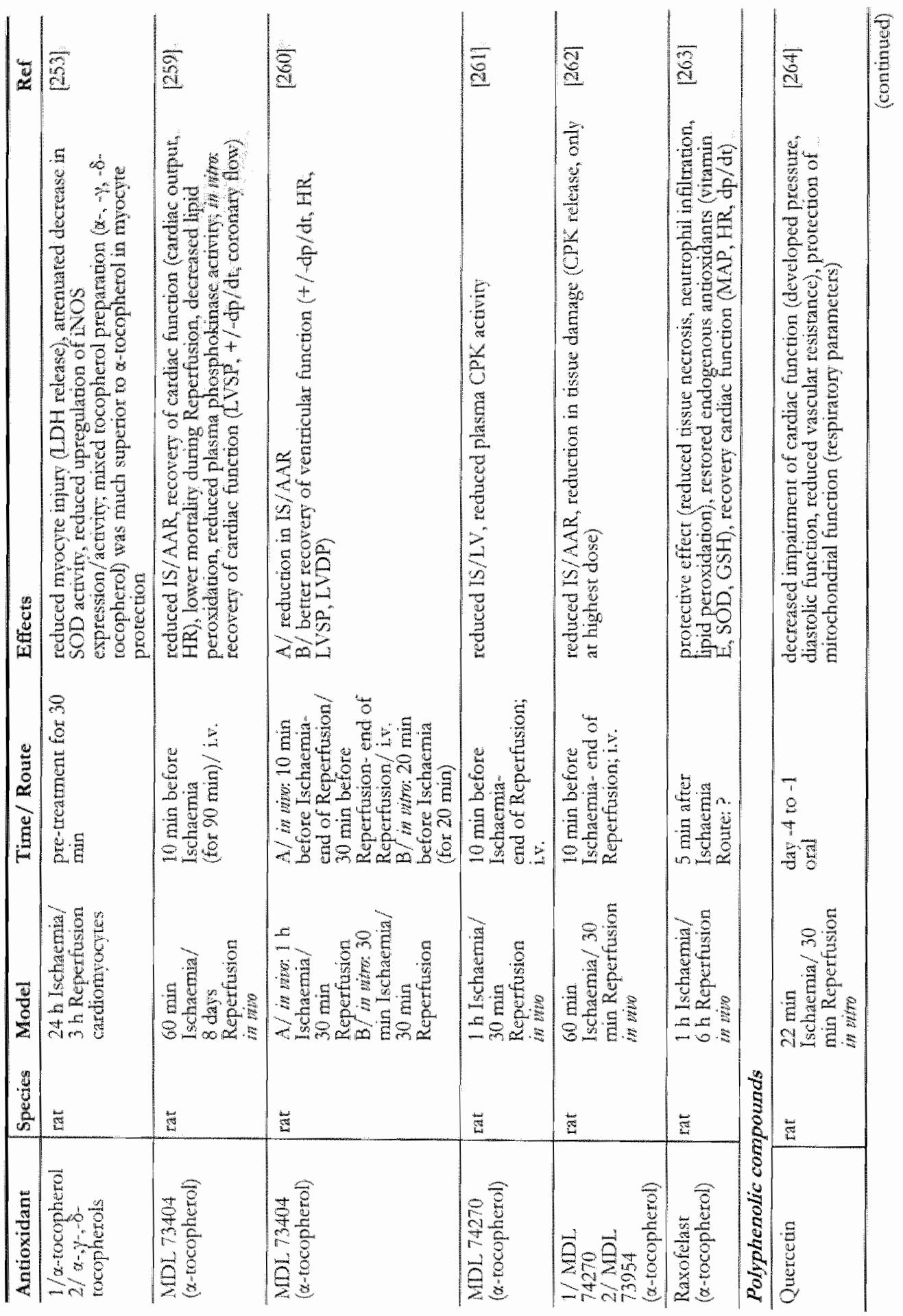


Genetal Introduction -

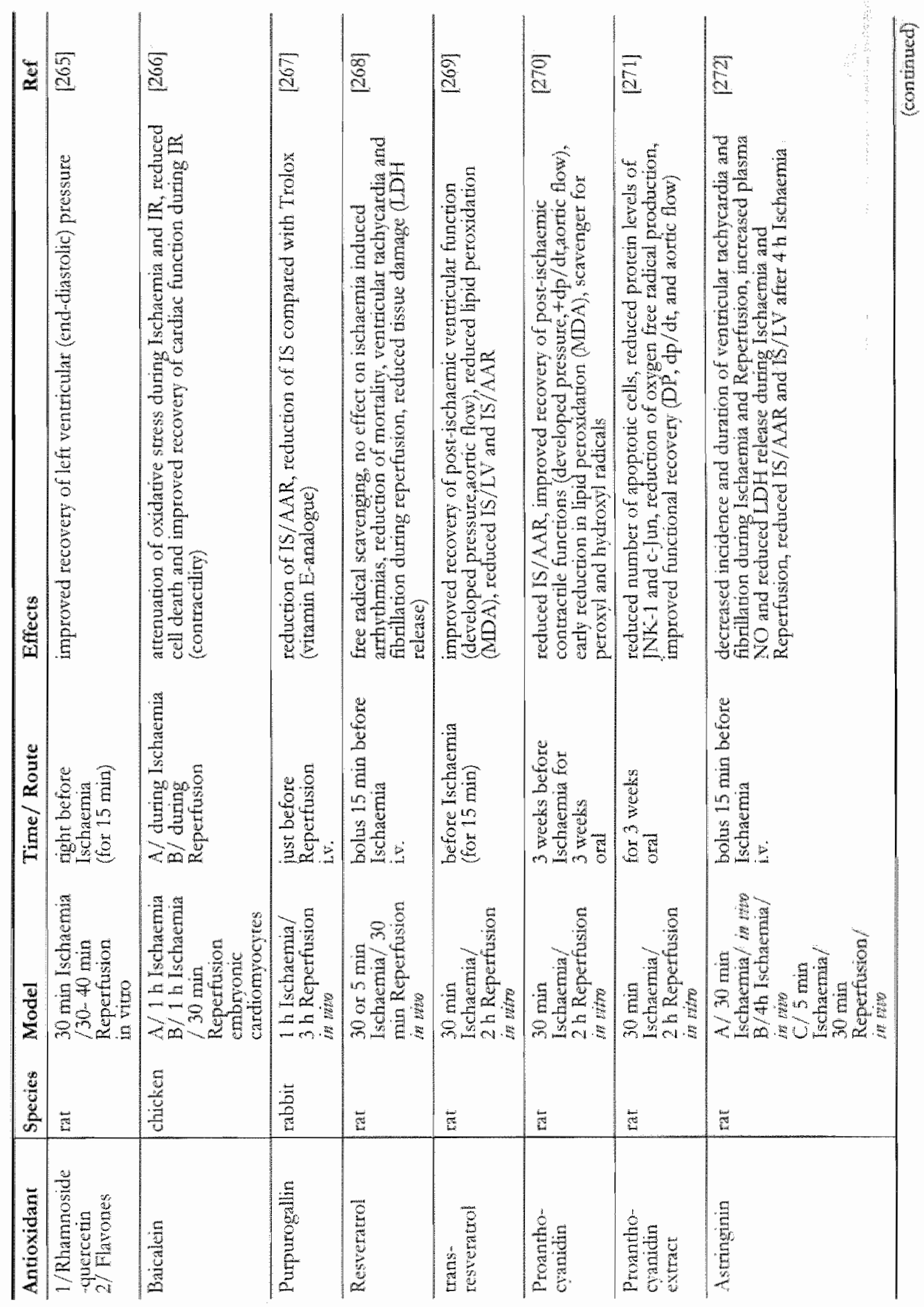




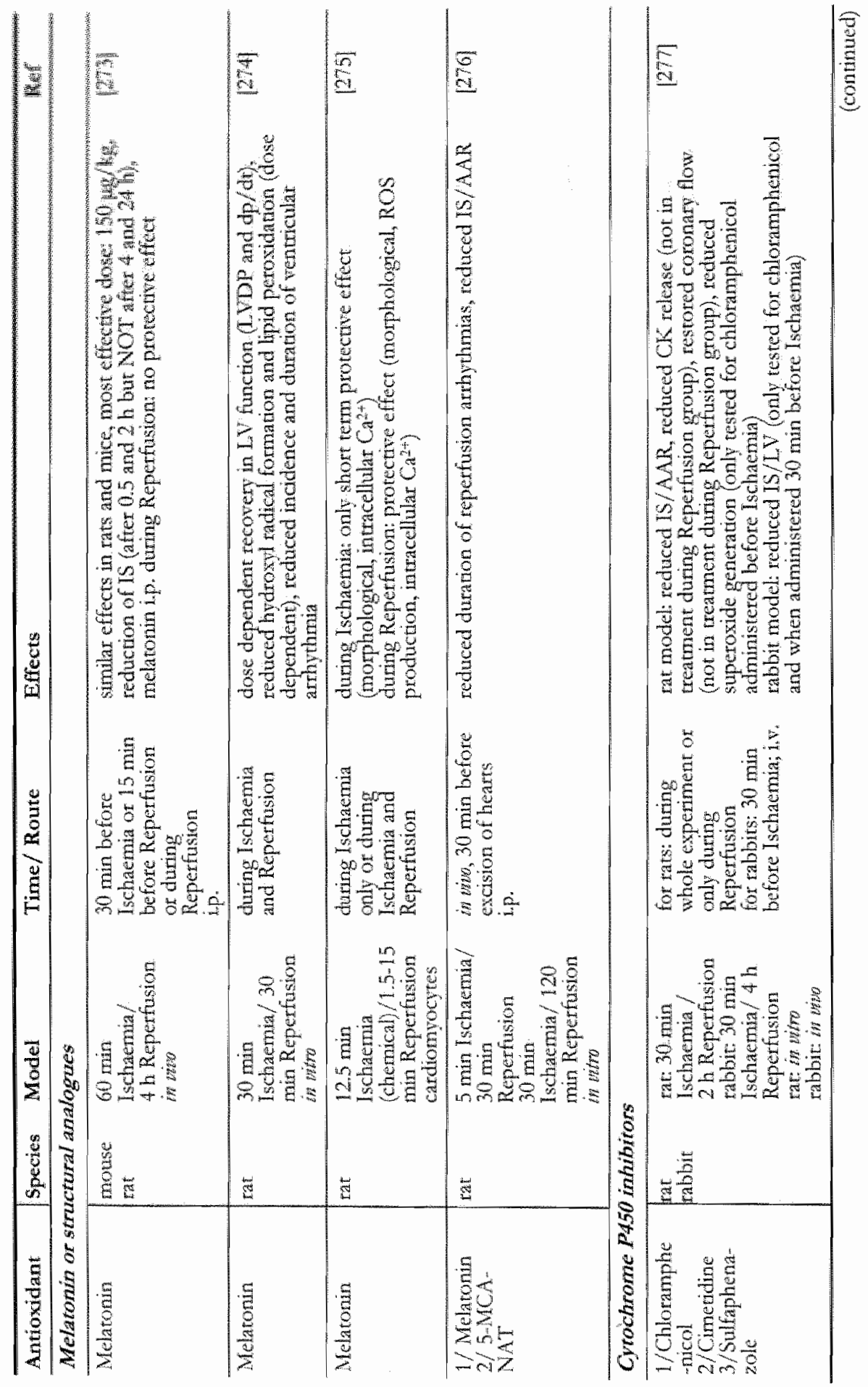


General Introduction -

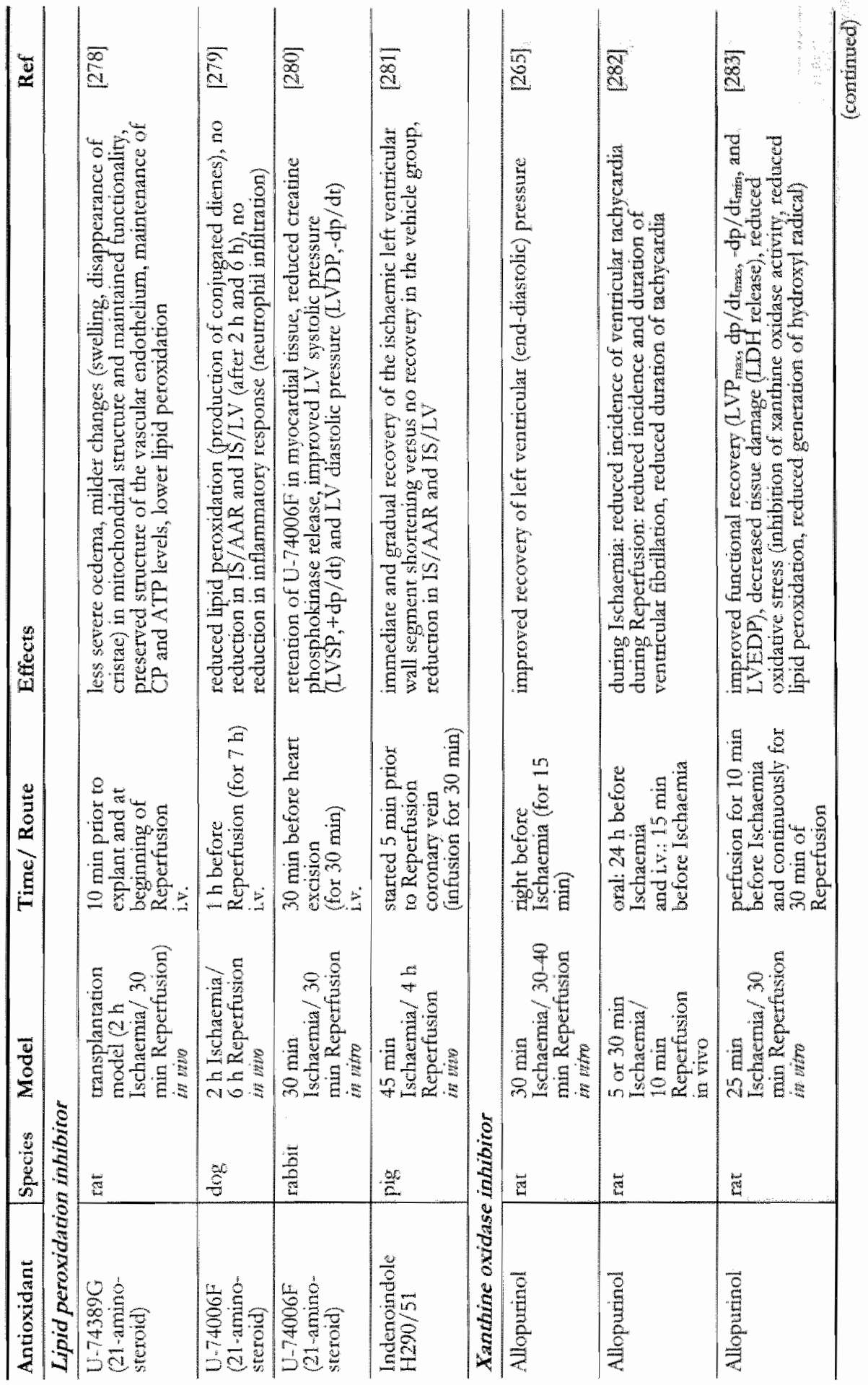


- Chaper 1

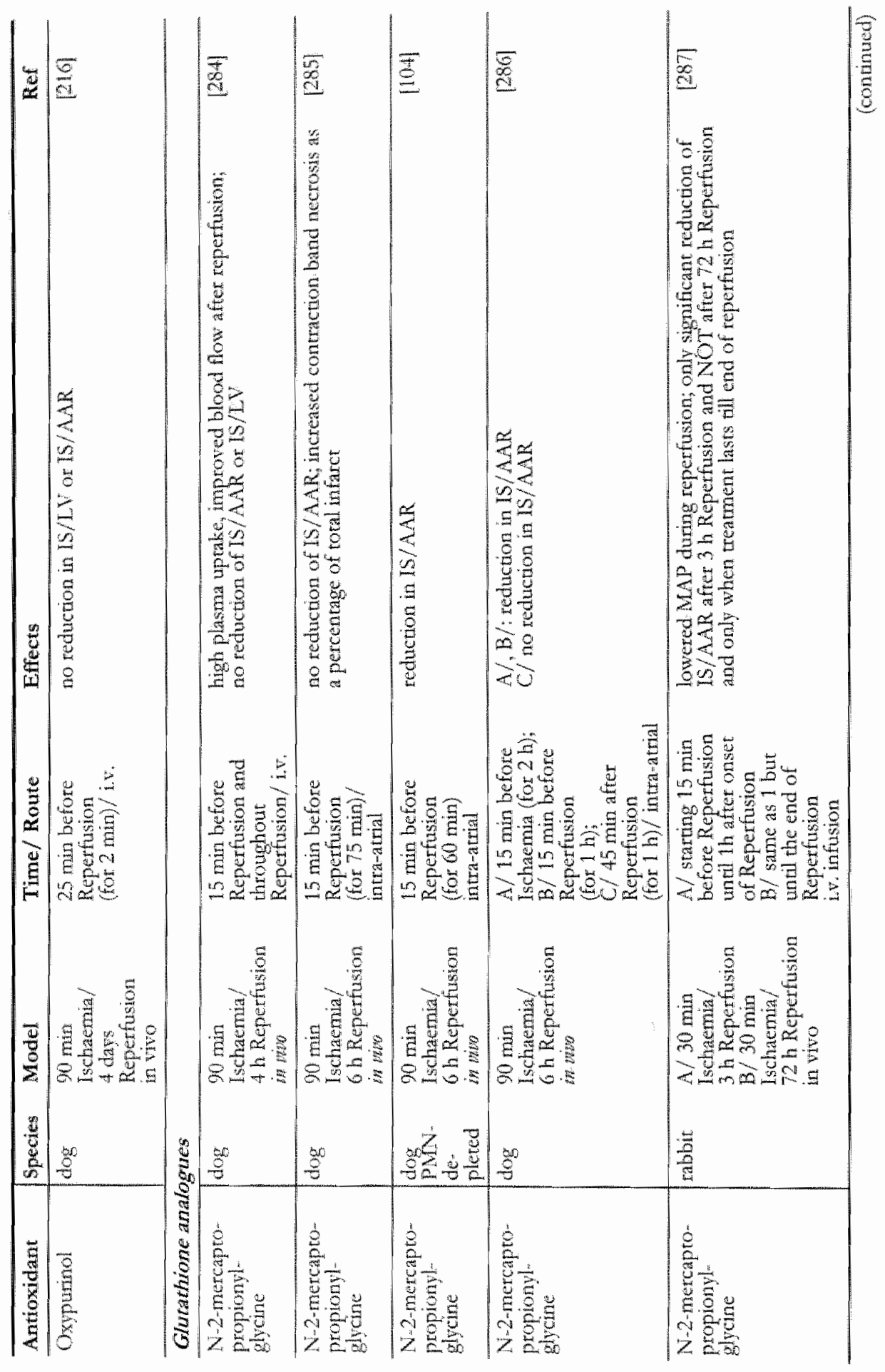


General Introduction .

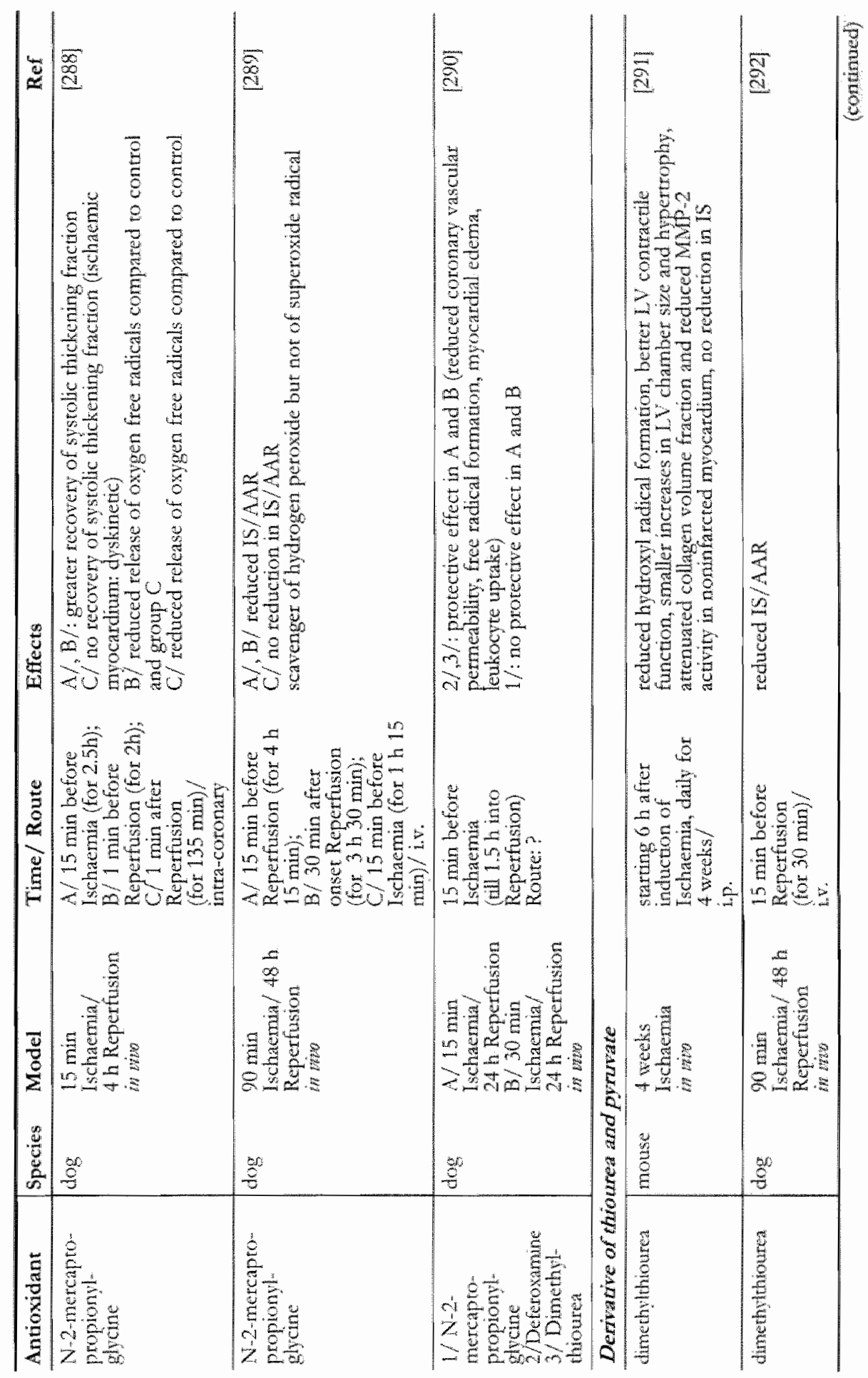


- Chapter 1

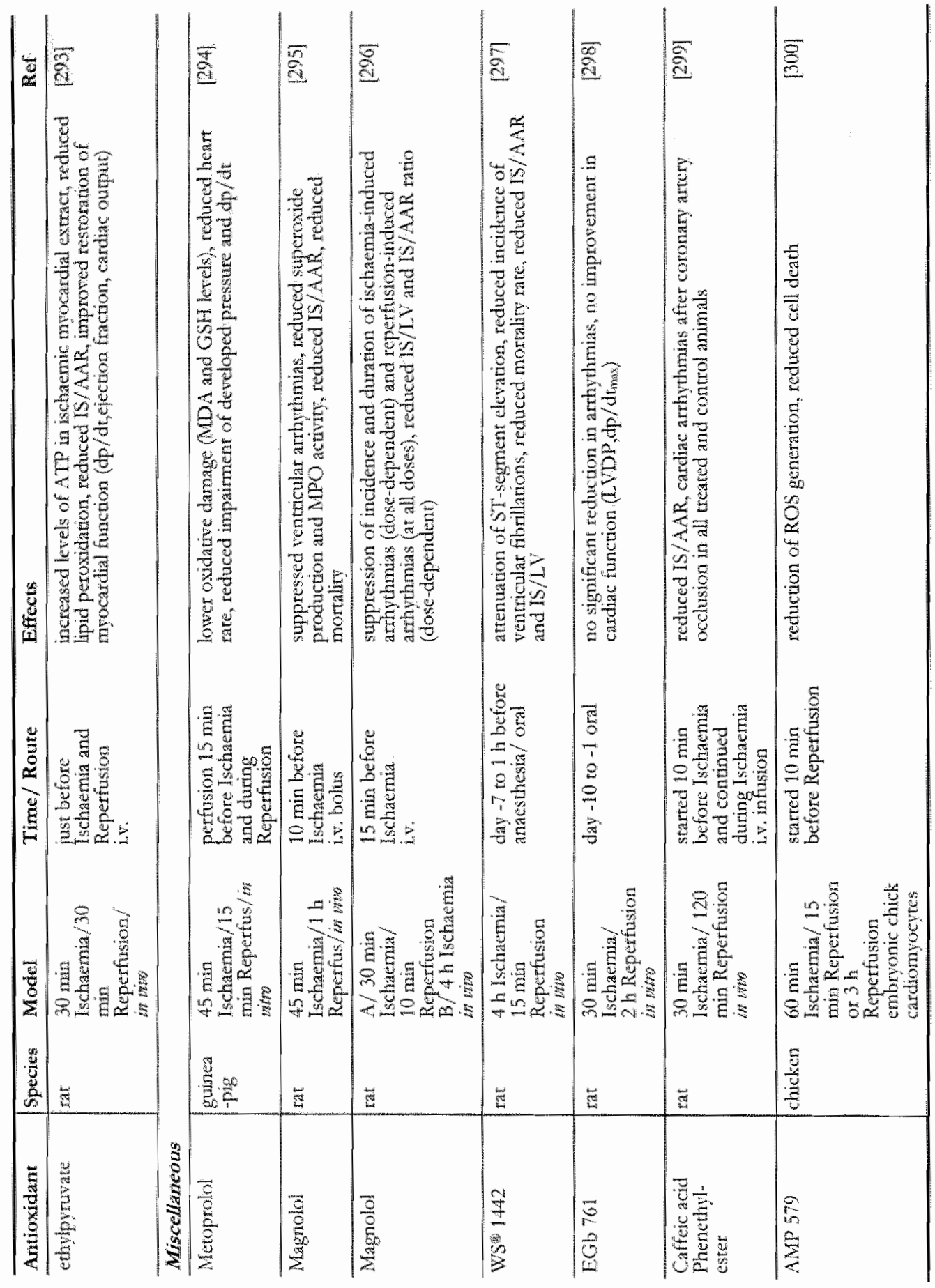




\title{
Derivative of thiourea and pyruvate
}

Dimethylthiourea (DMTU) is a low molecular weight agent which is highly diffusible, has a long half-life, and is an effective scavenger of hydrogen peroxide, hydroxyl radical, and hypochlorous acid [314]. DMTU reduces infarct size in an in vivo dog model of IR [292]. In addition, daily treatment with DM'TU prevented left ventricular remodelling (myocardial dilatation and hypertrophy, interstitial fibrosis) in an in wivo model of myocardial infarction [291]. This suggests a role for ROS in ventricular remodelling after myocardial infarction [291].

Ethyl pyruvate, a commercial food additive, is a lipophilic ester derivative of pyruvate with improved stability compared to pyruvate [293]. It was shown that ethylpyruvate attenuated myocardial oxidative injury, decreased infarct size, and preserved cardiac function after IR [293].

\section{Miscellaneous}

\begin{abstract}
Metoprolol
$\beta$-adrenergic blocking drugs are known to exert negative inotropic and chronotropic effects by reducing cardiac sympathetic nerve activity [294]. They are therefore used in the treatment after myocardial infarction to reduce myocardial energy demand and arrhythmias. Kalaycioglu et al. [315] showed that metoprolol also prevents myocardial IR injury by reducing oxidative stress and prevention of lipid peroxidation. However, if this lipid peroxidation reducing effect is due to an intrinsic antioxidant effect of metoprolol or an indirect effect due to the reduction of sympathetic nerve activity is not clear [315].
\end{abstract}

\section{Extracts from Cbinese medicinal berbs, trees or plants}

This group includes magnolol which is an active component extracted from the Chinese medicinal herb Magnolia officinallis; WS ${ }^{0} 1442$, an extract from the Hawthorn Crataegus; $E \mathrm{EG}$ 761, extracted from the tree Ginkgo bilobo, and finally caffeic acid phenethyl ester which is derived from honeybee propolis. Protective effects of these extracts in the setting of cardiac IR are not clear. Magnolol $[295,296]$ and WS 1442 [297] reduced arrhythymias and infarct size in an in vivo rat model of IR. In contrast EGb 761 [298] could not reduce arrhythmia or improve cardiac function during in vitro IR. Caffeic acid phenethyl ester $[299]$ could reduce infarct size but not the in wivo cardiac arrhythmias.

\section{AMP 579}

The rate at which isolated chick cardiomyocytes die following a period of simulated ischaemia was attenuated by the adenosine $A_{1} / A_{2}$ receptor agonist AMP 579 given just before reperfusion [300]. AMP 579 decreases the burst of reactive oxygen seen at reoxygenation. This effect was dependent on adenosine A2 receptor binding. However, adenosine could not duplicate these effects, indicating that AMP 579 has protective actions apart from its effect on adenosine receptors. 
- Chapter 1

\subsection{Antioxidants in clinical trials of reperfusion therapy}

Numerous studies have evaluated the influence of superoxide dismutase, vitamin $C$, vitamin $\mathrm{E}$, and thiol compounds alone or in vatious combinations on $\mathrm{R}$ injury in patients undergoing reperfusion therapy after myocardial infarction. However, despite many research efforts and a wide avalability of antioxidant agents, there is at the moment no clinical evidence for the routine use of antioxidants in the clinical setting of ischaemia and reperfusion.

\section{Recombinant human superoxide dismutase}

Recombinant h-SOD has been tested in two clinical trials of patients undergoing thrombolysis [316] or coronary angioplasty [317] for acute myocardial infarction. In the first trial in 34 patients with acute anterior myocardial infarction recerving thrombolytic agents, h-SOD was randomly administered just before reperfusion [316]. Although a significant reduction in the total number of ventricular premature complexes was observed during the first 15 minutes of reperfusion, SOD treatment failed to significantly improve left ventricular regional ejection fraction [316]. Subsequently, a multicenter, randomized, placebo-controlled clinical trial with 120 patients was designed to rest the hypothesis that free radical-mediated reperfusion injury could be reduced by intravenous administration of h-SOD, administered before PTCA, in patients with acute transmural myocardial infarction [317]. The results of this clinical trial failed to demonstrate a beneficial effect of h-SOD on global or regional left ventricular functions in patients who underwent successful PTCA [317]. The authors don't have a clear explanation for these disappointing results. They mentioned that a clinically significant benefit might have been missed with such a small sample size because of the heterogeneity of intercoronary collaterals, vascular risk regions, and other important uncontrolled wariables. They also indicate that the mean time to reperfusion was 4 hours after the onset of chest pain, a period sufficient to induce irreversible damage, without potential to recover [317].

\section{Vitamin C}

Results of the clinical studies of otal supplementation with vitamin $\mathrm{C}$ are rather contradictory. While most of the studies utilizing variable doses and regimens of vitamin supplementation achieved reduction in biochemical indices of reperfusion injury, this correction did not universally convert into better functional recovery and significant clinical betnefit $|318-320|$. In the studies of Dingchao at al protective effects of high-dose witamin $C$ on the myocardium were observed in patients undergoing cardiopulmonary bypass 13211 . They observed that postoperative cardiac index was higher in vitamin $C$-treated patients than in their controls. This effect was associated with shorter intensive care and hospital stay.

In contrast, when vitamin $C$ was infused intravenously prior to PTCA after acute myocardial infarction there was no lowering of the urine level of 8-epi prostaglandin 
$\mathrm{F} 2 \alpha$, an indicator of oxidative stress [322]. No functional cardiac parameters were tested in this study:

\section{Vitamin $\mathrm{E}$}

The data obtained with vitamin E supplementation are also variable. Studies with oral vitamin $E$ intake face the difficulty of achieving increased tissue concentrations of vitamin $\mathbb{E}$. This problem is demonstrated in the studies of Mickle at al where different doses administered the night before cardiac surgery or a 3 day course did not increase myocardial vitamin $\mathrm{E}$ concentrations [323]. They observed that 2 week oral therapy was required to double the myocardial vitamin $E$ concentration. In the studies of $\mathrm{Yau}$ et al [324] vitamin E had a small but significant metabolic and functional effect after elective coronary bypass operations in low-risk patients. Sisto et al [325] investigated higher risk patients and reported that the treated group had a reduced number of perioperative ischaemic events, myocardial infarctions, and arthythmias. However, since vitamin $E$ treatment was combined with vitamin $C$ and allopurinol, the individual contribution of the vitamin E treatment cannot be determined. In contrast to the above studies showing clinical benefit, another clinical study, pretreating patients undergoing coronary artery bypass grafting with oral vitamin E for 7-1.0 days and otal vitamin $\mathrm{C}$ for $12 \mathrm{~h}$, provided no measurable teduction in myocardial injury despite prevention of the depletion of vitamin $E$ in plasma [318]. Finally, in a study by Lassnigg et al normalization of plasma vitamin E concentrations with parenteral vitamin $\mathbb{E}$ emulsion did not affect biochemical markers of myocardial injury and clinical outcome after cardiac surgery [326].

\section{Thiol compounds}

Attempts to enhance intracellular glutathione, frequently utilized N-acetylcysteine (NAC), a membrane permeable precursor of GSH synthesis. Fertari at at reported beneficial effects in patients where the degree of oxidative stress following reperfusion was reduced and recovery of cardiac function improved [327]. Arstall at al 1328 | explored the safety of NAC in combination with nitroglycerin and streptokinase for the treatment of evolving myocardial infarction. NAC administration appeared to be safe and was associated with significantly less oxidative stress, a trend toward more rapid reperfusion, and better preservation of ventricular function. The ISI AND (Infarct Size Limitation: Acure N-acerylcysteine Defense) trial was a randomized, angiography-, and echocardiography-controlled study [329]. In patients with successful reperfusion induced by a combination therapy including streptokinase and NAC, there was a reduction in infarct size associated with improved $L V$ function when compared to patients with reperfusion induced by streptokinase alone or compared to patients with failed reperfusion. Despite these promising small-scale trials, no large-scale studies have been conducted uptill now, to confirm a clear benefit of NAC in reducing reperfusion injury in the reatment of acute myocardial infarction or surgically induced IR during candiac surgery [329]. 
- Chapter 1

\subsection{Conclusion}

Reactive oxygen species are generated at an accelerated level in the postischaemic myocardium and contribute to modifications of several biomolecules leading to myocardial tissue injury. Multiple enzymes and subcellular structures contribute to enhanced ROS production and oxidative stress associated with ischaemia and reperfusion. Despite many research efforts and a wide availability of antioxidant agents tesults ate conflicting and disappointing. A better understanding of the action of antioxidants in the setting of $\mathbb{R}$ is needed before the therapeutic potential of free radical-directed drugs can be fully realized in a clinical setting. 


\section{Proteomics in cardiovascular disease}

\subsection{Introduction}

Proteomics is the study of the "proteome" or the entire protein complement of a genome, a term first coined in 1995 by Marc Wilkins $[330,331]$. The proteome is far more complex than previously suggested by the one-gene, one-protein theory. The proteome consists of all proteins present in a cell, tissue or organism at a given time, including not only those translated directly from genetic material but also the variety of modified proteins arising from alternative splicing of transcripts, from extensive coand posttranslational processing, or from a combination of these. These protein modifications have the potential to alter protein structure and/or function.

Since proteins are involved in virtually every cellular function and in every regulatory mechanism, the proteome dictates the phenotype of the cell and, collectively, the tissue or organ that the cells comprise. This phenotype varies under normal conditions, such as cell cycle stage, differentiation, function, and ageing, or as a result of the onset of interventions or in response to acute injury or chronic diseases. In the acute phase, rapid posttranslational modifications of proteins occur, whereas in chronic disease or treatment states, co- and posttranslational protein modifications occur in concert with altered gene expression, leading to a wide variation in protein levels and modifications. For specific proteins, disease-induced modifications will substantially affect function, which in turn has the potential to affect the action of other proteins. The result is a dynamic, ongoing process of protein expression and modifications. Proteomics is aimed at identifying and characterizing these protein changes for example in relation to certain pathologies or drug therapy.

In the next sections we will explain the traditional technique of $2-\mathrm{D}$ gel electrophoresis and mass spectrometry employed to characterize changes in the proteome (section 3.2). A complete overview of the results achieved in cardiovascular reseatch by the use of this technique is given in section 3.3. Post-translational modifications and the advantages and usefulness of subcellulat proteomics are included in the latter section. In section 3.4, the results, (dis)advantages of transcriptomic (RNA) and proteomic (protein) analysis in the field of cardiovascular research are compared. We will finalize this chapter with an explanation about functional proteomics and illustrate it with the functional proteomic analysis of the PKCe complex.

\subsection{Two-D gel electrophoresis combined with mass spectrometry}

Two-dimensional gel electrophoresis has been the primary tool for obtaining a global picture of the expression levels of proteins in the total proteome of cells or tissue, under various conditions [332]. By this technique a protein mixture is separated by making use of two intrinsic protein characteristics, i.e. net charge and molecular mass.

The first stage involves isoelectric focusing (IEF), where proteins ate separated according to their isoelectric point ( $\mathrm{pl}$ ), using immobilised $\mathrm{pH}$ gradients (IPG). Proteins applied to these IPG strips migrate in an electric field and stop 
migrating through the pH gradient when their net charge is neutral. These IPG strips are widely avalable in vatious formats, from wide range covering many $\mathrm{pH}$ units, to narrow $\mathrm{pH}$ ranges covering just one or two $\mathrm{pH}$ units. Nartow range strips provide much greater resolution and can be overlapped to overspan the desired $\mathrm{pH}$ range $[333-335]$.

After completion of the first dimension separation by pl, protens are separated by molecular weight in polyacrylanide gels containing sodium dodecyl sulphate (SDS). SDS is an anionic detergent which denatures the proteins, converting them to a linear molecule by relaxing their secondary structure. Because of its anionic nature it gives proteins a net negative charge and proteins are therefore exclusively separated by moleculat mass.

Once the protein spots are separated they can be visualized on the gels using a variety of stains such as coomassie brilliant blue stain, which will detect proteins present in amounts between $10-40 \mathrm{ng}$. The sensitivity can be enhanced by silver staining, which can detect proteins in the 2-5 ng range [336]. However, with silver staining it is important to avoid cross-linking reagents such as glutaraldehycle, as the use of aldehydes makes the protein less susceptible to protease digestion and reduces therefore the efficiency of subsequent mass spectrometry [337]. Recently, developments in fluorescence technologies have led to the production of fluorescent protein dyes such as Sypro Ruby and CyDyes with sensitivity similar to silver stains. The advantages of protein detection with Sypro Ruby are that it is technically simple to use, its high sensitivity (1-10 ng), its linearity over 3 orders of magnitude and its compatibility with downstream analysis including mass spectrometry (see further) and Edman sequencing ( $N$-terminal tesidue identification) [338, 3391. CyDyes are used in fluorescence 2D difference gel electrophoresis (DIGE), where up to three different samples are separated on a single gel, because these samples have each been labelled before 2D electrophoresis with a different fluorescent cyanine dye (Cy2, Cy3, Cy5). Each dye can then be visualized under a different wavelength and the images overlaid, giving a combined image that can be analyzed with high teliability [ 340 ].

Afrer separation and detection, proteins of interest must be identified. For this, the most significant breakthrough in the evolution of proteomics is the development of mass spectrometry (MS) for protein identification [341]. Protein identification is based on the analysis of peptides generated by proteolytic digestion (for example trypsin digestion). In all mass spectrometers, peptides are ionized from the sample. This is achieved either by matrix-assisted laser desorption/ionization (MALDI) of a solid-state sample or by electrospray ionization (ESI) directly from the liquid phase. Ionized peptides are separated on the basis of their mass-to-charge ratio $(\mathrm{m} / \mathrm{z})$ and identified according to their time-of-flight (TOF) distribution or analyzed by quadrupole mass filters. In tandem MS/MS, an ionized peptide of interest is selected by the first MS and fragmented by collision with inert gas. 'The resulting fragments are then analyzed in the second MS. Modern ESI-based MS/MS may use liquid chromatography (1.C) systems such as capillary zone electrophoresis or very low flow-rate reversed phase high performance-IC (HPLC) before ionization, in order to fractionate complex mixtures. MS provides precise peptide masses for protein chatacterization, whereas more sophisticated instruments (particularly tandem MS) 
also allow peptide sequence determination to identify the protein. Nore recently, mass analyzers have been combined to create tandem mass spectrometers (TOF-TOF). In this instrument, $\mathrm{m} / \mathrm{z}$ values are selected by their time-of-light and all others are deflected from the flight path. The ions then pass into a collision cell and andergo high-energy collisions with an inert gas such as helium, causing fragmentation of the ions which is referred to as collision-induced dissociation (CID). The additionally obtained masses of these peptide fragments, allow more reliable chatacterization of the protein.

\subsection{Application of proteomics to cardiovascular research}

\subsubsection{Heart 2-DE protein databases}

Proteomics of the heart started in the 1990 s with the creation of 2 -DE protein databases. Pioneering proteomic work by the laboratories of Michael J. Dunn (United Kingdom) and Peter Jungblut (Germany) led to the creation of several online 2-DE databases of human, dog, rat and mouse atrial and ventricular myocardial proteins [342-345]. The four main databases are HSC-2DPAGE, HEART-2D-PAGE, HP-2DPAGE and RAT HEART-2DPAGE and conform to the rules for federated 2-DF protein databases [346]. Pleißner and co-workers have included a link to heart proteins associated with dilated cardiomyopathy in their database [347].

\subsubsection{Proteomics of dilated cardiomyopathy}

Until November 2004, in the area of cardiovascular research, the technique of proteomics has been predominantly applied to dilated cardiomyopathy (DCM) and is therefore discussed in more detail in this section.

Dilated cardiomyopathy in humans is a severe disease of the heart characterized by impaited systolic function with reduced ejection fraction, increased end systolic blood volume and dilatation of the ventricles 1348]. The pathophysiology of DCM is less clear and genetic factors, myocarditis from infectious agents, autoimmune mechanisms, cytokine activation, toxic damage like alcohol abuse and hormonal or" metabolic influences can play a role [348].

Two-dimensional gel electrophoresis has been applied to identify alterations in the myocardial protein pattern that characterize dilated cardiomyopathy. Subsequent identification of specific pathology-associated proteins has been achieved by visual comparison with database images, $\mathrm{N}$-terminal protein mictosecuencing, and MS. Cardiac tissue (ventriculat and atrial) from patients suffering from DCM 1349 3511 and animal models representative for human DCM, i.e. bovine hereditary DCM $[352,353]$ and a canine model of pacing-induced heart failure 352,354$]$ have bern analyzed. As table 6 shows, more than 50 cardiac proteins have been identified that significantly alter their expression level in DCM $[349,351,355-357]$.

Results of proteomic studies of cardiac tissue from the three species (human, canine and bovine) are very similar, i.e. the majority of these proteins being less abundant in the diseased heart (table 6) $[349,351,355-357]$. 


\section{- Chapter 1}

These proteins have been classified into three broad functional classes i.e. 1/ cytoskeletal and myofibrillar proteins, 2 / proteins associated with mitochondria and energy production and $3 /$ proteins associated with stress responses (table 6).

The most significant DCM-related change was a 7 - fold increase in ubiquitin carboxylterminal bydrolase (UCH) in bovine [353]. UCH is a deubiquitinating enzyme responsible for maintaining the cytoplasmic pool of free ubiquitin. In contrast to the other identified proteins, the possible consequences for the change in expression level of this enzyme have been investigated in mote detail $[349,359,360]$. Therefore we further limit outselves to this protein.

It was reasoned that an increase in the abundance of UCH during DCM, could increase the intracellular concentration of ubiquitin and thereby facilitate increased protein ubiquitination in the disease state, leading to proteolysis of the targeted proteins via the 265 proteasome pathway [359]. In relation to this, inappropriate ubiquitin conjugation has already been proposed to contribute to heart failure [359]. A follow-up study showed that UCH is also more than 8-fold elevated at the protein level and more than 5-fold elevated at the mRNA level in human DCM hearts [360]. As shown with immunohistochemistry, the increased expression of UCH was present in human DCM cardiomyocytes and not in control hearts [360]. 'The incease in UCH level in human DCM hearts was associated with a 5 -fold increase in overall protein ubiquitination relative to control hearts [360].

Using a selective affinity purification method enhanced ubiquitination of a specific set of proteins has been demonstrated in these human DCM hearts [360]. These proteins have been subsequenty identified by mass spectrometry. Some of these proteins were reduced in abundance in bovine DCM [349] and are marked in grey in table 6. It was bypothesized that these data add support to the theory that inappropriate ubiquitination and proteolysis of a specific set of proteins occurs in DCM and that this contributes to cardiac dysfunction in the diseased heart [360].

\subsubsection{Proteomics of ischaemia and ischaemia-reperfusion}

Two-dimensional gel electrophoresis combined with mass spectrometry has also been applied to identify proteins that changed in expression level following myocardial ischaemia and IR. The technique has been applied in an in wrobbit [361] and canine 1362 model of IR as well as in an in wro rat model of ischaemia and IR [363].

Firstly, in an in vino rabbit model of cardiac IR, Schwertz at. [361] found 10 protein spots that were differentially expressed. Two could be characterized as superoxide dismutase precursor and $\alpha$ B-crystallin and were both decreased in expression after TR. Secondly, Sawicki ef al. [362] found in an in win canine model of myocardial IR regional changes in the level of metabolic enzymes, with increased levels of NAD -isocitrate dehydrogenase, $\alpha$-subunit and mitochondrial ATP synthase $D$ chain, and decreased levels of the precursor of the $\alpha$-subunit of ATP synthase. Additionally they found creatine kinase $\mathrm{M}$ and the contractile protein ventricular: myosin light chain 1 to be decreased after IR. 


\section{Gemeral Introduction -}

Table 6: Myocardial. protein changes found in proteomic studes of human DCM and anmal models of DCM (modified from McGregor et al. [358]). The name of the ptotein and if this protein is ap ( $)$ ) or down $(\downarrow)$-regulated in DCM, together with the species used for study is indicated. proteins marked in grey, are proteins found to be ubiquitinated (see texty.

\begin{tabular}{|c|c|c|c|}
\hline Protein identification & $\downarrow / 1$ & Species & Ref \\
\hline \multicolumn{4}{|l|}{ Cyroskeletal and myofibrillar proteins } \\
\hline Sarcoplasmic reviculum CA-ATPase (SERCA2a) & $\downarrow$ & Canine & $|354|$ \\
\hline Actin & $\downarrow$ & $\begin{array}{l}\text { Canme } \\
\text { Human }\end{array}$ & $\begin{array}{l}352 \\
|349|\end{array}$ \\
\hline Npha-actin, cardiac & $\downarrow$ & Human & $1349]$ \\
\hline Desmin & $\begin{array}{l}\downarrow \text {, intact protein } \\
\uparrow, \text { in low } \mathrm{M} \\
\uparrow \\
\downarrow \text {, inact protein }\end{array}$ & $\begin{array}{l}\text { Cantine } \\
\text { Bomine } \\
\text { Human }\end{array}$ & $\begin{array}{l}{[354]} \\
\mid 353] \\
{[349 \mid}\end{array}$ \\
\hline $\mathrm{MCl} 2$ (ventuculat isoforms) & $\uparrow$ & Human & $\begin{array}{l}\mid 347,349 \\
350,357 \mid\end{array}$ \\
\hline MHCl (atrial isoform) & Varable & Human & $|35|$ \\
\hline MLC1 (ventricular isoform) & $\Downarrow$ & Hamban & $|349|$ \\
\hline Vimertus & $\uparrow$ & Human & 349 \\
\hline \multicolumn{4}{|c|}{ Proteins associated with mitochondria and energy production } \\
\hline 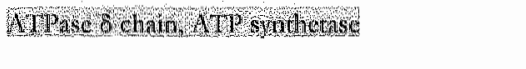 & variable & $\begin{array}{l}\text { Ganine } \\
\text { Human }\end{array}$ & $\begin{array}{l}|354| \\
|340,350|\end{array}$ \\
\hline Cyrodnome c oxidase polypeptide $Y A$ & $\downarrow$ & $\begin{array}{l}\text { Catrine } \\
\text { Dowine }\end{array}$ & $|352|$ \\
\hline Cytochrome bs & $\downarrow$ & Cannine & $|352|$ \\
\hline Fatty acid binding protein & $\downarrow$ & $\begin{array}{l}\text { Canine } \\
\text { Bowine }\end{array}$ & $\left\{\begin{array}{l}354 \mid \\
|353|\end{array}\right.$ \\
\hline 3,2-trathy-Inoyn-CoA-isomerase. & $\downarrow$ & Ganino & $|352|$ \\
\hline Dibydolipanide de wy drgenase & $\downarrow$ & $\begin{array}{l}\text { Canine } \\
\text { Human }\end{array}$ & $\begin{array}{l}{[354 \mid} \\
{[349]}\end{array}$ \\
\hline Isocitrate dehyodrogenase & $\downarrow$ & Bowilne & $|853|$ \\
\hline Greabind linase N-Chati & $\min _{\downarrow} \downarrow$ & $\begin{array}{l}\text { Canine } \\
\text { Human }\end{array}$ & $\left\{\begin{array}{l}352,354 \\
|349|\end{array}\right.$ \\
\hline Hydroxymerhylghtury Con synhase & Variable & Costantine & 13520 \\
\hline $\begin{array}{l}\text { Ubiquind cytrohrome c reduckase core } \\
\text { protein } 1\end{array}$ & $\downarrow$ & Bentine & $|35,3|$ \\
\hline Pyruvate dehydirogenase (11) componem & $\uparrow$ & Canine & $|534|$ \\
\hline Trosephospate isonertse & $\prod / \downarrow$ & $\begin{array}{l}\text { Crange } \\
\text { Human }\end{array}$ & $\begin{array}{l}352,3541 \\
{[349]}\end{array}$ \\
\hline Phosphughtycenate mutase (musele iseform) & $\uparrow$ & Conlane & $|352|$ \\
\hline 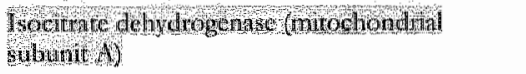 & $\downarrow$ & Canyne & 354 \\
\hline Mlongation factor Tu (mitodiondrial pre 43 ) & Wot presert & Canine & $|354|$ \\
\hline $\begin{array}{l}\text { Mirochondrial thoredoxin-dependent potowide } \\
\text { wedectase }\end{array}$ & $\downarrow$ & Bowinges: & $|353|$ \\
\hline Teruine hidnarase & $\downarrow$ & Mulnanty & $|349|$ \\
\hline Iactate dehydrogenase & $\downarrow$ & Humart & $|349|$ \\
\hline Phosphofucrokinase & 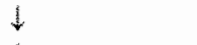 & Maman & {$[340]$} \\
\hline Dibydrofolate redictase & $\uparrow$ & Human & $|349|$ \\
\hline \multicolumn{4}{|l|}{ Proteins associated with stress respouses } \\
\hline HSP 70 (nameriblo & $\downarrow$ & $\begin{array}{l}\text { Cantine } \\
\text { Humban }\end{array}$ & $\begin{array}{l}{[354]} \\
{[349]}\end{array}$ \\
\hline
\end{tabular}


- Chapter 1

\begin{tabular}{|c|c|c|c|}
\hline Prouefin idemulateation & +11 & Species & Ref \\
\hline 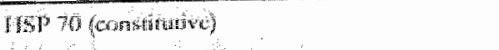 & $\downarrow$ & Homan & {$[349$} \\
\hline 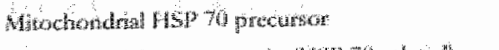 & $b$ & Wowne & 1353 \\
\hline 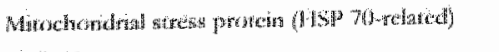 & t & Camine: & 1352 \\
\hline $9-1900$ & $\frac{1}{1}$ & $\begin{array}{l}\text { Caruine } \\
\text { Hurrunan }\end{array}$ & $\begin{array}{l}1344 \\
1749\end{array}$ \\
\hline 45127 & 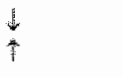 & $\begin{array}{l}\text { Hump } \\
\text { Human }\end{array}$ & $\begin{array}{l}(347,351] \\
(350,351]\end{array}$ \\
\hline wt coystatin & Variable & $\begin{array}{l}\text { Humaln } \\
\text { Conninat }\end{array}$ & 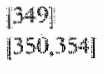 \\
\hline \multicolumn{4}{|l|}{ Ouder protedint" } \\
\hline 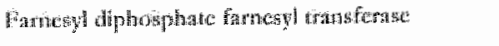 & 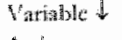 & Ganine & "35y \\
\hline 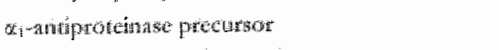 & $1 / 1$ & Bovine & {$[353 \mid$} \\
\hline 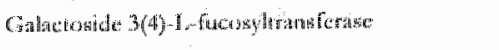 & 4 & Cantine & 1352 \\
\hline 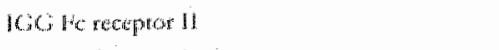 & $\uparrow$ & Camine & {$[352]$} \\
\hline 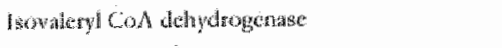 & 4 & Bowine & $\{35\}$ \\
\hline 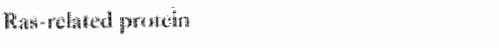 & 1 & Canne & {$[352\rceil$} \\
\hline Syendedn-2 & $\mathbb{t}$ & Caminive & [352] \\
\hline Nujor alletgen CAN 1 & $\downarrow$ & Cumine: & 452 \\
\hline Cystatur & 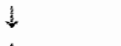 & Conninge & $\mid 352\rceil$ \\
\hline 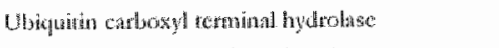 & $\uparrow$ & Bowine & $\{3,3\}$ \\
\hline 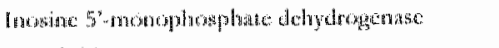 & 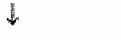 & Cantine & $\mid 352$ \\
\hline Myonglobin & $\downarrow$ & Canine & 1352 \\
\hline 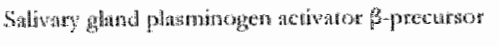 & $\downarrow$ & Connine & $352]$ \\
\hline 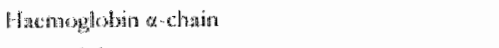 & $\downarrow$ & Caninc & 13521 \\
\hline Hupoglotin & $\downarrow$ & Huntm & $|344|$ \\
\hline 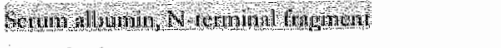 & $\downarrow$ & He:monasen & {$[349]$} \\
\hline Vrontesfextin & $\downarrow$ & Human & 1349 \\
\hline Apotipoperorein $A l$ & $\Downarrow$ & Muman & {$[349]$} \\
\hline Carbonnic anhydase & $\downarrow$ & Mtuman & {$[349]$} \\
\hline 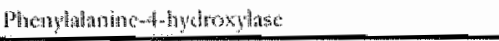 & $\downarrow$ & Humatiz & 1349 \\
\hline
\end{tabular}

Lastly, Sakai of 1363 ) found in an in tro tat model, 8 protein spots with altered expression after cardiac ischaemia or IR. Five protein spots were identified as the endoplasmatic teticulum entyme protein disulfide isomerase $\mathrm{A} 3$ precutsor, one as 60 kDa heat shock protein and two as mitochondrial elongation factor Tu. They also suggest that protein disulfide isomerase A3 underwent dephosphotylation during ischaemia and IR.

These data indicate that the individual proteins that are differentially expressed after myocardial infarction vary considerably between studies and can be classified to a number of functional groups, i.e. contractile proteins, antioxidant precursors, heat shock proteins, metabolism-related proteins and RNA translationrelated proteins.

The fact that different species were used and myocardial tissue was harvested at different tme points, i.e. differences in the duration of ischaemia (range: 40 min [363]$90 \mathrm{~min} 3621$ ) and in the dutation of reperfusion (range $20 \mathrm{~min}[363$ ] to $180 \mathrm{~min}$ [3611), possibly contributes to this phenomenon and shows the complexity of investigating changes in the proteome. 
Genewal Tntroduction *

\subsubsection{Post-translational modifications}

Through genome sequencing no information can be gained on post-translational modifications of proteins. Hence, detection and characterization of PTMs are a major task in the research field of proteomics. For example protein phosphorylation is a key PTM, crucial in the control of numerous regulatory pathways, enzyme activities, and degradation of proteins, whereas glycosylation is associated with biochemical alterations, developmental changes and pathogenesis. One of the strenghts of 2-DE is its capability to readily localize post-translationally modified proteins, as they frequently appear as distinct rows of spots in the horizontal and/or vertical axis of the 2-DE gel. The number of studies in cardiovascular research concerning these modifications is relatively scarce. The PTMs of troponin and HSP-27 are most. intensively investigated and will therefore be described separately in the next paragraphs.

\section{Modification of troponin I and $\mathrm{T}$}

Cardiac troponin I (cTnI), an important filament regulatory protein of the myocardium, is extensively modified post-translationally during acute injuries such as myocardial stunning, ischaemia, and IR. In the serum of patients with acute myocardial infarction, both a cTnI degradation pattern as well as the existence of phosphorylated cTnI have been documented [364]. In these studies, myofilament proteins were subfractionated and separated either by SDS-PAGE or HPLC, followed by MS analysis, as an alternative method to 2-DE. Proteolysis products of cTnI were also found in myocardial biopsies of patients who underwent coronary artery by-pass surgery [365]. Based on studies in animal models, it has been suggested that specific troponin I degradation is caused by the activation of proteases, such as calpain I, triggered by intracellular calcium overload [366-369]. The main proteolysis product in this regard is a fragment, $\operatorname{TnI}_{1-193}$ from the $\mathrm{C}$-terminus $[370]$. In addition, calcium activates transglutaminases, which form covalent complexes with the troponin degradation products [370].

Post-translational modification, most notably proteolysis, of cardiac troponin I ( $(\mathrm{Tn} \mathrm{T})$ may represent the underlying molecular lesion responsible for the postischaemic stunned myocardium $[365,366,369-372]$. Discrepant results, however, have been obtained [368, 373-376], leading to the speculation that the relationship between myocardial stunning and degradation of cTnI may be model- and species dependent $[366,367]$. In addition, Colantonio et al proved recently that stunned, but viable periinfarct canine myocardium is not characterized by degradation of troponin I but by a degradation of troponin $T$ [377]. However, the dissociation between cTnT degradation and myocardial wall thickening argues against a direct, "cause-and-effect" relationship between proteolysis of cTn'T and acute, post-ischaemic contractile dysfunction of stunned peri-infarct myocardium [377]. The discrepancy in results indicates that the relation between troponin modifications during cardiac diseases and cardiac dysfunction needs further investigation [377]. 


\section{Modification of heat shock protein- 27}

Heat shock proteins are considered as "molecular chaperones", the expression of which increases by cellular stress [378]. HSP-27 acts as a protective agent against hypoxic injury in cultured adult rat [379] and canine cardiomyocytes [380].

Two-DE investigation of human myocardial samples from the right ventricle revealed that HSP 27 appears as a huge family of protein species. Using immunostaining, 34 protein spots [350] or even 59 protein spots $[351,381]$ reacted with an antibody against human HSP-27. However, the character of these modifications could not be described, despite immunostaining with anti-phospho-antibodies, periodateglycostaining assays and biotinylation screening [381].

Differences of spot intensity within the HSP-27 spots between DCM and controls have been first described by Otto of al. $[382]$. Knowlton al. detected a two-fold increase of HSP-27 protein concentration in DCM and also a significant increase in ischaemic heart failure [383].

A thorough comparison by $2-\mathrm{DE}$ and immunostaining of the HSP-27 protein species pattern in human left ventricular tissue obtained from normal, DCM and ischaemic failing hearts revealed an increase of HSP-27 protein species at a molecular mass of $22-27 \mathrm{kDa}$ and a decrease of some HSP- 27 spots at $28 \mathrm{kDa}$, suggesting an enhanced HSP-27 degradation in heart failure [351].

A down-regulation of HSP-27 actually might be of functional relevance, since it belongs to the group of heat shock proteins acting as molecular chaperones, which are up-regulated in a number of cardiac diseases [378].

\subsubsection{Proteomic analysis of cardiac subproteomes: subcellular proteomics}

As described in section 3.2, the original approach of proteomics is characterized by a one-step sample preparation from a crude homogenate, followed by 2-D electrophoretic protein separation in order to display the whole body of expressed proteins under the given physiological or pathological condition. Despite the analytic power of this approach, systematic limitations of the approach became apparent.

First of all, there are certain classes of proteins, such as integral transmembrane proteins, that are difficult to extract and consequently not easily visible on the gel [384]. Futhermore, the analysis of post-translational modifications like protein phosphorylation and glycosylation $[385,386]$, oxidation of proteins [387] or the detection of intermolecular protein disulficle formation [388] requires a complex repertoire of additional analytical tools [389]. Moreover, there are also limitations with respect to the dynamic range of proteins that can be displayed on a gel compared with the dynamic range of protein abundance within cells which has been estimated to be as high as $10 \%$ 1390]. This problem increases with sample complexity because highabundant proteins muffle low-abundant proteins on the gel. The original approach may therefore fail in the discovery of gene products that are major proteins of particular subcellular compartments, but are minor proteins of the whole crude homogenate. Additionally, this original approach remains blind towards the dynamic changes at the subcellular level, e.g. protein translocation events between cell 
compartments, and therefore inevitably will miss significant alterations in the proteome.

Subcellular proteomics, i.e. the combination of classic biochemical fractionation techniques (fractionation by differential centrifugation and/or affinity purification) for the enrichment of particular subcellular structures, combined with 2 DE and MS therefore provides the opportunity to deal with some of these ptoblems. For that reason we futher describe some advantages for the use of subcellulat: proteomics. This is illustrated with applications in the field of cardiovascular research. A first line of information which can be provided by subcellular proteomics is the characterization of subcellular structures based on the entire protein population they contain. In addition to known physical and biochemical properties of these structures this offers a better understanding into the critical role of an organelle in the function of the cell. In relation to this, Taylor et al have compiled an extensive catalogue of the mitochondrial proteome using highly purified mitochondria from nomal human heart tissue [391]. This analysis identified a total of 615 distinct proteins which are involved in signaling, RNA-, DNA-, and protein-synthesis, ion transport, and lipid metabolism (see online http://www.mitokor.com/fyles/) [391]. The authors reported that the database of proteins provides a comprehensive resource for the discovery of novel mitochondrial functions and pathways [391]. Additional related examples in the field of cardiovascular research are the analysis of the mitochondrial proteome from mouse hearts deficient in creatine kinase [392], the nuclear membrane proteins in failing human dilated cardiomyopathy [393], myofilament protein entiched extract from failing swine heart [394], and sarcoplasmic reticulum and sarcolemmal proteins from rat heart [395].

A second line of information is provided by the fact that the subcellular localization of a protein is a characteristic that may provide an interesting hint to the function of that protein. For example, analysis of subcellular fractions of rat heart demonstrated that HSP-20, aB-crystallin, and myotonic dystrophy kinase binding protein were predominantly present in cytosolic fractions [396]. Moreover, immunofluorescence microscopy demonstrated that HSP-20 and $\alpha \mathrm{B}$-crystallin localize to distinct patterns as sarcomeric actin, which indicate that they might be involved in modulating cytoskeletal or contractile dynamics of cardiac myocytes [396]. A follow up study proved that phosphorylated HSP-20 increases myocyte shortening rate through increases in calcium uptake and more rapid relaxation of the cardiomyocytes $[396]$.

A third line of information is that the analysis of proteins at the subcellular level can be used to monitor dynamic changes in the proteome such as protein translocations, e.g. between the cytoplasm and nucleus.

Fourth, it provides opportunities for the identification of previously unknown gene products. In regard to this, a comparative study of human endothelial cell caveolae and rafts, using two different fractionation technigues combined with 2 DE and MS, identified several novel proteins that, until then, were only predicted from their DNA sequences [397]. Thus, subcellular proteomics is a promising technique that may advance our knowledge on these four mentioned research ffelds. 


\subsection{Transcriptomics and proteomics in cardiac diseases}

This section contains an overview of the findings from mictoarray studies in the field of cardiovascular research (section 3.4.1.). We further describe the advantages and disadvantages related to transcriptomic and proteomic studies (section 3.4.2.).

As an introductory rematk; however, we have to mention that transcriptomics (RNA) and proteomics (proteins) would not be possible without the previous achievements of genomics (DNA) which provided the 'blueprint' of possible gene products, the focal point of transcriptomics and proteomics. A description of the findings in genomics is beyond the scope of this chapter. Therefore we want to refer to two elegant reviews from Gibbons et al. [398] and Yoshioka et al. [399], describing the findings in the field of cardiovascular genomics and genetic markers, respectively.

\subsubsection{Microarrays for large-scale gene expression profiling in cardiac diseases}

The evolution of methods that enable large-scale gene expression analysis, like serial analysis of gene expression, in silico analysis of expressed sequence tag databases, cDNA microartays, and oligonucleoticle mictoarrays, allows researchers to establish organ-or pathology-specific transcriptional profiles.

Using both human tissue and animal disease models, initial cardiovascular microarray studies identified transcriptional changes associated with myocardial infarction [400403], cardiac hypetrophy [404-406], and human heart failure [407-413].

The effect of myocardial infarction on gene expression levels has been studied in mouse models [400] and rat models [401-403] by using microarrays. These studies are mainly restricted to a search for all the genes differently expressed after myocardial infarction without further unraveling possible functional consequences. For example, Stanton at al. found that more than 200 of 4000 genes related to metabolism, cell signaling, defence and structure were differentially expressed 2 and 16 weeks after myocardial infarction in rats [402]. Sehl et al used microarrays and identified 14 different genes associated with stress and wound healing with elevated expression at onc or more time points as long as 2 weeks after myocardial infarction in rats [401]. lyy th al. used a mouse model of myocardial infarction and found that decreased levels of cell cycle regulators and the oxidative tesponsive gene gutathione Suransferase were accompanied by an upregulation of the genes associated with cardiac muscle development i.e. $\alpha$-myosin heavy chain, fetal myosin alkali light chain and Egr-1 and Egr-3 transcription factors [400]. These Endings indicate that expression of genes associated with a fetal transcription program may be involved with the post-ischaemic remodelling process in heart ventricles [400].

Similar rechniques have been used by Jin of al. to identify new therapeutic drug targets $[403\}$. They evaluated the effects of the ACE-inhibitor captopril treatment on myocardial remodeling eight weeks after myocardial infarction in rats [403]. The results of these experiments showed 37 differentially expressed genes after myocardial infarction which could be clustered into 11 functional groups. Captopril, partially or completely, inhibited changes in 10 of these genes and six of the functional gene clusters contained one or more genes affected by the treatment. Because mortality and 
morbidity from heart failute after myocardial infuction remain high despite optimal ACE inhibitor therapy, the authors suggest that the genes whose expression was not affected by captoptil, i.e. mediators of inflammation, enzymes involved in energetics or ion and water channels, may provide clues to new treatment strategies [403].

Gene arrays were furthermore used for gene expression profiling in mouse models of hypertrophy, either pharmacologically induced [405] or by transverse aortic constriction (TAC) [404, 406]. Friddle of al. found 55 genes out of an array of 4000 genes that show reproducible changes in expression level during the time course of induction and regression of hypertrophy; 32 genes were altered only during induction, and 8 were altered only during regression [405]. This demonstrates that cardinc remodelling during regression utilizes a set of genes that are distinct from those used during induction of hypertiophy [405].

Zhao et al found an upregulation of 38 genes (48 hours), 269 genes (10 days) and 203 genes ( 3 weeks) and downregulation of 15 genes ( 48 hours), 160 genes ( 10 days) and 124 genes (3 weeks) after TAC [406]. These differentially exptessed transcripts were categorized into 12 functional groups, and revealed the presence of several transcriors as cell proliferation-related $\mathrm{Ki}-67$ and several apoptosis-felated genes [406].

In humans, differential gene expression associated with heart failure has been studied using oligonucleotide microarrays containing $\approx 7000$ genes $[407,410\}$ and by using cDNA microarrays, containing up to 12000 genes $[408,409,411,412]$. Barrans et al constructed the first human cardiovascular CDNA microarray containing 10368 genes and selected 38 genes from failing hearts [408]. Using a human cardiovascular based cDNA microarray, a molecular profile of dilated cardiomyopathy was also obtained [410-412]. Heart failure resulting from dilated cardiomyopathy or hypertrophic cardiomyopathy appears to develop through different remodelling and molecular pathways. Microartays of RNA samples of left ventricular tissne from patients with dilated cardiomyopathy and hypertrophic cardiomyopathy were hybridized against normal adult heart. The result showed more than 100 genes which were highly expressed in both dilated cardiomyopathy and hypetrophic cardiomyopathy, and several genes were differentially expressed comparing both pathologies [411]. In contrast, Steenman of a 1409] Found 95 genes differentally expressed between failing and nonfailing hearts samples although no genes were found to be differentially expressed between failing dilated cardiomyopathy and failing ischaenic cardiomyopathy left ventricular tissue samples.

The published transcriptomic studies of heart failure have been carried out on tissue samples from relatively small numbers of human patients and these samples are often pooled. An added degree of biological variability occurs in human heart failure studies of mixed aetiology. In regard to this, Boheler et al. 413$]$ found that most heart failure-candidate genes demonstrated significant changes in gene expression; however, the majority of differences among samples depended on variables such as age and/or sex, and not on heart fathre alone.

Therefore, Tan et al. correctly suggest that large numbers of samples, that talke into account absolute expression levels, need to be included in statistical analysis to generate unique profiles of a paricular disease aetiology [410]. These data illustrate the necessity to establish sound statistical protocols for human transcriptomic studics in 
- Chaptes 1

order to identify differentially expressed genes from large samples and which are able to distingush gene fingerprints between the different aetiologies of a disease.

\subsubsection{Transcriptomics versus proteomilcs}

The avallability of CDNA and oligonucleotide microarrays for several thousands genes from the buman and other mammalian genomes has made it possible to perform mRNA expression profiling on a truly global scale. Currently these microarrays allow the analysis of up to 12.000 human transcripts simultaneously. Therefore, it is clear that transcriptomic approaches allow a far greater coverage of the estimated 22.000 expressed genes in the human genome at the level of $\mathrm{mRNA}$ than is currently possible at the lavel of proteins $[414,415]$.

However, analysis at the protein level still has the distinctive advantage of analyzing the relative abundance of functional proteins that may not correlate with the levels of the corresponding mRNAs. Current data show that the transcriptome obtained with mRNA profiling for the characterization of cellular phenotypes, does not faithfully represent the ptoteome because the mRNA content seems to be a poor indicator of the corresponding protein levels [416-420]. Direct comparison of mRNA and protein levels in mammalian cells either for several genes in one tissue or for one gene product in many cell types reveals only poor correlations ( 0.5 or lower). For example, a correlation coefficient of 0.48 was obtained between mRNA and protein abundances in human liwer [417]. Similar low values can be expected for correlations in protein and mRNA levels caused by a disease process or treatment $[416,417,420$ 424 .

In addition proteomic analysis facilitates the analysis of co-and post-translational modifications that are not apparent at the mRNA level. Proteomic studies of heart disease so far have concentrated predominandy on comparing the relative abundance of proteins. However, it is certain that post-translational modifications, without concomitant changes in protein abundance, are involved in pathological consequences at the molecular level (see section 3.3.4).

Some other properties also favour the importance of directly studying proteins: mRNA is a disposable message with the function to serve temporarily for the transport of one piece of information from one place to another. Therefore, mRNA is much more labile than proteins, resulting in spontaneous chemical degradation and to degradation by enzymes. Furthermore, degradation may be dependent on specific sequences, resulting in non-uniform degradation of RNA. This may introduce cuantitative biases related to the time of tissue sampling and processing. In contrast, proteins are generally more stable, and exhibit slower turnover rates in most tissues. Certain high-turnover protein modifications (e.g. phosphorylation) and short half-life proteins can occur during tissue processing, although these changes are more restricted than effects on $\mathrm{mRNA}$.

In the field of cardiac diseases, the number of gene products screened as mRNA by transcriptomic studies (typically up to 12.000) is higher than those that have been screened as proteins by proteomics (typically up to 3000 ). However, differentially expressed genes fall into similar functional classes to those reported at 
the protein level by proteomics, i.e. genes encoding a) cytoslieletal and myofibrilar proteins, b) proteins associated with energy metabolism and mitochondria, c) proteins associated with stress responses, d) proteins involved in protein synthesis, and $\mathrm{c}$ proteins associated with protein degradation and disassembly. Despite a higher sensitivity of microarray analysis, the current generation of proteomic technologies also yielded reports on differential changes in the expression of less abundant gene products associated with a) cell signalling, b) cell division and c) apoptosis [410-413].

The success of genomic microarrays for high-throughput analysis of transcriptional profiles has prompted analogous proteomic approaches. In the past few years, numerous articles have been published, detailing different approaches to protein chip technology. Most of these studies involve the application of proteins or antibodies in artays on glass slides or membranes [425-429]. The technology is still in its infancy but has the potential to allow the analysis and characterization of thousands of proteins and their interactions in a single experiment. This would be a tremendous advantage for simultaneously screening large numbers of samples. The drawbacks of current methods are that post-translational modifications, which are known to be instrumental in the development of many diseases, will be difficult or impossible to track by these techniques. In an innovative departure from the traditional concept of protein chips, some researchers are implementing the mictofluidic printing of arrayed chemistries on individual protein spots blotted onto membranes [430]. This technique will effectively allow each spot on a $2-\mathrm{D}$ gel blot to act as a protein chip.

\subsection{Functional proteomics}

\subsubsection{General}

Transcriptomic and proteomic approaches are in general still descriptive, providing inventories of genes and proteins associated with heart disease. Many of these changes in expression level are compatible with the known pathophysiology of the disease processes involved. However, in some cases they are giving new insights into cellular processes that might be involved in cardiac dysfunction in a disease state.

A major challenge will be to investigate the detailed functional implications of these changes. Therefore, continuing technological developments and introduction of new approaches are leading to functional proteomic studies: conjunction of functional data from established biochemical and physiological methods with proteome information of the cellular or organ phenotype. Any phenotype is the sum of the contribution of all proteins present in the cell and a single observed phenotype may arise from multiple pathways. For that reason understanding of the precise role of each individual protein modification requires detailed physiological analysis. These analyses may range from in witro biochemical studies to the use of drugs and transgenic animals. To completely understand how every change in protein expression level and/or modification either contributes to or plays a role in an observed phenotype, it is important to delineate the exact sequence of events that occur. A time course of protein change with measured alterations in physiological and biochemical parameters allows a reconstruction of the events leading up to and/or resulting from an altered 
- Chapter 1

phenotype. As a result, it may be possible to determine exact functional changes arising from specific protein modifications. Under these conditions, functional proteomics may reveal whether a protein modification is the cause or the result of a particular disease process.

\subsubsection{Functional proteomic analysis of protein kinase $\mathrm{C} \varepsilon$ signalling complexes}

It has become increasingly clear that the molecular infrastructure supporting cellular function is composed of discrete multi-protein complexes that assemble and/or dissociate at given subcellular locations in order to accomplish specific tasks [431447]. Moreover it has been suggested that many organ phenotypes, including those associated with ischaemic heart disease, occur as a direct result of alterations in the formation of subcellular, multiprotein complexes $[431,432,439-441,443,444]$. Therefore, to understand organ phenotypes in health and disease, one must understand the nature of these subcellulat complexes.

Functional proteomic strategies are amongst others aimed at obtaining information regarding the expression profile of all proteins as well as the protein interactions within a signalling complex, thereby providing a holistic portrait of the entire signalling netwotk.

In the field of cardiovascular research, the group of Ping et al. was, to our knowledge, the only one who applied this approach in their research. They used an approach of functional proteomics to determine whether the cardioprotective protein kinase $\mathrm{Ce}$ ( $(\mathrm{KC}$ ) ) forms signaling complexes in the mouse heart and to identify the components of these complexes $[431,443]$. By using monoclonal antibody-based immunoprecipitation combined with 2-DE, 1-DE SDS-PAGE and solution trypsin digestion followed by identification with mass spectrometry they found that PKCE COlocalizes with various signalling molecules at a number of subcellular locations (see http://www.mcponline.org) [431, 443]. These PKCE-associated proteins can be classified into five functional groups, including 24 structural proteins (e.g. $\alpha$ myosin heavy chain, TuC, vimentin), 21 signaling molecules (e.g. Stc and Lck trosine kinases and JNK1), 11 stress-activated proteins (e.g. iNOS, HSP-27, COX-2), 15 metabolismrelated proteins (GAPDH, enolase, succinate dehydrogenase), 17 transcription- and translation-telated proteins (elongation factor "T'u, histone $\mathrm{H} 4$ and hnRNP K), and five proteins of unknown function.

Proteomic analysis additionally revealed that PKCe-mediated cardioprotection was related with associations and dissociations of these proteins into the signalling complex. Also positranslational modifications occurred, as determined by a shift in pI wh the 2-DE and/or MALDI analysis [431].

By this technique of functional proteomics, PKCe complexes have been found to contain at least four nonteceptor tyrosine kinases: PYK2, Bmx, ILck and Stc [431]. Further studies specifically characterized the roles of Src, Lck and Bmx in cardiac protective phenotypes. The degree to which these molecules associate with the PKCE complex was found to increase significantly in distinct forms of cardiac protection, including ischaemic preconditioning (for LcK [440]), PKCE-mediated cardiac protection (for Lck [440]; for Sre [448]), and nitric oxide donor-induced 
preconditioning (for Src [444]; for Bmx [449]). This suggests that the presence of the tyrosine kinases Src, Lck and Bmx in the PKCe complex may have distinctive consequences for the protective phenotype regulated by this complex. In support of this, post-translational modification of Src, Lck and Bmx in the PKCe complex, and altered enzymatic activities of these kinases were observed, indicating that association of Src, Lck and Bmx with the PKCe complex results in signal transduction [431]. In the case of $\mathbb{L} c k$, this signal transduction was found to involve the specific task of NFuB activation, a transcription factor known to participate necessarily in cardiac protection [440]. Importantly, these complexes formed between PKCs and nonreceptor tyrosine kinases appear to be essential for cardiac protection because their disruption (genetic or pharmacologic) results in a loss of the protective phenotype.

The information obtained with this proteomic analysis will expedite the understanding of $\mathrm{PKC}-\varepsilon$ dependent cardioprotection and signaling. In addition, the understanding gained from these studies lays the groundwork for molecular drugs to enhance the assembly of beneficial protein complexes and thereby reducing ischaemic cell death in the heart.

\subsection{Conclusion}

It can be concluded that proteomic technologies allow for the nonbiased large-scale analysis of protein expression levels and their post-ranslational modifications, with regard to the description of a cell phenotype, pharmacological interventions or during pathological situations. By the application of subcellalat and functional proteomics, it also empowers the investigator to conduct possible hypothesis-driven research, and to gain definitive answers concerning the specific roles played by individual proteins of interest under certain conditions. 
- Chapter 1

\section{Aims and outline of the thesis}

The first goal of this thesis was to investigate the potential cardioprotective effects of the antioxidant 7-monohydroxyethylrutoside (monoHER) in an in vivo mouse model of cardiac ischaemia-teperfusion (IR). The second goal was to determine the early alterations in cardiac protein expression in this IR model in order to delineate the mechanisms of action of monoHER in this setting. The background for these studies is outlined in the next paragraph.

The in vino mouse model of cardiac IR was first described by Michael et al. in 1995 [450]. Following transient occlusion of the left anterior descending coronary artery they described the histological appearance of leukocytes and contraction bands in the ischaenic region of the heart up to 24 hours after reperfusion. From that moment on, the murine model of IR has been frequently used to study the pathogenic mechanism of cardiac reperfusion injury or as a model to evaluate the efficiency of potential therapies. However, most of these studies have focused on the short-term consequences of reperfusion, using myocardial infarct size or neutrophil influx as parameters to describe the progression of cardiac tissue damage in the time frame of a few hours up to one or a few days after the initiation of reperfusion. The long-term effects of IR injury, in terms of weeks or months, are less well examined in this mouse model. However, this is a relevant aspect for extrapolation to the clinical setting. It may be that the outcome of interventions that are beneficial shortly after initiation of reperfusion is different when the evaluation takes place at later stages. To examine such aspects we investigated the long-term morphological and functional consequences of cardiac IR in an in wivo mouse model (chapter 2). As a validation we compared the effects of IR with the effects of permanent ischaemia on these morphological and functional parameters. This was important as these models were the study objects for the next chapters in which potential protective effects of an antioxidant were evaluated and alterations in the cardiac proteome were investigated.

As illustrated previously, potential protective effects of exogenously administered antioxidants on reperfusion injury have already extensively been described in literature. However, as described in chapter 1, the beneficial effects of antioxidant treatment in these models temain controversial. Moreover, most of these studies only investigated potential short-term protective effects after initiation of reperfusion and did not examine sustained protective effects. Therefore in chapter 3 , we investigated potential short- and long-term protective effects of the antioxidant monoHER after cardiac ischaemia-reperfusion. In this study monoHER was administered one hou: before ischaemia. MonoHER was chosen for this study because it has strong radical scavenging and iron chelating properties. This capacity makes it a potential drug for the prevention of oxidative stress-related reperfusion injury. In addition, monoHER protects against doxorubicin-induced cardiotoxicity in vivo in mice.

In the prevention of "reperfusion injury", administering an antioxidant as a protective drug before the onset of ischaemia has less clinical relevance. In addition, recent pharmacolinetic data revealed that following intravenous injection of 
monoHER in mice, maximal myocardial tissue concentrations of the drug are reached almost immediately. For that reason, in chapter 4 we examined whether nonoHIR also acts cardioprotective when administered right before reperfusion of an ischaemic mouse heart.

To our knowledge, only three studies have applied 2-D gel electrophoresis to identify changes in protein levels after myocardial infarction i.e. in an w wo canine [362] and rabbit model [361] of myocardial ischaemia-reperfusion and in an who rat model [361] of cardiac ischaemia or ischaemia-reperfusion. The classes of proteins that are differentially expressed after myocardial infarction vary considerably between these studies. To date, two-dimensional gel electrophoresis combined with mass spectrometry has not been applied to identify alterations in protein expression in myocardial tissue after who myocardial infarction in mice. In addition, only one study compared changes in protein expression after both ischaemia and ischaemiareperfusion, although they used an in witw rat model and no in wivo model. Therefore, the goal of the study described in chapter 5 was to identify changes in cardiac proten expression after in vivo myocardial infarction in the mouse. Our mouse models of permanent myocardial infarction and ischaemia-reperfusion were used to identify and distinguish common and specific changes in protein expression in these models. We studied early changes in protein expression in order to identify potential new targets for cardioprotection that are beneficial in the first few hours of myocardial infarction. In addition, by separately analyzing the soluble cytosolic fraction and the membrane fraction we investigated potential pathology-related protein translocations.

To explain the discrepancy in results obtained with the two time points of monoHER administration, i.e. before ischaenia versus right before reperfusion, we hypothesized that monoHER has an influence on a signal transduction pathway that might be associated to its protective mechanism of action. Consequently in chapter 6 we used this proteomics approach in ordet to find related changes in protein expression or post-translational modifications of certain proteins specifically influenced by monoFER therapy.

In chapter 7 , a summary with conclusion and implications is represented. 


\section{- Chapter 1}

\section{References}

1. Janssen B, De Celle T, Paquay I, Smits J, Blankestejin M. Structural and Functional Adaptations of the Heart after Coronary Artery Ligation in the Mouse. In: Ince $C$, ed. The Physiological Genomics of the Critically IIl Mouse. Vol. 16. Boston/Dordtecht/London: Kluwer Academic Publishers; 2003: 211 .

2. Redfield MM. Heart failure--an epidemic of uncertain proportions. N Eng! I Med. 2002; 347: 1.442.

3. Bayat $\mathrm{H}$, Swaney JS, of al. Progressive heart failute after myocardial infarction in mice. Basic Res Cardiol. 2002; 97: 206.

4. Kanno $S$, Lemer DL, af al Echocardiographic evaluation of ventricular remodeling in a mouse model of myocardial infarction. J Am Soc Echocardiogr. 2002; 15; 601.

5. Liao Y, Ishikura $F$, at Echocardiographic assessment of LV hypertrophy and function ir aontic-banded mice: necropsy validation. An I Physiol Heart Circ Physiol. 2002; 282: H1703.

6. Maning WJ, Wei JY, at Echocardiographically detected myocardial infarction in the mouse. Lab Anim Sci. 1993; 43: 583.

7. Patten RD, Aronovitz MJ ef af Ventricular remodeling in a mouse model of myocardial infarction. Am J Physiol. 1998; 274: H1812.

8. Scherrer-Crosbie $M$, Steudel W, of at. Three-dimensional echocardiographic assessment of left ventricular watl rnotion abnomalities in mouse myocardial infarction. I Am Soc Echocardiogr. 1999; $12: 834$.

9. Scherrer-Crosbie M, Steudel W, at achocardiographic determination of risk area size in a murine model of myocardial ischemia. Am J Physiol. 1999; 277, 1496.

10. Yang XP, Liu YH, at al. Echocatrdiographic assessment of cardiac function in conscious and anesthetized mice. An J Physiol. 1999; 277: H1967.

11. Ross AJ, Yang $Z$, et al. Serial MRI evaluation of cardiac structure and function in mice after reperfused myocardial infarction. Magn Reson Med. 2002; 47: 1158 .

12. Whesmann F, Frydrychowicz $A$, at and Analysis of right ventricular function in healthy mice and a murine model of heart failure by in viwo MRI. Am I Physiol Heart Circ Physiol. 2002; 283 : $\mathrm{H} 1065$

13. Takemum G, Fujiwata $\mathrm{H}$, et al. High frequency of spontaneous acute myocardial infarction due to small coronary artery disease in dead (NZWXBXSB)F1 male mice. Am f Pathol 1989; 135: 989.

14. Yoshida $H$, liujwata $H$, af. Quantative analysis of myocardial infarction in (NZW $x$ BXSB)Hil hybrid mice with systemic lupus erythematosus and small coronary artery disease. Am I Pathol. 1987: 129:477.

15. Anto CI. Mckinsey TA, at Acrivated glycogen synthase-3 bem suppresses cardiac hypertrophy in vivo. Proc Nat Acad Sci U S A. 2002;99:907.

16. van Acker $S A$, Kramer $K$, at . Monohydroxyethylrutoside as protector against chronic doxorubicin- induced cardiotoxicity. Br J Pharmacol. 1995; 115: 1260.

17. Yoshida $A$, Kand $T$, a al Interleukin-18 reduces expression of cardiac tumor necrosis factoralpha and atrial natriuretic peptide in at murine model of viral myocarditis. Life Sci. 2002; 70 ; 1225.

18. I.utgens E, Dacmen MJ, et a. Chronic myocardial intarction in the mouse: cardiac stractutal and functional changes. Cardiovasc Res. 1999; 41 : 586.

19. Blankesteijn W/, Creemers E, ot al. Dynamics of cardiac wound healing following myocardial infintction: obsetvations in genetically altered mice. Acta Physiol Scand. 2001; 173: 75. 


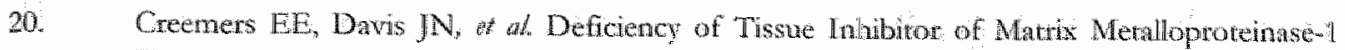
Exacerbates LV Remodeling Following Myocardial Infartetion in Mice. Am J Physiol Heart Circ Physiol. 2002; 26:26.

21. Tall AR. MIghty mouse. Circ Res. 2002; 90: 244 .

22. Eiten $M$, Painter $\mathrm{CA}$, A. Age-dependent spontaneous coronary arterial thrombosis in transgenic mice that express a stable form of human plasminogen actiontor inahibitor-1. Circulation. 2002; 106: 491.

23. Aartsen WM, Schuijt MP, at The role of locally expressed angiotensin converting engyme in cardiac remodeling after mpocardial infarction in mice. Cardiovasc Res. 2002; 56:205.

24. Creemers EE, Cleutiens JP, ef al Matrix metalloproteinase inhibition after myocardial infarction: a new approach to prevent heart falure? Circ Res. 2001; 89:201.

25. Kogan ME, Belov $\mathrm{LN}_{\mathrm{N}}$, ef al. Modieling of myocardial pathology in mice with the surgical methods]. Kardiologiia. 1977; 17: 125.

26. Janssen B, Debets $j_{\text {, }}$ ot at. Chronic measurenent of cardiac output in conscious mice. Am J Physiol Regul Integr Comp Physiol. 2002; 282: R928.

27. De Celle T, Heeringa $P$, et al. T-Monohydroxyethylrutoside, a semisynthetic Aawonoid, ptevents deteriotation of cardiac function in a mouse model of myocardial-ischenuia. Hypertension. 2002; $40: 568$ (abstract).

28. Chien GL, Wolff RA, et al, "Nomothermic range" temperature affects myocardial infaret size. Cardiovase Res. 1994; 28: 1014.

29. Guo Y, Wu WJ, at al Demonstration of an early and a late phase of ischemic preconditioning in mice. Am J Physiol. 1998; 275: 11375 .

30. Dumont EA, Horstra $L$, et al. Cardiomyocyte death induced by myocardial ischemia and reperfusion: measurement with recombinant human annexin $-V$ in a mouse model. Circulation. 2000; 102: 1564 .

31. Willems IE, Havenith $M$, ef at. The alpha-smooth muscle actin-positive cells in healing human myocardial scars. Am J Pathol. 1994; 1.45: 868.

32. Michael I.H, Ballantyne CM, ef at. Myocardial infarction and remodeling in mice: effect of teperfusion. Am J Physiol 1999; 277: $\mathrm{H} 660$.

33. Gao XM, Dat AM, of of Serial echocardiographic assessment of left ventricular dimensions and function after myocardial infarction in mice. Cardiowasc Res. 2000; 45:330.

34. Xu J. Carretero $O \mathrm{~A}_{\text {, }}$ at al. Role of AT2 receptors in the cardioprotective effect of $\mathrm{AT}$ I antagonisits in mice. Hypertension. 2002; 40;244.

35. Creemers E, Cleutiens J, et at. Disruption of the plasminogen gene in mice abolishes wound healing after myocardial infarction. Am J Pathol. 2000; 156: 1865.

36. Heymans $S$, Lutrun $A$, et al Inhibition of plasminogen activators or matrix metallopioteinases prewents cardiac rupoure but impairs therapeutic angiogenesis and causes cardiac failure. Nat Med. 1999); 5: 1135 .

37. Blankesteijn WM, Essers-Janssen YP, ef af. A homologue of Drosophila tissue polatity gene frizzled is expressed in migrating myofibroblasts in the infarcted rat heart. Nat Med. 1997; 3: 541 .

38. Gijn $M v$, Eftekhari $P$, al. Imnunization of mice with a fragment of the frizaled 2 protein atrentuates wound healing after myocardial infarction. Circulavion. 2001; 104: II.

39. Barandon $L$, Couffinhal $T$, et at. FrzA overexpression in tranggenic mouse reduces infarct size and modifes inforct bealing. Circulation. 2002; 106: II

40. Blankestein WM, van Gijn ME, al Beta-catenin, an inducer of uncontrolled cell proliferation and migration in malignancies, is localized in the cytoplasm of vascular endothelium during neovascularization after myocardial infarction. An j Pathol. 2000; 157:877.

41. Hoffmeyer MR, Jones SP, at Myocardial ischemia/reperfusion injury in NADPH oxidasedeficient mice Circ Res. 2000, $87: 812$. 


\section{- Chapter 1}

42. Yang $Z$, Bove $C M$, al Angiotensin II type 2 receptor overexpression preserves left ventricular function after ringeardial infarction. Circulation. 2002; 106: 106.

43. Shusterman $V$, Usiene 1, et al. Strain-specific patems of autonomic nervous system activity and heart fallure susceptibility in mice. Am J Physiol Heart Circ Physiol. 2002; 282: H2076.

44. Gould $\mathrm{KN}$, Taffet GE, at aleart fajure and greater infarct expansion in middle-aged mice: a relevant model for postinfarcton failute. Am / Physiol Heart Cixc Physiol 2002; 282. H615.

45. Nemoto $S$, Def teitas $G$, af al. Effects of changes in left ventricular contractility on indexes of contactilty in mice. An J Physiol Heart Circ Physiol. 2002; 283: H2504.

46. Janssen B], Smits JF. Autonomic control of blood pressure in mice: basic physiology and effects of generic modification. Am J Physiol Regul Integr Comp Physiol. 2002; 282: R1545.

47. Georgalsopoulos D, Kass D. Minimal force-frequency modulation of inotropy and relaxation of in situ murine heari. I Physiol. 2001; 534:535.

48. Williams TD, Chambers JB, et. Cardiovascular tesponses to caloric restriction and thermoneutrality in C57BL/60 mice. Am I Physiol Regul Integr Comp Physiol. 2002; 282: R.1459.

49. Janssen B], Leenders PJ, at Short-term and long-term blood pressure and heart rate variability in the mouse. Am J Plyysiol Regul Inregr Comp Physiol. 2000; 278: R215.

50. Just A, Faulhaber $\mathrm{J}$ et ar. Autonomic cardiovasculat control in conscious mice. Am J Physiol Regull Integr Comp Plysiol. 2000; 279: R2214.

51. Radaelli A, Perlangeli $S$, at al. Altered blood pressure variability in patients with congestive heart failure. I Hypertens. 1999; 17: 1905.

52. Stassen FR, Fazzi GE, et al. Coronary arterial hyperreactivity and mesenteric arterial hyporeactivity after myocardial infarction in the rat. / Cardiovasc Pharmacol. 1997; 29: 780.

53. Koren $\mathrm{G}$, Weiss $\mathrm{AT}$, ef at. Prevention of myocardial danage in acute myocardial ischemia by: early treatment with intravenous streptokinase. N Engl J Med. 1985; 313: 1384.

54. Bratumwald $\Xi_{\text {, }}$ Kloner RA. Myocardial reperfusion: a double-edged sword? I Clin Invest. 1985; 76: 1713.

55. Simpson PJ, Lucchesi BR. Free radicals and myocardial ischemia and reperfusion injury. J Lab Clin Med. 1987, 110: 13.

56. Hansen PR. Role of neutrophils in myocardial ischemia and reperfusion. Circulation. 1995; 91 : 1872.

57. Ma XI, Weyrich AS, of at. Diminished basal nitric oxide release after myocardial ischemia and reperfusion promotes neutrophil adherence to coronary endothelium. Circ Res. 1993; 72: 403.

58. Arroyo CM, Kramer JH, at al. Tentification of free radicals in myocardial ischemin/reperfusion by spin trapping with nitrone DMPO. FEBS Lett. 1987; $221: 101$.

59. Arroyo $\mathrm{CM}$, Kramer JH, ot Spin trapping of oxygen and carbon-centered free radicals in ischenic canine myocardium. Free Radic Biol Med. 1987; 3: 313 .

60. Kramer JH, Arroyo CM, at Spin-trapping evidence that graded myocardial ischemia alters post-ischemic superoxide production. Free Radic Biol Med. 1987; 3: 153.

61. Godin DV, Garnet ME. Altered antioxidant stans in the ischemic/reperfused rabbit myocardium: effects of allopurinol. Can J Cardiol. 1989; $5: 365$.

62. Chatham JC, Seymour $A \mathrm{~L}_{\text {, }}$ et al. Depletion of myocardial glutathione: its effects on heart function and metabolism during ischaemia and reperfusion. Catdiovasc Res. 1988; $22: 833$.

63. Leichtweis $S$, ji L.J.. Glutathione deficiency intensifies ischaemia-reperfusion induced cardiac dysfunction and oxidative stress. Acta Physiol Scand, 2001; 172:1.

64. Pyles $\mathbb{L A}$, formey JE, at. Plasma antioxidant depletion after cardiopulmonary bypass in operations for congenital heart disease. J Thorac Cardiowasc Surg. 1995; 110: 165.

65. Pictri $S$, Culcasi $M$, ef at. Ascorbyl free radical as a reliable indicator of free-radical-mediated. myocardial ischemic and post-ischemic injury. A real-time continuous-flow ESR study. Eur J Biochem. 1990; 193: 845 . 
66. Ko KM, Garnett ME, at Altered sncioxidant status in ischemic/repertused rabbit myocardium: reperfusion time-course study. Can J Cardiol. 1990, 6:299.

67. Bolli R. Mechanism of myocardial "stumning". Circulation. 1990; 82: 723.

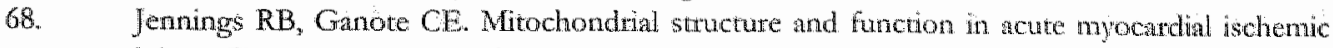
injury. Circ Res. 1976; 38: 180.

69. Moncada S, Palmer RM, at Biosynthesis of nitric oxide from L-arginine. A pathway for the regulation of cell function and communication. Biochem Pharnacol. 1989; 38: 1709.

70. Sadeli HA, Nulton-Persson AC, et at Cardiac ischemia/repetfusion, aging, and redoxdependent alterations in mitochondrial function. Arch Biochem Biophys. 2003; 420: 201 .

71. Chance B, Williams GR. The respiratory chain and oxidative phosphorylation. Adv Enzymol Relat Subj Biochem. 1956; 17: 65.

72. Cadenas E, Davies KJ. Mitochondrial free radical generation, oxidative stress, and aging. Free Radic Biol Med. 2000; 29:222.

73. Cadenas $E$, Boveris $A$, et al. Production of superoxide radicals and bydrogen peroxide by NADH-ubiquinone teductase and ubiquinol-cytochrome $c$ reductase from beeflineart mitochondria. Arch Biochem Biophys. 1977; 180: 248.

74. Cadenas E, Boveris A. Enhancement of bydrogen peroxide formation by protophores and ionophores in antimycin-supplemented mitochondria. Biochem J. 1980; 18:8: 31 .

75. Turtens JF, Boveris A. Generation of superoxide anion by the NADH dehydrogenase of bovine heart mitochondria. Biochem J. 1980; 191: 421.

76. Nohl $\mathrm{H}$, Breuninger $\mathrm{V}$, at anfluence of mitochondrial radical formation on energy-linked. respiration. Eur J Biochem. 1978; 90: 385.

77. Nohl H, Hegner D. Do mitochondria produce oxygen radicals in wivo? Eur J Biochem. 1978; 82: 563 .

78. Boveris A, Chance B. The mitochondrial generation of hydrogen peroxide. Genemal properties and effect of hyperbaric oxygen. Biochem J. 1973; 134: 707.

79. Boveris A, Cadenas E. Mitochondrial production of superoxide anions and its relationship to the antimycin insensitive respiration. FEBS Lett. 1975; 54: 311.

80. Loschen G, Azzi A, et al. Mitochondrial $\mathrm{H}_{2} \mathrm{O} 2$ formation: relationship with energy conservation. FEBS Lett. 1973; 33: 84.

81. Boveris A. Determination of the production of superoxide radicals and hydrogen peroxide in mirochondria. Methods Enzymol. 1984; 105: 429.

82. Duan J, Karmazyn M. Relationship between oxidative phosphorylation and adenine nucleonide translocase acrivity of two populations of cardiac mitochondria and mechanical recovery of ischemic hearts following reperfusion. Can I Physiol Pharmacol. 1989; 67: 704.

83. Hardy $\mathrm{L}$, Clark JB, ef al. Reoxygenation-depencent decrease in mitochondral NADH: CoQ reductase (Complex I) activity in the hypoxic/reoxygenated tat heart. Biochem J. 1901; 274 ( Pt 1): 133 .

84. Lesnefsky Ef, Tandler B, et al. Myocatdial ischemia decreases oxidative phosphorylation through cytochrome oxidase in subsarcolemmal mitochondria. Am J Physiol. 1997; 273: HI544.

85. Veitch $\mathbb{K}$, Hombroeckx $A$, at Global ischaemia induces a biphasic response of the mitochondriall respiratory chain. Anoxic pre-perfusion protects against ischaemic damage. Biochem ]. 1992; 281 ( P 3): 709 .

86. Vuorinen $\mathrm{K}$, Yliralo $\mathrm{K}$, ot al. Mechanisms of ischemic preconditioning in rat myocardium. Roles of adenosine, cellular energy state, and mitochondrial F1F0-ATPase. Circulation. 1995; 91: 2810 .

87. Rouslin W. Mitochondrial complexes 1, II, IIT, IV, and V in myocardial ischemia and autolysis. Am J Physiol. 1983; 244: H743. 
- Chapter 1

88. Chen J, Hendexson Gl, at al Role of 4-hydroxynonenal in modification of cytochrome c oxidase in ischemia/reperfused rat heart. J Mol Cell Cardiol. 2001; 33: 1919.

89. Vander Heide RS, Hill ML, et af Effect of reversible ischemia on the activity of the mitochondrial ATPase relationship to ischemic preconditioning. J Mol Cell Cardiol 1996; 28: 103.

90. Granger DN, Rutili $G$, et at. Superoxide radicals in feline intestinal ischemia. Gastroenterology. $1981 ; 81: 22$.

91. Berry CE, Hare JM. Xanthine oxidoreductase and cardiovascular disease: molecular mechanisms and pathophysiological implications. I Physiol. 2004; $555: 589$.

92. Parks DA, Granger DN. Xanthine oxidase biochemistry, distribution and physiology. Acta Physiol Scand Suppl. 1986; 548:87.

93. Jarasch ED, Bruder $G$, ef af. Significance of xanthine oxidase in capillary endothelial cells. Acta Physsiol Scand Suppl. 1986; 548: 39

94. de Jong $J W$, wan der Meer $P$, al. Xanthine oxidoreductase activity in perfused hearts of warous species, including humans. Circ Res. 1990;67: 770.

95. Muxfeldt $M$, Schaper $W$. The activity of xanthine oxidase in heart of pigs, guinea pigs, rabbits, rats, and humans. Basic Res Cardiol. 1987; 82: 486.

96. Tincler: $N$, Rapola J, et al. Cellular expression of xanthine oxidoreductase protein in normal human tissues, Eab Invest. 1999; 79: 967.

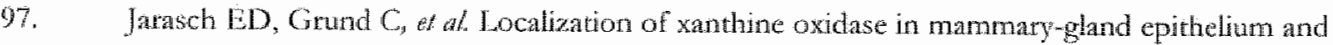
capillary endothelium. Cell. 1981;25:67.

98. Bruder $G$, Jarasch ED, $e t$ al. High concentrations of antibodies to xanthine oxidase in human and animal sefa. Molecular chatacterization. J Clin Inwest. 1984; 74: 783.

99. Abadeh $\mathrm{S}$, Case PC, et al. Purification of xanthine oxidase from human heart. Biochem Soc Trans. 1993; 21: 99S.

100. Cappola TP, Kass DA, et al. Allopurinol improves myocardial efficiency in patients with idiopathic dilated catdiomyopathy. Circulation. 2001; 104: 2407.

101. Vickers $S$, Schiller H], of al Immunoaffinity locallization of the enzyme xanthine oxidase on the ourside surface of the endothelial cell plasma membrane. Surgery. 1998; 124: 551.

102. Eddy LI, Srewart JR, ot at. Free mdical-producing enzyme, xanthine oxidase, is undetectable in human hearts. Am J Phystol. 1987; 253: H709.

103. Rouquerte M, Page $S$, of al. Xanthine oxidoreductase is asymmetrically localised on the outer surface of humatn endothelial and epithelial cells in culture. FEBS l.ett. 1998; $426: 397$.

104. Mitsos SE, Askew TE, at a. Protective effects of N.2 mercaptopropionyl glycine against mycardial reperfusion injury after neutrophil depletion in the dog: evidence for the role of intracellular-deriwed free ndicals. Circulation. 1986; 73: 1077.

105. Duilio C. Ambrosio (is at al. Neutrophils are primary source of $\mathrm{O} 2$ radicals during reperfusion after prolonged myocardial ischenia. Am J Physiol Heart Circ Physiol. 2001; 280; H2649.

106. Rossi 1: The O2 forming NADPH oxidase of the phagocytes: nature, mechanisms of Activation and function. Biochim Biophys Acta. 1986; 853: 65.

107. Thingma Y, Griendling KK. Reacrive oxygen species in the vasculature: molecular and cellular mechanisms. Hypertension. 2003; 42: 1075.

108. Nathan C. Inducible nitric oxide synthase: what difference does it make? J Clin Irvest. 1997; 100: 2417 .

109. Bates TE, Loesch $A$, at Immunocytochemical evidence for a mitochondrially located nitric oxide synthase in brain and liver. Biochem Biophys Res Commun. 1995; $213: 896$.

110. Bates TE, Loesch A, af al. Mitochondrial nitric oxide synthase: a ubiquitous regulator of oxidative phosphonylation? Biochen Biophys Res Commun. 1996; 218:40.

111. Bringold $U$, Ghafourifar $\mathrm{P}$, ef al. Peroxynitrite formed by mitochondrial NO synthase promores mirochondrial Ca2 + release. Free Radic Biol Med. 2000; $29: 343$. 
112. Packer MA, Porteous CM, ef sh Superoxide production by mitochondta in the presetace of mitric oxide forms peroxynitrite Biochem Mol Biol Int. 1996; 40:527.

113. Groves JT, Wang CC. Nitric oxide synthase models and medraisms. Gurr Opin Chem Biol, 2000; $4: 687$.

114. Aust SD, Roerig DL a al. Exidence for supetoxide generation by NADPH-cytochrome c teductase of rat liver microsomes. Biochem Biopliys Res Connun. 1972; 47: 1133.

115. Capdevila J, Parkhill L, of al. The oxidative metabolism of arachidonic acid by purified cytochtomes P-450. Biochem Biophys Res Commun. 1981; 101: 1357.

116. Freeman BA, Crapo JD. Biology of disease: free radicals and rissue injury. Lab Invest. 1982; 47: 412.

117. Halliwell B, Gutteridge. Free Radicals in Biolog: and Medecine: Oxford Univestity Press; 1989: 22 .

118. Boveris $A$, Oshino $N$, at. The cellutat ptoduction of hydrogen peroxids. Biochem J. 1972; 128: 617 .

112. Tolbert NE, Essner E. Microbodies: peroxisomes and glyoxysomes. J Cell Biol. 1981; 91 : $271 \mathrm{~s}$.

120. Baud L, Ardaillou R. Reactive oxygen species: production and tole in the kidney. Am I Physiol. $1986 ; 251: 1765$.

121. I.im LK, Hunt NH, et at. Reactive oxygen production, atachidonate membolism and cyclic AMP in macrophages. Biochem Biophys Res Commun. 1983; $114: 549$.

122. Nakamura $\mathrm{Y}$, Colbum $\mathbb{N H}$, et al. Role of reactive oxygen in tumor promotion: implication of superoxide anion in promotion of neoplastic transformation in JB-6 cells by TPA. Carcinogenesis. $1985 ; 6: 229$.

123. Singh $\mathrm{D}$, Greenwald JE, et at. Evidence for the generation of hydroxyl radical during arachidonic acid metabolism by human platelets. Am J Hematol. 1981; 11: 233.

124. Garlick PB, Davies MJ et al. Direct detection of free radicals in the reperfused rat heart using electron spin resonance spectroscopy. Circ Res. 1987; 61: 757.

125. Zweier JL, Flaherty JT, of al. Direct measurement of free radical generation following repertusion of ischemic myocardium. Proc Natl. Acad Sci US A. 1987; 84: 1404.

126. Zweier IL. Measurement of superoxide-derived free nadicals in the reperfused heart. Evidence for a free radical mechanism of teperfusion injury. I Biol Chem. 1988; 263: 1353.

127. Bolli R, Patel BS, ef al Demonstration of free tadical genetation in "stunned" myocardium of intact dogs with the use of the spin trap alphatphenyl N-tert-buryl nitrone. I Clin Invest. 1988; 82: 476 .

128. Flaherty JT, Weisfeldt MT. Reperfusion injury. Fee Radic Biol Med. 1988; 5 : 409.

129. McCord JM. Free radicals and myocardial ischemin: overwew and outlook. Free Radic Biol Med. 1988; 4: 9 .

130. Ambrosio G, Zweier JI., ef at. The relationship between oxygen radical gentration and impaiment of myocardial energy netabolism following post-ischemic reperfusion. I Mol Cell Cardiol. 1991; 23: 1359.

131. Xia $Y$, Khatchibian $G$, ed adenosine deaminase inhibition prevents free radical-mediated injury in the postischemic heart. If Biol Chem. 1996; 271: 10096.

132. Kuzuya $\mathrm{T}$, Hoshicla $\mathrm{S}$, at al. Detecrion of oxygen-derived free madical generation in the canine postischemic heare during lare phase of reperfusion. Circ Res. 1990; 66: 1160.

133. Berlett BS, Stadtman ER. Protein oxidation in aging, disease, and oxidative stress. J Biol Chem. $1997 ; 272: 20313$.

134. Kaplan P. Matejoxicova M, et al. Effect of myocatdial stuming on thiol status, myofilyillat ATPase and troponin I proteolysis. Mol Cell Biochem. 2002; $233: 145$.

135. Eaton P, Wright $\mathrm{N}$, of alyceraldehyde phosphate debydrogenase oxidation duing cardiac ischemia and reperfusion. J Mol Cell Cardiol. 2002; 34: 1549. 
- Chapter 1

136. Faton $P$, Byers $H H_{\text {, }}$ al. Detection, quantiation, purificarion, and identification of cardiac protens S-thiolated during ischemia and reperfusion. J Biol Chem. 2002, 277: 9806.

137. Esterbatet $H$, Schaur $R$, at Chemistry and biochemistry of 4-hydrosynonenal, malonaldehyde and related aldefyydes. Free Radic Biol Med. 1991; 11: 81.

138. Uchida $K$, Stadtman ER. Cowalent attachment of 4-hydroxynonenal to glyceraldehyde-3phosphate delhydrogenase. A prossible inwolvement of intra and intermoleculat cross-linking reaction. J Biol Chem. 1993; 268: 6388.

139. Kristal BS, Yu BP. An emerging hypothesis: synergistic induction of aging by free radicals and Maillard teactions. J Cerontol. 1992; 47: B107.

140. Levine RL, Williams $\mathrm{JA}$, al Carbonyl assays for determination of oxidatively modified proteins. Methods Finzymol. 1994, 233: 346.

141. Powell $\mathrm{SR}$, Gurzenda EM, et at. Actin is oxidized during myocardial ischemia. Free Radic Biol Med. 2001; 30: 1171.

142. Canton $M$, Neverova I, at al. Evidence of myofibrillar protein oxidation induced by postischemic reperfusion in isolated rat hearts. Am J Physiol Heart Circ Physiol. 2004; 286: H870.

143. White MY, Cordwell SJ, et al. Modifications of myosin-regulatory light chain correlate with function of stunned myocardium. I Mol Cell Cardiol. 2003; 35; 833.

144. Grune T, Merker K, et al. Selective degradation of oxidatively modified protein substrates by the proteasome. Biochem Biophys Res Commun. 2003; 305: 709.

145. Bulteau $\mathrm{AL}_{\text {, }}$ leundberg $\mathrm{KC}$, oxidative modificarion and inactivation of the proteasome during coronary occlusion/reperfusion. I Biol Chem. 2001; 276: 30057.

146. Eaton P, Hearse DJ, ef al. Lipich hydroperoxide modification of proteins during myocardial ischaemia. Cardiovasc Res. 2001; 51:294.

147. Koller P.T, Bergmann SR. Reduction of lipid peroxidation in reperfused isolated rabbit hearts by diltiazem. Circ Res. 1989; 65:838.

148. Ambrosio G, Flahenty J $\mathrm{T}$, ef ax. Oxygen radicals generated at reflow induce peroxidation of membrane lipids in reperfused hearts. J Clin Invest. 1991; 87: 2056.

149. Tavazzi $\mathbb{B}$, Lazzarino $G$, et al. Malondialdehyde production and ascorbate decrease are associated to the reperfusion of the isolated postischemic rat heart. Free Radic Biol Med. 1992; 13: 75.

150. Kramer JH, Misik V, al. Jipid peroxidation-derived free radical production and postischemic myocardial reperfusion injury. Ann N Y Acad Sci. 1994; 723: 180.

151. Bhsig TE, Grune T, at 4- Flydroxynonenal, a novel indicator of lipid peroxidation for mperfusion injury of the myocardium. Am J Physiol. 1995; 269: H14.

152. Cordis GA, Maulik $\mathrm{N}$, ef al. Detection of oxidative stress in heart by estimating the dinitrophenyllyydrazine derivative of malonaldehyde. J Mol Cell Cardiol. 1995; 27: 1645.

153. Pucheu $S$, Coudray $C$, of al Assessment of radical accivity during the acute phase of myocardial intaction following fibrinolysis: utility of assaying plasma malondialdehyde. Free Radic Biol Med. 1995; 19:873.

154. Friguer: B, Stadtman ER, ef at. Modification of glucose-6-phosphate dehydrogenase by 4hydroxy-2-nonenal. Formation of cross-linked protein that inhibits the multicatalytic protease. I Biol Chem. 1994; $269: 21639$.

155. Nadkarni DV, Sayre LM. Structural definition of early lysine and histidine adduction chemistry of 4hydroxynonenal. Chem Res Troxicol. 1995; 8: 284.

156. Tsai $\mathrm{L}$, Sokoloski EA. The reaction of 4-hycloxy-2-nonenal with $\mathrm{N}$ alpha-acetyl-L-histidine. Free Radic Biol Mecl. 1995; 19: 39.

157. Cohn JA, Thai $\mathrm{L}$, th Chemical characterization of a protein-4-hydroxy-2-nonenal cross-link: immunochemical detection in mitochondria exposed to oxidative stress. Arch Biochem Biophys. 1996; 328: 158. 
158. Szweda I. Uchida $K$, et al. Inactivation of glucose 6 phosphate dehydrogenase by 4 hyddroxy2-nonenal. Selective modification of an acrive-site lysine. J Biol Chem. $1993,268,3342$.

159. Chen $\mathrm{J}$, Bertrand $\mathrm{H}$, et al. Inhibicion of adenine nucleotide translocator by lipid peroxidation products. Free Radic Biol Med. 1995; 19: 583.

160. Eaton P, Li JM, ef al. Formation of 4-hydroxy-2-nonenal-modined proteins in ischemic rat heart. Am J Physiol. 1999; 276: H935.

161. Das DK, Geotge A, et al Detection of hydroxyl radical in the mitochondria of ischemicteperfused myocardium by trapping with salicylate. Biochem Biophys Res Commun. 1989; 165: 1004.

162. Ambrosio $G$, Zweier $J \mathrm{~L}$, ef al. Evidence that mitochondrial tespiration is a source of potentially toxic oxygen free radicals in intact rabbit hearts subjected to ischemia and reflow. I Biol Chem. $1993 ; 268: 18532$.

163. Lucas DT, Szweda LI. Cardiac reperfusion injury: aging, lipid peroxidation, and mitochondrial dysfunction. Proc Natl Acad Sci U S A. 1998; 95: 510.

164. Humphries KM, Yoo $\mathrm{Y}$, eft al Inhibition of NADH-linked mitochondrial respirntion by 4lhydroxy-2-nonenal. Biochemistry. 1998; 37: 552 .

165. Lucas DT, Szweda LI. Declines in mitochondtial tespiration during cardiac reperfusion: agedependene inactivation of alpha-ketoglutarate dehydrogenase. Proc Natl Acad Sci U S A. 1999; 96: 668\%.

166. Haenen GR, Plug HJ, ef al. Contribution of 4-bydroxy-2,3-trans-nonenal to the reduction of beta-adrenoceptor function in the heart by oxidative stress. Life Sci. 1989; 45: 71.

167. Kasai $\mathrm{H}$. Analysis of a form of oxidative DNA damage, 8uhydroxy-2"-deoxyguanosine, as a marker of cellulat oxidative stress during carcinogenesis. Mutat Res. 1997; 387: 147.

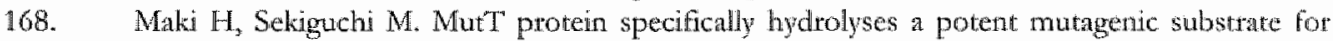
DNA synthesis. Nature. 1992;355:273.

169. Hayakawa M, Hattori $\mathrm{K}$, th al. Age-associated oxygen darnage and mutations in mitochondral DNA in human hearts. Biochem Biophys Res Commun. 1992; 189: 979.

170. Meloy S, Coskun P, at al. Mitochondrial disease in superoxide dismutase 2 mutant mice. Proc Nati Acad Sci U S A. 1999; 96: 846.

171. Ide $\mathrm{T}$, Tsutsui $\mathrm{H}$, et al. Mitochondrial DNA damage and dysfunction associated with oxidative stress in failing hearts after myocardial infarction. Circ Res. 2001; 88:529.

172. Tsutsui $\mathrm{H}$, Ide $\mathrm{T}$, ef al 8-oxo-dGTPase, which prevents oxidative stress-induced DNA damage, increases in the mitochondria from failing hearts. Circulation. 2001; 104: 2883.

173. Gilad E, Zingarelli $B$, ef al. Protection by inlubition of poly (ADP-ribose) synthetase against oxidant injury in cardiac myoblasts In vitro. J Mol Cell Cardiol. 1997, 29: 2585.

174. Grupp II. Jackson TM, at at. Protection against hypoxia-reoxygenation in the absence of polyr (ADP-ribose) synthetase in isolated working hearts. J Mol Cell Cardiol. 1999; 31:297.

175. Jacobson MK, Jacobson EL. Discovering new ADP-ribose polymer cycles: protecting the genome and mote. Trends Biochem Sci. 1999; 24: 415.

176. Lindah. T, Satoh MS, ot al. Post-translational modificaron of poly(ADP-ribose) polymense induced by DNA strand breaks. Trends Biochem Sci. 1995; 20: 405.

177. Radons J, Heller $B$, et al. Nitric oxide toxicity in isliet cellis involves poly (ADP-ribose) polymerase activation and concomitant $\mathrm{NAD}+$ depletion. Biochem Biophys Res Commun. 1994; 199: 1270.

178. Szabados E, Fischer GM, of at. Role of reactiwe oxygen species and poly-ADP ribose polymerase in the development of AZT-induced cardionyopathy in rat. Free Radic Biol Med. 1999:26: 309 .

179. Szabo $G$, Bahrle $S$, et al. Poly(ADP-Ribose) polymerase inhibition recluces reperfusion injury after heart transplantation. Circ Res. 2002; 90; 100. 
180. Szabados $\mathrm{E}$, Literati-Nagy $\mathrm{P}$, af al BGP-15, a nicotinic amidoxime deriwate protecting heart from ischemia repeffusion injury through modulation of poly(ADP-ribose) polymerase. Biochem Pharmacol. 2000; 59:937.

181. Halmosi $R$, Betente Z, et al. Effect of poly (ADP-ribose) polymerase inhibitors on the ischemiareperfusion-induced oxidative cell damage and mitochondrial metabolism in Langendorff heart perfusion system. Mol Pharmacol. 2001; 59: 1497.

182. Faro R, Toyoda $Y$, et al Myocardial protection by PJ34, a nowel potent poly (ADP-ribose) synthetage inhibitos. Ann Thorac Surg. 2002; 73: 575.

183. Thiemernann $\mathrm{C}$, Bowes $\mathrm{J}$, at al Inhibition of the activity of poly(ADP ribose) synthetase reduces ischerini-reperfusion injury in the heart and skeletal muscle. Proc Nat Acad Sci U SA. $1997 ; 94: 679$.

184. Bowes ], Ruetten H, at. Reduction of myocardial teperfusion injury by an inhibitor of poly (ADP-rbose) synthetase in the pig. Eur J Pharmacol. 1998; 359: 143.

185. Dhalla NS, Elmoselhi $A B$, at al. Status of myocardial antioxidants in ischemia-reperfusion injury. Cardiovase Ress. 2000; 47: 446 .

186. Guarnieri $\mathrm{C}$. Flamigni $\mathrm{F}$, et at. Glutathione peroxidase activity and release of glutathione from oxygen-deficient perfused tat heart. Biochem Biophys Res Commun. 1979; 89: 678.

187. Ferran $\mathrm{R}$, Ceconi $\mathrm{C}$, at. Oxygen-mediated myocardial damage during ischaemia and reperfusion: role of the cellular defences against oxygen toxicity. J Mol Cell Cardiol. 1985; 17: 937.

188. Peterson DA, Asinger RW, et at Reactive oxygen species may cause myocardial reperfusion injury. Biochem Biophys Res Conmun. 1985; 127 : 87.

189. Shlafer M, Myers CI, et at. Mitochondrial hydtogen peroxide generation and activities of ghtathione peroxidase and superoxide dismutase following global ischemia. J Mol Cell Cardiol. 1987, 19:1195.

190. Atduni A, Mezzeti A, af affect of ischemia and reperfusion on antioxidant enzymes and mitochondrial inner membrane proteins in perfused rat heart. Biochim Biophys Acta. 1988; 970: 113.

191. Barsacchi R, Coassin M, of al. Tncreased ultra weak chemiluminescence emission from rat heart at postischemic reoxygenation: protecrive tole of vitamin E. Free Radic Biol Med. 1989; 6: 573.

192. Coudray $C$, Pucheu $S$, at Ischemia and reperfusion injury in isolated rat heart: effect of reperfusion dutation on xanthine oxidase, lippid peroxidation, and enzyme antioxidant systems in myocardium. Basic Res Cardiol 1992; 87; 478 .

193. Porteca $E$, Du Boccio $G$, of al. Myocatdial antioxidant defense mechanisms: time related changes after reperfusion of the ischemic rat heart. Free Radic Res. 1904: 20: 171.

194. Lingelman DT, Watanalue $M$, ef al. Hypoxic preconditioning preserves antioxidant reserve in the worling the hert Cadiovasc Res. 1995; 29: 133.

195. Harmaki $\mathrm{N}$, Stewart $\mathrm{DB}$, at ad. Networking antioxidants in the isolated rat heart are selectively depleted by ischemia-reperfusion. Itee Radic Biol Med. 1998; $25: 329$.

196. Mexzeti A, Lapenna D, al Myocardial antioxidant defenses during cardiopulmonary bypass. If Card Surg. 1993; 8: 167.

197. Barsacchi $\mathbb{R}$, Pelosi $G$, w at. Myocardial wiamin $E$ is consumed during cardiopulmonary bypass: indirect evidence of free radical generation in human ischemic heart. Int | Cardiol. 1992; 37 : 339.

198. England MD, Cavarocchi NC, of a. Influence of antioxidants (mantuitol and allopurinol) on oxygen free radical generation during and after cardiopulmonary bypass. Circulation. 1986; 74: 111134

199. Coghlan $\int G$, Flitrer $W D$, af Allopurnol pretreatment inproves postoperative recovery and reduces lipid peroxidation in patients undergoing coronary artery bypass grafting. I Thorac Candiovasc Surg, 1924; 107: 248. 
200. Coghlan $J G$, Flinter WD, ah Lipid peroxidation and changes in vitamin $\mathrm{E}$ levels during cotonary artery bypass grafting. J Thorac Cardiowasc Surg. 1993; 106: 268.

201. Pantke $\mathrm{U}$, Volk $\mathrm{T}$, at al Oxidized proteins as a makker of oxidative stress during cotonary heart surgery. Free Radic Biol Med. 1999; 27: 1080.

202. De Vechi $E_{\text {, }}$ ala $M G$, ef al. Relation beween left ventricular function and oxidative stress in patients undergoing bypass surgery. Heart. 1998; 79: 242.

203. Starkopf J, Zilmer K, et al. Time course of oxidative stress during open-heart surgery. Scand J Thorac Cardiovasc Surg. 1995; 29: 181.

204. Ferrari $R$, Ceconi $C$, al. Myocardial damge during ischaemia and reperfusion. Bur Heart J. 1993; 14 Suppl G: 25.

205. Ferrari $\mathrm{R}$, Alfieri $\mathrm{O}$, ef al. Occurrence of oxidarive stress during reperfusion of the human heart. Circulation. 1990; 81: 201.

206. Buffon A, Santini SA, et al. Large, sustained cardiac lipid peroxidation and reduced antioxidant capacity in the coronary circulation after brief episodes of myocardial ischemia. $1 \mathrm{Am}$ Coll Cardiol. 2000; 35: 633.

207. Rigattieri $\mathrm{S}$, Buffon $\mathrm{A}$, et al. Oxidative stress in ischemia-reperfusion injury: assessment by three independent biochemical markers. Ital Heart J. 2000; 1: 68.

208. Tomasetti $\mathrm{M}$, Alleva $\mathrm{R}$, et al. Evaluation of ischetnia-teperfusion danage during coronary angioplasty. Electrocardiographic assessment and biochemical modifications in blood from the coronary sinus. Ital Heart J. 2000; $1: 216$.

209. Jolly $\mathrm{SR}$, Kane WJ, et al. Canine myocardial reperfusion injury. Its teduction by the combined a dministration of superoxide dismutase and catalase. Circ Res, 1984; $54: 277$.

210. Galang $\mathrm{N}$, Sasaki $\mathrm{H}$, ot al. Apoptotic cell death during ischemia/reperfusion and its atrentation by antioxidant therapy. Toxicology. 2000; $148: 111$.

211. Naslund U, Haggmark S, of af. Limitation of myocardial inf farct size by superoxide dismutase as an adjunct to reperfusion after different durations of coronary occlusion in the pig. Circ Res. 1990; 66: 1294 .

212. Przyklenk $\mathrm{K}$, Kloner RA. Effect of oxygen-derived free radical scavengers on infarct size following six hours of permanent coronary artery occlusion: salvage or delay of myocyte necrosis? Basic Res Cardiol. 1987; 82: 146.

213. Nejima J, Knight. DR, et a/. Superoxide dismurase reduces reperfusion arrbythmins but fails to salvage regional function or myocardium at risk in conscious dogs. Circulation. 1989; 79: 143.

214. Watanabe BI, Premaratne S, at ah. High- and low-dose superoxide dismutase plus catalase does not reduce myocardial infarct size in a subhuman primate model. Am Heart J. 1993; 126: B460.

215. Tanaka M, Richard V], et at. Superoxide dismutase plus catalase therapy detays neither cell death nor the loss of the TTC reaction in experimental myocadial infurction in doggs. / Mol Cell Cardiol. 1993; 25: 367.

216. Richatd V], Murry CE, of a. Therapy to reduce free adicals during carly reperfusion doces not limit the size of myocardial infarcts caused by 90 minutes of ischemia in dogs. Circulation. $1988 ; 78: 473$.

217. Mehra Jl Nichols wN, of a Superoxide dismutase decreases reperfusion arrthythmias and preserves myocardial function during thrombolysis with tissue plasminogen activatot. I Cardiovasc Pharmacol. 1990; 16: 112.

218. Qian ZM, Xu MF, ef al. Superoxide dismutase does protect the culnured rat cardiac myocyles against hypoxia/reoxygenation injury. Free Radic Res. 1997; $27: 13$.

219. Burton K. S. Superoxide dismutase enhances recowery following myocardial ischemia. An J Physiol. 1985; 248: 14637 .

220. Werns SW, Simpson PJ, at al Sustained limitation by superoxide dismutase of canine myocardial injury due to regional ischemia followed by reperfusion. I Cardiowasc Phatmacol. 1988; $11: 36$. 


\section{- Chapter 1}

221. Haron $\mathrm{N}$, Tadokoro $\mathrm{H}$, ta at. Beneficial effects of coronary venous retroinfusion but not left atrial administration of superoxide dismurase on myocardial necrosis in pigs. Eur Heart J. 1991; 12: 442 .

222. Ambrosio $G$, Becker $L C$, at al. Reduction in experimental infarct size by recombinant human superoxide dismutase: insights into the pathophysiology of reperfusion injury. Circulation. $1986 ; 74: 1.424$

223. Atmbrosio $G$, Zweter $J J_{\text {, al }}$ Apoptosis is prevented by administration of superoxide dismutase in dogs with reperfused myocardial infarction. Basic Res Cardiol. 1998; 93: 94.

224. Werns SW, Shea MJ ef al. The independent effects of oxggen tadical scavengers on canine infarct size. Reduction by superoxide dismutase bur not catalase. Circ Res. 1985; 56: 895.

225. Nakajilma $H$, Hangaishi $M$; et af. Iecithinized copper, zinc-superoxide dismutase ameliorates ischemia-indueed myocardial damage. Life Sci. 2001; 69: 935.

226. Nakajima H, lshizaka $\mathrm{N}$, ef at Lecithinized copper, zinc-superoxide dismutase ameliorates prolonged hypoxia-induced injury of cardionyocytes. Free Radic Biol Med. 2000; 29: 34.

227. Tanaka $M$, Fuipara $\mathrm{H}$, ef at Superoxide dismutase and $\mathrm{N}$-2-mercaptopropionyl glycine attenuate infarct size limitation effect of ischaemic precondirioning in the rabbit. Cardiovasc Res. 1994; 28: 980.

228. Unazee A, Reimer KA, at Failure of superoxide dismutase to limit size of myocardial infarction after 40 minures of ischemia and 4 days of reperfusion in dogs. Circulation. 1987; 75; 1237.

229. Patel $\mathrm{BS}_{8}$ Jeroud $\mathrm{MO}$, at at. Effect of human recombinant superoxide dismutase on canine myocardial infarction. Am J Physiol. 1990; 258: H369.

230. Gallagher KP, Buda AJ, et al. Falure of superoxide dismutase and catalase to alter size of infarction in conscious dogs after 3 hours of occlusion followed by teperfusion. Circulation. 1986; $73: 1065$.

231. Naslund $\mathbb{U}$, Haggmark $S$, of al. Superoxide dismutase and catalase reduce infarct size in a porcine myocardial occlusion-reperfusion model. I Mol Cell Cardiol. 1986; 18: 1077.

232. Tanutat $\mathrm{Y}$, Chi $L G$, at al Superoxide dismutase conjugated to polyethylene glycol provides sustained protection against myocardial ischemia/reperfusion injury in canine heart. Circ Res. $1988 ; 63: 944$.

233. T'anaka M, Stoler RC, at. Evidence against the "early protection-delayed death" hypothesis of supetoxide dismutase therapy in experimental myocardial infarction. Polyethylene glycolsuperoxide dismutase plus catalase does not limit myocarcial infarct size in dogs. Circ Res. $1990 ; 67: 636$.

234. Hangaishi $\mathrm{M}$, Nakaima $\mathrm{H}$, at at. Lecithinized $\mathrm{Cu}$, Zn-superoxide dismukase limits the infarct size following ischemia-reperfusion injury in rat hearts in vivo. Biochem Biophys Res Commutr. 2001; $285: 1220$.

235. Masini $\mathrm{E}$, Cuzzoctea $\mathrm{S}$, et a/. Protective effects of M40403, a selective superoxide dismutase minetic, in myocardial ischaemia and reperfusion injury in vivo. Br I Pharmacol. 2002; 136 : 905 .

236. Kilgore KS, Friedrichs GS, ald Protective effects of the SOD-minetic SC-52608 against ischemia/reperfusion damage in the rabbit isolated heart. J Mol Cell Cardiol. 1994; $26: 995$.

237. Li Q. Bolli R, al. Gene therapy with extracellular superoxide dismutase protects conscious rabbits against myocardial infarction. Circulation. 2001; 103: 1893.

238. Woo Y J Zhang IC, at al Recombithant adenovirus-mediated cardiac gene transfer of superoxide dismutase and catalase attenuares postischemic contractile dysfunction. Circulation. 1998; 98: 11255.

239. Chen Z, Siu B, at at. Overexpression of M.nSOD protects againse myocardial ischemia/reperfusion injury in transgenic mice. J Mol Cell Cardiol. 1998; 30: 2281. 
240. Dewald $O$, Frangogianis $N G$, at Development of murine ischenic cardiomyopathy is associated with a transient inflammatory reaction and depends on reactive oxygen species. Proc Nad Acad Sci U S A. 2003; 100: 2700.

241. Wang $\mathrm{P}_{*}$ Chen $\mathrm{H}$, ef al. Overexpression of haman copper, zinc-superoxide dismuase (SOD1) prevents postischemic injury. Proc Nat Acad Sci U S A. 1998; 95: 4556.

242. Chen $Z$, Oberley TD, et al. Overexpression of CuZnSOD in coronary vascular cells atrenuates myocardial ischemia/reperfusion injury. Free Radic Biol Med. 2000; 29:589.

243. Yoshida T, Maulik N, at. Tangeted distuption of the mouse Sod I gene makes the hearts vulnerable to ischemic repertusion injury. Circ Res. 2000; $86: 264$.

244. Jones SP, Hoffmeyer MR at Role of intracellular antioxidant enzymes after in viwo myocardial ischemia and teperfusion. Am J Physiol Heart Circ Physiol. 2003; 284: 17277.

245. Asimakis GK, Lick $S$, at astischemic recovery of contractile funcrion is impaired in SOD2 $(+/-)$ bur not SOD1 $(+/-)$ mouse hearts. Circulation. 2002; 105: 981.

246. Vulapalli $S R$, Chen $Z$, et al Cardioselective overexpression of $\mathrm{HO}-1$ prevents $I / R$-induced cardiac dysfunction and apoptosis. Am I Physiol Heart Circ Physiol. 2002; 283: H688.

247. Yet SF, Tian $\mathbb{R}$, et al. Cardiac-specific expression of theme oxygenase-1 protects against ischemia and teperfusion injury in transgenic mice. Circ Res. 2001; 89: 168.

248. Yoshida T, Watanabe M, of at. Transgenic mice overexpressing glutathione peroxidase are resistant to myocardial ischemia reperfusion injury. J Mol Cell Cardiol. 1996;28: 1759.

249. Yoshida $T$, Maulik $\mathrm{N}$, et al. Glutathione peroxidase knockout mice are susceprible to myocardial ischemia reperfusion injury, Circulation. 1997; 96: 11.

250. Tappel AL.. Vitamin E and free radical petoxidation of lipids. Ann N Y Acad Sci. 1972; 203: 12.

251. Guarnieri C, Ferrari $R$, et al. Effect of alpha-tocopherol on hypoxic-perfused and reoxygenated rabbit heart muscle. J Mol Cell Cardiol. 1978; 10: 893.

252. Massey KD, Burton KP. alpha-Tocopherol attenuates myocardial membrane-related alterations resulting from ischemia and reperfusion. Am J Physiol. 1989; 256: H1192.

253. Chen $\mathrm{H}, \mathrm{Ii} \mathrm{D}$, of al. Mixed tocopherol preparation is superior to alpha-tocopherol alone against hypoxia-reoxygenation injury. Biochem Biophys Res Commun. 2002; 291: 349.

254. Axford-Gatley RA, Wilson G]. Reeduction of experimental myocardial infarct size by oral administration of alpha tocopherol. Cardiovasc Res. 1991; $25: 89$.

255. Klein $\mathrm{HH}$, Pich $\mathrm{S}$, et ad. Failure of chronic, high-dose, oral vitamin $\mathrm{E}$ treatment to protect the ischemic, reperfused porcine heart. J Mol Cell Cardiol. 1993; 25; 103.

256. Ooiwa $\mathrm{H}$, Janero $\mathrm{DR}_{b}$ al. Examination of two small-molecule anciperoxidative agents in a rabbit model of postischemic myocardial infarction. J Cardiovasc Pharmacol. 1991; $17: 761$.

257. Klein $\mathrm{HH}$, Pich $\mathrm{S}_{8}$ at al. Combined treatment with witamins $\mathrm{E}$ and $\mathrm{C}$ in experimental myocardial infarction in pigs. Am Heart J. 1989; 118:667.

258. Altavilla D, Deodato B, of al. IRFI 042, a nowel dual vitamin E-like antioxidant, inlubits activation of nuclear factor-kappaB and reduces the inflammatory response in myocardial ischemin-reperfusion injury. Cardiowase Res, 2000; 47:515.

259. Lukowic L, Pety MA, at. Protecion of infarcted, chronically reperfused hearts by an alphatocopherol analogue. Eur J Pharmacol. 1993, 233: 63.

260. Petry MA, Grisar JM, of al. Protective effects of an alpha-tocopherol analogue against myocardial reperfusion injury in rats. Eur ] Pharmacol. 1992; $210: 85$.

261. Petty M, Grisar $\mathbb{M}$ M, of $a$. Eeffects of an alpha-tocopherol analogue on myocardial ischaemia and reperfusion injury in rats. Eur I Pharmacol. 1990; 179: 241.

262. Petty MA, Dow ], at al. Effect of a cardioselective alpha-tocopherol analogue on reperfusion injury in rats induced by myocardial ischaemia. Eur J Pharrnacol. 1991; 192: 383.

263. Campo GM, Squadrito F, at al Beneficial effect of raxofelast, an hydrophilic vitamin $E$ analogue, in the rat heart after ischemia and reperfusion injury. I Mol Cell Cardiol. 1998; 30: 1493. 


\section{- Chapter 1}

264. Brookes PS, Digemess SB, ef at Mitochondriad function in response to cardiac ischemiat reperfusion after oral treamert with quercetin. Free Radic Biol Med. 2002; 32: 1220.

265. Lebenu J, Neviere $\mathrm{R}$, est. Beneficial effects of different havonoids, on funcuonal recovery after ischemia and repetfusion in isolated rat heart. Bioorg Med Chem Lett. 2001; 11: 23.

260. Shao ZH, Vanden Hoek TL, et al. Baicallein attenuates oxidant stress in cardiomyocytes. Am ] Physiol Heart Citc Physiol. 2002; 282: 4999.

207. Wu TW, Wu J, al: Purpurogallin: in vivo evidence of a novel and effective cardioprotector. Life Sci. 1994; 54: PL23.

268. Hung $\mathrm{LM}_{\text {, Chen }} \mathrm{JK}$, et at. Cardioprotective effect of resweratrol, a natural antioxidant derived from grapes. Cardiovasc Res. 2000; 47:549.

269. Ray $\mathrm{PS}$, Maulik $\mathrm{G}_{\text {, }}$ et al The red wine antioxidant resveratrol protects isolated rat hearts from ischemia reperfusion injury. Free Radic Biol Med. 1999; 27: 160.

270. Sato $M$, Maulik $G$, at at Cardioprotective effects of grape seed proanthocyanidin against ischemic reperfusion injury. I Mol Cell Cardiol. 1999; 31: 1289.

271. Sato $M$, Bagchi $D$, et al. Grape seed proanthocyanidin teduces cardiomyocyte apoptosis by inhibiting ischemia/reperfusion-induced activation of JNK-1 and C-JUN. Free Radic Biol Med. $2001 ; 31: 729$.

272. Hung LM, Chen JK, et af. Beneficial effects of astringinin, a resveratrol analogue, on the ischemia and reperfusion damage in rat heart. Free Radic Biol Med. 2001; 30: 877.

273. Chen $Z$, Chua $\mathrm{CC}_{\mathrm{s}} \mathrm{w}$ al. Protective effect of melatonin on myocardial infarction. Am J Physiol Heart Girc Physiol. 2003; 284: 11618 .

274. Kaneko S, Okumura $\mathrm{K}$, af Melatonin scavenges hydroxyl radicall and protects isolated rat hearts from ischemic reperfusion injury. Life Sci. 2000; 67: 101.

275. Salie R, Harper 1, of al. Melatonin protects against ischaemic-reperfusion myocardial damage. I Moll Cell Cardiol. 2001; 33:343.

276. Lagneux $C$, Joyeux $M$, et al. Protective effects of melntonin against ischemia-reperfusion injury in the isolated tat heart. Ifite Sci. 2000; 66:503.

277. Granville DJ, Tashaklior $\mathbb{B}$, et al Reduction of ischemia and reperfusionwinduced myocardial damage by cywochrome P450 inhibitors. Proc Natl Acad Sci U S. A. 2004; 101:1321.

278. Pema AM, Jiguoti $P$, et al. Protection of at heatt from ischaemia-reperfusion injury by the 21aminosteroid U-74389G. Phamacol Res. 1996; 34: 25.

279. Ovize $M$, de Lorgeril $M$, af U74006F, a novel 21 aminosteroid, inhibits in vivo lipid peroxidation but fails to limit infarct size in a canine model of myocardial ischemia reperfusion. Am Fearl 1. 1991; 122: 681.

280. Carrea $\mathbb{P}$, Lesnefsky E) at. The lazaroid U740065, a 21 -aminosteroid inhibitor of lipid peroxiclation, antenuates myocatdial injury from ischemia and reperfusion. I Cardiovast Pharmacol. 1992; 20: 230 .

281. Shimizu M. Wang QD, at. The lipid peroxidation inhibiror indenoindole H290/51 protecs myocardium at risk of injury induced by ischemia-reperfusion. Free Radic Biol Med. 1998; 24: 726.

282. Manning $A S_{n}$ Coltart D!, at d. Ischemia and reperfusion-induced arthythmias in the rat. Effects of xanthine oxidase inhibition with allopurinol. Circ Res. 1984; 55: 545.

283. Kinugasa $\mathrm{Y}$, Ogino $\mathrm{K}$ a al. Allopurinol improves cardiac dysfunction after ischemiarepertision wat reduction of oxidative stress in isolated perfused rat hearts. Circ J. 2003; 67: 781.

284. Venrurini CM, Flickinget $A G$, at al The Antioxidant, N-(2-mercaptopropionyl)-glycine (MPG), Does Not Reduce Myocardial Infarct Size in an Acute Canine Model of Myocardial Ischemia and Reperfusion. J Thromb Thrombolysis. 1998; 5: 135.

285. Widman SC, liang CS, of at. Contraction band necrosis: its modification by the free radical scavenger N-2-mercsptopropionyl glycine. J Cardiovasc Pharmacol. 1994; 24: 694. 
286. Mitsos SE, Fantone $1 \mathrm{C}$, th al. Canine myocardial repertusion injury" protection by a free radical scavenger, N-2-mercaptopropionyl glycine. I Cardiovasc Pharmacol. 1986. 8: 978.

287. Miki $\mathrm{T}$, Cohen MV, al. Failure of N-2-mencaptoptopionyl glycine to reduce myocardial infarction after 3 days of reperfusion in rabbits. Basic Res Cardiol. 1999; 94: 180.

288. Bolli $\mathrm{R}$, feroudi $\mathrm{MO}$, at at. Marked reduction of free radical gencration and contractile dysfunction by antioxidant therapy begun at the time of reperfusion. Evidence that myocardial "stunning" is a manifestation of reperfusion injury. Circ Res. 1989; 65: 607.

289. Horwitz LD, Fennessey $\mathrm{PV}_{n}$ of al. Marked reduction in myocardial infarct size due to prolonged infusion of an antioxidant during reperfusion. Circulation. 1994; 89: 1792.

290. Patterson E. Coronary wascular injury following transient coronary artery occlusion prevention by pretreatment with deferoxamine, dimethylthiourea and $\mathrm{N}-2$ mercaptoproprionyl glycine. I Pharmacol Exp Ther. 1993; 266: 1528 .

291. Kinugawa $\mathrm{S}$, Tsutsui $\mathrm{H}_{3}$ at al Treatment with dimethy thiourea prevents left ventricular remodeling and failure after experimental myocatdial infarction in mice: role of oxidative stress. Circ Res. 2000; 87: 392.

292. Carrea FP, Lesnefsky Ej, at. Reduction of canine myocardial infaret size by a diffusible reactive oxygen metabolite scavenger. Efficacy of dimethylthiourea given at the onser of reperfusion. Circ Res. 1991; 68: 1652.

293. Woo Y], Taylor MD, et al. Ethyl pymivate preserves cardiac function and attenuates oxidative injury after prolonged myocardial ischemia. I Thorac Cardiovasc Surg. 2004; 127: 1262.

294. Lin XK Engelman RM, ef al. Preservation of membrane phospholipids by propranolol, pindolol, and meroprolol: a nowel mechanism of action of beta-blockers. J Mol Cell Cardiol. 1991; 23: 1091 .

295. Lee YM, Hsiao G, et al. Magnolol teduces myocardial ischemia/reperfusion injury via neutrophil inhibition in rats. Eur J Pharmacol. 2001; $422: 159$.

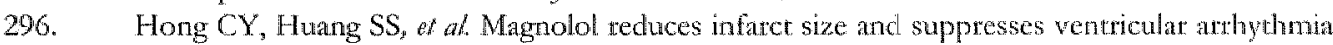
in rats subjected to coronary ligation. Clin Exp Pharmacol Physiol. 1996; 23:660.

297. Veveris M, Koch E, ot at. Crataegus special extract WS 1442 improves cardiac function and reduces infarct size in a rat model of prolonged coronary ischemia and reperfusion. Life Sci. 2004; 74: 1945.

298. Haines DD, Bak I, at al Cardioprotective effects of the calcineurin inhibiror FK506 and the PAF receptor antagonist and free radical seavenger, EGib 761, in isolated ischemic/reperfused rat hearts. J Cardiovasc Pharmacol. 2000; 35: 37.

299. Ozer MK, Parlakpinar $\mathrm{H}$, $e$ at. Reduction of ischemin - teperfusion induced myocardial infaren size in rats by caffetic acid phenethyl ester (CAPI). Clin Bioclhem. 2004; 37: 702 .

300. Xu $Z$, Cohen MVV, at. Attenuation of oxidant steess during reoxygenation by AMP 570 in Cardiomyocytes. Am I Physiol Heart Circ Physiol. 2001; 281: H2585.

301. Rimm EB, Giovannucei El, at. Prospective study of alcohol consumption and risk of cotonary disease in men. Lancer. 1991: 338: 464 .

302. St Leger AS, Cochrane AL, of al. Foctors associated with cardiac mortality in developed countries with particular reference to the consumption of wine. 1 Iancet. 1979; 1:1017,

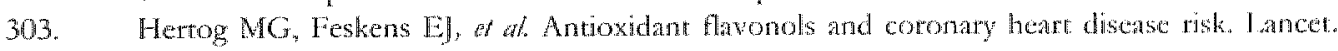
1997; $349: 699$.

304. Soleas $G]$, Diamandis $\mathbb{E P}$, whe as a biological fluid: history, production, and role in disease prewention. J Clin I.ab Anal. 1997; 11:287.

305. Salah $\mathrm{N}$, Miller NJi, et Polyphenolic flavanols as scavengers of aupueous phase radicals and as chain-breaking antioxidants. Arch Biochem Biophys. 1995; 322: $33 \%$.

306. Reiter R], Melchiorri D, et al. A review of the evidence supporting melatonin's role as an antioxidant. J Pineal Res. 1995; 18: 1. 


\section{- Chapter 1}

307. Reiter $\mathrm{R}$, Tang $\mathrm{L}$, ef al. Phatmacological actions of melatonin in oxygen radical pathophysiology. Life Sci. $1997 ; 60: 2255$.

308. Raynaud $\mathrm{F}$, Mauviat $\mathrm{F}$, ef al Plasma 6-hydroxymelatonin, 6-sulfatoxymelatonin and melatonin kineries after melatonin administration to rats. Biol. Signals. 1993; 2: 358 .

309. Schaper J, Mulch $\mathrm{J}$, at al. Ultrastructural, functional, and biochemical criteria for estumation of reversibility of ischemic injury: a study on the effects of global ischemia on the isolated dog heart ] Mol Cell Cardiol. 1979; 11:521.

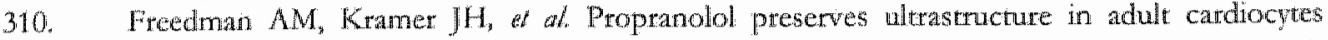
exposed to anoxia/reoxygenation: a morphometric analysis. Free Radic Biol Med. 1991; 11: 197.

311. Taylot IM, Shaikh NA, et al. Ultrastructural changes of ischemic injury due to coronary artery occlusion in the porcine heart. J Moll Cell Cardiol. 1984; 16: 79.

312. Braughter JM, Pregenzer JF, et al Novel 21-amino steroids as potent inhibitors of irondependent lipid peroxidation. J Biol Cherr. 1987; 262: 10438.

313. Braughler JM, Chase RJ, et al. A new 21 -aminosteroid antioxidant lacking glucocorticoid activity stimulates adrenocorticotropin secretion and blocks arachidonic acid release from mouse pituitary tumor (At'T-20) cells. J Pharmacol Exp Ther. 1988; 244: 423.

314. Fox RB. Prevention of granulocyte-mediated oxidant lung injury in rats by a hydroxyl radical scavenger, dimethylthiourea. J Clin Invest. 1984; 74: 1456.

315. Kalaycioglu S, Sinci V, et al. Metoprolol prevents ischemia-reperfusion infury by reducing lipid peroxidation. Jpn Circ J. 1999; 63: 718.

316. Murohata $Y, Y u i Y$, et al. Effects of superoxide dismutase on reperfusion arrhythmias and left ventricular function in patients undergoing thrombolysis for anterior wall acute myocardial infarction. Am J Cardiol. 1991; 67: 765.

317. Flaherty JT, Pitt B, ef al. Recombinant human superoxide dismutase (h-SOD) fails to improve recovery of ventricular function in patients undergoing coronary angioplasty for acute myocardial infarcion. Circulation. 1994; 89: 1982.

318. Westhuyzen J, Cochrane AD, at alfect of preoperative supplementation with alpha tocopherol and ascorbic acid on myocardial injury in patients undergoing cardiac opetations. I Thorac Cardiovasc Surg. 1997; 113: 942.

319. Demirag K, Askar $\mathbb{F Z}$, at al. The protective effects of high dose ascorbic acid and diltiazem on myocardial ischaemia-teperfusion injury. Middle East I Anesthesiol. 2001; 16:67.

320. Barta 1 , Pechan 1 , af at Protective effect of alpha-tocopherol and $\mathrm{L}$-ascorbic acid against the ischemic-reperfusion injury in patients during open-heart surgery. Bratisl Lek Listy. 1991; 92 : 174.

321. Dingchao $H$, Zhiduan $Q$, of al. The protective effects of high-dose ascorbic acid on myocardium against reperfusion injury during and after cardiopulmonary bypass. Thorac Curdiovase Surg. 1994; 42:276.

322. Guan W, Osana T, al at Time course of free radical production after primary cononary angioplasty for acute myocardial infarction and the effect of vitamin C. Jpn Circ J. 1999; 63: 924.

323. Mickle DA, Weisel RD, et al. Effect of onally administered alpha-tocopheryl acetate on human myocardial alphat-tocopherol levels. Cardiovase Drugs Ther. 1991; 5 Suppl 2: 309.

324. Yau TM, Weisel RD, ef al Vitamin E for cononary bypass operations. A prospective, doubleblind, randomized trial, J Thorac Cardiovasc Surg. 1994; 108: 302.

325. Sisto T, Paajanen $H$, ef at. Prerreatment with antioxidants and allopurinol diminishes cardiac onset events in coronary artery bypass grafting. Ann Thorac Surg. 1995; 59: 1519.

326. Tassnigg $A$, Punz $A$ ef al. Influence of intravenous vitamin $E$ supplementation in carcliac surgery on oxidative stress; a double-blinded, randomized, controlled study. Br J Anaesth. 2003; 90: 148 . 


\section{General Introduction •}

327. Ferrari $\mathrm{R}$, Ceconi $\mathrm{C}_{\mathrm{g}}$ et al Oxygen free radicals and myocatdial damage protective role of thiolcontaining agents. Am J Med. 1991: $91: 955$.

328. Arstall MA, Yang J, at al. N-acetylcysteine in combination with nitroglycerin and streptokinase for the treatment of evolwing acute myocardial infarction. Safery and biochemical effects. Circulation. 1995; 92: 2855 .

329. Sochman J. N-acetylcysteine in acute cardiology: 10 years later: what do we know and what would we like to know? J Am Coll Cardiol. 2002; 39: 1422.

330. Wasinger VC, Cordwell S], at al. Progress with gene-product mapping of the Mollicutes: Mycoplasma genitalium. Electrophoresis. 1995; 16: 1090.

331. Wilkins MR, Sanchea JC, at al. Progress with proteome projets: why all proteins expressed by a genome should be ddentified and how to do it. Biotechnol Genet Eng Rev, 1996; 13: 19.

332. Rabilloud T. Two-dimensional gel electrophoresis in proteomics: old, old fashioned, but it still dimbs up the mountains. Proteomics 2002; 2: 3.

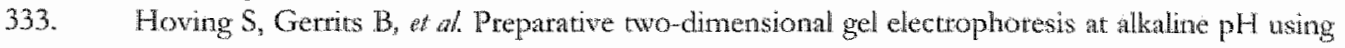
narrow range immobilized $\mathrm{pH}$ gradients. Protemics. 2002; 2:127.

334. Westbrook JA, Yan JX, ef al. Zooming-in on the proteome: very namow-mange inmobilised pH gradients reveal more protein species and isoforms. Electrophoresis. 2001; 22:2865.

335. Howing $\mathrm{S}$, Voshol $\mathrm{H}$, at Towards high performance two-dimensional gel electrophoresis using ultrazoon gels. Electrophoresis. 2000; 21:2617.

336. Humphery-Smith 1, Cordwell S1, et al. Proteome research: complementarity and limitations with respect to the RNA and DNA worlds. Electrophoresis. 1997; 18: 1217.

337. Shewchenko A, W/im M, ef al Mass spectrometric sequencing of proteins silver-stained polyacrylamide gels. Anal Chem. 1996; 68: 850.

338. Lopez MF, Berggren K, ef al A comparison of silwer stain and SYPRO Ruby Protein Gel Stain with respect to protein detection in two-dimensional gels and icientification by peptide mass profling. Electrophoresis. 2000; $21: 3673$.

339. Patton WF. A thousand points of light: the application of fluorescence detection rechnologies to two-dimensional gel electrophoresis and proteomics. Electrophoresis. 2000; $21: 1123$.

340. Tonge $\mathbb{R}$, Shaw J, et al. Validacion and development of furorescence two-dimensional differential gel electrophoresis proteomics technology. Proteonics. 2001; 1:377.

341. Lahn $\mathrm{HW}_{3}$ Langen H. Mass spectrometry: a tool for the identification of proteins separated by gels. Electrophoresis. 2000; $21: 2105$.

342. Jungblut $P$, Oto $A$, at al. Identification of human myocard proteins separated by two dimensional electrophoresis. Electrophoresis. 1992; 13: 739.

343. Janghlut $\mathrm{P}, \mathrm{Otto} \mathrm{A}_{\mathrm{r}}$ at at. Protein composition of the human heat: the construction of a myocardial two-dimensional electrophotesis database. Electrophotesis. 1994: 15: 68.5.

344. Baker CS, Corbett JM, at at. A human myocardial two-ciumensional electrophoresis database: protein characterisation by microseguencing and immunobloting. Electrophoresis. 1992; 13 : 723.

345. Corbet $\mathrm{JM}_{*}$, Wheeler $\mathrm{CH}$, at at. The human myocardial two-dimensional get protein database: update 1994. Electrophoresis. 1994; 15: 1459

346. Li XP, Pleissner KP, of at a twomensional electrophoresis database of rat heart proteins. Electrophotesis. 1999; 20: 891.

347. Pleissner KP, Soding $P$, af al. Dilated cardiomyopatyy associated proteins and their presentation in a WWW-accessible wo-dimensional gel protein database. Electrophoresis. 1997; 18:802.

348. O'Grady MR, O'Sulliwan ML. Dilated cardiomyopathy. an update. Ver Clin North Am Small Anim Pract. 2004; 34: 1187.

349. Corbet JM, Why HJ, et al Cardiac protein abnormalities in dilated cardiomyopathy detected by two-dimensional polyacrylamide gel electrophoresis. Electrophoresis. 1998; 19:2031. 


\section{- Chapter 1}

350. Thiede $\mathrm{B}$, Otro $A$, at al. Identification of human myocardial ptoteins separated by twodimensional electophoresis with matrix-assisted laser desorption/ionjarion mass spectrometry. Electrophoresis: 1996; 17:588.

351. Scheler C, Li XP, et at. Comparison of two-dimensional electrophoresis patterns of heat shock protein Hsp27 species in normal and cardiompopathic hearts: Electrophoresis. 1999; 20:3623.

352. Heinke $\mathrm{MY}$, Whecler $\mathrm{CH}$, et al Changes in myocatdial protein expression in pacing-induced cantine heart fallure. Hectiophoresis. 1999; 20: 2086.

353. Weekes $\mathrm{J}$, Whecler $\mathrm{CH}$, ef al Bovine dilated cardiomyopathy: proteomic analysis of an animal: model of human dilated cardiomyopathy. Electrophoresis. $1999 ; 20: 898$.

354. Heinke $\mathrm{MY}$, Wheeler $\mathrm{CH}$, al Protein changes observed in pacing-induced heart failure using two-dimensional electrophoresis. Electrophoresis. 1998; 19:2021.

355. Knecht $\mathrm{M}$, Regitz-Zagrosek V, at al. Dilated cardiomyopathy: computer-assisted analysis of endomyocardial biopsy protein parterns by two-dimensional gel electrophoresis. Eur J Clin Chem Clin Biochem. 1994; 32: 615 .

356. Knech $M$, Regizz Zagrosek $\mathrm{V}$, et al Characterization of myocardial protein composition in diated cardiomyopathy by two-dimensional gel electrophoresis. Eur Heart J. 1994; 15 Suppl D: 37.

357. Pleissner KP, Regitz-Zagrosek $V$, of at. Chamber-specific expression of human myocardial proteins detected by two-dimensional gel electrophoresis. Electrophoresis. 1995; $16: 841$.

358. McGregor E; Dunn MJ. Proteomics of heart disease. Hum Mol Genet. 2003; 12 Spec No 2: $\mathbb{R} 135$.

359. Field ML, Claris JF. Inappropriate ubiquitin conjugation: a proposed mecharism contributing to heart failure. Cardiovasc Res. 1997; 33: 8.

360. Weekes J, Morrison K, at al. Hyperubiquitination of proteins in dilated cardionyopathy. Proteomics. 2003; 3: 208.

361. Schwertz $H$, Langin $T$, et at. Two dimensional analysis of myocardial protein expression following myocardial ischemia and reperfusion in rabbits. Proteomics. 2002; 2: 988.

362. Sawicki G, Jugdutt BI. Detection of regional changes in protein levels in the in wivo canine model of acute heat failure following ischemia-teperfusion injury: functional proteomics studies. Proteomics. 2004; 4: 2195.

363. Sakai \, Tshikawa $\mathrm{H}$, ot a. Proteomic analysis of rat heart in ischemia and ischemia-reperfusion using fluorescence two dimensional difference gel electrophoresis. Proteomics. 2003; 3: 1318.

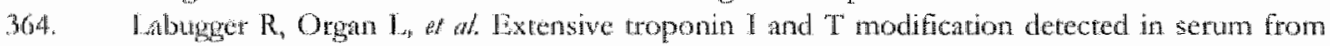
patients witl acute myocadial infarction. Circulation. 2000; 102: 1221.

365. McDonough If, Labugger $\mathbb{R}$, ef al. Cardiac troponin I is modified in the myocardium of bypass patients. Citculation. 2001; 103: 58.

366. Van Eyk JE, Murplyy AM. The role of troponin abnormalities as a cause for stunned myocardium. Coron Artery Dis. 2001; 12: 343.

367. Canty JM, Lee TC. Troponin I Proteolysis and Myocardial Stunning. J Mol Cell Cardiol. 2002; 34: 375 .

368. Feng J, Schaus B], at Prelond induces troponin I degradation independently of myocardial ischemia. Circulation. 2001; 103: 2035.

369. Gao WD, Atar D, al Role of troponin I proteolysis in the pathogenesis of stunned myocardium. Circ Res. 1997; 80: 393.

370. McDonough Jl, Arrell DK, a al. Troponin I degradation and covalent complex formation accompanies myocardial ischemia/reperfusion injury. Circ Res. 1999; 84: 9.

371. Van Eyk JE, Powers $F$, ef al. Breakdown and release of myofilament proteins during ischemia and ischemia/reperfusion in rat hearts: identification of degradation products and effects on the pCa-force relation. Circ Res. 1998; 82: $26 \%$ 
372. Murphy AM, Kogler H, at Transgenic mouse model of stumed mocardiun. Science 2000 ; 287: 488 .

373. Thomas SA, Fallavollita JA, ef ual. Absence of troponin I degradarion or strered sarcoplasmic reticulum uptake protein expression after reversible ischemia in swine. Clrc Res. 1999;85:446.

374. Sherman AJ, Klocke FJ ef al Myofibrillat distuption in hyocontractile mocardium showing perfusion-contraction matches and mismatches. Am J Physiol Feart Circ Physiol. 2000; 278: H1320.

375. Kin SJ, Kudej RK, et at. A novel mecharism for myocardial stunning involving irmpaired Ca(2+) handling. Circ Res. 2001; 89: 831.

376. Peasan AM, McCarron HC, of al Effect of treatment on ventricular function and troponin 1 proteolysis in reperfused myocardium. I Mol Cell Cardiol 2002; $34: 401$.

377. Colantonio DA, Van Eyk JE, et ad. Stunned peri-infarct canime myocardium is chancterized by degradation of troponin T, nor troponin I. Cardiovasc Res. 2004; 63: 217.

378. Knowtton AA. The role of heat shock proteins in the heart. J Mol Cell Cardiol. 1995; 27: 121.

379. Martin JL, Mescril $R$, of Small heat shock proteins and protection against ischemic injury in cardiac myocytes. Circulation. 1997; 96: 4343.

380. Vander Heide RS. Increased expression of HSP27 protects canine myocytes from simulated ischemia-reperfusion injury. Am ] Physiol Heart Circ Physiol. 2002; 282: H935.

381. Scheler $\mathrm{C}_{,}$Muller EC, et al. Identification and characterization of heat shock protein 27 protein species in human myocardial two-dimensional electrophoresis partems. Electrophoresis. 1997; 18: 2823 .

382. Otto A, Thiede B, ef al Identification of human myocardial proteins separated by twodimensional electrophoresis using an effecrive sample preparation for mass spectrometry. Electrophoresis. 1996; 17: 1643.

383. Knowlton AA, Kapadia S, ot ol. Differential expression of heat shock proteins in normal and failing human hearts. J Mol Cell Cardiol. 1998; 30: 811.

384. Stanley $B A$, Neverova I, ef al. Optimizing protein solubility for two-dimensional gel electrophoresis analysis of human myocardium. Proteomics. 2003; 3:815.

385. Chu G, Egnaczyk GF, ef at. Phosphoproteone analysis of cardiomyocytes subjected to betaadrenergic stimulation: identification and characterization of a cardiac heat shock protein $p 20$. Circ Res. 2004; $94: 184$.

386. Whelan SA, Hart GW. Proteomic approaches to analyze the dynanic relationships between nucleocytoplasmic protein glycosylation and phosphorylation. Circ Res. 2003; 93: 1047.

387. Ghezai P. Bonetto V. Redox proteomics: identification of oxidatively modified proteins. Proteonics. 2003; 3: 1145 .

388. Btennan $\mathrm{JP}$, Wait $\mathrm{R}$, at al. Detection and mapping of widespread intemolecullar ptotein disulfide formation during cardiac oxidative stress using proteomics with dingonal electrophoresis. J Biol Chem. 2004; 279: 41352.

389. Mann M, Ong SE, at Analysis of protein phosphorylation using mass spectronetry: deciphering the phosphoproteome. Trends Biotechnol. 2002; 20:261.

390. Gygi SP, Corthalls GL, of al. Evaluation of two-dimensional gel electrophoresis-based proteome analysis technology. Proc Nad Acad Sc U S A. 2000; 97: 9390.

391. Taylor SW, Fahy E, et al. Characterization of the human heart mitochondral proteome. Nat Biorechnol. 2003; 21:281.

392. Kernec $\mathrm{F}$, Unlu $\mathrm{M}$, et al Changes in the mitochondrial proteome from mouse hears deficient in creatine kinase. Physiol Genomics. 2001; 6:11.7.

393. Berry DA, Keogh $A$, of al Nuclear membtane proteins in failing human diated cardiomyopathy. Proteomics. 2001; 1: 1507 .

394. Neverova I, Van Eyk JE. Application of reversed phase high performance liquid chromatography for subproteomic analysis of cardiac muscic. Proteomics, $2002 ; 2: 22$. 


\section{- Chapter 1}

395. Macri J, McGee B, at. Cardiac sarcoplasmic reticulum and sarcollemmal proteins separated by two-dimensional electrophorests: surfactant efrects on membrane solubilization. Electrophoresis. $2000 ; 21: 1685$.

396. Pipkin W, Jotnson JA, wh. Localization, macromolecular associarions, and function of the gmall heat shock-related protein HSP20 in rat heart. Circulation. 2003; 107: 469.

397. Sprenger RR, speijer D, ef al Comparative proteonics of human endothelial cell caveolae and tafts using two-dimensional gel electrophoresis and mass spectrometry. Electrophoresis. 2004; 25: 156

398. Gibbons $\mathrm{GH}$, Jew $\mathrm{CC}$, at al. Genetic markers: progress and potential for cardiovascullar discase. Circulation. 2004; 109: IV47.

399. Yoshioka J, Lee RT. Cardiovascular genomics. Cardiorase Pathol. 2003; 12: 249.

400. Lyn $\mathrm{D}$, Liu $\mathrm{X}$, at al. Gene expression profile in mouse myocardium after ischemia. Physiol Cenomics. 2000; 2: 93.

401. Sehl PD, Tai JT, et al. Application of cDNA microarrays in determining molecular phenotype in cardiac growth, development, and response to injury. Circulation. 2000; 101: 1990.

402. Stanton LW, Garrard LJ, at al Atered patterns of gene exptession in response to myocardial infarction. Circ Res. 2000; 86: 939.

403. Jin $\mathrm{H}_{3}$ Yang $\mathrm{R}$, af al. Effects of early angiotensir-converting enzyme inhibition on cardiac gene expression after acute myocardial infarction. Circulation. 2001; 103: 736.

404. Weinberg EO, Mirotson $M_{n}$ at al Sex dependence and temporal dependence of the left ventricular genonic response to pressute overload. Plyssiol Genomics. 2003; 12: 113 .

405. Friddle $\mathrm{C}$, Koga $\mathrm{T}$, ef al. Expression profiling reveals distinct sets of genes altered during induction and regression of cardiac hypertrophy. Proc Narl Acad Sci U S A. 2000; 97:6745.

406. Zha $M$, Chow $A$, ef at Microatray analysis of gene expression after transverse aortic constriction in mice. Physiol Genomics. 2004; 19:93.

407. Yang J, Moravec CS, et al. Decteased SLIM1 expression and increased gelsolin expression in hiling human hearts measured by high-density oligonucleotide arrays. Circulation. 2000; 102: 304.6 .

408. Barrans JD, Siamatiou D, et al Construction of a human cardiovascular cDNA microarray: portrait of the failing heart. Biochem Biophys Res Commun. 2001; $280: 964$.

409. Steenman $M$, Chen $Y W$, ex at Transcriptomal analysis of failing and nonfailing human hearts. Physiol Genomics. 2003; 12:97.

410. Tan FL, Moravec CS, at. The gene expression fingerprint of human heart failure. Proc Nat Acad Sci U S A. 2002; 99: 11387.

411. Hwang 1]. Allen PD, of al. Mictoaray gene expression profles in dilated and hypertrophic cardiomyopathic end-stage heart failure. Physiol Genomics. 2002; 10: 31.

412. Batrans JD, Allen PD, at al. Global gene expression profiling of end-stage dilated cardiomyopathy using at human cardiovascular-based CDNA microarray. Am ] Pathol. 2002; $160: 2035$.

413. Boheler $K R$, Volkova $M$, at. Sox- and age-dependent human transcriptome variability: implications for chronic heart failure. Proc Nart Acad Sci US A. 2003; 100: 2754.

414. Lander ES, Linton L.M, et at. Initial sequencing and analysis of the human genome. Nature. 2001; 409: 860 .

415. Venter JC, Adams MD, al. The sequence of the thrman genome. Science. 2001; 291: 1304.

416. Tew KD, Monks $A$, at al. Glutathione-associated enzymes in the human cell lines of the National Cancer Institure Drug Screening Program. Mol Pharmacol. 1996; 50: 149.

417. Anderson L, Sellhamer $\mathrm{J}$. A comparison of selected mRNA and protein abundances in human liver. Electrophotesis. 1927; 18:533.

418. Gygi SP, Rist B, et al. Quantitarive analysis of complex protein mixtures using isotope-coded affinity tags. Nat Biotechnod. 1999, 17: 994. 
419. Furcher B, Latrer GI, a/ A sampling of the yeast proveme. Mol Gell Bul. $1999 ; 19: 7357$.

420. Hoogeveen $\mathrm{RC}$, Rexves SK, at a Copper deficiency increases hepatic apolpopmotein $\mathrm{A}$ synthesis and secretion but does not ater hepatic tom celluar apolipoprotein A. mRNA abundance in rats. J Nutr. 1995; 125: 2935.

421. Skidmore AF, Beebee TJ. Rat lactate dehydrogenase A and B subunir concentations ste not regulated by mRNA abundance in liver and heart. FEBS Lett. 1990, 270:67.

422. Le Naou $\mathrm{F}$, Hohenkirk L, at. Profling changes in gene expression during differentiation and maturation of monocyte-derived dendritic cells using both oligonucleotide microarrays and proteonirs. ] Biol Chem. 2001; 276: 17920.

423. dos Remedios $\mathrm{CG}$, Berry $\mathrm{DA}$, a a. Different electrophoteric techniques produce conticung data in the analysis of myocardial samples from dilated cardiomyopathy patients protein levels do not necessarily refect nRNA levels. Electrophoresis. 1996; 17: 235.

424. Chen $G$, Gharb $T G$, ef al Discondat protein and mRNA expression in lung adenocarcinomas. Mol Cell Proteomics. 2002; $1: 304$.

425. Hab BB, Dunham MJ, of a. Protein microarras fot highly parallet detection and quantition of specific proteins and antibodies in complex solutions. Genome Biol. $2001 ; 2(2): 1$.

426. Cahill DJ. Protein and antibody arrays and theit medical applications. I Immunol Methods. $2001 ; 250: 81$.

427. Bashir R, Gomez R, af al Adsorption of svidin on microfabricated surfaces tor protein biochip applications. Biotechnol Bioeng. 2001; 73:324.

428. Willams DM, Cole PA. Kinase chips hit the proteomics era. Tixends Biochem Sc. 2001; 26: 271 .

429. Zhu $\mathrm{H}$, Bilgin $\mathrm{M}$, of Global analysis of protein activities using proteone chips Science. 2001" 293: 2101 .

430. Herbert BR, Harry JII, at al What place for polyacrylamide in proteomics? Trends Botechnol. 2001; 19: $\$ 3$.

431. Ping $\mathrm{P}$, zhang $\mathrm{J}$, at al. Functional proteomic analysis of protein kinase $\mathrm{C}$ epsilon signaling complexes in the nomal heart and during cardioprotection. Circ Res. 2001; 88: 59.

432. Vondriska TM, Klein JB, at $a$. Use of functional proteomics to investigate PKC epsilonmediated cardioprotection: the signaling module hypothesis. An I Physiol Heart Circ Physiol. $2001 ; 280: 111,434$.

433. Iiu $Y$, Ranish JA, at Yeast nuclent extract contains two major forns of RNA polymerase It mediator complexes. \Biol Chen. 2001; $276: 7169$.

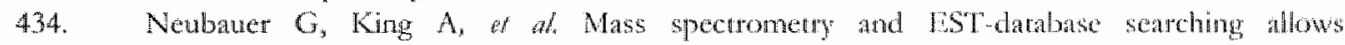
characterization of the multi-proten splicesome complex. Nat Genet. 1008; 20; 46.

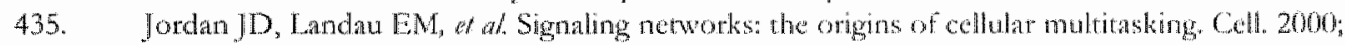
103: 193 .

436. Diviani D, Scot JD, AKAP signaling complexes at the cytoskeleton. J Cell Sci. 2001; $114: 1431$.

437. Gavin AC, Bosche M, af Funcrional organzation of the yeast protecme by systematio analysis of protein complexes. Nature. $2002 ; 415: 141$.

438. Ho $Y$, Gruller A, at Systematic identifican of protein complewes in Sacohatomycos cerewisine by mass spectometry. Nanure 2002; 415:180.

439. Husi $\mathrm{H}$, Wand MA, at Proteomic analysis of NMDA receptoradhesion protein signaling complexes. Nat Neutosci. 2000; 3: 601.

40. Ping P, Song $\mathrm{C}$. a f Fomation of protein kinase C(epsilon) l...ck signaling modules comfers cardioprotection. I Clin Invest 2002; 109:49\%.

411. Baines CP, Zhang J, ef al. Mitochondrial PKCepsilon and MAPK form sigmaling modules in the murine heart: enhaned mitochondrial PKCepsiton-MAPK interactions and differential MA PK. activation in PKCepsilon-induced cardioprotection. Curc Res. 2002; 90: 390. 
- Chapter 1

442. Soskic $\mathrm{V}$, Gorlach $\mathrm{M}$, at al. Functional proteomics analysis of signal transduction pathways of the phateleterived growth factor beta receptor. Biochemistry. 1999; 38: 1757 .

443. Edmondson RD, Vondriska TM; et at Protein kinase $C$ epsilon signaling complexes include metabolism- and transcription/translation-telated proteins: complimentary separation techniques with LC/MS/MS. Mol Cell Proteomics: 2002, 1: 421.

444. Vondtiska TM, Zhang J; at al Protein kinase C epsilon-Src modules direct signal ttansduction in nitric oxide-induced cardioprotection: complex formation as a means for cardloprotective signaling. Circ Res, 2001; 88: 1306 .

445. Nedelkov D, Nelson RW. Delineation of in wivo assembled multiprotein complexes vira biomolecular interaction analysis mass spectrometry. Proteomics. 2001; 1: 1441.

446. Ohi MD, Lirik Af, at at. Proteomics analysis reveals stable multiprotein complexes in both fission and budding yeasts containing Myb-related Cdc5p/Ceflp, novel pre-mRNA splicing factors, and snRNAs. Mol Cell Biol. 2002; 22: 2011.

447. Allen NP, Fluang $\mathrm{L}$, et al. Proteomic analysis of nucleoporin interacting proteins. $J$ Biol Chem. 2001:276:20268.

448. Song C, Vondrislia 'TM, et al. Molecular conformation dictates signaling module formation: example of PKCepsilon and Stc tyrosine kinase. Am J Physiol Heart Circ Physiol. 2002; 282: H1166.

449. Zhang J, Ping $P$, et al. Bmx, a member of the Tec family of non-receptor tyrosine hinases, is a novel participant in pharmacological cardioprotection. Am J Physiol Feart Circ Plysiol. 2004.

450. Michael LH, Entman ML, et al. Myocardial ischemia and reperfusion: a murine model. Am J Plnysiol, 1995; 269: H2147. 
Chapter 2

\title{
Long-term structural and functional consequences
}

of cardiac ischaemia-reperfusion injury

in vivo in mice

\author{
Tijl De Celle ${ }^{1}$, Jack P. Cleutjens ${ }^{2}$, W. Matthijs Blankesteijn', \\ Jacques J. Debets ${ }^{1}$,Jos F. Smits ${ }^{1} \&$ Ben J. Janssen ${ }^{1}$
}

Experimental Physiology; 2004; 89(5): 605-615

Departments of Pharmacology \& Toxicology and Pathology ${ }^{2}$, Cardiovascular Research Institute Maastricht; Universiteit Maastricht, The Netherlands 
- Chapter 2

\section{Abstract}

The short-term ( $<24$ h) consequences of oxidative stress induced by ischaemiareperfusion (IR) have been studied extensively in the mouse heart. However, much less is known about the long-term effects inflicted by a brief ischaemic period on the murine heart.

We therefore examined the structural and functional consequences of a 30 -min ischaemic period after 2 and 8 weeks of reperfusion and compared these to the effects of permanent ischaemia induced by permanent acclusion of the left anterior descending coronary artery (LAD).

The latter procedure resulted in transmural myocardial infarcts of about $52 \%$ of the left ventricle. In contrast, the single $30-\mathrm{min}$ ischaemic period led to infarct sizes of about $13 \%$ of the left ventricle (range $4-23 \%$ ) at 2 and 8 weeks after reperfusion. Maximal cardiac contractility responses ( $+\mathrm{dp} / \mathrm{dt}$ ) to dobutamine infusion and volume loading were depressed at 2 weeks, but not at 8 weeks after $\mathbb{I R}$. The restoration of cardiac contractility at 8 weeks after IR was associated with a significant $20 \%$ enlargement of the end-diastolic volume and $16 \%$ increase of the left ventricular wall thickness. "These changes in cardiac geometry were less pronounced at 2 weeks after $I \mathbb{R}$.

Histological examination revealed that the IR injury was associated with prominent calcification. At 2 and at 8 weeks after IR, $25 \pm 5 \%$ and $38 \pm 5 \%$ of the injured area was calcified as observed in $69 \%$ and $73 \%$ of the animals, respectively. After permanent occlusion of the LAD, calcification was not observed and wound healing was characterized by thinning and dilatation of the infarcted myocardium.

These data indicate that, in mice, a single 30-min period of ischaemia reduced ventricular contractility up to at least 2 weeks after IR. However, 8 weeks after IR, cardiac function was restored by eccentric hypertrophy associated with calcification of the injured ventricular wall. 
Cardiac ischaemia-repertusion injury *

\section{Introduction}

Cardiac reperfusion injury is a clinical problem associated with revascularization therapy as thrombolytic therapy, coronary artery bypass gratting and percutaneous transluminal coronary angioplasty [1]. Although these theraples are successfully used to restore blood flow to the previously ischaemic myocardium after myocardial infarction, reperfusion induces a complex cascade of events that can result in myocardial stunning, myocyte damage, microvascular and endothelial injury, and necrosis [2]. The destructive effects of reperfusion arise mainly from the acute generation of extremely reactive oxygen species (ROS), which are reduced oxygen species including superoxide anion $\left(\mathrm{O}_{2}{ }^{\circ}\right)$, hydrogen peroxide $\left(\mathrm{H}_{2} \mathrm{O}_{2}\right)$ and bydroxyl radicals $(\mathrm{OH})$. These $\mathrm{ROS}$ cause direct tissue damage through interaction with proteins, carbohydrates, lipids and nucleic acids leading to an inflammatory reaction and further damage [3].

The in wivo mouse model of cardiac ischaemia-reperfusion (IR) was first published by Michael et al in 1995 [4]. Following transient acclusion of the left antetior descending coronary artery (LAD) they described the histological appearance of leukacytes and contraction bands in the ischaemic region of the heart up to $24 \mathrm{~h}$ after reperfusion.

It should be noted that in this model infarct size is dependent on the dutation of the ischaemic period. Infarct size is smaller after 30 min than after 60 min of ischaemia. However, when the ischaemic period is extended up to $2 \mathrm{~h}$, infarct size is comparable to those resulting from permanent occlusion of the LAD [5].

The murine model of IR has been frequenty used to study the molecular mechanism of cardiac reperfusion injury or to evaluate potential therapies [6-9]. Most of these studies have focused on the short-term consequences of reperfusion with myocardial infarct size or neutrophil influx as parameters to describe the progression of cardiac tissue clamage in the time frame of a few hours [10-12], 1 day [13-16] or 3 days $[17,18]$ after the initiation of reperfusion.

The long-term effects of IR injury, in terms of weeks or months, are less well examined in this mouse model. However, this is relevant for extrapolation to the clinical setting. The outcome of interventions that are beneficial shortly after initiation of reperfusion may be different when the evaluation takes place at later stages. For example, a study by Metzler of al. [19], showed that genetic disnuption of intercellulat: adhesion molecule-1 was associated with a beneficial effect and reduced influx of neutrophils in the heart in the early phase following IR. However, at 3 weeks following $I R$, left ventricular scar size did not differ compated to values obtained in wild-rype mice.

In addition, long-tem adaptations to IR may differ from those induced by permanent occlusion of the LAD. As described by Michael of at. (1999) the degree of septal hypertrophy was smaller after IR than after permanent occlusion of the LAD, despite a comparable infarct size [5].

The goal of the present study was to characterize the long-term functional and morphological consequences of cardiac IR in the $i n$ wiv mouse model. The ischaemic period was set to 30 min because this interval is most commonly used in 
- Chapter 2

literature. We examined cardiac function by direct ventricular pressure measurements and cardiac geometry by echocardiography at three time points after IR ( 1 day, 2 weeks, and 8 weeks). In addition standard histological techniques were applied to describe the morphological adaptations of the injured heart over time. We noticed that the long-term histological adaptations to IR were associated with prominent calcification. To evaluate whether this latter effect was specific for the IR process, data were compared to those obtained in mice subjected to permanent ischaemia (PI).

\section{Methods}

\section{Animalsi}

Male outbred Swiss mice (8-11 weeks old, body weight of $35-40 \mathrm{~g}$ ) were purchased from Charles River (Somaren, The Netherlands). Experiments were performed according to the guidelines of the University of Maastricht and were approved by the institutional animal ethics committee. The animals were kept on a $12 \mathrm{~h}$ light-12-h dark cycle in a temperature controlled $\left(21 \pm 2{ }^{\circ} \mathrm{C}\right)$ room. After surgery, animals wete housed individually with ad libitum access to standard food pellets (type Ssiniff, Soest, Germany) and water.

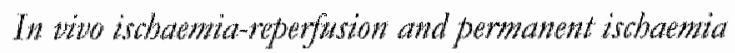

Mice were anaesthetized with ketamine (100 $\mathrm{mg} / \mathrm{kg}$ i.m.) and xylazine (5 mg/kg s.c.). Body temperature was monitored with a tectal probe and maintained at $37{ }^{\circ} \mathrm{C}$ using a watming pad and heating lamp. The trachea of each mouse was intubated perorally with a stainless-steel tube connected to a respirator (Hugo Sachs Electronic rodent ventilator type 845 , March-Hugstetten, Germany) set at a stroke volume of $250 \mu \mathrm{L}$ and a rate of 210 strokes/min. After left thoracotomy and exposure of the heart, the LAD was ligated with 6-0 polypropylene suture (Surgipro, Connecticut, USA) just proximal to its main branching point. The suture was tied around a 3-mm long polyethylene tube (PE-10) to induce ischaemia. In the IR group, blood flow was reestablished after $30 \mathrm{~min}$ of ischaemia by removal of the tube and suture. The occurtence of reperfusion was assessed by the observation of blood flow in the epicardial coronary arteries through a surgical microscope.

In the PI group, the suture was tied permanently. Sham procedures were identical, with the exception of the actual tying of the polypropylene suture. The chest was closed with 500 silk sutures. The animals were then weaned from the respirator, and the intratracheal tube was removed once they were breathing spontaneously. Then 0.2 $\mathrm{mg} / \mathrm{kg}$ body weight buprenorphine hydrochloride (Buprenex; Reckitt and Colman Pharmaceuticals, Richmond, VA, US) was injected s.c. as an analgaesic.

\section{Ehowardiograpby}

Echocardiographic measurements were performed under light isoflurane anaesthesia. One recording was taken prior to surgical procedures (week 0) and two recordings were taken at 2 and 8 weeks thereatter. "The in wiv transthoracic echocardiography of the left ventricle $(\mathrm{LV})$ was performed using a Hewlett-Packard 15-MHz linear array transducer (15-6L) interfaced with a Sonos 5500 echocardiography system (Philips, 
Eindhoven, The Nethetlands). Two-dimensional B-Mode echocardiogtams were captured at a rate of $90-120 \mathrm{~Hz}$ from parasternal long-axis views as well as from midpapillary short-axis views of the left ventricle. The spatial resolution in the B-Mode is 5 times higher than in the M-Mode. Data were obtained from at least 3 different images taken in end-diastole and systole using BnConcert software (Agilent Technologies, Andover, MA, USA). Representative examples of these images are given in figure 2 (control). From the long-axis B-mode echocardiograms, the LVAd and LVAs, (the LV area in diastole and systole, respectively), as well as the LVId and LVLs (the length of the LV lumen from base to apex in diastole and systolle, respectively) were determined. The end-diastolic volume (EDV) and end-systolic volume (ESV) were calculated from area and length measurements as $8(\mathrm{LVAd})^{2} / 3 \pi$ LVLd and $8(\mathrm{LVAs})^{2} / 3 \pi \mathrm{LVLs}$, respectively. Stroke volume was determined as EDVESV and the ejection fraction was defined as 100 (EDV-ESV)/EDV. From the shortaxis B-mode echocardiograms we determined the left ventricular wall thickness at two sites. Given the anatomical location of the coronary arteries in a mouse heart [20], the anterior wall contains the ischaemia-associated lesion, while the posterior wall represents the non-ischaemic part of the LV wall. In addition to wall thickness, LV internal chamber diameters were determined in diastole (LVIDd) and systole (LVIDs). The LV percent fractional shortening (FS) was calculated according to the following equation: 100 (LVIDd - LVIDs)/ILVIDd.

\section{Evaluation of left wentricular contractility}

Left ventricular contractility was evaluated at 1 day as well as 2 and 8 weeks after IR. For this purpose mice were anaesthetized with urethane $(2.5 \mathrm{mg} / \mathrm{g}$ body weight i.p. Sigma). Body temperature and respiration were controlled as described above. $A$ highfidelity catheter tip micromanometer (Mikro-tip, 1.4F, SPR-671; Millar Instruments, Houston, TX, USA) was inserted through the right carotid artery into the left ventricular cavity. Ventricular pressure was measured and sampled at a rate of $2 \mathrm{kHz}$. Maximal positive pressure development $(+\mathrm{dp} / \mathrm{dt}$ ) and heart rate were deremined on a beat to beat basis and one-second averages were stored on disk. The heat was then stimulated by an i.v. tamp-infusion of dobutamine (Sigma) using a microinjection pump (Model 200 Series, KdScientific, Boston, MA, USA). The infusion rate of dobutamine was increased every $2 \mathrm{~min}$ by $0.5 \mathrm{ng} / \mathrm{g} / \mathrm{min}$ (last step $=5 \mathrm{ng} / \mathrm{g} / \mathrm{min}$ ). Following recovery from dobutamine infusion (taking $10.20 \mathrm{~min}$ and assessed by restoration of $+\mathrm{dp} / \mathrm{dt}$ and heart rate to around baseline levels), hearts were additionally stressed by loading the circulation with an $i_{\text {.v. }}$. infusion of warmed $\left(37^{\circ} \mathrm{C}\right.$ ) Ringer"s solution for $1 \mathrm{~min}$ at a rate of $2.5 \mathrm{ml} / \mathrm{min}$. Maximal values of $+\mathrm{dp} / \mathrm{dt}$ were recorded and the changes of $+\mathrm{dp} / \mathrm{d}$ value from baseline were callculated. At the end of the experiment ventricles and lungs were excised, washed with isotonic saline and weighed. Ventricles were further incubated for $24 \mathrm{~h}$ in formalin and embedded into paraffin for histochemical staining and evaluation of infarct size as described below.

\section{Evaluation of ischaentic area at risk and infard size}

Twenty-four hours after IR, the infarcted area was measured on triphenyltetrazoliumchloride (TTC)- stained tissue sections [4]. In short, mice were 
anasthetized with pentobatbital $(120 \mathrm{mg} / \mathrm{kg})$, the jugulat vein was canulated and the thotar was reopened, the LAD was re-oceluded and $500 \mu \mathrm{L}$ of $2.5 \%$ trypan blue was injected into the jugular vein to delineate the non-ischaemic tissue and to quantify the areat risk $(A M)$. The heart was then excised, briefly washed with isotonic saline and cut into 2 parts: along the frontal plane and centrally through the ventricles. These wats were incubated for $20 \mathrm{~min}$ at $37^{\circ} \mathrm{C}$ in $5 \mathrm{ml}$ of $1 \% 2,3,5$-triphenyltetrazolium chorde solution (TTC, Sigma Chemicals Co., St. Louis, MO, USA). Viable myocardium is stained red by TTC while the nectotic, infarcted area remains unstaned [21]. Surface of the left ventricle (LV), the AAR as well as the infarcted area (infarct) were measured in both parts of the heart. The percentages AAR/LV, infarct/AAR and infarct/LV were calculated and expressed as the mean of both parts. To determine infarct size 2 and 8 weeks after IR or PI, mice were anaesthetized with pentobarbital $(120 \mathrm{mg} / \mathrm{kg}$ ), hearts were excised, washed with isotonic saline, cut into 2 parts as described above and embedded in paraffin. One section $(5 \mu \mathrm{m})$ from each of the two parts of the heart was stained with AZAN [22]. The surface of the blue stained parts and the surface of the left ventricle were measured on both sections and the percentage infarct/LV was calculated and expressed as the mean of both sections. All measurements were done using a computerized morphometry system (Quantimet 570C, Leica, Cambridge, UK, [23].

\section{Histocheswistry}

For histological examination, tissue sections were deparaffinized and stained with hematoxylin-eosin (HE staining). To localize calcium phosphate crystals, sections were stained using von Kossa staining [24]. The same computerized morphometry system was used to measure the relative surface area of the calcified regions to the infarcted area.

\section{Statistical anabsis}

All parameters are expressed as mean $\pm S$.E.M. Infarct sizes and maximal changes in $+\mathrm{dp} / \mathrm{dt}$ evoked by dobutamine and volume loading were evaluated using a Student's t-test. The dose response curves for dobutamine were compared using a two-way analysis of variance (ANOVA) and a post-hoc Bonferonni t-test. Parameters serially obtained by echocardiography were compared using an ANOVA for repeated measures and a post-hoc Fishers t-test to identify the time-related and between-group differences. $P$-values $\leq 0.05$ were regarded as staristically significant. 
Cardiac ischaemia-reperfusion injury *

\section{Results}

\section{General}

A total of 102 animals was used for this study of which $82(\sim 80 \%)$ survived the entite protocol. Nine animals died during or shortly after sham, IR or PI surgery because of complications due to anaesthesia, arthythmia or bleeding. Six animals died between 3 and 7 days after surgery of which 2 PI animals had a ruptured heart and the other 4 (1) sham, 3 IR) died for unknown reasons. Five animals died between 2 and 8 weeks after IR or PI (2 sham, 2 IR, 1 PI). A total of 70 animals were used for the cardiac contractility experiments, 7 animals of which were excluded because of difficulties in passing the aortic valves with the catheter tip, and 2 animals because they had died just before measurement due to complications with anaesthesia ( 1 sham, 1 IR).

\section{Morphometric characteristics}

Table 1 summarizes morphometric characteristics of the different groups of mice at the different time points in this study. Body weight was slightly decreased 1 day after surgery, but was increased in all groups (sham, IR and PI) at later time points. Ventricular weight and ventricular weight/body weight ratio were slightly, but insignificantly increased 2 weeks after IR compared to sham at that time point.

A significant positive cortelation between infarct size and ventricular weight $(R=+0.72)$ was found 2 weeks after IR. At 8 weeks after IR the increase in ventricular weight was much more pronounced $(P<0.01)$ compared to sham at that time point and comparable to changes observed in the PI group. Also at this time point a significant positive correlation between infarct size and ventricular weight $(R=+0.69)$ was found. Jung weights and lung weight/body weight ratios were significantly increased 8 weeks after PI $(P<0.05$ compared to sham at that time point), but not after IR.

Table 1: Myocardial infarct size and morphometric characteristics at three different time points after sham surgery (sham), ischaemiameperfusion (IR) or permanent ischaemia (PT).

\begin{tabular}{|c|c|c|c|c|c|c|c|}
\hline & \multicolumn{2}{|c|}{ Iday } & \multicolumn{2}{|c|}{2 weeks } & \multicolumn{3}{|c|}{8 weeks } \\
\hline & $\begin{array}{l}\text { sham } \\
(N=10)\end{array}$ & $\begin{array}{l}\mathbb{R} \\
N=102\end{array}$ & $\begin{array}{l}\text { sham } \\
N=10)\end{array}$ & $\mathrm{IR}=13$ & $\begin{array}{c}\text { sham } \\
(N=11)\end{array}$ & $\begin{array}{l}\mathrm{TR} \\
(\mathrm{N}=11 \mathrm{~h}\end{array}$ & $\mathrm{PI}=72$ \\
\hline Age (weeks) & $11.0 \pm 0.5$ & $10.3 \pm 0.5$ & $8.1+0.2$ & $8.7 \pm 0.1$ & $9.1 \pm 0.2$ & 8.640 .2 & $8.2 \pm 01$ \\
\hline $\mathrm{BW} 1(\mathrm{~g})$ & $30.9 \pm 110$ & $39.8 \pm 1.1$ & $36.7 \pm 0.6$ & $38.4 \pm 0.8$ & $37.1 \pm 0.7$ & $36.7 \pm 01$ & $38.4 \pm 1.0$ \\
\hline $\mathbb{B W} 2(\mathrm{~g})$ & $37.3 \pm 1.0$ & $37.1 \pm 0.9$ & $30.2 \pm 0.6$ & $38,9 \pm 1.1$ & $42.7+0.8$ & 42,0406 & $430+1.2$ \\
\hline$V w(g)$ & $0.17 \pm 0.01$ & $0.17+0.01$ & $0.18 \pm 0.00$ & $0.19 \pm 0.01$ & $0,18+0.00$ & $0.22+0.01 *$ & $0.22+0.01$ \\
\hline LWW $(\mathrm{g})$ & $0.23 \pm 0.01$ & $0.24 \pm 0,01$ & $0.23 \pm 0.01$ & $0.24+0.01$ & $0.25 \pm 0.02$ & $0.25+0.02$ & $0.33+0.03$ \\
\hline $\mathrm{VW} / \mathrm{BW} 2(\%)$ & $0.45 \pm 0,01$ & $0.46 \pm 0,01$ & $0.45+0.001$ & $0.49 \pm 0.02$ & $0.41 \pm 0.01$ & $0.52 \pm 9.02$ & $0.51 \pm 0.013 *$ \\
\hline $\mathbf{L W} / \mathbf{B W} 2(\%)$ & $0.63 \pm 0.03$ & $0.64 \pm 0.02$ & $0.59 \pm 0.01$ & $0.59 \pm 0.03$ & $0.57 \pm 0.04$ & $0.58+0.004$ & $0.80 \pm 0000$ \\
\hline Infarct $/ \mathrm{LV}(\mathbb{\%})$ & 0 & $21.2+3.5$ & 0 & $12.9 \pm 1.8$ & 0 & $12.3 \pm 1.9$ & $52.0 \pm 2.5$ \\
\hline
\end{tabular}

Abbreviations: BW1: body weight before sham-surgery, IR or P1; BW2: body weight before sacrifice; $V W$ : ventriculat weight; $L W$ : lung weight; $V W / B W 2$ : percentage of $V W$ relative to $B W 2$;.WW/BW2: percentage of LW relative to $\mathrm{BW} 2$; Infarct/LV: percentage of infaret size relative to left ventricular atrea.

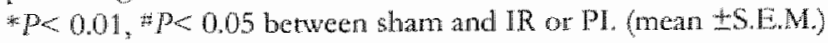



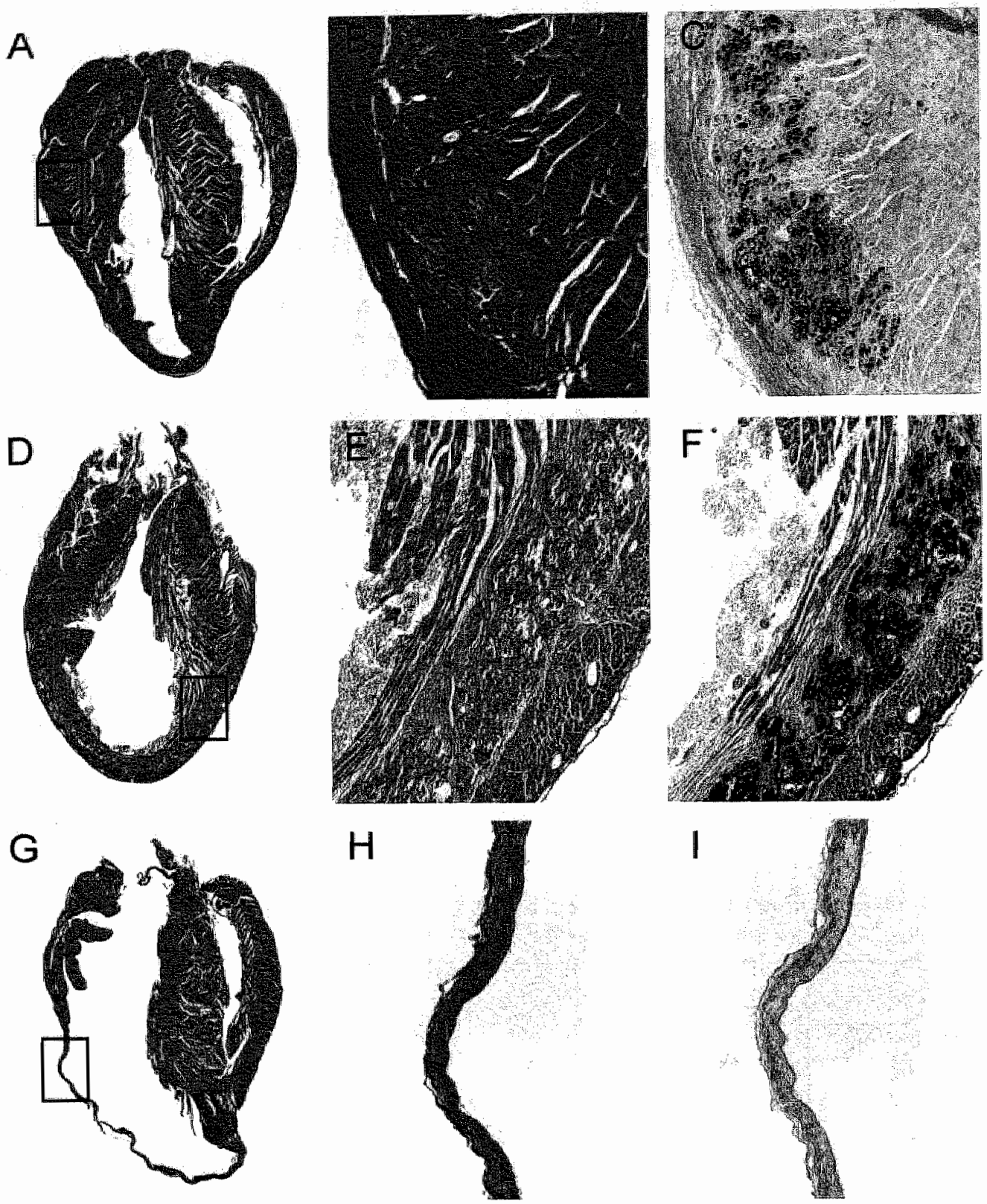

Figure 1: Photomicrograph of AZAN stained longitudinal heart sections of a 2 week IR animal $(A)$, an 8 week IR animal (D) and an 8 week PI animal (G) (magnification 16x). Derailed images focusing on an injured part of the left ventricle of these $A Z A N$ stained sections are shown in $B, E$, and $H$ (magnification $100 \mathrm{x}$ ). Nore the transmural infaret and the pronounced infarct thinning and dilatation in the 8 week PI animal compared to the IR animals. C, F, I are images of the same region stained by von Kossa staining (magnification 100x). Note that calcium deposits stained black in the IR animals and no calcification was observed in the PI group. 
Myocardial infarit size

One day after IR the AAR was $47 \pm 2 \%$ of the left ventricular area. $51 \pm 8 \%$ of the AAR was identified as infarcted area, meaning that $21 \pm 4 \%$ of the left ventricle was infarcted area (table 1). The magnitude of infarcted area/left ventricle natio did not differ at 2 and 8 weeks after IR, but was considerably less than in the PI group. As shown by the AZAN staining in figure $1 \mathrm{~A}, \mathrm{~B}, \mathrm{D}, \mathrm{E}$, the ventricular wall of mice subjected to the IR protocol consisted of viable endo- and epicardial layers of myocytes and patchy distributed scar tissue. In contrast, 8 weeks after PI, the infarcted wall of the left ventricle was thinned with an almost transmural appearance of granulation tissue (figure $1 \mathrm{G}, \mathrm{H}$ ).

\section{Calcifiation}

In the majority of animals subjected to $\mathbb{I R}$ a ptocess of calcification occurred in the infarcted area of the ventricular wall. Calcium deposits wete macroscopically observed as fine, white granules or clumps. By HE staining they appeared as basophilic, clumped and amorphous granules lying in a pattern of previous cardionyocytes and encircled by fibrous tissue. The calcium crystals were stained black by the ron Kossa staining (figure $1 \mathrm{C}, \mathrm{F}$ ) and appeared in a frequency of $9 / 13$ animals $(69 \%)$ in the 2 week reperfusion group and $8 / 11$ animals $(73 \%)$ in the 8 week IR group.

In the calcified hearts, the size of the calcified area was $25 \pm 5 \%$ of the infarcted area in the 2 -week $\mathbb{I R}$ group and $38 \pm 5 \%$ of the infarcted area in the 8 -week IR group. The calcification of the wound healing area was specific for the IR protocol because no calcification was observed in mice subjected to PI (figure 1 I).

Table 2: Compatison of echocardiographic parameters in mice subjected to the $30 \mathrm{~min}$ ischaemiareperfusion (IR) procedure, permanent ischaemia (PI) or sham-procedure. Data were obtained before (0 weeks cime point) as well as 2 and 8 weeks after the surgical interventions. Fot the PI group orsly data at week 0 and 8 ate shown.

\begin{tabular}{|c|c|c|c|c|c|c|c|c|}
\hline Paraneter & $\begin{array}{l}\text { O weeths } \\
\text { Sham }\end{array}$ & $\begin{array}{l}\text { 0 weeks } \\
\text { IR }\end{array}$ & $\begin{array}{c}0 \text { weeks } \\
\text { pl }\end{array}$ & $\begin{array}{l}2 \text { weeks } \\
\text { Sharn }\end{array}$ & $\begin{array}{c}2 \text { wecks } \\
\text { IR }\end{array}$ & $\begin{array}{l}\text { Sweeks } \\
\text { Sham }\end{array}$ & $\begin{array}{l}8 \text { weeks } \\
\text { IIR }\end{array}$ & $\begin{array}{c}\text { g weoks } \\
\text { PI }\end{array}$ \\
\hline$\sqrt{1}$ & 9 & 9 & 7 & 7 & his & 9 & 9 & 7 \\
\hline \multicolumn{9}{|c|}{ Long aris derived parameters } \\
\hline $\mathrm{EDV} i \mathrm{H}$ & $65+3$ & $65 \pm 3$ & $84 \pm 5^{*}$ & $77+6$ & $83+10 \%$ & $78+4$ & $87 \pm 8 *$ & $281+47 \cdot 64$ \\
\hline $\mathrm{ESW}(\mathrm{iul})$ & $31+3$ & $31 \pm 2$ & $43 \pm 4^{4}$ & $36+3$ & $36 \pm 6$ & $40+4$ & $44 \pm 5$ \% & $258 \pm 44$ \\
\hline$S V($ uil) & $34 \pm 4$ & $34 \pm 2$ & $41 \pm 4$ & $41 \pm 4$ & $46 \pm x$ & $39+3$ & $43+5$ & 30106 \\
\hline EF & $32 \pm 5$ & $51+3$ & $49 \pm 3$ & $54+3$ & $50 \pm 6$ & $50 \pm 4$ & $48 \pm 3$ & 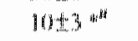 \\
\hline \multicolumn{9}{|c|}{ Short-axis derived parameters } \\
\hline AWTd (mm) & $1.00 \pm 0.02$ & $1.07 \pm 0.04$ & $0.80+0.13$ & $1.013 \pm 0.08$ & $1.24 \pm 0.68$ & $1.12 \pm 0.04 \%$ & $1.14+0.05$ & $0.51 \pm 0.08 * 6$ \\
\hline PWTd (mm) & $1.01 \pm 0.03$ & $1.08+0.02$ & $0.98+0.05$ & $1,12 \pm 0,08$ & $1.18 \pm 0.06$ & $1.14+0.04$ & 1.3140 .085 & $1.04 \pm 0.15$ \\
\hline AWTs (mun) & $1.27 \pm 0.00$ & $1.33+0.07$ & $1.11 \pm 0.94$ & $1.24 \pm 0.10$ & $1.54 \pm 0.606$ & $1.42 \pm 0,06$ & $1.54 \pm 0.0 .44$ & $0.53 \pm 00066^{6 t}$ \\
\hline PWTs (mom) & $126+0,03$ & $133 \pm 0.04$ & 12040.05 & 1.3340 .08 & $1.44+008$ & $1.38 \pm 0.04$ & $1.55 \pm 0.060^{5}$ & $1.541020 \%$ \\
\hline CVIDd (mam) & $4.16 \pm 0.09$ & $4.22 \pm 0.12$ & $4.51+0.10$ & $4.50 \pm 0.15$ & $4.69+40.17 *$ & $432 \pm 0.13$ & $4.08 \pm 0.13$ & $7,26 \pm 0141$ \\
\hline LVIDs (nor) & $3.09+0.15$ & $3.20 \pm 0.14$ & $3.53+0,17$ & $3.40 \pm 0.17$ & $3.59+10.19$ & $328 \pm 017$ & $3.59 \pm 0.17$ & 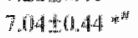 \\
\hline $\mathbf{P S}(\%)$ & $26 \pm 3$ & $24+3$ & $22 \pm 3$ & $23 \pm 2$ & $22 \pm 2$ & $24+4$ & $23+3$ & $3 \pm 1: x^{3 / 4}$ \\
\hline
\end{tabular}

Abbreviations: EDV, ESV: end diastolic and end systolic left ventricular volume; SV: stroke wolume; FF: ejection fraction; AWTd, PWTd, AWTs, PWTs: anterior wall and posterior wall thickness in diastole and systole, respectively; IVIDd, LVIDs: left ventricular internal caviry diameter in diastole and systolk, respectively; $\mathrm{FS}$ : fractional shortening. " $P<0.05$ : different from control at week 0 , $\$ p<0.05$ : between sham and IR; $P<0.05$; between IR and PI. (mean $\pm S$. E.M.) 


\section{Echoucardiograpty}

The results of the in wito echocardiographic measurements are given in table 2 . The compatison of the echocardiographic parameters at week 0 indicates that baseline values of end diastolic volume (EDV) and end systolic volume (ESV) were somewhat greater in the PI group than in the sham or IR group. This is probably due to normal time-clependent biological watiation given the fact that the mice used for the PI series of experments were not simultancously purchased.

\section{diastole}

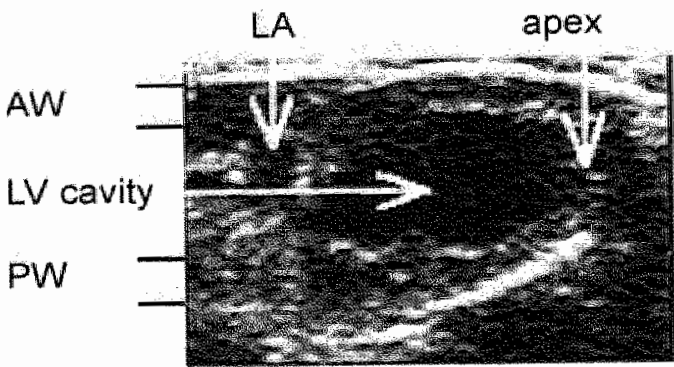

control

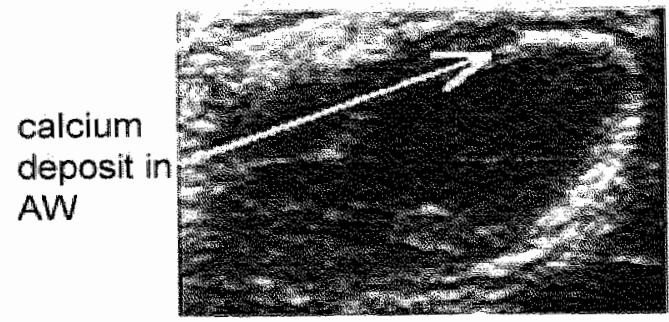

IR

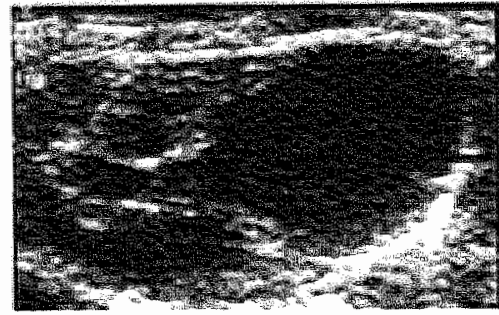

$\mathrm{PI}$ systole

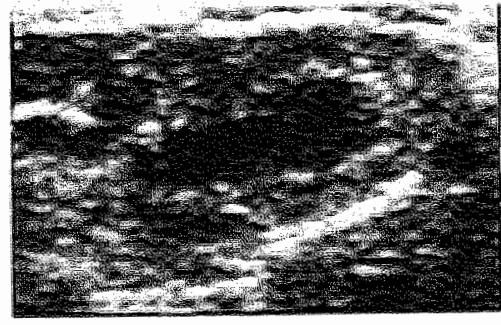

control

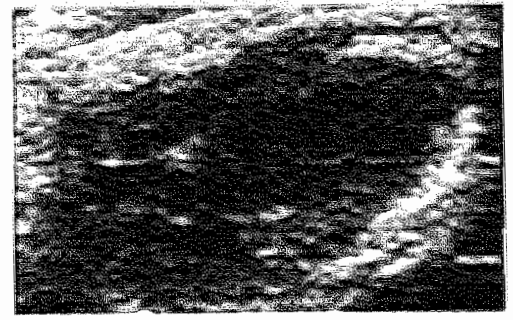

$\| R$

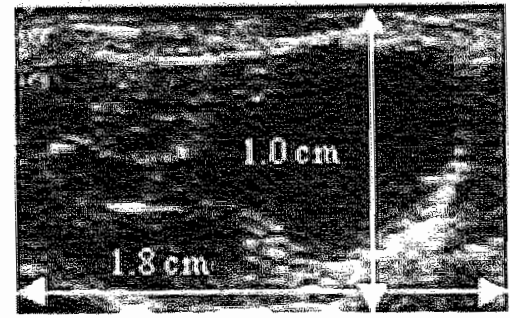

PI

Figure 2: Long-axis echocardiographic images of the heart taken 8 weeks after mice were subjected to sham-surgery, ischatmia-reperfusion (IR) or pormanent isctaemia (PJ). Notc the extreme dilatation in the Pl model and occourrence of a white area within the AW of the IR heart, histologically confrmed as it calcium deposit. Abbreviations; $L A=$ left atrum, $L V=$ left ventricle, $A W=$ anterior wall, $P W=$ posterion wall. 
Compared to the baseline value, the EDV was significantly increased at 2 and 8 weeks after IR while this was not the case in the sham-operated mice. However, when compared to the PI group, the dilatory remodeling response to the IR injury was relatively small ( $40 \pm 15 \%$ for IR versus $250 \pm 70 \%$ for $\mathrm{PI}$, figure 2 ). The timedependent changes in EDV 8 weeks after IR wete paralleled by those in BSV. However, cardiac function, as assessed by stroke volume (SV), ejection fraction (EF) and fractional shortening (FS), was not significantly altered at 2 and 8 weeks after IR. In contrast, the geometrical changes in the PI group had significant functional consequences for $\mathrm{SV}, \mathrm{EF}$, and FS (figure 2).

The echocardiogtaphic measurements also identified a small but significant thickening of the anterior wall (AW) at 2 and 8 weeks after IR, especially during systole. At 8 weeks after IR the posterior wall (PW) thickness was significantly increased as well. After PI the affected AW became very thin whereas the PW showed a comparable hypertrophic response as observed 8 weeks after IR.

\section{Ventrialar contractility}

Figure 3 presents LV function as evaluated in sham, IR and PI groups at the different time points by measuring the rate of left ventricular pressure development $(+\mathrm{dp} / \mathrm{dt}$ ) and heart rate (HR). Under basal conditions, $+\mathrm{dp} / \mathrm{dt}$ did not differ between sham, IR, or PI. Also systolic blood pressures did not differ at baseline between sham, IR or PI $(74 \pm 2 \mathrm{mmHg}, 71 \pm 2 \mathrm{mmHg}, 72 \pm 2$ respectively; data not shown). Baseline HR values were significantly $(P<0.01)$ higher in the IR group than in sham-operated mice 1 day after reperfusion. When hearts were stimulated with dobutamine, $t \mathrm{dp} / \mathrm{dt}$ levels increased dose-dependently in sham-operated animals, whereas the increase was blunted in IR animals at 1 day and 2 weeks after reperfusion (figure $3 \mathrm{~A}$ ). Dose response curves for heart rate were comparable between groups. One day after IR, the increase in $+\mathrm{dp} / \mathrm{dt}$ was significantly smaller $(2456 \pm 475 \mathrm{mmHg} / \mathrm{s})$ when compared to increments observed in the sham group $(5939 \pm 928 \mathrm{mmHg} / \mathrm{s} ; P=0.004)$. The blunted response was still present 2 weeks after IR (IR: $3174 \pm 1066 \mathrm{mmHg} / \mathrm{s}$ versus sham: $7487 \pm 1209 \mathrm{mmHg} / \mathrm{s} ; \quad P=0.01)$. In contrast, 8 weeks after IR, the contractility response to dobutamine was nearly restored to control levels $(5828 \pm 735 \mathrm{~mm}-\mathrm{Hg} / \mathrm{s}$ in IR versus $6620 \pm 735 \mathrm{~mm} \mathrm{Hg} / \mathrm{s}$ in sham-opetated mice). At this time point, the contractile response to dobutamine in the PI group was significantly blunted.

Figure $3 \mathrm{~B}$ shows that comparable results were obtained with volume loading. The increase of $+\mathrm{dp} / \mathrm{dt}$ at 2 weeks after IR $(1758 \pm 991 \mathrm{mmHg} / \mathrm{s})$ was significantly smaller than in the sham group $(6129 \pm 1247 \mathrm{mmHg} / \mathrm{s} ; P=0.02)$. At 8 weeks after IR the increase in $+\mathrm{dp} / \mathrm{dt}$ following volume loading $(5149 \pm 820 \mathrm{~mm} / \mathrm{gg} / \mathrm{s})$ did not differ from values observed in the sham group $(4669 \pm 466 \mathrm{mmHg} / \mathrm{s})$. In the PI group the response was significantly reduced $(2245 \pm 665 \mathrm{mmHg} / \mathrm{s} ; P<0.03$ ). 

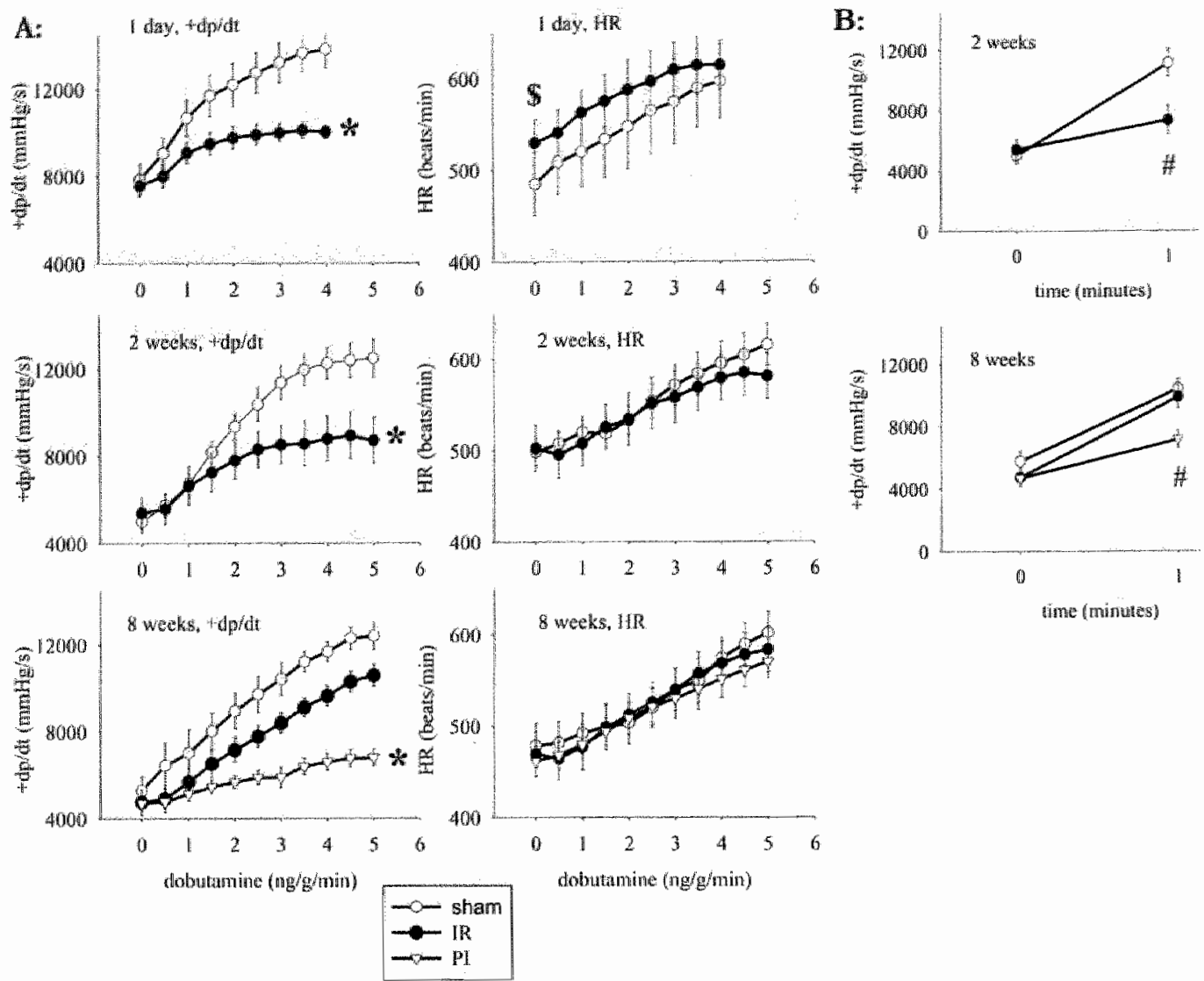

Figure 3: It who assessment of left ventricular contractility.

A: Change in cardiac contactility $(+\mathrm{dp} / \mathrm{d})$ and heart rate $(\mathrm{HR})$ during dobutamine stimulation $(0-5$ $\mathrm{ng} / \mathrm{g} / \mathrm{min}$ ) in sham groups, IR groups and PI group at 1 day, 2 weeks and 8 weeks ( $\mathrm{N}=7-10$ per group). "p<0.01, Spe0.01. (Results are expressed as means \pm S.E.M.)

B: Change in cardiac contractility ( $+\mathrm{dp} / \mathrm{dr}$ ) under volume loading $(2.5 \mathrm{ml} / \mathrm{min}$ Ringer solution) in sham groups, IR groups and Pl group at 2 weeks and 8 weeks $(\mathrm{N}=7$ to 10 per group). $P<0.05$. (Results are expressed as means \pm S.E.M.)

To examine whether the amount of calcification was associated with deficits in cardiac function, infarct size was plotted against the maximal $+d p / d t$ responses to dobutamine in the 2 and 8 week IR groups (figure 4). The subgroup of mice with the largest calcified LV areas is separately indicated in this figure. The figure shows that atthough the mice with the largest amount of calcification were among those with the largest infarct size, no obvious relation to cardiac contractility was observed.

\section{Discussion}

The present study shows that a single 30 -min ischaemia-reperfusion protocol has long-term consequences for cardiac morphometry and function in mice. 


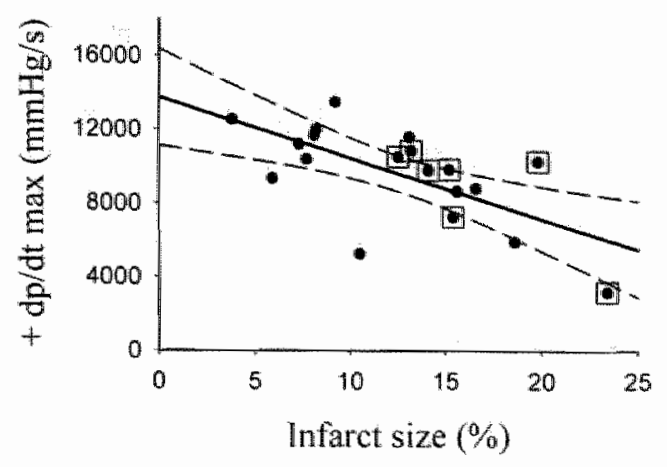

Figure 4: Linear correlation $(R=-0.64, N=19, P<0.01)$ between infurct size and maximal left pentricular. pressure development $\left(+\mathrm{dp} / \mathrm{dt}_{\mathrm{max}}\right.$ ) following dobutamine in mice at 2 weeks and 8 weeks after $\mathrm{IR}$. The subgroup of mice with the largest calcified left ventricular area is indicated by squares.

Left ventricular contractility was depressed up to 2 weeks after IR, but was restored 8 weeks after the intervention. The recovery of cardiac contractility was associated with left ventricular dilatation and hypertrophy. Remarkably, in the IR model, but not in the PI model, the long-term repair mechanisms were associated with considerable calcification.

The degree of cardiac injury and survival rate is related to the duration of the ischaemic stimulus. In the present study, we chose a commonly used time frame of 30 min of ischaemia and the survival rate was more than $80 \%$ at 8 weeks after $\mathbb{R}$.

In a study by Michael et at. [5] it has been described that following a $2 \mathrm{~h}$ ischaemic period the survival rate was $60 \%$ after $24 \mathrm{~h}$ and only $45 \%$ several weeks after reperfusion. In that study, left ventricular infarct size was about $30 \%$ and did not differ from infarct sizes found after permanent ischaemia. In the present study, following the shorter $30 \mathrm{~min}$ ischaemic period, left ventricular infarct size was $21 \%$ at 1 day after IR. Two and 8 weeks after IR the LV infarct size was smaller (about 13\%). This time-related difference in infarce size is most likely a consequence of the technique used to assess infarct size. Staining by 'TTC is based on the ability of living cells to reduce TTC to an insoluble red pigment. It cannot be excluded that $24-\mathrm{h}$ after IR, part of the cardiomyocytes, were unable to metabolize TTC because they were in a hibernating state. Jater on in the process these cells may have regenerated to vital cardiomyocytes which may explain the reduced infarct size measured at 2 and 8 weeks after IR $[25,26]$.

As shown in figure 1, permanent occlusion of the LAD in the PI model resulted in large transmural infarcts with thinning of the left ventricular wall and did not involve the septum and right ventricle. In contrast, in the IR model, infarcts were never transmural, but characterized by a patchy distribution of granulation and scar tissue localized between an endo- and epicardial layer of vital cardiomyocytes.

At 2 and 8 weeks after IR we observed in about $70 \%$ of the animals pronounced calcified regions in the left ventricular wall that were surrounded by granulation and fibrous scar tissue. This phenomenon was completely absent in the PI animals.

Dystrophic calcium deposition appears in many pathological conditions due to passive precipitation of calcium and phosphates. In cardiovascular diseases this process is 
- Chapter 2

mosty described in atherosclerosis in which arterial plaque calcification occurs and in degencrative diseases of heart valves $[27,28]$. To our knowledge only two reports are published about calcification in relation to reperfusion. A case study of Tseng et al. [29] reported acute calcification following transient ligation of the rodent middle cerebral artery, while Jennische $[30]$ showed post-ischaemic calcification in skeletall muscle of the rat. However, following myocardial ischaemia-reperfusion, tissue calcification is not documented. Lipids, apoptotic bodies and necrotic debris in the wound-healing area may play a role in the nucleation of calcium hydroxyapatite crystalls [31]. When blood flow is restored after ischaemia, debris of death cells may accumulate with calcium and phosphates from the blood before the inflammatory cells infiltrate the damaged tissue. After permanent occlusion of the area at risk, blood flow is not restored and hence the deposition of calcium crystals is prevented, enabling the inflammatory cells to clear the necrotic debris. The present study was not designed to clarify the mechanisms of this aspect of wound healing. We observed that the animals with the largest area of calcification were among those that had the largest infarct size (figure 4). However, the calcification process did not seem to thave a negative impact on cardiac function because it returned to normal 8 weeks after IR. Further studies are necessary to investigate this issue in more depth.

Cardiac contractility was measured in order to characterize the evolution of cardiac function over time after ischaemia-reperfusion. Baseline heart rates were slightly elevated $24 \mathrm{~h}$ after IR compared to sham-operated animals. This was probably due to neurohumoral compensation following the acute $I R$ injury. Baseline heart rates did not differ between sham-operated and IR mice at 2 and 8 weeks after surgery, suggesting a normalization of this response.

Baseline $+\mathrm{dp} / \mathrm{dt}$ levels were not different between the IR and sham-operated mice at any time point. Also, baseline $+\mathrm{dp} / \mathrm{dt}$ values obtained 8 weeks after PI were not different from those found in the sham group, despite the increase in lung weights, which suggest signs of congestive heart failure. In contrast, other studies have reported decreased $+d p / d t$ values after PI at baseline conditions $[32,33]$. Differences in anaesthetic regimens and other experimental circumstances may explain these discrepancies. 'To obtain a better insight into the physiological consequences of IR injury, contractility changes were measured while the heart was stressed with dobutamine or a volume load. In comparison to sham-operated mice, cardiac contractility responses to dobutamine were reduced 1 day and 2 weeks after IR. At 8 weeks after IR, but not after PI, responses to dobutamine and wolume loading were nearly testored.

The recovery of cardiac contractility at 8 weeks after IR occurred simultaneously with morphological adaptations as determined by echocardiography and was paralleled by a significant increase in ventricular weight. Part of this hypertrophic response is due to normal physiological growth. However, the enlargement of the end-diastolic volume (40\% in IR versus $20 \%$ in sham-operated mice) and thickening of the posterial wall (23\% in IR versus $13 \%$ in shammoperated mice) suggest an eccentric hypertrophic response to IR injury. Early signs of this process were detected already at 2 weeks after $I R$, as suggested by the positive correlation between infarct size and ventricular weight. "The remodeling response may 
be too small at that time point to compensate for the reduced cardiac contractility response.

The process of dilatation was much smaller after IR than after PI. Eight weeks after PI the end-diastolic volume was increased by a factor 2.5. Despite the enlargement of the ventricular cavity, stroke volume and ejection fraction were significantly reduced because the infarcted and thinned myocardial wall remained fully akinetic. These functional impairments as detected by echocardiography ate in agreenent with those obtained before by direct ascending aortic blood flow measurements in this model [34].

We conclude that in our mouse model, long-term cardiac consequences following ischaemia-reperfusion are different from those observed after permanent ischaemia. Contractility of the heart was depressed for at least 2 weeks after IR, but was restored after 8 weeks. Given the significant negative correlation between infarct size and cardiac contractility the functional differences between the IR model and the PI model are most likely of a quantitative nature. After reoxygenation of the ischaenic heart, calcification, hypertrophy and minor dilatation characterized the wound healing process. However, the gross architecture of the ventricular wall was preserved. This aspect differed qualitatively from the permanent ischaemia model. When reperfusion was not established, the ischaemic area was not calcified, but completely replaced by connective tissue. In addition, the ventricular wall was severely dilated and loss of cardiac function was permanent.

\section{References}

1. Kaminski KA, Bonda TA, et at. Oxidative stress and neutrophil activation-the wwo keystones of ischemia/reperfusion injury. Int J Cardiol. 2002; 86:41.

2. Verma $S$, Fedak PW, ef al. Fundamentals of repetfusion injury for the clinical cardiologist. Circulation. 2002; 105: 2332.

3. Li C, ]ackson RM. Reactive species mechanisms of cellular hypoxia-reoxygenation injury. Am ] Physiol Cell Physiol. 2002; 282: C227.

4. Michael LH, Enman ML, of at. Myocardial ischemia and reperfusion: a menine model. Am J Physiol. 1995; 269: H2147.

5. Michael LH, Ballantyne CM, of al. Myocatdial infaretion and remodeling in mice: eftect of reperfusion. Am J Physiol. 1999; 277: H660.

6. Chen $Z$, Chua $C C$ ef al. Protective effect of melatonin on myocardial infarction. Am I Physiol Heart Circ Physiol. 2003; 284: H1618.

7. Jones SP, Lefer DJ. Myocardial Reperfusion Injury: Insights Gained from Gene-Targeted Mice. News Physiol Sci. 2000; 15: 303.

8. Jones SP, Hoffmeyer MR, at Role of intracellular antioxidant enzymes after in vivo myocardial ischemia and reperfusion. Am f Physiol Heare Circ Physiol. 2003; 284: H277.

9. Yer SF, Tian $\mathrm{R}$, at Cardac-specific expression of heme oxygenase-1 protects against ischemia and reperfusion injury in transgenic mice. Circ Res. 2001; 89:168.

10. Girod $\mathrm{WG}_{\mathrm{G}}$, Jones $\mathrm{SP}$, et al. Effects of hypercholesterolemia on myocardial ischemia-reperfusion injury in I.DL receptor-deficient mice. Artetioscler Thromb Vase Biol. 1999; 19: 2776.

11. Jones SP, Girod WG, et al. Reperfusion injury is not affected by blockade of P-selectin in the diabetic mouse heart. Am J Physiol. 1999; 277: H763. 


\section{- Chapter 2}

12. Palazto A, Jones SP, et al Myocardial ischemia-reperfusion injury in CD18- and ICAM-1deficien mice. Am J Physiol 1998; 275: $\mathrm{H} 2300$.

13. Scalia R, Gooszen ME, th al. Simvastatín exerts both andinflammatory and candioprotective effects in apolipoprotein E-deficient mice. Circulation. 2001; 103: 2598.

14. Jones SP: Trocha SD, ef at. Cardioprotecrive actions of endogenous IL-10 are independent of iNOS. Am J Physiol Heart Circ Physiol. 2001; 281: H48.

15. Jones $\mathrm{SP}$, Gibson $\mathrm{MF}$, et af Direct wascular and cardioprotective effects of rosuvastatin, a new HMG CoA reductase inhibitor. I Am Coll Cardiol. 2002; 40: 1172.

16. Hoffmeyer MR, Scalia $\mathrm{R}$, ef al. PR-39, a potent neutrophil inhibitor, attenuates myocardial ischemita-reperfusion injury in mice. Am J Physiol Heart Circ Physiol. 2000; 279; H2824.

17. Briaud SA, Ding ZM, et al Leukocyte trafficking and myocardial reperfusion injury in ICAM1/P-selectin-knockour mice. Am J Physiol Heart Circ Physiol. 2001; 280: H60.

1.8. Yang J, Jones SP, et ant: Endothelial cell ovetexpression of fas ligand attenuates ischemiarepetfusion injury in the heart. J Biol Chem. 2003; 278: 15185.

19. Metaler $\mathrm{B}$, Muir J, ef at Mouse model of myocardial remodelling after ischemia: role of intercellular adhesion molecule-1. Cardiovasc Res. 2001; 49; 399.

20. Janssen B, De Celle T, Paquay J, Smits J, Blankesteijn M. Structural and Functional Adaptations of the Heart after Coronary Artery J.jigation in the Mouse. In: Ince $C_{y}$ ed. The Physiological Genomics of the Critically IIl Mouse. Vol. 16. Boston/Dordecht/London: Kluwer Academic Publishers; 2003: 211.

21. Vivaldi MT", Kloner RA, ef al. Triphenyltetrazolium staining of irreversible ischemic injury following coronary artery occlusion in rats. Am J Pathol. 1985; 121:522.

22. Clleutiens JP, Verluyten MJ, at. Collagen remodeling after myocardial infarction in the rat heart. Am J Pathol 1995; 147: 325.

23. Smits JF, wan Krimpen $\mathbb{C}_{p}$ at angiotensin Ill receptor blockade after myocardial infarction in rats: effects on hemodynamics, myocardial DNA synthesis, and interstitial collagen content. J Cardiovasc Pharmacol. 1992; 20:772.

24. Bills CE, Eisenberg H, al. Complexes of organic acids with calcium phosphate: the Von Kossa stain as a clue to the composition of bone mineral. Johns Hopkins Med J. 1974; 128: 194.

25. Vanoverschelde JL, Melin JA. The pathophysiology of myocardial hibernation: current controversies and future directions. Prog Cardiovasc Dis. 2001; 43: 387.

26. Ausma J, Cleutiens J, w al. Chronic hibemating myocardium: interstitial changes. Mol Cell Biochem. 1995; 147; 35.

27. Doherty TM, Asora $K$, at alcification in atherosclerosis: bone biology and chronic inflammation at the arterial crossionds. Proc Natl Acad Sci U S A. 2003; 100: 11201.

28. David TE, Ixanow J. Is degenerative calcification of the mative aortic valve similar to calcitication of bioprosthetic heart valves? I Thorac Cardiovase Surg. 2003; 126: 939.

20. Tseng MT, Chan SA, at A case study of ligation induced calcification in middle cerebral artery in rat. Histol Histoparhol. 2000; 15: 483.

30. Jennische E. Post-ischemic calcification in skeletal muscle. A light microseopic study in the rat. Acta Pathol Microbiol Tmmunol Scand |A. 1984: 92: 139.

31. Proudfoor D, Skepper JN, et af. Apoptosis regulates human vascular calcification in vitro: evidence for initistion of vascular calcification by apoptotic bodies. Circ Res. 2000; 87: 1055 .

32. Lurgens $\mathrm{E}$, Datemen $\mathrm{MJ}$, of at. Chronic myocardial infarction in the mouse: cardiac structural and functional changes. Cardiovasc Res. 1999; 41: 586.

33. Patten RD, Aronovitz M, of ventricular temodeling in a mouse model of myocardial infarction. Am I Plyysiol. 1998; 274: H1812.

34. Janssen B, Debets J, et al. Chronic measurement of cardiac output in conscious mice. Am J Physiol Regul Inregr Comp Physiol. 2002; 282: R928. 


\section{Chapter 3}

\section{Sustained protective effects of}

\section{7-monohydroxyethylrutoside in an in vivo model of cardiac ischaemia-reperfusion}

Tijl De Celle ${ }^{1}$, Peter Heeringa ${ }^{2}$, Agnieska E. Strzelecka ${ }^{1}$, Aalt Bast ${ }^{1}$,Jos F. Smits ${ }^{1} \&$ Ben J. Janssen ${ }^{1}$

European Joumal of Pharmacology; 2004; 494: 205-212

Departments of Pharmacology \& Toxicology ${ }^{1}$ and Clinical \& Experimental Immunology ${ }^{2}$, Cardiovascular Research Institute Maastricht, Universiteit Maastricht, The Netherlands 
- Chagtex 3

\section{Abstract}

Earlier studies have shown that 7-monohydroxyethylrutoside (monoHER), an antioxidant flavonoid, protects against doxorubicin-induced cardiotoxicity. In this study we investigated potential sustained cardioprotective effects of monoHER in a model of ischaemia-teperfusion (IR) in mice.

Ischaemia was induced for $30 \mathrm{~min}$ by ligating the left anterior descending coronary artery. Afterwarcls the ligature was removed and reperfusion allowed for $6 \mathrm{~h}, 24 \mathrm{~h}$ or 2 weeks. MonoHER (500 $\mathrm{mg} / \mathrm{kg}$ ) or saline was given intraperitoneally, $1 \mathrm{~h}$ before ischaemia.

Treatment with monoHER significantly attenuated myocardial neutrophil influx both at $6 \mathrm{~h}$ and $24 \mathrm{~h}$ after reperfusion by $77 \%$ and $76 \%$, respectively. Infarct size was also significantly reduced, $24 \mathrm{~h}$ and 2 weeks after reperfusion by $58 \%$ and $49 \%$, respectively. Wheteas IR had no influence on basal levels of cardiac contractility $(+\mathrm{dp} / \mathrm{dt})$, responses to dobutamine were blunted $24 \mathrm{~h}$ and 2 weeks after reperfusion. In mice treated with monoHER, cardiac contractility response was significantly restored.

These results indicate that monoHER exerts a sustained cardioprotective effect on IR injury and prevents deterioration of cardiac contractility. 
MonoHER and ischaemia-reperfucion injary (part 1 )

\section{Introduction}

Myocardial reperfusion through thrombolysis, percutaneous transluminal coronary angioplasty or coronary artery bypass grafung, is standard treatment in acute myocardial infarction. However, these revascularization therapies initiate a second phase of myocardial injury either by acceleration of detrimental processes initiated during ischaemia, or by inducing additional pathological processes following reperfusion $[1,2]$.

Many studies support a role of "reactive oxygen species" (ROS) in myocardial ischaemia-reperfusion (IR) injury $[2,3]$. The mechanism implicates the sequential reduction of molecular oxygen into these $\mathrm{ROS}$, including superoxide anion $\left(\mathrm{O}_{2}{ }^{\circ}\right)$, hydrogen peroxide $\left(\mathrm{H}_{2} \mathrm{O}_{2}\right)$, and hydroxyl radicals $(\mathrm{OH})$ in an amount that overwhelms the scavenging capacity of endogenous antioxidants in the heart. The interaction of these ROS with cell membrane lipids and essential proteins contributes to myocardial cell damage, leading to inflammatory reactions, irreversible tissue injury and, consequently, to impaired cardiac function [4]. Reperfusion injury triggers an acure inflammatory response in which polymorphonuclear neutrophils infiltrate the myocardium, under the influence of chemotactic attraction and activation of the complement cascade $[5,6]$. Although essential in wound healing, these neutrophils may have detrimental effects by producing additional ROS and proteolytic enzymes $[4,6,7]$.

Flavonoids are a group of narurally occurring polyphenolic compounds with excellent iron chelating as well as radical scavenging properties [8]. The semisynthetic flavonoid, 7-monohydroxyethylrutoside (monoHER), has been shown to protect in wiv against chronic doxorubicin-induced cardiotoxicity in mice 19,101 and is now being tested in a phase II clinical trial.

Potential protective effects of exogenously administered antioxidants on reperfusion injury have already been described in literature, but the results are controversial [3]. Moreover, most of these studies only investigated possible shotr-tem protective effects after initiation of reperfusion (range 1-24 h) and did not prove sustained protective effects.

In the present study we investigated potential short- $(6,24 \mathrm{~h})$ and long-term (2 weeks) protective effects of monoHER after th to cardiac IR in mice. We did this by examining neutrophil tissue infiltration, infarct size and cardiac contractility. Possible dose-dependent effects of monol IER on mean arterial pressure and heart rate were examined in a separate set of experiments.

\section{Materials and Methods}

\section{Awimals}

Male outbred Swiss mice ( $8-11$ week old, weighing $35-40 \mathrm{~g}$ ) were used. "The mice wete purchased from Charles River (The Netherlands). Experiments were performed according to the guidelines of the Universiteit Maastricht and were approved by the institutional animal ethics committee. The animals were kept on a $12 \mathrm{~h}$ light- $12 \mathrm{~h}$ dark cycle in a temperature-controlled $\left(21 \pm 2^{\circ} \mathrm{C}\right.$ ) room. After surgery, animals were housed 
- Chapter 3

individually with ad hitum access to standard food pellets (type Ssniff, Soest, Germany) and water.

Measurement of blood pressure and beat rate in conscious animals

A carheter was implanted in the femoral attery and in the jugular vein under isoflutane anaesthesia $(1.5-2.5 \%$, as described in detail [11]. The arterial catheter was connected to a pressure transducer (micro-switch, model 156PC 156WL, Honeywell, Amsterdam, The Netherlands) and to an amplifiet that delivered a high-voltage signal to an analogto-digital converter board (model 2814, Data Translation, CN Rood, Rijswijk, the Netheilands) mounted in an IBM 486-compatible computer. The blood pressure signal was sampled at $2,000 \mathrm{~Hz}(\sim 200$ data samples/beat). Beat-to-beat values of mean arterial pressure were calculated as the area under the curve of each pressure wave using the end-diastolic value to determine the heart rate. Animals were allowed to recover from surgery for 2 days and on the 3 rd day blood pressure and heart rate were measured continuously in the conscious state after $i . v$. administration of monoHER $(\mathrm{pH}: 7.9-8.1)$ in a dose range from $1-100 \mathrm{mg} / \mathrm{kg}$ with an interval of $15 \mathrm{~min}$ between each dose.

\section{Ischatma-reperfusion of the munine beant in wivo}

Mice were anaesthetized with ketamine $(100 \mathrm{mg} / \mathrm{kg}$ im.) and xylazine $(5 \mathrm{mg} / \mathrm{kg} \mathrm{s.c.)}$. Body temperature was monitored with a rectal probe and maintained at $37 \circ \mathrm{C}$ using a warming pad and heating lamp.

The trachea of each mouse was intubated perorally with a stainless-steel tube connected to a respitator (Hugo Sachs Elektronic rodent ventilator type 845 , MarchHugstetten, Germany) set at a stroke volume of $250 \mu \mathrm{l}$ and a rate of 210 strokes $/$ min. After left thoracotomy and exposure of the heart, the left anterior descending cotonary artery (LAD) was ligated with 6-0 polypropylene (Surgipro, Connecticut, USA) just proximal to its main branching point. The suture was tied over a 3-mm long polyethylene tube (PE-10) that was left in place for $30 \mathrm{~min}$. Blood flow was then reestablished by removal of the tube. The occurrence of teperfusion was assessed by the observation of blood flow in the epicardial coronary arteries through a surgical microscope.

Sham procedures were identical, with the exception of the actual tying of the polypropylene suture. The chest was closed with 5-0 silk sutures. The animals were then weaned from the respirator, and the intratracheal tube was removed once they were breathing spontaneously. Afterwards, $0.2 \mathrm{mg} / \mathrm{kg}$ buprenorphine was given s.c. as an inalgaesic.

\section{Theothyent}

MonofliR (7-monohydroxyethylrutoside, molecular weight 654.6 , figute 1) was kindly donated by Zyma S.A. (Nyon, Swizerland). Before injection, monoHER was dissolved in $36 \mathrm{mM} \mathrm{NaOH}$ in sterile water, in a final concentration of $20 \mathrm{mg} / \mathrm{ml}$ $(\mathrm{pH}=7.9-8.1)$. Based upon its proven efficacy in earlier studies, monoHER was given i. p. in a dose of $500 \mathrm{mg} / \mathrm{kg}, 1$ hour before induction of ischaemia [9]. Control mice were given $25 \mathrm{ml} / \mathrm{g}, 0.9 \% \mathrm{NaCl}$ solution (same $\mathrm{pH}$ ) i.p., 1 hour before ischaemia. In 
our study four groups were compared: sham saline, sham monoHER, IR saline and IR MONOHER.<smiles>CCOc1cc(O)c2c(=O)c([GeH2])c(-c3ccc(O)c(O)c3)oc2c1</smiles>

Figure 1: Basic structure of the semisynthetic flawonoid 7-monohydroxyethylrutoside

\section{Evaluation of ischaemic area at risk and infarts size}

Depending on the time point of reperfusion ( $24 \mathrm{~h}$ or 2 weeks), infarct size was measured on triphenyltetrazolium chloride (TTC)-stained [12] or AZAN-stained tissue sections with the use of a computerized morphometry system (Quantimet 570, Leica, Cambridge, UK). Briefly we describe these methods.

In the $24 \mathrm{~h}$ IR group, mice were anaesthetized with pentobarbital ( $120 \mathrm{mg} / \mathrm{kg}, \mathrm{i} . \mathrm{p}$.$) ,$ the jugular vein was canulated and the thorax was reopened, the $\mathrm{LAD}$ reoccluded, and $500 \mu \mathrm{l}$ of $2.5 \%$ trypan blue was injected into the jugular vein to delineate the nonischamic tissue and to quantify the area at risk (AAR). The heart was then excised, briefly washed with isotonic saline, and cut into 2 parts in the frontal plane, central through the ventricles. These parts were then incubated for $20 \mathrm{~min}$ at $37^{\circ} \mathrm{C}$ with $5 \mathrm{ml}$ of $1 \% 2,3,5$-triphenyltetrazolium chloride solution ( $\mathrm{TTC}$, Sigma Chemicals Co., St. Louis, MO, USA). Viable myocardium is stained ted by TTC and the necrotic, infarcted area temains unstained [13]. The surface of the left ventricle (LV), the AAR and the infarcted area was measured on both pats of the heart. The percentage $A A R / L V$, infarct/AAR and infarct/LV was calculated and expressed as the mean of both parts.

For the 2 week IR group, mice were also anaesthetized under pentobarbital (120 $\mathrm{mg} / \mathrm{kg}$, i.p.), hearts were excised, washed with isotonic saline and cut into 2 parts in the frontal plane, central through the ventricles, and embedded in paraffin. From each part, one slide $(5 \mu \mathrm{m})$ was taken and stained with $A Z A N$. The surface of the infarct and the left ventricle were measured on both slides and the percentage infarct/1.V was calculated and expressed as the mean of both slicles.

\section{Evaluation of wentrioular function}

Mice were anaesthetized with urethane ( $2.5 \mathrm{mg} / \mathrm{g}$ body weight, i.p., Sigma). Body temperature and respiration were controlled as described before. 
- Chapter 3

A bigh-fidelity catheter ip micromanometer Mikto-tip, 1.4F, SPR-671; Millat Instruments, Houston, TX, USA) was inserted through the right carotid artery into the left ventricular cavity. Ventricular pressure was measured and sampled at a rate of $2 \mathrm{kH}$. Maximal positive pressure development ( $+\mathrm{dp} / \mathrm{dt}$ ) and heart rate were determined on a beat to beat basis and one-second averages were stored on disk.

The heart was then stimulated by an A.v. ramp-infusion of dobutamine (Sigma) using a microinjection pump (Model 200 Series, KdScientific, Boston, MA, USA). The infusion rate of dobutamine was increased every $2 \mathrm{~min}$ by $0.5 \mathrm{ng} / \mathrm{g} / \mathrm{min}$ (last step $=5$ $\mathrm{ng} / \mathrm{g} / \mathrm{min}$ ). In the 2 week IR group, followng recovery from dobutamine infusion (taking 10-20 min and assessed by restoration of $+\mathrm{dp} / \mathrm{dt}$ and heart rate to around baseline levels), hearts were additionally stressed by loading the circulation with an i.v. infusion of warmed $\left(37^{\circ} \mathrm{C}\right.$ ) Ringer's solution for $1 \mathrm{~min}$ at a rate of $2.5 \mathrm{ml} / \mathrm{min}$.

Maximal values for $+\mathrm{dp} / \mathrm{dt}$ were recorded and the difference between the maximal value and the value at baseline was calculated. At the end of the experiment, hearts were excised, washed with isotonic saline and ventricular weights were determined.

\section{Inymunotistochensisty}

To determine the number of infiltrating polymorphonuclear neutrophils (PMNs), heart specimens were immediately frozen and stored at $-80^{\circ} \mathrm{C}$. Frozen sections $(6$ $\mu m)$ were stained for neutrophils with a rat anti-mouse neutrophil specific antibody, NIMP-R14 [14] using peroxidase-labelled rabbit anti-rat immunoglobulin (Ig) as the secondary $\mathrm{mAb}$ and 3-amino-9-ethylcarbazole as a chromogen followed by a hematoxylin counterstain. The numbers of PMNs per grid $\left(0.25 \mathrm{~mm}^{2}\right)$ were counted under a high-power microscope field ( $x$ 200) in a blinded fashion. Average numbers of PMNs were obtained by counting 9 grids per slide in 8 apical slides per heart and compared between saline and monoHER-treated animals at both $6 \mathrm{~h}$ and $24 \mathrm{~h}$ reperfusion.

\section{Statistical amalysis}

All parameters are expressed as mean $\mathrm{E}$.E. M. Numbers of neutrophils, infarct size and increase in $+\mathrm{dp} / \mathrm{dt}$ by dobutamine and volume loading were ewaluated using Student's t-test.

Dose response curves for dobutamine were compared using a two-way analysis of variance (ANOVA) and a post-hoc Bonferonni test. $P$-values $<0.05$ were regarded as statistically significant.

\section{Results}

\section{General}

A total of 50 animals were subjected to sham surgery or IR, and studied for ventriculat contractility after $24 \mathrm{~h}$ reperfusion. Six of these animals died prematurely because of complications due to anaesthesia, arthythmia or bleeding. In 5 animals we conld not measure contractility because of difficulties in passing the cardiac valves with the catheter tip. 
MonoHER and ischaemia-reperfusion injury (part $)$.

Table 1: Biometric data of mice subjected to sham surgery and ischatemia-reperfusion.

\begin{tabular}{|c|c|c|c|c|c|c|}
\hline Time & Group & & $\mathrm{N}$ & Age (weeks) & $\mathrm{BW}(\mathrm{g})$ & $\mathrm{VW} / \mathrm{BW}(\%)$ \\
\hline \multirow[t]{4}{*}{$\overline{24 h}$} & \multirow[t]{2}{*}{ Sham } & Saline & 10 & $110 \pm 0.5$ & $37.3 \pm 1.0$ & $0,44 \pm 0,01$ \\
\hline & & MonoHER & 10 & $10.7 \pm 0.5$ & $38.0 \pm 1.1$ & $0.45+0,01$ \\
\hline & \multirow[t]{2}{*}{$\pi R$} & Saline & 10 & $10.3 \pm 0.5$ & $37.1 \pm 0.9$ & $0.44 \pm 0.02$ \\
\hline & & MonoHER & 9 & $10.4 \pm 0.4$ & $37.7 \pm 0.7$ & 0.401005 \\
\hline \multirow[t]{4}{*}{2 weeks } & \multirow[t]{2}{*}{ Sham } & Saline & 9 & $10.1 \pm 0.3$ & 39.240 .8 & $0.45 \pm 0.01$ \\
\hline & & MonoHER & 7 & $11.0 \pm 0.3$ & $38.3 \pm 07$ & $0.44 \pm 0.01$ \\
\hline & \multirow[t]{2}{*}{ IR } & Salline & 10 & $10.7 \pm 0.3$ & $40.0 \pm 1.6$ & $0.49 \pm 0.02$ \\
\hline & & MonoHER & 9 & $11.1 \pm 0.2$ & $39.1 \pm 0.9$ & $0.44+005$ \\
\hline
\end{tabular}

Abbreviations: $\mathrm{BW}=$ body weight; $\mathrm{VW}=$ ventricular weight.

For the 2 week IR group, 43 animals were subjected to surgery. Two animals died during or shortly after surgery, 2 animals died between 3 and 7 days after reperfusion and 1 animal died after 12 days, for unknown reason. In 3 animals we could not measure contractility due to technical complications as mentioned above.

Table 1 summarizes age and body weights of mice in the different groups used for evaluation of cardiac contractility. There were no significant differences between groups in any of the parameters. The ventricular weight/body weight ratio (VW/BW) was slightly increased in the 2 week saline IR group compared to the sham groups and the monoHER-treated IR group at that time point.

\section{Bhood pressure and beart rate}

Figure 2 shows mean arterial pressure and heart rate in conscious mice $(N=4)$ measured under control conditions (marker $C$ ) and after i.v. administration of cumulative amounts of monoHER. MonoHER was found to have no acute influence on blood pressure and heart rate.
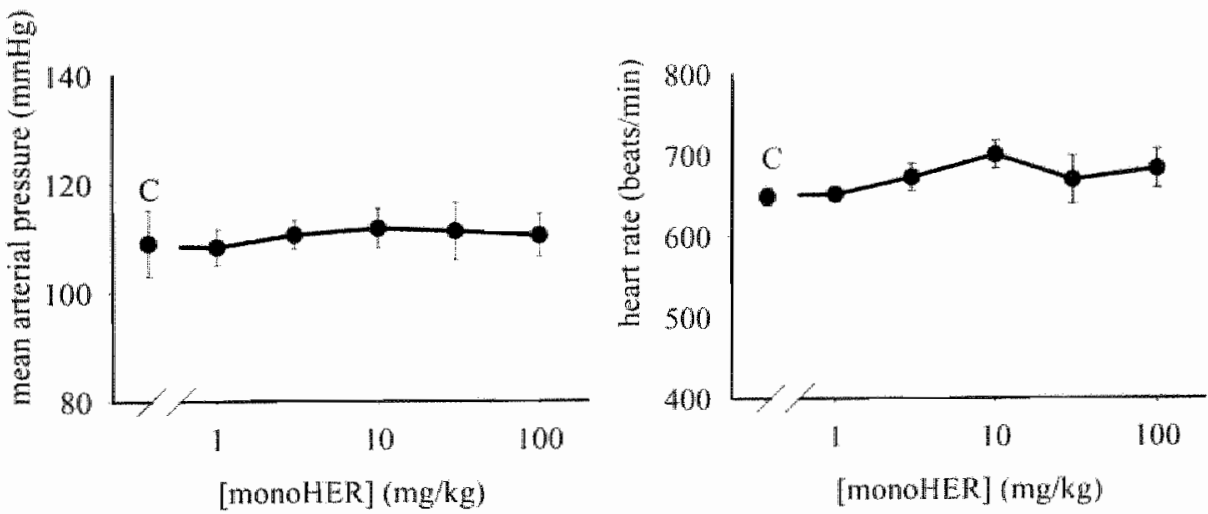

Figure 2: Mean arterial pressure and heart rate measured in conscious mice (Ne-4) undet controt conditions (marker $C$ ) and after i. administration of monoHER in a cumulative fashion from 1.100 mg/kg. Data points represent the mean values obtained from 5.15 nim after injection. 
- Chapter 3

\section{Nentropbil infilration}

Figure 3 illustrates the inflammatory response following $I R$ as evidenced by neutrophil infiltration within the injured tissue. In the saline group, the amount of neutrophils in cardiac tissue was more than doubled from 6 to $24 \mathrm{~h}$ after reperfusion. The number of neutrophils was significandy lower in the monoHER-treated group, $6 \mathrm{~h}$ after reperfusion (saline: $22 \pm 5$, monoHER $5 \pm 1 ; P=0.006$ ) and $24 \mathrm{~h}$ after reperfusion (saline: $51 \pm 11$, monoHER. $12 \pm 3, P=0.007$ ). In the sham groups, no neutrophils were detected in cardiac tissue.

A:
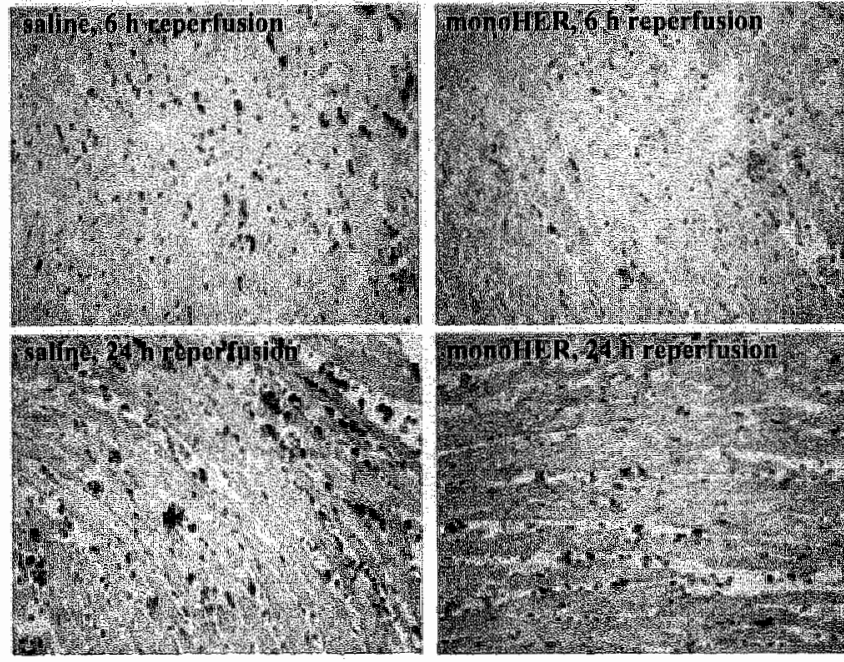

B:

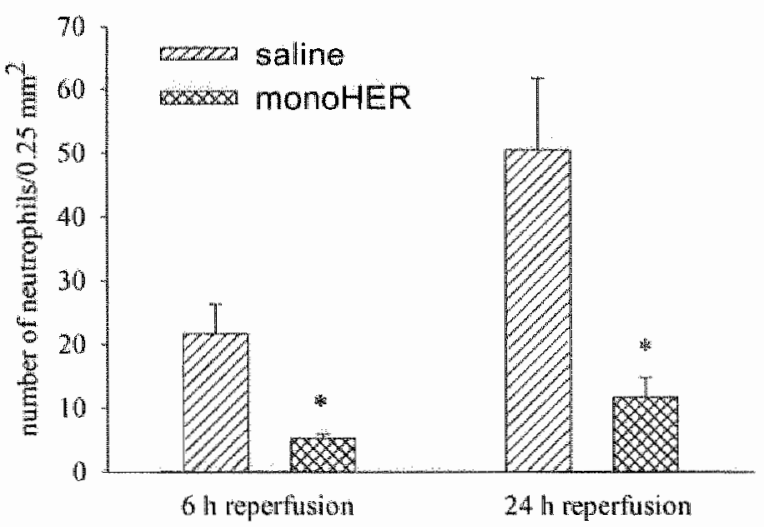

Figure 3: Neutrophil infiltration in the ischaemic heart after $6 \mathrm{~h}$ and $24 \mathrm{~h}$ of reperfusion $\mathrm{N}=10$ per group). A: Cardiac tissue sections with NIMP-R14 positive cells (brown), representing neutrophils.

B: Avernge number of infiltating neutrophils per grid (magnification $\times 200$ ).

Ar both $6 \mathrm{~h}$ and $24 \mathrm{~h}$ of reperfusion, neutrophil numbers were significantly lower $(* P<0.01)$ in monoHER-treated mice than in time-matched saline groups. 


\section{Moacandial andart size}

Twenty-four hous after reperfusion the AAR of the left ventricle was comparable in the saline group and the monoHER-treated group $(47 \pm 2 \%$ and $50 \pm 7 \%$, respectively), indicating that the ligation was placed reproducibly (figure $4 \mathrm{~B}$ ).

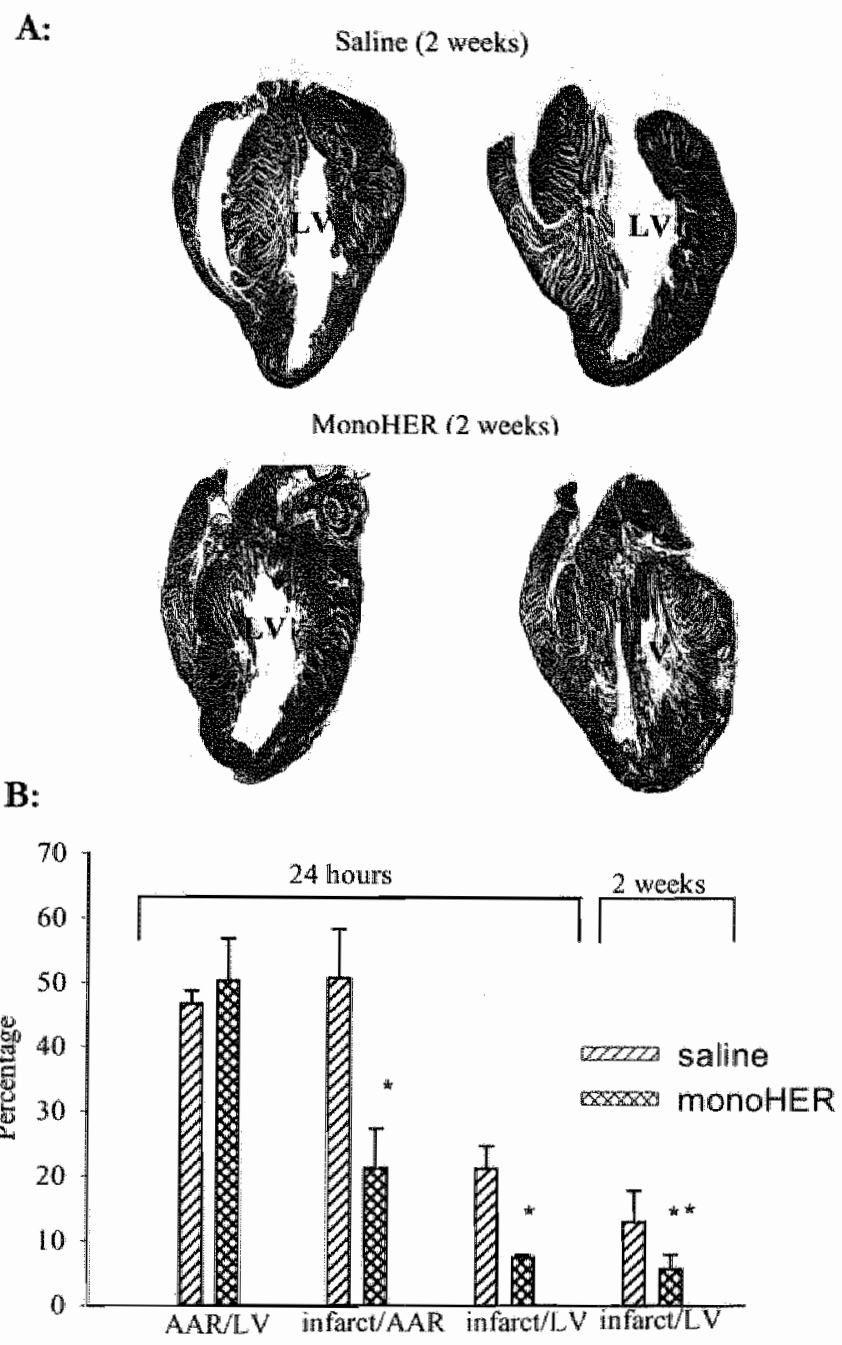

Figure 4: Evaluation of area at risk (AAR) and infarct size (infuret) after $24 \mathrm{~h}$ and 2 weeks of teperfusion. A: AZAN stained heart tissue sections of animals after 2 weeks of IR. Infarcted area (bluc) in the wall of the left ventricle (indicated as LV) versus non-infarcted atrea (red). Note the reduced infarcted area in the monoHER-treated animal.

B: There was no significant difference in myocardial AAR/LV ratios in monoHER-rreated mice and mice from the saline group at $24 \mathrm{~h}$ of reperfusion. Infarct/A.AR and infarct/LV ratios were significantly smaller in monoHER-treated mice than in mice from the saline group after 24 h $(* P<0.01)$ and 2 weeks $(* x=0.014)$ of reperfusion. 
- Chapter 3

However, the infarc/AAR ratio was significantly smaller in the monoHER-treated group than in the salne group (saline: $51 \pm 8 \%$, monoHER: $21 \pm 6 \% ; P=0.009 ; \mathrm{N}=13$ per group). The infarct/LV ratio was also significantly smaller in the monoHERtreated group than in the saline group (saline: $21 \pm 4 \%$, monoHER: $9 \pm 4 \% ; P=0.005$ ).

Figure $4 A$ represents 2 sections of a heart from the saline group versus 2 sections of the heart of a monoHER-treated animal 2 weeks after reperfusion. Infarct size 2 weeks after reperfusion was significantly smaller in the monoHER-treated group than in the saline group (figure $4 \mathrm{~B}$; saline: $13 \pm 4 \%$, monoHER: $7 \pm 2 \% ; P=0.014 ; \mathrm{N}=10$ per group).

\section{Ventricular contractity}

Cardiac function was evaluated 24 h and 2 weeks after reperfusion by measuring heart rate and the rate of left ventricular pressure development $(+\mathrm{dp} / \mathrm{dt})$. Under basal conditions $+\mathrm{dp} / \mathrm{dt}$ and heart rate did not differ between sham and IR groups. Basal heart rate was significantly higher in the saline IR group compared to the saline sham group ( $P<0.01)$ after $24 \mathrm{~h}$. When the heart was stimulated with an increasing dose of dobutamine (i.v.), $+\mathrm{dp} / \mathrm{d}$ levels increased dose-dependently in the sham animals whereas the increase was significantly blunted in the saline IR animals (figure $5 \mathrm{~A}$ ).

The increase of $+d p / d t$ was significantly restored in the monoHER-treated IR group at both time points ( $24 \mathrm{~h}$ and 2 weeks after reperfusion). Dose response curves for heart rate were comparable between groups (figure 5B). In the $24 \mathrm{~h}$ IR saline group, increase in $+\mathrm{dp} / \mathrm{dt}$ was significantly smaller $(+2456 \pm 475 \mathrm{mmHg} / \mathrm{s})$ than in the sham saline group $(+5939 \pm 928 \mathrm{mmHg} / \mathrm{s} ; P=0.004)$ and the TR monoHER-treated group $(+5515 \pm 928 \mathrm{mmHg} / \mathrm{s} ; P=0.0003)$. Similar effects were seen in the 2 week IR saline group where the increase in $+\mathrm{dp} / \mathrm{dt}(+3174 \pm 1066 \mathrm{mmHg} / \mathrm{s})$ was significantly lower than in the sham saline group $(+7487 \pm 1209 \mathrm{mmHg} / \mathrm{s} ; \quad P=0.01)$ and the monoHERtreated IR group ( $+7274 \pm 687 \mathrm{mmHg} / \mathrm{s} ; P=0.005)$. Comparable results were obtained following volume loading (figure $5 \mathrm{C}$ ). The increase of $+\mathrm{dp} / \mathrm{dt}$ in the 2 week IR saline group $(+1758 \pm 991 \mathrm{mmHg} / \mathrm{s})$ was significantly smaller than in the sham saline group $(+6129 \pm 1247 \mathrm{mmHg} / \mathrm{s} ; P=0.02)$ and the monollER-treated IR group $(+5723 \pm 575$ $\mathrm{mm} / \mathrm{g} / \mathrm{s} ; P=0,006)$.

\section{Discussion}

The results of this study show that 7-monohydroxyethyltutoside (monofHER), when administered i.p. one hour before ischaemia, exerts a significant cardioprotective effect after IR in mouse hearts and that this effect is sustained.

MonoHER was chosen for this study because it has strong radical scavenging and iron chelating propetties 115]. "This capacity makes it a potential drug for the prevention of oxidative stress-related reperfusion injury. In addition monolHE protects against doxorubicin-induced cardiotoxicity in wivo $[9,10]$.

Flavonoids have effects on a variety of inflammatory responses and immune function [16]. An in witro study showed that monofHER has anti-inflammatory effects by reducing neutrophil adhesion through inhibition of doxorubicin-induced expression of vascular cell adhesion molecule (VCAM) and E-selectin [17]. 
A:

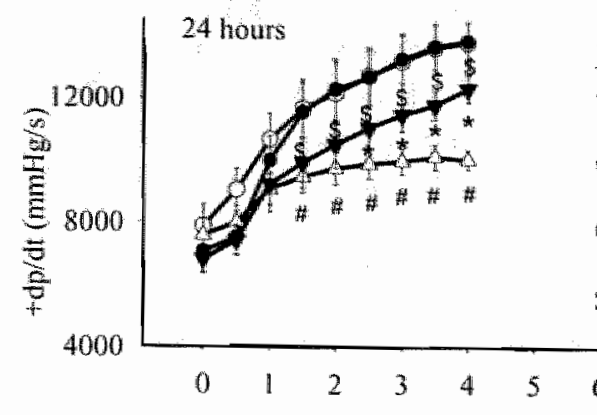

B:

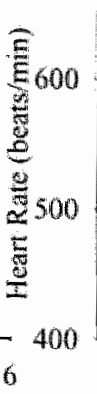

24 hours

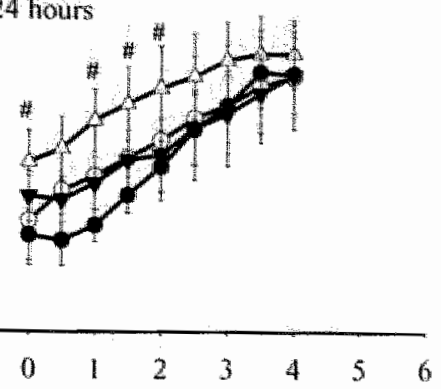

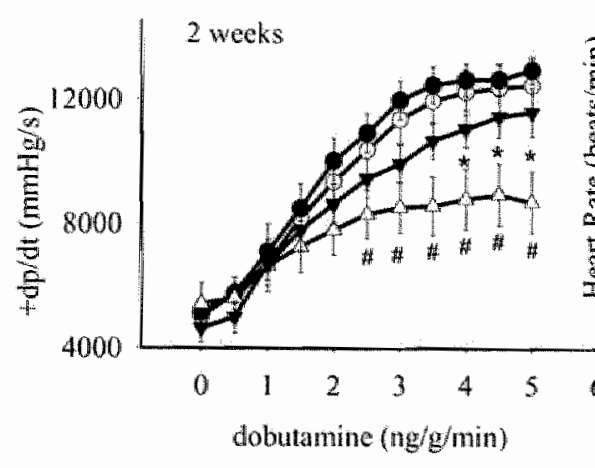
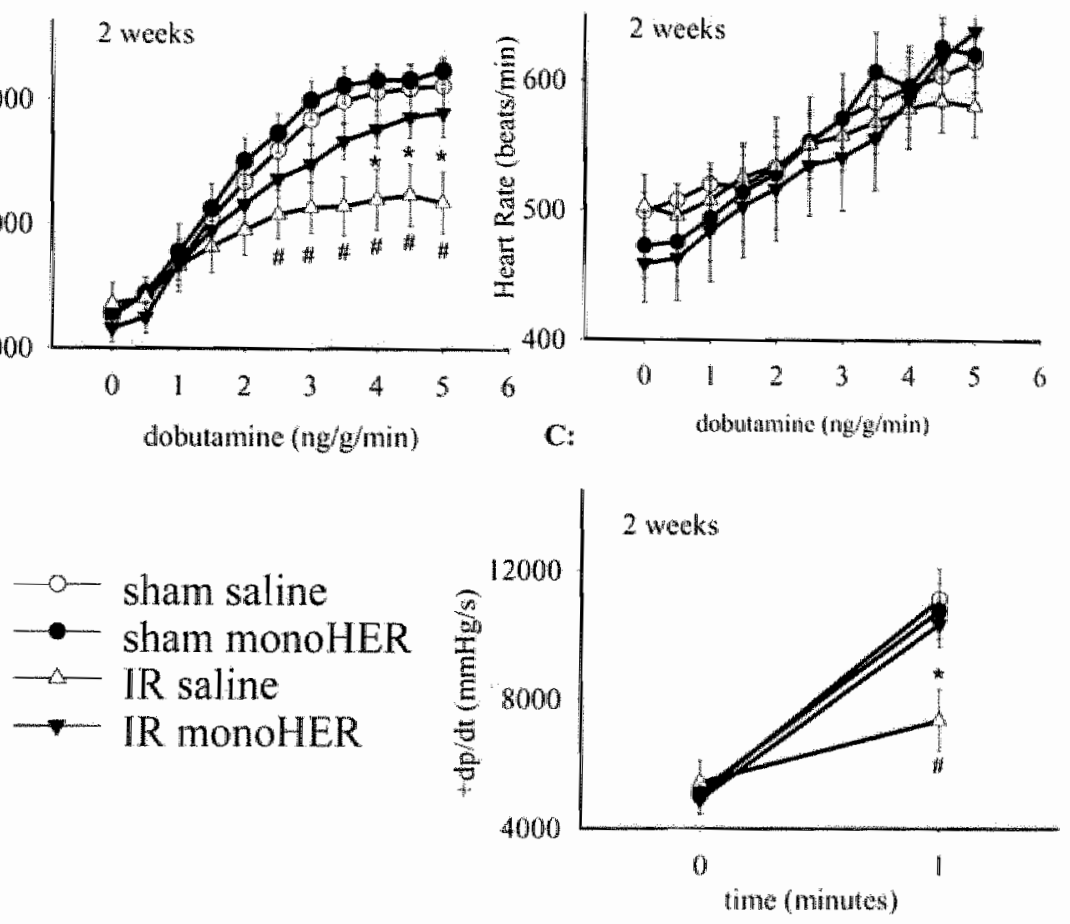

Figure 5; In mo assessment of left ventricular contuctilitg:

A: Cardac contractilivy during dobutamine stimulaton at 24 hand 2 weeks after repertusion.

w $P<0,01$ : significantly diferent between non-reated $I R$ (RR saline) and shammperated controls (sham Saline); * $<<0.01$ : significanty different between non-tneted TR (TR saline) and noonoHIER treated IR (TR monoHER; sp<0.01: significandy different berween monoHER-treated IR (TR monolHaR and monoHER-brated sham (sham monoH FR).

B: Inctense in heart tare after dobutanine stimulation. Ar both time poine, 24 h and 2 wecks after reperfusion, thete was no signifcant difference beween the groups. Basal heart wate in the saline $\| R$ group was significantly higher than in the saline sham group ( P<0.01).

C: Conmerilin (tdp/dt) measured before and after volume londing at 2 weeks of repertusion. " $1=0.006$ : significandy difterent beween $\mathbb{R}$ saline and $\mathrm{R}$ monol $\mathrm{H} \mathrm{R}_{\text {; }} \mathrm{p} \leq 0.02$ : signifucandy diferent between nonweated IR (IR saline) and sham-operated controls (sham saline). 
In the present study we showed that monoHER also reduces the inflammatory response in wo by reducing influx of neutrophils in the infarcted area of the heart. The reason for this reduction in the number of neurrophils by monoHER in our model is probably dual. First, due to a reduction in tissue damage and therefore a reduced stimulus for an inflammatory response, and second, due to a direct antiinflammatory effect of monoHER. However, the role of the teduction in neurrophils itself by monoHER treatment on the reduced infarct size 2 weeks after reperfusion is unknown. A direct causal association between the number of neutrophils and myocardial cell death is still under debate [18-23]. To our knowledge, there is only one in wo study that has examined the effects of neutrophil depletion after a prolonged time (in terms of weeks) of reperfusion.

Metzle to al (2001) demonstrated that in mice deficient in intercellular adhesion molecule-1 (ICAM-1), protection occurred in the early phase after reperfusion, but that at a later stage, 1 and 3 weeks after reperfusion, scar size in the ventricles was comparable between knock-out and wild-type mice. This suggests that neutrophil infiltration into the infarcted area may help promote repairing cardiac tissue, and consequenty, the enhancement of leukocyte recruitment might be beneficial.

However, following monotFR treatment, infarct size temained significantly smaller 2 weeks after reperfusion, indicating that monoHER prevents, rather than delays myocardial IR injury. In contrast to the study of Metzler ef al. (2001), monoHER treatment was applied to prevent the initial damage before the influx of neutrophils occurs. This means that the reduction in myocardial neutrophil influx and infarct size and the prevention of deterioration of cardiac contractility by monoHER was effective and that no significant additional damage occurred during the subsequent period of teperfusion. "The present data therefore support the view that IR injury due to free radicals occurs in the initial phase after initiation of reperfusion [24-27] and effective antioxidant treatment must therefore be directed to this phase.

In the saline groups, infarct size/left ventricle tatio was higher at 24 th than at 2 weeks after repetfusion, most likely due to the different techniques that were required to measure infarct size. TTC staining is used to detect infarct size shortly afrer reperfusion, whereas AZAN staining is used after longer periods of reperfusion to derect the amount of granulation tissue. There is, however, a clear reduction in infarct size in the monoffER-treated reperfusion group compared to the saline reperfusion group at both time points.

MonoHER did not influence baseline levels of heart rate and mean arterial pressure in conscious mice. This finding excludes the notion that protective effects of monoHIE are due to possible hemodynamic changes which can have preconditioning and therefore protecrive effects [28].

Baseline $+\mathrm{dp} / \mathrm{dt}$ levels were not different between the $\mathbb{R}$ and sham-operated mice at any time point. This is probably due to the fact that the infarct size is relatively small after cardiac IR in mice. Farlier experiments from our group showed a significantly reduced cardiac contractility at baseline in mice with permanent myocardial infarction and related larger infarcts of around $45 \%$ of the left ventricle [29]. The significantly higher heart rate at basal level, 24 h after reperfusion in the saline group is probably due to neurohumoral compensation to maintain cardiac output after cardiac damage. 
"This phenomenon was not observed 2 weeks after reperfuston wugesting a normalization of this response. Stressing the heart by an infusion of dobutarine did reveal differences in cardiac contractility between groups. Ischaema-reperfusion resulted in a blunted response to dobutamine. Treatment with monoHER improved the increase of cardiac contractility, both $24 \mathrm{~h}$ and 2 weeks after reperfucion. To examine if the blunted response to dobutamine was primarily due an impaired $\beta$ adrenergic effect we also stressed the heart by wolume loading. Because the incrense in contractility was comparable to the effects obtained by dobutamine stimulation, we can conclude that the improved cardiac response is due to a reduced infatce size tather than a change in $\beta$-adrenergic effectiveness.

Timing, route and amount of monoHER administration in this study were based on the design of the earlier in wizo studies in which monolHER was proven to act protective in a model of doxorubicin cardiotoxicity. For later clinical application of monoHER in the reduction of IR injury, further studies has to be done in which different time points of administration (as post-ischaemia) and lower amounts of monoHER should be tested.

In conclusion the present study shows that the antioxidant 7monohydroxyethylrutoside strongly recluced myocardial neutrophil influx, infarct size and prevented deterionation of cardiac contractility in an in wo mouse model of cardiac ischaemia-reperfusion. To our knowledge, this is the first time that sustained protective effects (in terms of weeks) of a flavonoid are demonstrated in a model of cardiac ischaemia-reperfusion.

\section{References}

1. Dhalla NS, Elmoselhi AB, at Status of myocardial anvioxidants in ischemulateperfusion injury. Cardiovasc Res. 2000; 47:446.

2. Jolly SR, Kane WJ, at al. Canime myocaudial reperfusion injury. Its reduction by the combined administration of superoxide dismutase and catalase. Circ Res. 1984; 54:277.

3. Leter DI, Granger DN. Oxidatwe stress and cardine disease. Am ] Med. 2000; $100 ; 315$.

4. Kaminski KA, Bonda TA, al. Oxidatwe stress and netrophil activation-whe wo keystones of ischemia/teperfusion injury Int I Cardiol. 2002; $86: 41$.

5. Frangoginnis $\mathrm{NG}$, Smith CW, th the infammatory responge mo myocardat infarction. Cardiowasc Res. 2002; $53: 31$.

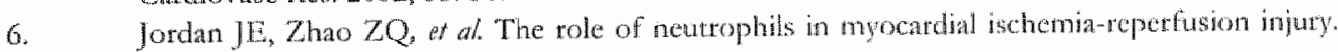
Catidiovasc Res. 1999; 43: 860.

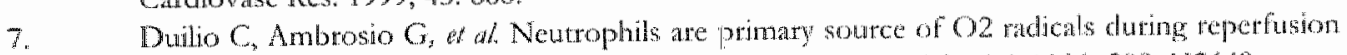
after prolonged myocardial ischemia. Am J Physiol Hear Circ Physiol. $2001 ; 280:$ : 2640 .

8. Rekka $\mathrm{E}$, Kourounakis PN. Effect of hydtoxyethy rutosides and relatod compounds on lipid peroxidacion and free radical scavenging activiry. Some structural aspects. I Pharm Phamacol. $1991 ; 43: 486$.

9. van Acker SA, Kramer K, of al. Monobydroxyethylrutoside as protector against charomic doxorubicin-induced cardiotoxicity. $\mathrm{Br}$ ] Phatmacol. 1905; 115: 1260 .

10. van Acker FA, van Acker SA, at al 7-monohydroxyethytutoside proiect against chronic doxorubicin-induced cardiotoxicity when aministed only once per week Clin Cancer Res. $2000 ; 6: 1337$. 


\section{- Chapter 3}

11. Jaxtusen B], Leenders PJ, at al. Shorttem and long term blood pressure and heart rate variability in the mouse. Am J Physiol Regul Integr Comp Physiol. 2000; 278: R215.

12. Nachlas MM, Slinitka TrK. Macroscopic identification of early mocardial infarcts by alterations in dehydrogenase activity. Am J Pathol. 1963; 42:379.

13. Vivaldi MT, Kloner $\mathrm{RA}_{\text {, }}$ et al. Triphenyltetrazolium staining of inteversible ischemic injury following coronary artery occlusion in tats. Am J Pathol. 1985; 121: 522.

14. McLaren DJ. Strath M, of Schistosona mansoni: evidence that immunity in vaccinated and chronically infected $\mathrm{CBN} / \mathrm{Ca}$ mice is sensitive to treatment with a monoclonal antibody that depleres cutaneous effector cells. Parásite lmmunol. 1987; 9:667.

15. Van Acker FA, Hageman $J A$, at Synthesis of novel 3,7-substituted-2- $\left(3^{\circ}, 4^{\prime}-\right.$ dihydroxyphenyly flavones with improved antioxidant activity. J Med Chem. 2000; $43: 3752$.

16. Manthey IA. Biological properties of flavonoids pertaining to inflammation. Microcirculation. $2000 ; 7: \$ 29$.

17. Abou El Hassan MA, Verheul HM, et at. The new catdioprotector Monohydroxyetiylnutoside protects against doxorubicin-induced inflammatory effects in vitro. Br J Cancer. 2003; 89: 357.

18. Baster GF. The neutrophil as a mediator of myocardial ischemia-reperfusion injury: time to move on. Batsic Res Cardiol. 2002; $97: 268$.

19. Hoffneyer MR, Sealia R, ef of, PR -39, a potent neutrophil inhibitor, attenuares myocardial ischemia-reperfusion injury in mice. Am J Physiol Heart Circ Physiol. 2000; 279: H2824.

20. Metzler: B, Mair J, et at. Mouse model of myocardial remodelling after ischemia: role of intercellutar adhesion molecuie-1. Cardiovasc Res. 2001; 49:399.

21. Arai $M_{3}$ L.efer DJ, ef al. An anti-CD18 antibody limits infarct size and preserves left ventricular function in dogs with ischenia and 48-h reperfusion. J Am Coll Cardiol. 1996; 27: 1278.

22. Birnbaum $Y$, Patterson $M$, et at. The effect of CY1503, a sialyl Lexwisx analog blocker of the selectin adhesion molecules, on infarct size and "no-reflow" in the rabbit model of acute myocaudal infartion/reperfusion. I Mllol Cell Cardiol. 1997; 29:2013.

23. Briaud $S A_{3}$ Ding $Z \mathrm{MM}$, et al. Leukocyte trafficking and myocardial reperfusion injury in ICAM1/P-selectin-knockout mice. Am J Physiol Heart Circ Physiol. 2001; 280: H60.

24. Zweier JL, Flaherty JT, of al. Direct measurement of thee radical generation following reperfusion of ischemic myocardium. Proc Nacl Acad Sci U S A. 1987; 84: 1404.

25. Shao ZH, Vanden Hoek TL, et al. Baicalein attenuates oxidaut stress in cardiomyocytes. Am I Physiol Heart Circ Physiol. 2002; 282: 1999.

26. Bolli $\mathrm{R}$, Jeroudi $\mathrm{MO}$, a a. Direct evidence that oxygen-derived free tadicals contribute to postischemic myocardial dysfunction in the intact dog. Proc Nad Acad Sci U S A. 1989; 86: 4605.

27. Wang P, Zweier J. Measurement of nirric oxide and peroxynitrite generation in the postischemic heart. Evidence for peroxynitrite-mediated reperfusion injury. I Biol Chem. 1996; 271:29223.

28. Thomton JD, Liu CS, at Intravenous prertearment with A1-selective adenosine analogues protects the heart against infarction. Circulation. 1992; 85:659.

29. Lutgens L, Daemen M! of ath Chtonic myocardial infarction in the mouse: cardiac structural and tunctional changes. Cardiovasc Res. 1999; 41:586. 
Chapter 4

In vivo protective effects of

7-monohydroxyethylrutoside in a mouse model of cardiac ischaemia-reperfusion are dependent on the time point of administration

Tijl De Celle, Nicole Bitsch, Peter Leenders, Aalt Bast, Jos F. Smits \& Ben J. Janssen

Departments of Pharmacology \& Toxicology, Cardiovascular Research Institute Maastricht, Universiteit Maastricht, The Netherlands 
- Chapter 4

\section{Abstract}

Previously (chaptet 3) we demonstrated that monoHER has strong and sustained cardioprotective effects in an in wo mouse model of cardiac ischaemia-reperfusion when it was administered intraperitoneally, one hour before ischaemia.

The chosen route and timing of administration of monoHER were based on historic results. Recent pharmacokinetic data in mice revealed that following intravenous (i.w) injection of monoHER, maximal myocardial tissue concentrations of the drug are reached almost immediately. Therefore, we set out a study to test if monoHER would be also effective when administered five min before reperfusion, a time point that has more clinical relevance.

Ischaemia was maintained for $30 \mathrm{~min}$ by ligation of the left anterior descending coronary artery. Then the ligature was removed and reperfusion allowed for $24 \mathrm{~h}$. MonoHIR (150 $\mathrm{mg} / \mathrm{kg}$ ) or saline was administered i.v. 5 min before reperfusion.

Treatment with monoHER at this time point did neither influence the influx of neutrophils in the injured tissue (IR, saline: $39 \pm 12$ neutrophils $/ 0.25 \mathrm{~mm}^{2}$; $I R$, monoHER: $40 \pm 8$ neutrophils $/ 0.25 \mathrm{~mm}^{2}$ ) nor the increase in cardiac contractility $(+\mathrm{dp} / \mathrm{dt})$ in response to dobutamine $(\mathbb{R}$, saline: $+2509 \pm 567 \mathrm{mmHg} / \mathrm{s}$; $I R$, monoHER: $+2839 \pm 734 \mathrm{mmHg} / \mathrm{s}$ ), 24 hours after reperfusion.

Based on these data we conclude that the time point of administration is crucial to elicit a cardioprotective effect with monoHER.

Among the explanations for the lack of a clear pharmacodynamic effect of monoHER in this setting are 1) the potential restriction in myocardial uptake in conditions of cardiac IR; 2) the necessity of formation of active metabolites of monoHER; and 3) the possibility that cardioprotective effects of monoHER are due to interference with specific signal transduction pathways during the ischaemic period. Further research is necessary to examine these hypotheses. 


\section{Introduction}

Reintroduction of oxygen to ischaemic nyocardium after myocardial infarction adrances the damage caused by ischaemia. This phenomenon, temed the "oxygen paradox" is believed to result from the metabolites of oxygen produced in the reperfused ischaemic milieu [1]. These reactive oxygen species (ROS) are potent cytotoxic compounds capable of distupting cellular structures and generating myocardial damage. Subsequenty, neutrophils adhere to the endothelium and invade the myocardial tissue [2]. Although essential in wound healing, these neutrophils may turn injurious by producing additional ROS and proteolytic enzymes [3-5]. Therefore, the inflammatory response has been linked to lethal injury of myocardium during ischaemia and reperfusion [6].

As described in the general introduction (chaptex 1), numerous studies have evaluated the influence of superoxide dismutase, vitamin $C$, vitamin $\mathbb{E}$, and thiol compounds alone or in various combinations on oxidative stress injury in patients undergoing reperfusion therapy after myocardial infarction. Despite much research and the wide availability of antioxidant agents, there are, however, no clinical indications for the toutine use of an antioxidant in the setting of ischaemia and reperfusion.

Flavonoids are a group of naturally occurting polyphenolic compounds with excellent iron chelating as well as radical scavenging properties [7]. In a previous study we demonstrated that the semi-synthetic flavonoid monoHER has potent cardioprotective effects in an in wiv mouse model of cardiac ischaemia-reperfusion when administered intraperitoneally (i.p.) one hour before ischaemia [8]. MonoHER treatment significantly reduced myocardial neutrophil influx and infarct size and strongly prevented deterioration of cardiac contractility [8]. These cardioprotective effects were still present two weeks after reperfusion when wound healing is completed. Therefore they can be regarded as being sustained [8].

The timing, route and dose of monoHER administration in that study were based on earlier $i w$ mouse studies in which monoHER protected against doxorubicin-induced cardiotoxicity 19,10$]$. In these studies monollER was administered i.p. one hour before doxorubicin injection.

Obviously, to minimize damage evoked by chemotherapeutic agents such as doxorubicin it is logical to pre-treat patients with radical scavenging agents such as monoHER. However, when preventing "reperfusion injury", administering an ancioxidant as a protective drug before the onset of ischaemia, has less clinical relevance. In addition, recent phamacokinctic data revealed that following intravenous (i.v.) injection of monoHER, maximal myocardial tissue concentrations of the drug are reached almost immediately $[11]$. Therefore, we examined whether monoHER would also be cardioprotective if the chug is administered shorty before reperfusion of the ischaemic mouse heart. 


\title{
- Chapter 4
}

\section{Materials and Methods}

\author{
Antmals \\ Male Swiss mice weighting $35-40 \mathrm{~g}$ were used. The animals were purchased and \\ housed as described in detail in chapter 3 . The experimental protocol was approved by \\ the animal ethics committee of the Universiteit Maastricht.
}

\section{Ischaemia-reperfinsion of the nurine beant in wivo}

Mouse hearts were subjected to a $30 \mathrm{~min}$ ischaemia and $24 \mathrm{~h}$ reperfusion procedure as. described in detail in chapter 3. Two experimental groups were compared; one group treated with monoHER and one group in which saline was used as a placebo.

Before injection, monoHER (7-monohydroxyethylrutoside, molecular weight 654.6) was dissolved in $36 \mathrm{mM} \mathrm{NaOH}$ in sterile water, in a fual concentration of $20 \mathrm{mg} / \mathrm{ml}$ $(\mathrm{pH}=7.9-8.1)$. MonoHER was given $\mathrm{i}_{\mathrm{v}} \mathrm{v}$ in a dose of $150 \mathrm{mg} / \mathrm{kg}$, five min before reperfusion. In control mice $25 \mu \mathrm{l} / \mathrm{g}, 0.9 \% \mathrm{NaCl}$ solution (same pH) was injected i.v., five min before reperfusion.

\section{Evaluation of zentrioular function}

Under urethane anaesthesia, a Millar pressure transducer was inserted into the left ventricle 24 h after reperfusion. Maximal positive pressure development $(+\mathrm{dp} / \mathrm{dt}$ ) and heart rate were determined in baseline conditions and during a ramp-infusion of i.v. dobutamine ( 0.5 to $5 \mathrm{ng} / \mathrm{g} / \mathrm{min}$ ) in both groups. For a detailed description the reader is referted to chapter 3 .

\section{Inwwwabistochemisty}

At the end of the experiment the area at risk of the heart was excised and the numbers of infiltrating neutrophils were determined by immunocytochemistry as described in detail in chapter 3.

\section{Stathisical analysis}

All parameters are expressed as mean $\pm S$.E.M. Numbers of neutrophils and maximal increase in tdp/dt by dobutamine between monoltER and saline group were compated by Student's t-test. Dose response curves for dobutamine were compared using a twomay analysis of variance (ANOVA) and a post-hoc Bonferonni test. $P_{-}$ values $\leq 0.05$ wete considered to indicate statistical significance. 


\section{Results}

\section{Nentrophilinfilration}

Figure 1 illustrates the inflammatory response following cardiac ischaemia-teperfusion as evidenced by neutrophil infiltration within the injured tissue. After $24 \mathrm{~h}$ of reperfusion, the number of neutrophils was comparable in the $\mathbb{R}$, saline group ( $39 \pm 12$ neutrophils $/ 0.25 \mathrm{~mm}^{2} ; \mathrm{N}=7$ ) and the IR, monoHER group (40土8 neutrophils $/ 0.25 \mathrm{~mm}^{2} ; \mathrm{N}=8$ ).

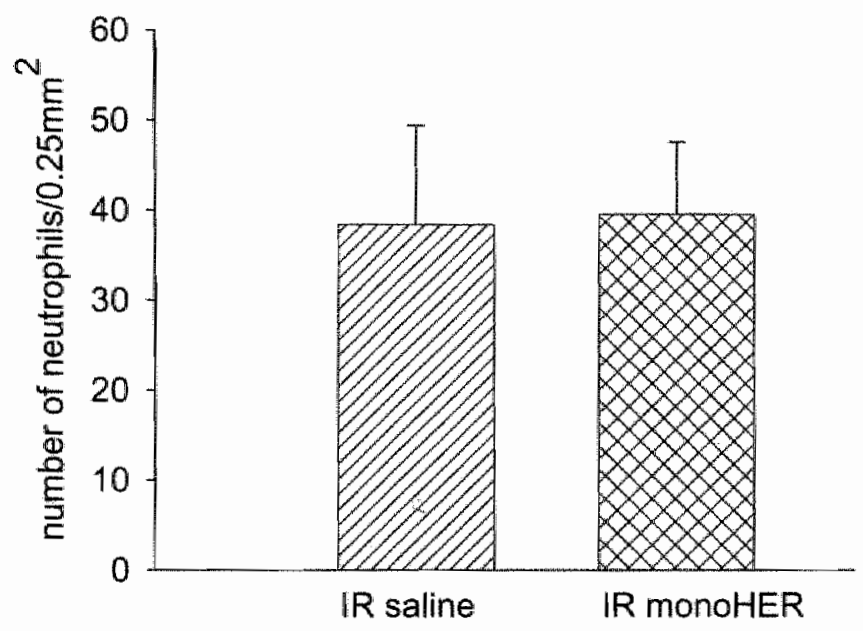

Figure 1: Quantification of the infiltration of neutrophils $24 \mathrm{~h}$ after initiation of reperfusion in the ischaemic heart tissue of mice from the IR, saline group and the IR, monoHER group. Average number of infiltrating reutrophils per grid (magnification $\times 200$ ). Neutrophil numbers were sinvilar in the IR, monoFER group $(N=8)$ and the $R$, saline group $(N=7)$. 


\section{Dentricular contractility}

Cardiac function was evaluated $24 \mathrm{~h}$ after reperfusion by measuring heart rate and the tate of left ventricular pressure development $(+\mathrm{dp} / \mathrm{dt})$ in both the $I R$, saline group $(\mathrm{N}=7)$ and the $\mathrm{IR}$, monoHER group $(\mathrm{N}=7)$. Baseline levels of $+\mathrm{dp} / \mathrm{dt}$ and heart rate were comparable between both groups. Duriag dobutamine stimulation, dose response curves fot $+\mathrm{dp} / \mathrm{dt}$ (figure $2 \mathrm{~A}$ ) and heart rate (figure $2 \mathrm{~B}$ ) were comparable in the IR, saline group and the IR, monoHER group. After $24 \mathrm{~h}$ of repettusion the increase in $+\mathrm{dp} / \mathrm{dt}$ was similar in the $\mathrm{IR}$, saline group $(+2509 \pm 567 \mathrm{mmHg} / \mathrm{s})$ compated to the $[\mathrm{R}$, monoHER group $(+2839 \pm 734 \mathrm{mmHg} / \mathrm{s})$.
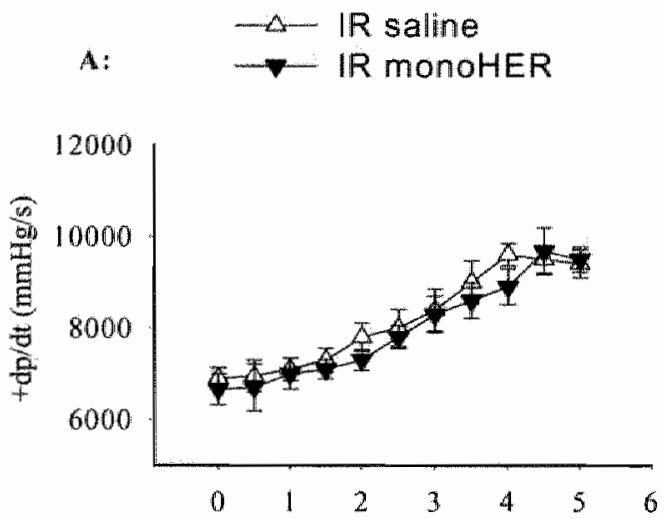

B:

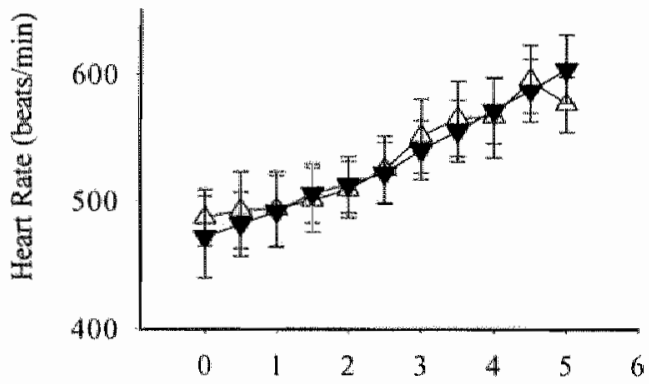

Figure 2: In whas assesment of left ventriculat contactility*

A: Cardiac contratily during dobutamine stimulation at $24 \mathrm{~h}$ of reperfusion. There was no signifrant difference between the $I R$, saline $(N=7)$ and the $I R$, monoHER group $(N=7)$ in the cardiac contractility tesponse to dobutamine.

B: Increase in heat wte duing dobutamine stimulation. Twenty-four hours after repertusion there was no significant diference between the IR, saline and the IR, monollER group in the heart rate response to dobutanime. 
MonoHER and ischaemia-reperfusion injury (part 1i) •

\section{Discussion}

This study indicates that the antioxidant 7-monohydroxyethyltutoside (monoHER) has no cardioprotective effects in our in who mouse model of myocardial ischaemiareperfusion when administered i.v. five min before reperfusion. Administration of monoHER at this time point neither affects the influx of neutrophils in the injured tissue nor improved stimulated cardiac contractility, $24 \mathrm{~h}$ after reperfusion.

These results are in contrast with our previous study in the same animal model when monoHER was administered i.p. one hour before ischaemia and did reduce myocardial neutrophil influx and infarct size and strongly prevented deterioration of cardiac contractility [8].

This discrepancy in results suggests that the time point of monoHER administration is very crucial to obtain cardioprotective effects.

Abou El Hassan et al showed that the peak concentration of monoHER in heart tissue of mice was reached almost immediately after i.v. administration [11]. This implies that in our current IR model the highest levels of monoHER in heart tissue are most likely reached very early (within one minute) after the initiation of reperfusion. Since this corresponds with the phase at which the production of reactive oxygen species is the highest $[12,13]$ it was expected that monoHER should have optimal beneficial effects under these conditions. However, it should be mentioned that these pharmacokinetic properties of monoHER were determined in healthy mice that did not undergo cardiac IR. It is possible that the occlusion of the LAD at the moment of monoHER administration prohibited the fast uptake of monoHER in the injured area so that the concentration of monoHER in the affected area was insufficient. In contrast, when monoHER was applied one hour before ischaemia there was no apparent restriction in uptake of monoHER in cardiac tissue. In parallel to these results it has recently been demonstrated that monoHER has also no cardioprotective effects when administered i.p., five min before doxorubicin treatment (unpublished observation, Aalt Bast). This is in contrast with the protective effects which have been demonstrated when monoHER was administered i.p. one hour before doxorubicin injection $[9,10]$.

In the doxorubicin model there is no restriction at all in the uptake of monoHER in cardiac tissue. Therefore it is doubtful that the limited uptake of monoHER in our cardiac IR model is a major cause for its failure when applied five min before reperfusion. However, tissue concentrations of monoHER should be determined in the area that undergoes IR to clarify this point.

A second explanation for the lack of effect is that not the parent compound but an active metabolite of monoHER is responsible for its beneficial effects. If this is true, five min before reperfusion may be too late to obtain a reasonable concentration of this metabolite and hence cardioprotection against "reperfusion injury". Except for the aglycones, no metabolites of monoHER have been described today [1.1. Blood samples of patients treated with monoHER are currently sampled to investigate this possibility (personal communication, W.J.F. van der Vigh, Amsterdam Free University). 
The dominant concept of antioxidant therapy during cardiac IR is that it results in a teduction of the detrimental effects of oxidative stress and therefore a direct reduction of tissue damage and impairment of cardiac function. However, recent studies have shown that antioxidant therapy, as a side effect and independent of its antioxidant action, may induce specific signalling cascades [14]. Therefore, a thind explanation can be that cardioprotection is not related to the antioxidant effect of monoHER only, but to an unknown side-effect of this compound, or one of its metabolites, on proteins critically involved in the determination of cellular fate, i.e. injury, death or adaptation during ischaemia. In this case it is clear that the time point of monoHER administration, i.e. before ischaemia versus right before reperfusion, may be very crucial.

Furthermore, in some reports it has been shown that production of ROS may occur during the period of ischaemia [15-18]. Specifically, when exposed to hypoxia, cardiomyocytes have been shown to increase production of ROS derived from the mitochondrial electron transport chain [19]. The general physiological consequences of hypoxic mitochondrial ROS production are not completely understood. Mitochondrial ROS may 1) promote the stabilization and activity of hypoxia inducible factor-1 a (HIF-1 $\alpha$ ) transcription factor [20]; 2) alter cardiac myocyte contractility [19]; 3) modulate $\mathrm{Na}^{+} \mathrm{K}^{+}$-ATPase activity [21]; or 4) influence mitochondrial depolatization [22]; and 5) mitogen-activated protein kinases [23].

These studies reveal that ROS, besides their direct detrimental effects on cellular structures, influence a variety of cellular signal transduction cascades during ischaemia. Therefore, our fourth explanation is that monoHER, by reducing ROS during ischaemia, may have an influence on such pathways.

We conclude that monoHER has potential strong and sustained cardioprotective properties in an in wivo mouse model of cardiac ischaemiareperfusion. However, these protective effects of monoHER are highly dependent on the time point of administration. Future studies are necessary to determine the mechanisms of action of monoHER and the clinical efficiency of monoHER in the serting of cardiac ischaemia-reperfusion.

\section{References}

1. Hess MI, Manson NH. Molecular oxygen: friend and foe. The role of the oxygen free radical systcm in the calcium paradox, the oxygen paradox and ischemia/tepertusion injury. $\$ Mol Cell Cardiol. 1984; $16: 969$.

2. Entman MT, Michael 1, w Infammation in the conse of early myocandial ischenia Faseb. $1091: 5: 2529$.

3. Dulio $C$, Ambrosio $G$, al Neutephils are primary source of 02 radicals during teperfusion ater protonged myocandal ischema. Am J Physiol Hart Circ Physiol. 2001; 280: H2640.

4. Jondan JF, Zhao ZQ at athe tole of neutrophils in myocatdial ischemia-reperfusion injury. Cardiovase Res. 1999; 43:860.

5. Kaminski $\mathrm{KA}$, Bonda TA, at Oxidative stress and neutrophil activarion-the two keystones of ischemia/teperfusion injuy. Int J Cardiol. 2002; 86: 41.

6. Hansen PR. Role of neutrophils in myocatdial ischentia and reperfusion. Circulation. 1995; 91 . 1872 
7. Rekka E, Kourounakis PN. Effect of hydroxyethyl rutosides and related compounds on lipid peroxidation and free radical scavenging activity. Some structural aspects. J Pharm Pharmacol. $1991 ; 43: 486$.

8. De Celle $T$, Heeringa $P$, at al. Sustained protective effects of 7 -monohydroxyethylrutoside in an in vivo model of cardiac ischemia-reperfusion. Eur I Pharmacol. 2004; 494: 205.

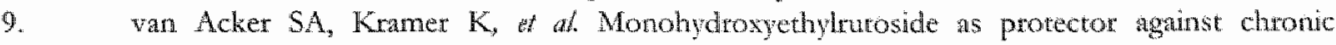
doxorubicin-induced cardiotoxicity. Br J Pharmacol. 1995; 115: 1260.

10. van Acker FA, van Acker $S A$, et al. 7 -monohydroxyethylrutoside protects against chronic doxorubicin-induced cardiotoxicity when administered only once per week. Clin Cancer Res. 2000; 6: 1337.

11. Abou El Hassan MA, Kedde MA, at al. Bioavailability and pharmacokinetics of the cardioprotecting flaxonoid 7-monohydroxyethyltutoside in mice. Cancer Chemother Pharmacol. 2003; 52: 371 .

12. Bolli $\mathrm{R}$, Jeroudi $\mathrm{MO}$, et al. Marked reduction of free radical generation and contractile dysfunction by antioxidant therapy begun at the time of reperfusion. Evidence that myocardial "stunning" is a manifestarion of reperfusion injury. Circ Res. 1989; 65: 607.

13. Mitsos SE, Fantone JC, et al. Canine myocardial reperfusion injury: protection by a free radical scavenger, N-2-mercaptopropionyl glycine. J Cardiovasc Pharmacol. 1986; 8:978.

14. Marczin $\mathbb{N}$, El-Habashi $\mathrm{N}$, of al. Antioxidants in myocardial ischemia-reperfusion injury: therapeutic potential and basic mechanisms. Arch Biochem Biophys. 2003; 420: 222 .

15. Vanden Hoek TL, Li C, at al. Significant levels of oxidants are generated by isolated cardionyocytes during ischemia prior to reperfusion. J Mol Cell Cardiol. 1997; 29: 2571.

16. Przyklenk $\mathbb{K}$, Kloner $R A$. Effect of oxygen-derived free radical scavengers on infatct size following six hours of permanent coronary artery occlusion: salvage or delay of myocyte necrosis? Basic Res Cardiol. 1987; 82: 146.

17. Kevin $\mathrm{LG}$, Camara $\mathrm{AK}$, of al. Ischemic preconditioning alters real-time measure of $\mathrm{O} 2$ radicals in intact hearts with ischemia and reperfusion. Am J Physiol Heart Circ Physiol. 2003; 284: H566.

18. Becker LB. New concepts in reactive oxygen species and cardiovascular reperfusion physiology. Cardiovasc Res. 2004; 61: 461.

19. Duranteau ], Chandel NS, ot at. Intracellular signaling by reactive oxygen species during hypoxia in cardiomyocytes. J Biol Chem. 1998; 273; 11619.

20. Schroed C, MCClintock DS, at Hypoxic but not anoxic stabilization of HIF-lapha tequires mitochondrial reactive oxygen species. Am J Physiol Lung Cell Mol Physiol. 2002; 283: 1.922.

21. Dada ILA, Chandel NS, et al. Hypoxia-induced endocytosis of Na,K-ATPase in alveolar epithelial cells is mediated by mitochondrial reactive oxygen species and PKC zeta. I Clin Invest. 2003; 1.11: 1057.

22. Levraut J, Iwase $H$, of at. Cell death during ischemia: relationship to mitochondral depolarization and ROS generation. Am J Physiol Heart Circ Physiol. 2003; 284: 1-154\%.

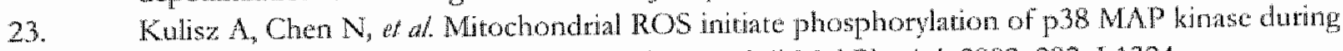
hypoxia in cardiomyocytes. Am I Physiol l.ung Cell Mol Plyysiol. 2002; 282: I.4. 1324. 

Chapter 5

\section{Alterations in mouse cardiac proteome after in vivo myocardial infarction: permanent ischaemia versus ischaemia-reperfusion}

Tijl De Celle ${ }^{1}$, Frank Vanrobaeys ${ }^{3}$, Peter Lijnen ${ }^{1}$, W. Matthijs Blankesteijn ${ }^{1}$, Sylvia Heeneman ${ }^{2}$, Jozef Van Beeumen ${ }^{3}$, Bart Devreese ${ }^{3}$, Jos F.M. Smits ${ }^{1}$, Ben J.A. Janssen ${ }^{1}$

Departments of Pharmacology \& Toxicology $^{1}$ and Pathology ${ }^{2}$, Cardiovascular Research Institute Maastricht, Universiteit Maastricht, The Netherlands Labotatory of Protein Biochemistry and Protein Engineering ${ }^{3}$, Universiteit Gent, Belgium 
- Chapter 5

\section{Abstract}

Mice are increasingly used to study the early molecular mechanisms inducing injury to the heart following myocardial infarction. To date, two-dimensional gel electrophoresis combined with mass spectrometry has not been applied to identify changes in protein expression in myocardial tissue of mice subjected in wiv to permanent ischaemia (PI) or ischaemia-repetfusion (TR).

In the PI group, ischaemia was induced for $210 \mathrm{~min}$ by ligation of the left anterior descending coronary artery while in the IR group, ischaemia was maintained for 30 min and reperfusion was allowed for $180 \mathrm{~min}$. In both groups, the area at risk of the left ventricle was processed for 2-D gel electrophoresis.

By comparing protein density changes in cytosolic as well as membrane fractions, we found a total of thirty-two protein spots that were differentially expressed. 'Twenty spots changed in expression level after PI alone, four spots after IR alone, and eight spots changed in both models. Identified proteins with MALDI TOF-TOF and LCMS/MS can be classified into functional groups being anticoagulant proteins, structural proteins, inflammatory-related proteins, transcription- and translationrelated proteins, heat shock proteins (HSPs), metabolism-related proteins, and miscellaneous. A remarkable finding was the IR specific translocation of annexins (A3 \& A5) from the cytosolic to the membrane compartment, a phenomenon that was verified by Western blotting. Four proteins were changed in expression level at multiple spot locations, characterized by a difference in isoelectric point. In the case of cardiac troponin T and HSP-20, these changes were also dependent on the model. In addition, one spot for the proteins adenylate kinase 1, cardiac troponin T and HSP-20 was uniquely present in the IR and/or PI groups and not in the respective sham groups.

The specific alterations in protein expression that took place after PI and IR may stimulate the search for new tools to diagnose myocardial infarction and to characterize specific pathology related changes in protein expression. 
Cardiac protein expression after myocstrdinl infarction *

\section{Introduction}

Myocardial infarction is one of the most frequent cardiovascular events in the Western world. Current treatment of myocardial infarction is directed to restore blood flow to the ischaemic region by thrombolysis, coronary artery bypass surgery or percutaneous transluminal coronary angioplasty. Depending on the degree of success of the therapeutic intervention, the area at risk (AAR) remains either hypoxic ot is fully salvaged. When the AAR remains hypoxic, the myocardial tisswe loses its contractile function, becomes necrotic and a wound-healing process is initiated [1]. In contrast, when blood flow through the myocardium is re-established in time, hibernating myocardial tissue may regain its function but may also experience additional damage due to the reperfusion process itself. This reperfusion injury is mainly induced by the generation of reactive oxygen species $[2,3]$.

Proteomic studies of human heart tissue may provide new insights into the specific early molecular mechanisms that underlie the responses to ischaemia or ischaemia-reperfusion injury and therefore may have important implications for the specificity and efficacy of diagnosis and treatment. In relation to this, Van Eyk et al. have described a two-dimensional electrophoresis technique on myocardial biopsies from patients undergoing coronary artery bypass surgery [4]. However, these studies are complicated by factors such as small size of sample, availability, disease state, rissue heterogeneity, genetic variability, medical history, and therapeutic interventions [5].

Alternatively, standardized animal models of myocardial infarction and ischaemiareperfusion are available $[6,7]$. To our knowledge in three studies, $2 \cdot \mathrm{D}$ gel electrophoresis was used to identify changes in protein levels after myocardial infarction [8-10]. Sawicki at al [10] found, in an wh dog model of myocardial ischaemia-reperfusion, changes in the level of four metabolic enzymes (NAD+isocitrate dehydrogenase, $\alpha$ subunit; creatine kinase, chain $M$; $\alpha$ subunit ATP synthase isoforms precursor; ATP synthase D chain, mitochondrial) and a contractile protein (ventricular myosin light chain 1). Also, in an in wivo tabbit model of cardiac ischaemiareperfusion, Schwertz of al. [8] found ten protein spots that were differentially expressed. Two could be characterized as the protective proteins superoxide dismutase and $\alpha \mathrm{B}$-crystallin. In addition, Sakai et a. [9] found in an in who rat thodel eight protein spots with altered expression after cardiac ischaemia or ischaemiareperfusion. Five protein spots were identified as the endoplasmatic reticulum enayme protein disulfide isomerase A3, one as $60 \mathrm{kDa}$ heat shock protein and two as mitochondrial elongation factor Tu. These data indicate that the classes of proteins that are differentially expressed after myocardial infarction vary considerably between studies. The fact that different species were used and myocardial tissue was harvested at different time points (i.e. between 60 and 240 min after initiation of ischaemia) may contribute to this.

The mouse has been increasingly used to study the early moleculat mechanisms inducing injury to the heart following myocardial infarction. "To date twodimensional gel electrophoresis combined with mass spectrometry has not been applied to identify alterations in protein expression in myocardial tissue after in wivo 
myocardial infarction in mice. In addition, only the study of Sakai at al. [9] compared changes in protein expression after both ischaemia and ischaemia-teperfusion, although they used an in witro rat model and no in wizodel.

Thus, the goal of the present study was to identify changes in cardiac protein expression after in wivo myocatdial infarction in the mouse. A model of pemanent ischaemia (PI) and a mode of ischaemia-reperfusion (IR) were used to identify and distinguish between common and specific changes in protein expression induced by in who IR and PI. We studied early (210 min) changes in protein expression in order to identify potential new targets for cardioprotection that are beneficial in the first few hours of myocardial infarction. In addition, by separately analyzing the soluble cytosolic fraction and the membrane fraction we wete not only able to increase the resolution but also to detect pathology-related protein translocations between both compartments.

\section{Materials and methods}

\section{Animals}

Male outbred Swiss mice (7-9) weeks old, body weight of 35-40 g) were purchased from Charles River (Maastricht, The Netherlands). Experiments were performed according to the guidelines of the University of Maastricht and were approved by the institutional animal ethics commitree. The animals were kept on a $12 \mathrm{~h}$ light-12-h dark cycle in a temperature-controlled $\left(21 \pm 2^{\circ} \mathrm{C}\right)$ room. After surgery, animals were housed individually with ad Howitw access to water and standard food pellets (type Ssniff, Soest, Germany).

In wiwo ischaemiatreperfusion and permanent ischamia

Mice were anaesthetized with ketamine (100 mg/ kg i.m.) and xylazine $(5 \mathrm{mg} / \mathrm{kg} \mathrm{s.c.).}$ Body temperature was monitored with a rectal probe and maintained at 37 o $\mathrm{C}$ using a warming pad and heating lamp. The trachea of each mouse was intubated per orally with a stainless-steel tube connected to a respirator (Hugo Sachs Electronic rodent ventilator type 845, Match-Hugstetten, Germany) set at a stroke volume of $250 \mathrm{uL}$ and a rate of 210 strokes/min. After left thotacotomy and exposure of the heart, the L.AD was ligated with a 6-0 polypropylene suture (Surgipro, Connecticut, USA) directly prowmal to its main branching point. The suture was tied around a 3 -mm long polyethylene tube (PE-10) to induce ischaemia.

After 30 min of ischaemia, in the IR group, the ligature around the IAD was removed and the occurrence of reperfusion was assessed by the observation of blood flow in the epicardial coronary arteries through a surgical microscope. The ischaemic myocardium was reperfused for $180 \mathrm{~min}$. In the PI group, the suture was tied permanendy for $210 \mathrm{~min}$. Separate sham groups for both IR and PI models were made following an identical procedure but without the actual tying of the polypropylene suture. The chest was closed with 5-0 silk sutures. The animals were then weaned from the respirator, and the intratracheal tube was tremoved once they were breathing spontaneously. 
Cardiac tissue was harwested 210 min after initiation of ischaema. At this point, mice were re-anaesthetized with pentobarbital (120 $\mathrm{mg} / \mathrm{kg}$ intraperitoneally) and the thorax was reopened. In the IR animals the LAD was re-occluded and $500 \mu \mathrm{L}$ of $2.5 \%$ trypan blue (Merck, Darmstadt, Germany) was injected into the jugular vein to delineate the non-ischaemic tissue from the ischaemic tissue. This ischaemic aren is defined as the area at risk (AAR). Immediately afterwards the heart was excised and cleared from blood by rinsing in isotonic saline $\left(0^{\circ} \mathrm{C}\right.$ ). In the PI and IR group, the AAR was cut out whilst in the sham-operated animals the corresponding left ventricular region was taken. Only these tissue samples (AAR and corresponding region in the sham animals) were snap frozen in liquid nitrogen, stored at $-80^{\circ} \mathrm{C}$ and used whole for further study. As the AAR is not perfused with trypan blue, there can't be an influence of the dye on the proteome. The amount of myocardial necrosis and apoptosis in these in wice models has previously been determined in our lab [7, 11].

\section{Sample preparation}

The frozen tissue samples were pulverized to fine powder under liquid nitrogen using a mortar and pestle and homogenized using a handheld homogenizer in $40 \mathrm{mM}$ Tris buffer $(\mathrm{pH}=10.0$ ) containing $300 \mathrm{U}$ DNase and RNase and a protease inhibitor mix (Complete Mini ${ }^{3}$, Merck, Darmstadt, Germany). We used a technique of high-speed sedimentation/centrifugation that separates the total membrane fraction from all soluble cytosolic proteins as described by Pasquali et al. [12]. To assure the reliability, all samples from the IR group (or PI group) and its respective sham group wete processed simultaneously. After $30 \mathrm{~min}$ on ice, cytosolic fractions were separated by centrifugation at $100.000 \mathrm{~g}$ for $60 \mathrm{~min}$ at $4^{\circ} \mathrm{C}$ and stored at $-80^{\circ} \mathrm{C}$ for further analysis. To avoid contamination with remaining cytosolic proteins, the $100.000 \mathrm{~g}$ pellet fraction was additionally dissolved in $40 \mathrm{mM}$ Tris buffer and precipitated under the same conditions. After the supernatant was removed, the remaining membrane pellet was dissolved in $40 \mathrm{mM}$ Tris buffer ( $\mathrm{pH}=7.5$ ) containing $7 \mathrm{M}$ urea, $2 \mathrm{M}$ thiourea, $1 \%$ DTT, $1 \%$ CHAPS and a protease inhibitor mix (Complete Mini , Merck, Darnstadt, Germany) and stored at $-80^{\circ} \mathrm{C}$. The final protein concentration of both homogeneous fractions was determined using a protein assay (BioRad, Veenendaal, The Netherlands).

\section{Twa-dimensional gel electrophoresis}

For the cytosolic fraction as well as the membrane fraction, $400 \mu \mathrm{g}$ of protein were dissolved in rehydration solution (8 M urea, $2 \%$ CHAPS, $0.5 \%$ IPG-buffer, pH 4-7 linear and a trace of coomassie brilliant blue) up to a volume of $450 \mu \mathrm{L}$. Only for the cytosolic fraction, a 2-D Clean-Up kit (Amersham Pharmacia, Uppsala, Sweden) was used in order to remove "Tris buffer and to dissolve only the protein fraction in the rehydration solution ( $\mathrm{pH}:$ 7.5). Immobiline DryStrips (Amershan Phamacia, Uppsala, Sweden), $24 \mathrm{~cm}$, pH $4-7$ linear, were allowed to rehydrate $(14 \mathrm{~h}, 30 \mathrm{~V})$ in the protein solution under low viscosity oil in strip holders. Then, isoelectrical focusing was performed at $200 \mathrm{~V}$ for $1 \mathrm{~h}, 500 \mathrm{~V}$ for $1 \mathrm{~h}, 1000 \mathrm{~V}$ for $1 \mathrm{~h}$ and $8000 \mathrm{~V}$ for $16 \mathrm{~h}$ (approximately $128 \mathrm{kWh}$ in total). The rehydration step and isoelectric focusing (IEF) 
- Chapter 5

steps were accomplished using an IPGphot unit (Amershatn Pharmacia, Freiburg, Germany) with the temperature being maintained at $20^{\circ} \mathrm{C}$.

After the first dimensional run, the individual strips were equilibrated by gently shaking twice for $15 \mathrm{~min}$ in a solution containing $50 \mathrm{mM}$ Tris- $\mathrm{HCl}$ (pH 8.8), $6 \mathrm{M}$ urea, $30 \% \mathrm{v} / \mathrm{v}$ glycerol, $2 \%$ SDS and a trace of coomassie brilliant blue. Additionally, the first equilibration step contained $1 \%$ DTT and the second $2.5 \%$ iodoacetamide.

After equilibration, the IPG strips were placed on top of a $12 \%$ polyacrylamide gel (37:5:1) and proteins were then separated according to their molecular weight $\left(M_{*}\right)$ using an electrophotesis system (Ettan Dal, Amersham Pharmacia, Freiburg, Gemany). The run was completed when the coomassie brilliant blue front reached the bottom of the gel.

We used 6 animals per group and the material from each animal corresponded with one gel for the cytosolic fraction and one gel for the membrane fraction. The system allowed a maximal run of 12 gels simultaneously. We therefore completed both the cytosolic and the membrane fraction separately using a run for the IR group with its respective sham group and a run for the PI group with its respective sham group. The gels were then washed for $1 \mathrm{~h}$ in a $10 \% \mathrm{v} / \mathrm{v}$ methanol and $7 \% \mathrm{v} / \mathrm{v}$ acetic acid solution and were stained overnight (12h) with Sypro Ruby fluorescent stain (Bio-Rad, Veenendaal, The Netherlands). Before scanning the gels, they were destained for $1 \mathrm{~b}$ in a $10 \% \mathrm{v} / \mathrm{v}$ methanol and $7 \% \mathrm{v} / \mathrm{v}$ acetic acid solution.

\section{Spot detertion and analysis}

Gel images were scanned at a resolution of $100 \mu \mathrm{m}$ (Molecular Imager FX, BioRad, Veenendaal, The Netherlanils) and further analyzed using PDQuest 7.1 software (BioRad, Veenendaal, The Netherlands). The gels were ordered in the appropriate matchset and protein spots were manually matched according to the manufacturer's guidelines. Four different matchsets were used to compare separately the IR and PI group with their respective sham group for both the cytosolic fraction as well as the membrane fraction. The quantity of each spot was normalized by total quantity in valid spots using PDQuest 7.1. This normalized walue was used to calculate the mean quantity of each spot per group. The fold change (density ratio) for a protein spot that was increased in quantry after IR (or PI) was calculated by dividing the mean quantitative value of that spot in the IR (or PI) group with the mean quantitative value of that spot in the respective sham group. For a protein spot that was decreased in quantity after IR (or Pl) the inverse was taken. Using the PDQuest 7.l software, a correlation coefficient was measured between the quantities of all spots in a gel and its quantities in another gel from the same matchset. "The reproducibility of the $2-\mathrm{D}$ gels was expressed as the mean correlation coefficient between all gels in a matchset.

\section{Statistical analysis}

A statistical comparison of the telative abundance of each matched protein spot berween the IR group $(\mathrm{N}=6)$ or PI group $(\mathrm{N}=6)$ and their respective sham group (both $N=6$ ) was accomplished using a two-tailed t-test (PDQuest). Between groups, qualitative differences means that the spot is present in the samples from one of the groups (IR or $\mathrm{PI}$ ) and not in its respective sham group or vice versa. Between group 
quantitative or qualitative differences $\geq 1.6$ times and a significant difference with $P_{\text {. }}$ value $\leq 0.05$ were registered. All values are expressed as mean $\pm \mathrm{SD}$.

\section{In-gel digestion}

Protein spots of interest were excised from Sypro Ruby stained gels with an automatic spot cutter (Proteome Works Spot Cutter system, BioRad). Each spot was pooled out of 3-6 gels, washed twice with $200 \mathrm{mM}$ ammonium bicarbonate in $50 \%$ acetonitrile/water $\left(20 \mathrm{~min}\right.$ at $30^{\circ} \mathrm{C}$ ), and allowed to dry at room temperature. The tubes were then chilled on ice and $8 \mu \mathrm{L}$ of digestion buffer $(50 \mathrm{mM}$ ammonium bicarbonate, pH 7.8) containing 150 ng modified trypsin (Promega, Madison, WI, USA) were added. The samples were incubated on ice for 45 min with $15 \mu \mathrm{I}$ digestion buffer and afterwards incubated overnight at $37^{\circ} \mathrm{C}$. The supernatant was recovered, and the remaining peptides were extracted from the gel plece by washing twice with $60 \%$ acetonitrile $/ 0.1 \%$ formic acid in water. The extracts were combined and the samples were dried in a Speedvac. The samples were resuspended in $10 \mu$ of $0.1 \%$ formic acid.

\section{Protein identification-mass spectrometry}

The pepride mixture was analyzed on a 4700 Ptoteomics Analyzer, a MALDI TOITOF mass spectrometer (Applied Biosystems, Framingham, CA, USA). We applied 1 $\mu \mathrm{L}$ of the digest mixture, mixed with $1 \mu \mathrm{L} 100 \mathrm{mM} \alpha-\mathrm{cyano}-4$-hydroxycinnamic acid in $50 \%$ acetonitrile and $0.1 \%$ TFA onto a MAIDI target plate. MS and MS/MS analysis of the peptides was performed. MS spectra were acquired after accumulation of 2000 consecutive laser shots and MS/MS spectra were obtained after 3000 laser shots and air used as collision gas (1.2 $\times 10^{-7}$ Torr). This approach could not unambiguously identify all protein spots. Thus, a second strategy was used to identify the remaining 2D-spots and to confirm the identification of the MALDI analysis. Hence, the samples were loaded on an automated nano-HPLC system (Dionex-LC Packings, Amsterdam, The Netherlands) and separated peptides wete then detected on-line by an ESI-Q-TRAP mass spectrometer (Applied Biosystems, Franingham, CA, USA), In this method, an automated MS to MS/MS switching protocol was used for on-line LC-MS/MS analysis of the peptides [13]. For identification, MASCOT 1.9 was used for searching the MS and MS/MS data, obtained by either MALDI or LC-ESI analysis [14]. Searches were performed against the NCBI protein database. For the ILC-MS/MS analyses, MASCOT was used with the following parameters: peptide tolerance $0.6 \mathrm{Da}$, fragment tolerance $0.8 \mathrm{Da}$, trypsin, specificity two possible missed cleavage sites, variable modifications carbamidonethylation and methionine oxidation and ESI-"TRAP selected as the instrument.

\section{Westem blot analyint}

Equal amounts of sample protein $(10 \mu \mathrm{g})$ were separated by $10 \%$ SDS-PAGE. After transfer to polyvinylidene difluoride membranes, they were blotted with rabbit antiannexin 5 polyclonal (Hyphen BioMed, France) or rabbit anti-annexin 3 polyclonal (gift from F. Russo-Marie, Bionexus Pharmaceuticals SA, Gif sut Yrette, France) and 
- Chapter 5

scanned. Densities were detemined arbitrarily by ImageQuant Molecular Dynamics, Sunnyvale, CA, USA).

\section{Results}

\section{General}

The average amount of ventricular tissue from the AAR, collected per animal was $54.0 \pm 6.6 \mathrm{mg}$ and $50.0 \pm 11.5 \mathrm{mg}$ after IR and PI respectively. The final protein fraction per amount of tissue was $4.2 \pm 0.6 \%$ and $5.3 \pm 1.7 \%$ for the cytosolic fractions and $8.9 \pm 2.2 \%$ and $7.8 \pm 3.2 \%$ for the membrane fractions of the IR and the PI group, respectively. Typical $2 \mathrm{DE}$ spot pattens of both the cytosolic and membrane fraction, representative for the sham and PI group are shown in figure 1.

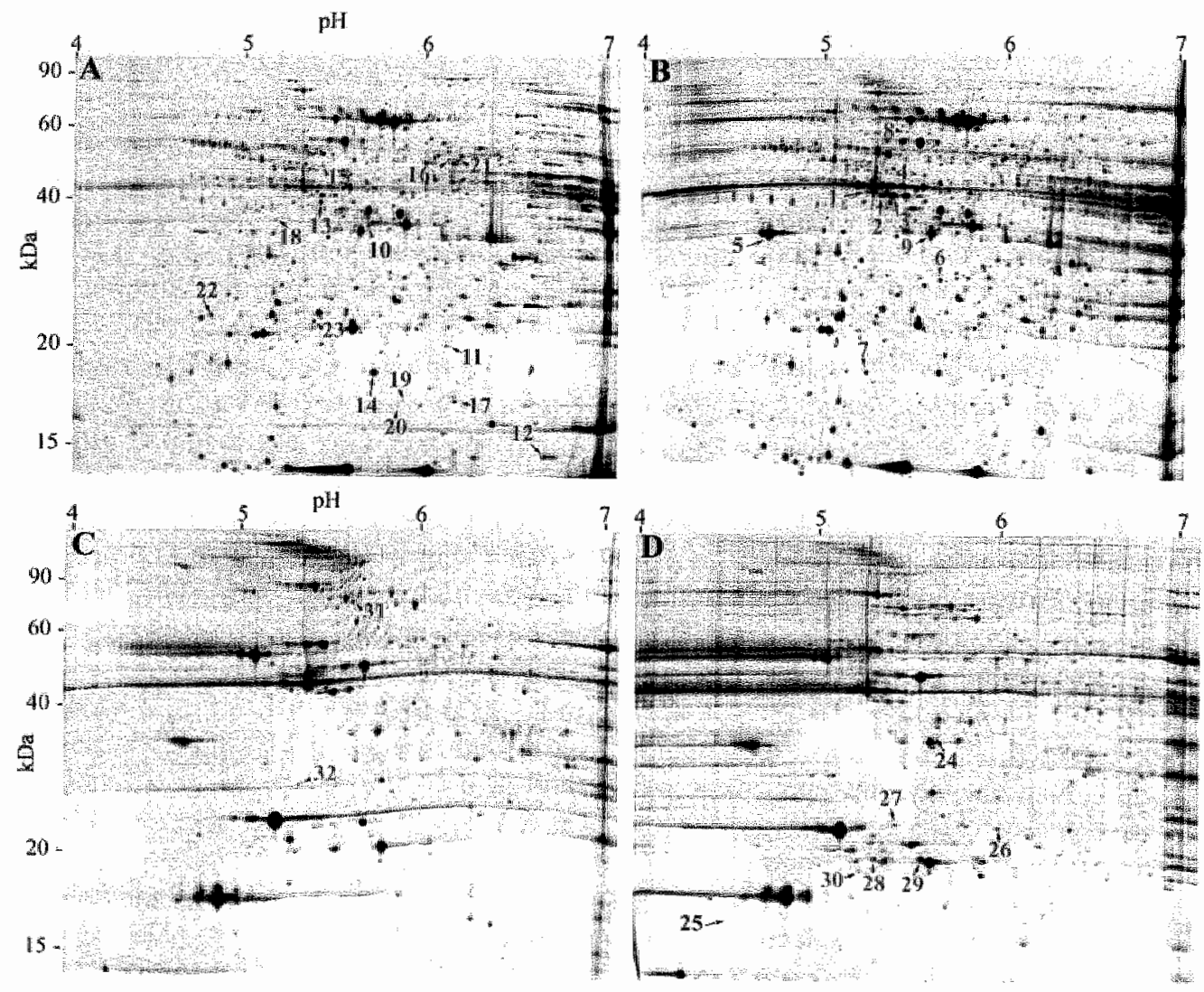

Figure 1. Sypro Ruby stained 2-DE gels of the cytosolic fraction (A, B) and the membrane fraction (C, D) from a slam animal $(A, C)$ and a PI animal $(B, D)$. Coloured numbers depict protein spots displaying significant quantiative or qualitative changes in expression level $(P \leq 0.05$ and density ratio $\geq 1.6)$. Protein spots changing in expression level after IR alone, after PI alone or after both IR and PI are numbered in blue, ted and green, tespectively. Spot numbers tefer to the numbers given in table 1 (1A-1D) 


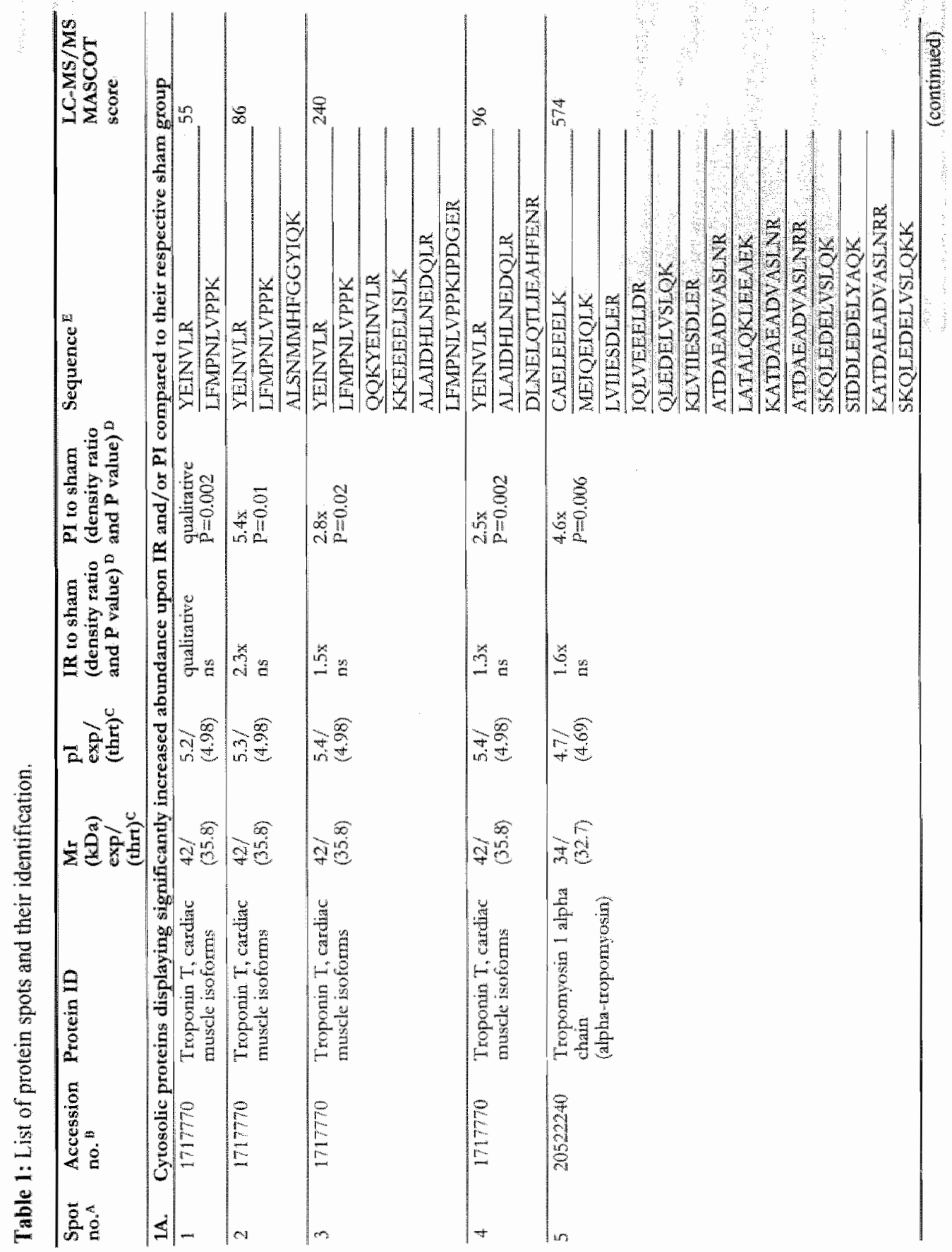


- Chapter 5

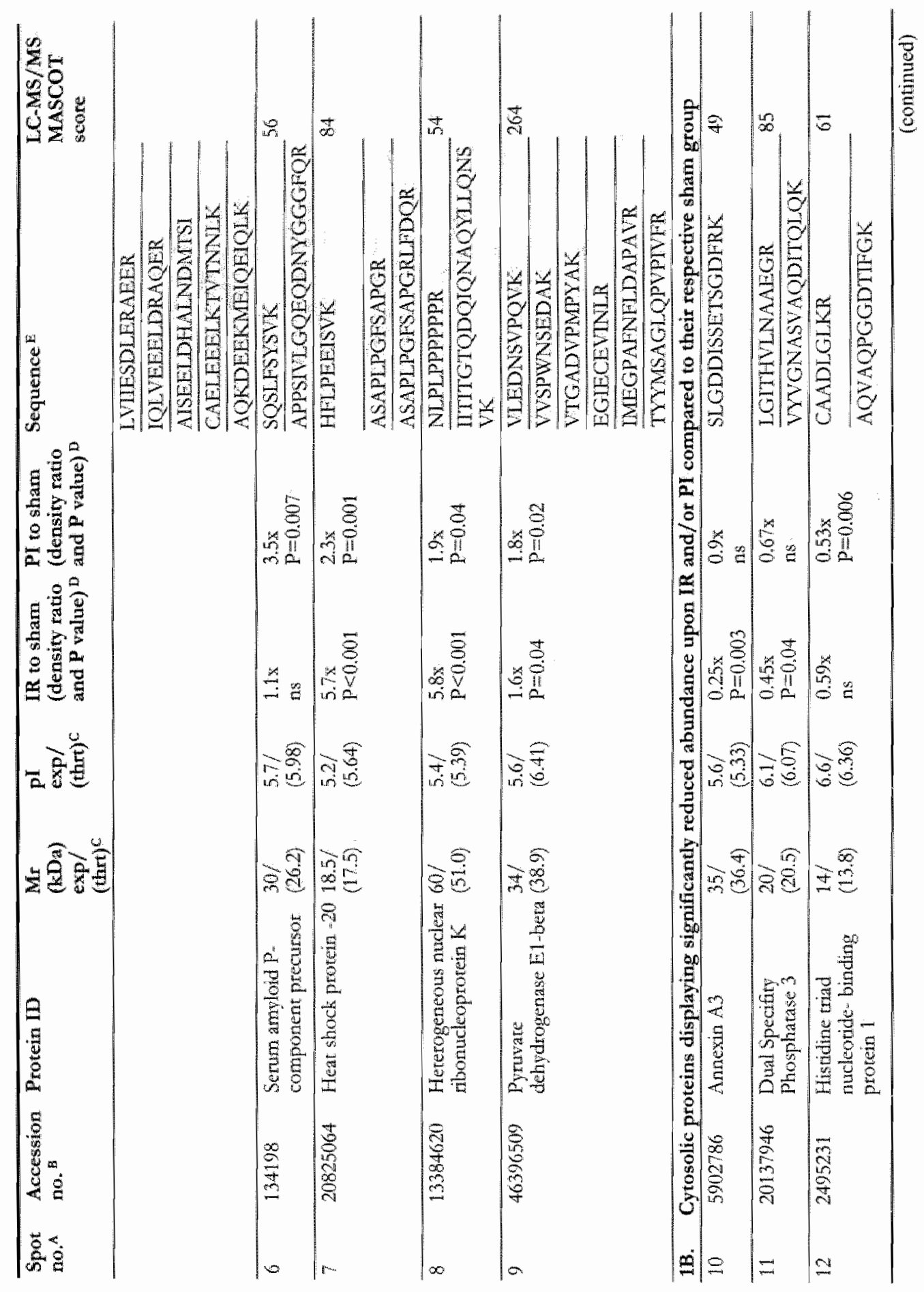


Cardiac protein expression after myocardial infarction

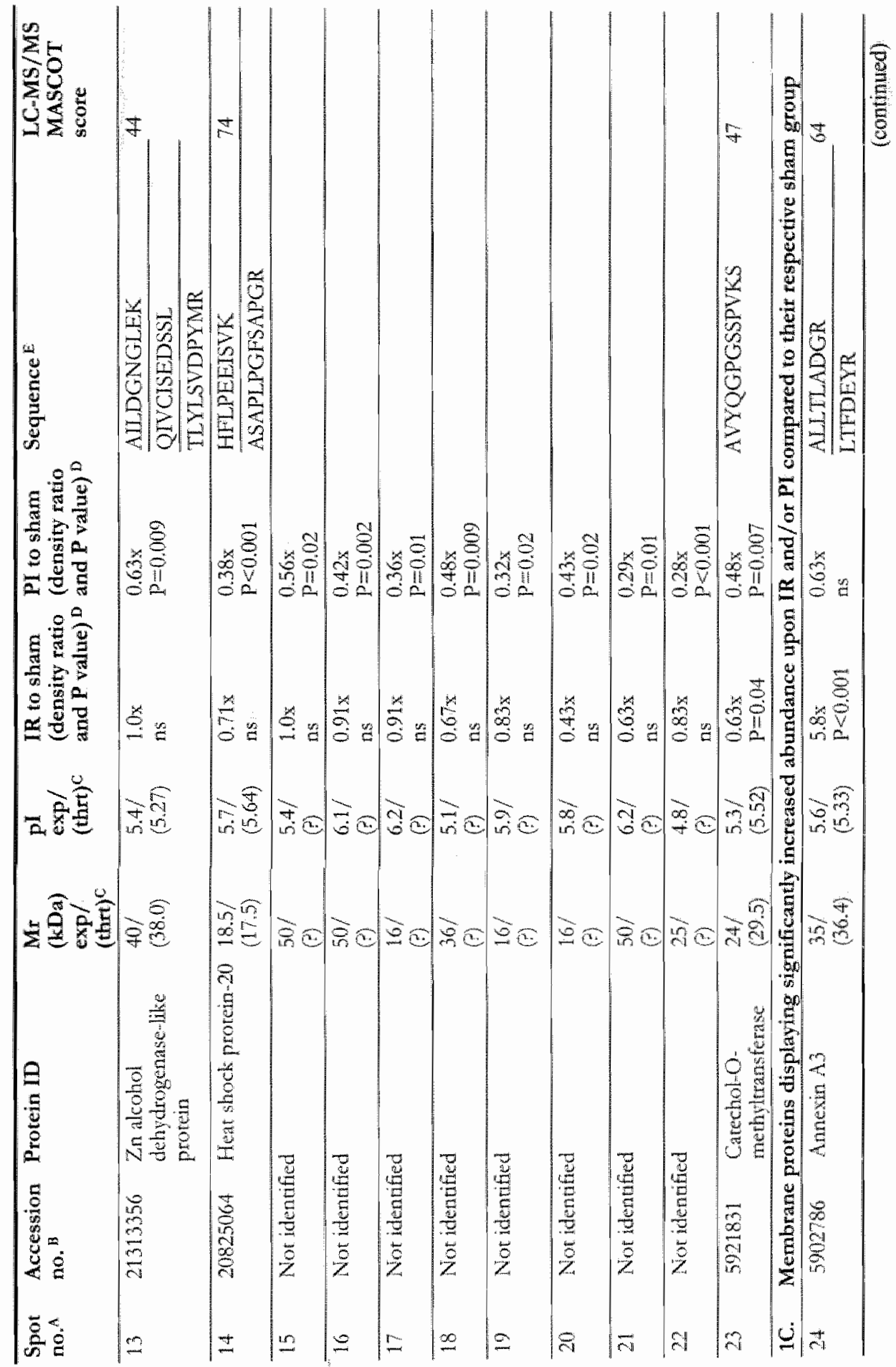


- Chapter 5

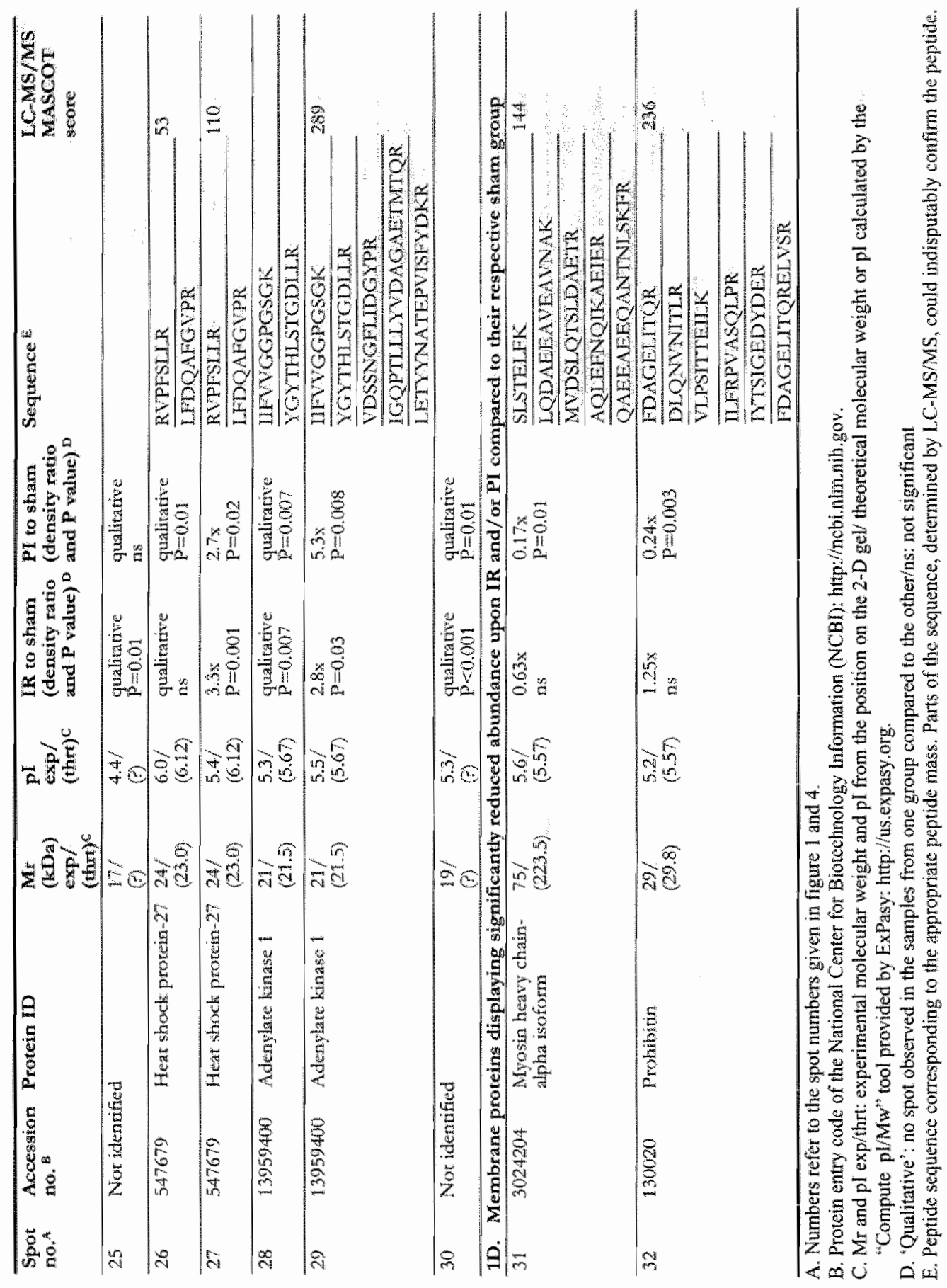


The digitized master gel was composed of a total of 12 gels in which the IR or PI group was compared with its respective sham group. The neatr number of spots in each gel that matched with the master gel was $495+106$ for the cytosolic fraction and $116 \pm 22$ for the membrane fraction. The reproducibility of the $2 \mathrm{D}$ gels was high. The mean correlation coefficient between all gels within the matchset of the IR group (and is respective sham group) was $0.83 \pm 0.04$ (cytosolic fraction) and $0.84 \pm 0.07$ (membrane fraction). The mean correlation coefficient between all gels within the matchset of the PI group (and its respective sham group) was $0.81 \pm 0.07$ (cytosolic fraction) and $0.83 \pm 0.07$ (membrane fraction).

\section{Idenifucation of protein spots changed in expression level after PI and IR}

Figure 1 indicates the protein spots on the 2-DE spot patterns that significantly changed in expression level after IR and/or PI compared with their respective sham group. "These protein spots are numbered in separate colours to distinguish between protein spots that changed significantly in expression level after IR alone (blue), after PI alone (red) or commonly after IR and PI (green). The spot numbers in this figure refer to the numbers in table 1 (1A-1D) which lists these protein spots and their protein identification. The experimental and theoretical mass and pl of the proteins and the density ratio (with $P$ value) of expression level after IR and PI compared with the respective sham group are also listed in table 1.

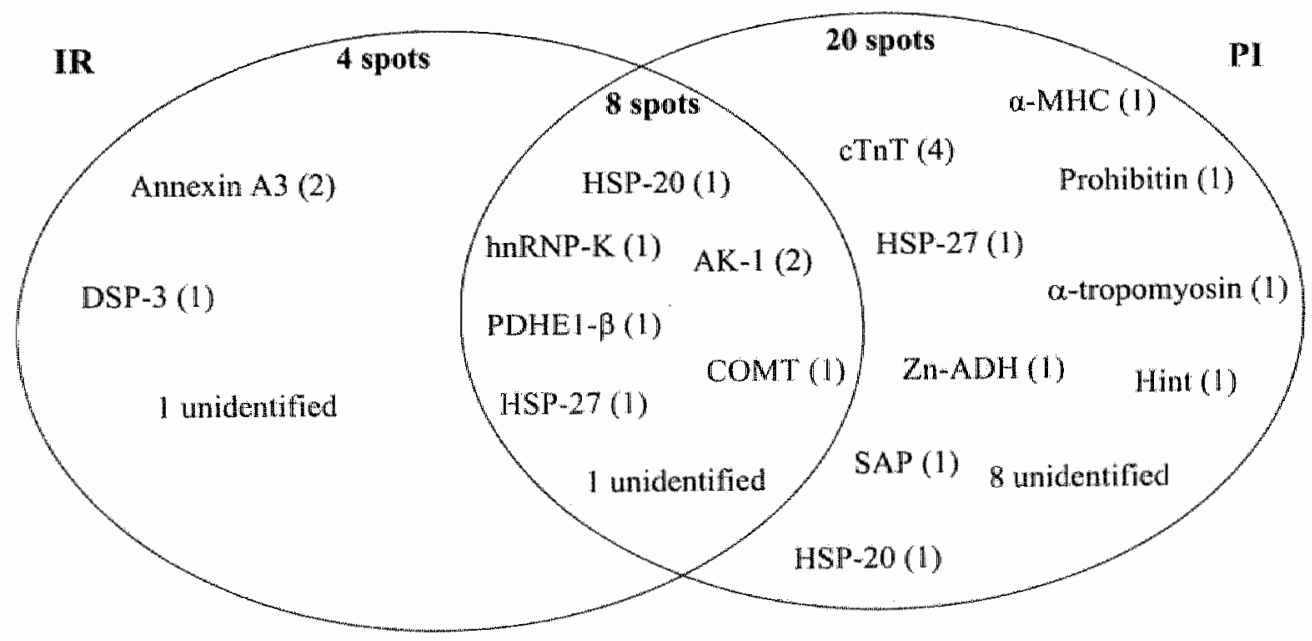

Figure 2. Venn diagram indicating the number of protein spots that changed significantly in expression level and the abbreviated names of the proteins they represent. The numbers of spot locations at which the identified proteins occur in each model (IR or PI) or both models ate indicated between brackets. The amount of unidentified protein spots is also indicated. Four protein spots changed significantly in expression level after IR alone, 20 protein spots changed significantly in expression level after PI atlone and 8 protein spots are commonly changed in borh models compated to their respective sham group. 
The Venn diagtam (figure 2) gives an overview of the amount of spots significantly changed in expression level. Some proteins occur at one spot location while other proteins are present at several locations. The number of spot locations at which each protein occurred is indicated in the Venn diagram, within parentheses, after the abbreviated names of the proteins.

Four protein spots changed significantly in expression level after IR alone while 20 protein spots changed significantly in expression level after PI alone. Eight protein spots changed significantly in both models.

As indicated in this Venn diagram, 22 protein spots ( 3 spots after IR alone, 12 spots after PI alone, 7 spots after both PI and IR) could be identified by MS while 10 protein spots (1 spot after IR alone, 8 spots after PI alone, 1 spot after both PI and IR) could not. Thus about $70 \%$ of the protein spots could be identified by mass spectrometry. In table 1, the MASCOT score of the identified peptides is given together with (parts of) the deduced amino acid sequences. The unidentified proteins were relatively low in abundance and probably fell, despite pooling, below the detection limit of the technique.

Protein spots present on the 2-D gels showing no significant change in expression level after IR or PI or with < 1.6-fold change were not identified by mass spectrometry.

As indicated in figure 2, proteins (or protein spots) that significantly changed in expression level after IR but not after PI were annexin-A3 (spot 10,24) and dual specificity phosphatase-3 (DSP-3, spot 11). Proteins (or protein spots) that significantly changed in expression level after PI but not IR were cardiac troponin T (cTnT, spot 1-4), $\alpha$-tropomyosin (spot 5), $\alpha$-myosin heavy chain ( $\alpha$-MHC, spot 31 ), serum amyloid P-component precursor (SAP, spot 6), Zn-alcohol dehydrogenase (Zn$\mathrm{ADH}$, spot 13), prohibitin (spot 32), histidine triad nucleotide binding protein (Hint, spot 12), heat shock protein-27 (HSP-27, spot 26) and heat shock protein-20 (HSP-20, spot 14). The proteins (or protein spots) that significantly changed in expression level in both models were heterogeneous nuclear ribonucleoprotein- $K$ (hnRNP-K, spot 8), pyruvate dehydrogenase $\mathrm{E} 1-\beta$ (PDHE1- $\beta$, spot 9), catechol-O-methyltransferase (COMT, spot 23), adenylate kinase-1. (AK-1, spot 28, 29), HSP-20 (spot 7) and HSP27 (spot 27). In genertal these identified proteins can be classified into functional groups i.e. anticoagulant proteins, structural proteins, inflammatory-related proteins, transcription and translation-related proteins, heat shock proteins, metabolism-related proteins and miscellaneous.

\section{Thanilocation of annexin 43 and annexin 45}

2-DE analysis showed that the quantity of annexin A3 in the cytosolic fraction was 4 times lower $(P=0.003)$ in the IR group than in the respective sham group. In contrast, in the membrane fraction of the IR group, the amount of annexin $A 3$ was 5.8 times higher $(P=0.001)$ than in the sham group. These findings were verified using Western blots for annexin A3 as well as annexin A5 (figure 3). Annexin A5 was significantly reduced in the cytosolic fraction $(P<0.001)$ and significantly increased in the membrane fraction after IR $(\rho<0.001)$. It is remarkable, that for both annexin A3 and annexin A5, such changes were specific for IR and did not occur after PI. As indicated 
in the Venn diagram (figure 2), annexin A 3 is significantly changed in expression level at two spot locations: one in the cytosolic fraction (decreased) and one in the membrane fraction (increased). Annexin A5 was not included in the Venn diagram (figure 2) because this protein was not found on the 2-DF gels:

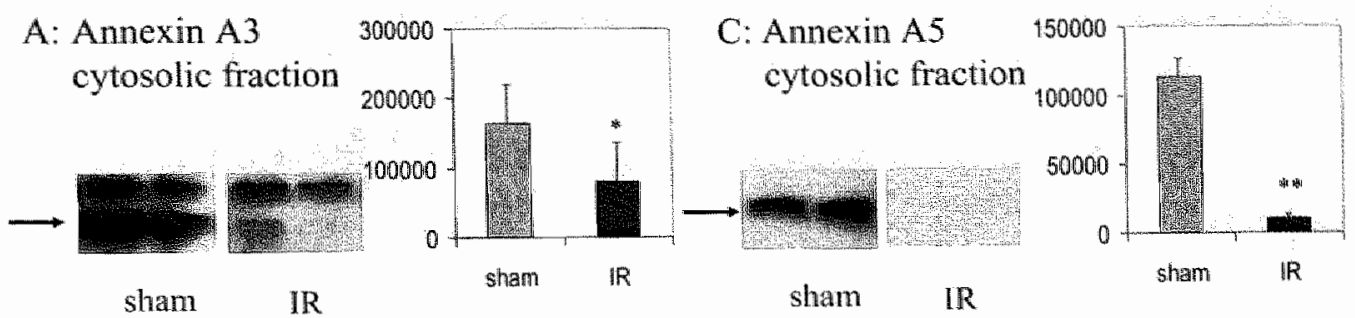

B: Annexin $\mathrm{A} 3$ membrane fraction

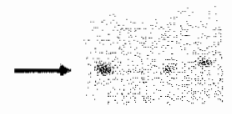

sham

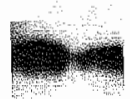

IR

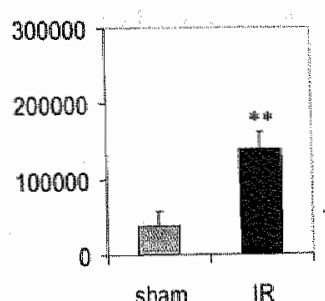

sham IR
D: Annexin A5 membrane fraction

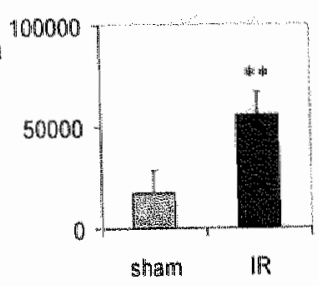

Figure 3. Western blot analysis for the cytosolic fraction (A) and membrane fraction (B) of annexin A3 and the cytosolic fraction (C) and the membrane fraction (D) of annexin A5 compared between sham and IR. The artow indicates the position of the annexin band. Panels next to every Western blot picture show significant quantitative density differences between the IR group and their respective sham group $(* P=0.017, * * P<0.001, N=6$ per group).

\section{Post-translational modifiation of proteins}

Four of the identified proteins that changed in expression level were found at multiple spot locations, characterized by a difference in isoelectric point (pl), on the gels (figure 2). This suggests that these are isoforms or proteins that underwent post-translational modifications under IR and/or PT. Mass spectrometry was not able to accurately distinguish between isoforms or to determine potential post-translational modifications. Figure 4 represents detailed 2-DE patterns of Sypro Ruby stained 2 DE gels showing these protein spots. In the cytosolic fraction of the PI group but not: in the IR group, HSP-20 shifted to a lower $\mathrm{pl}$ with a difference in pl of approximately 0.43. Cardiac troponin $T$ was identified at 4 spot locations of which 3 spots had the same apparent molecular weight but had a $\mathrm{pl}$ difference of apptoximately 0.07 . These 4 spots were significantly up-regulated only in the PI group and not in the IR group. In the membrane fraction of the PI group, adenylate kinase 1 and HSP-27 were 
significantly up-regulated at 2 spot locarions separated by a pI range of 0.27 and 0.60 , respectively.

For adenylate kinase 1, the spot at the lowest pI and for HSP-27, the spot at the highest pl were not preserit in the sham group. The same phenomenon was observed for the IR group although the HSP-27 spot at the highest $\mathrm{pI}$ was not significantly upregulated compared to the respective sham group.
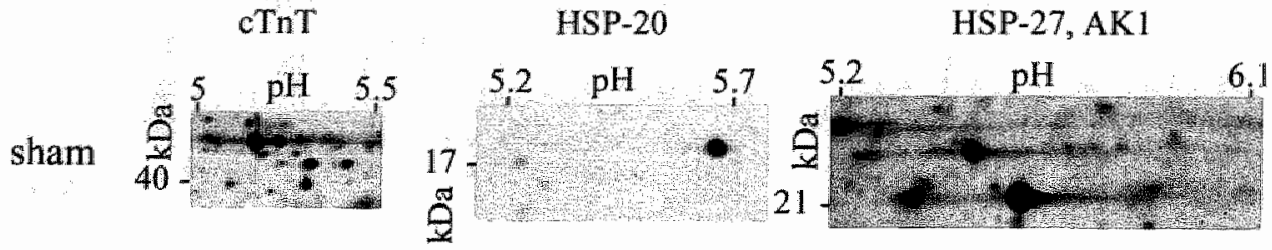

IR
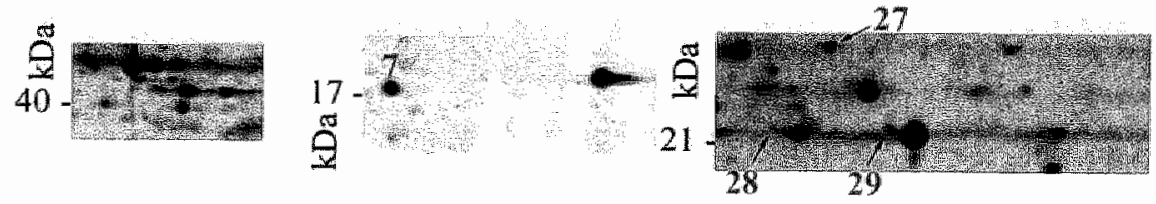

PI
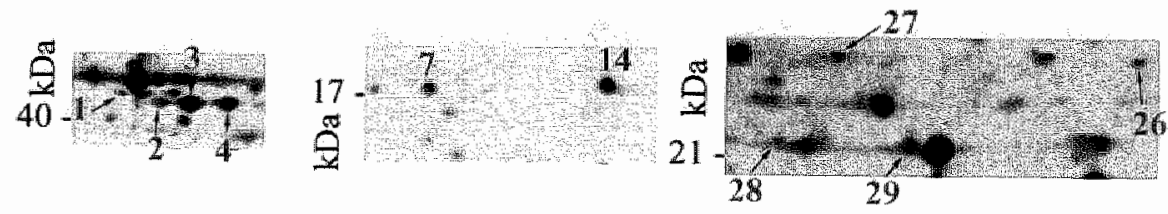

Figure 4. Detailed 2-DE pattern of the Sypro Ruby stained 2-DE gals showing identifed proteins that are present at multiple spot locations. Different colours are used to indicate if these protein spots significanty changed in expression level after PI alone (red) or both after IR and PI (green). These proteins are cTnT (spot 1-4), HSP-20 (spot 7 and 14), HSP-27 (spot 26 and 27) and AK1 (spot 28 and 29) and they are shown for the sham group (upper panel), the TR group (middle panel) and the PI group (lowex panel). Note that ano of these protein spots changed significantly in expression level after lR antote. Spot numbers also nefer to the numbers given in tigure ll and table 1.

\section{Discussion}

This study is the first to describe changes in cardiac protein expression by 2-DE in in vivo mouse models of myocardial infarction, i.e. a model of PI and a model of IR. Twenty protein spots changed significantly in expression level after PI alone, 4 protein spots changed significantly after IR alone, while 8 protein spots changed significantly in both models. We classified the identified proteins into functional groups: anticoagulant proteins, structural proteins, inflammatory-related proteins, transcription- and translation-related proteins, heat shock proteins, metabolism-related proteins and miscellaneous. We discuss their potential tole in PI and IR in separate sections below. It is remarkably that none of the individual proteins we identified were differentially expressed in one of the three previous studies in this area. However, a few are functionally related as discussed below [8-10]. Moreover the number of 
proteins that changed in expression level in our study was higher than in these previous studies. Several factors may account for this discrepancy. Firstly, we analyzed the cytosolic and membrane fraction separately to make low abundance proteins more easily detectable. Secondly, our study was conducted in the mouse while others used the dog [10], rabbit [8] and rat [9]. Thirdly, differences in the duration of ischaemia (range: $40 \mathrm{~min}$ [9]-90 $\mathrm{min}$ [10]) or in the duration of reperfusion (range $20 \mathrm{~min}$ [9] to $180 \mathrm{~min}[8])$ could contribute to the differences in outcome.

\section{Anticocoghlont proteins}

The significant decrease of annexin $A 3$ in the cytosolic fraction and the significant increase in the membrane fraction was specific for the IR model. This was also verified by Western blot analysis and suggests translocation of annexin A3 to the membrane fraction triggered by reperfusion. This phenomenon was also observed for annexin $A 5$, as verified by Western blot analysis and cortelates with the fact that the C-terminal protein core, which is responsible for the calcium-mediated membrane recognition and binding, is highly conserved between annexins [15]. An explanation for the fact that annexin A5 was not detected on 2-D gels could be that other proteins masked the corresponding spot. In wivo functional properties for annexins are diverse and include membrane trafficking, endo- and exocytosis, membrane-cytoskeleton interactions, regulation of membrane protein activity, cell signalling, and roles in inflammatory and coagulation processes (see [16] for review). The fact that this phenomenon occurred after IR alone and not after PI suggests a specific related mechanism that triggers translocation of annexins to the membrane fraction during reperfusion. These findings may give new impetus for further studies in relation to annexins and early diagnosis of reperfusion injury in connection with earlier studies from our laboratory [17].

\section{Structural proteins}

Cardiac troponin $T\left(c^{\prime} \operatorname{Tn}^{\prime} T\right)$ and another myofilament protein, $\alpha$-tropomyosin, were significantly increased in the cytosolic fraction after PI but not after IR. CTnT is known as an $\alpha$-troponyosin binding protein, and both proteins are involved in the process of muscle contraction [18]. Several animal studies have shown that the appearance of $\mathrm{CTn} T$ in blood is a highly sensitive and specific marker for myocardial injury and is directly correlated with infarct size $[19,20]$. We have recently described that in mice after PI, infarct size is almost 4 times greater than after IR [7]. With respect to this, the data suggest that the increased cytosolic levels of cTn'T and $\alpha$ tropomyosin are markers for high breakdown of the contractile apparatus after PI compared to IR.

\section{Inflammatory-related proteins}

Myocardial infarction is associated with an early inflammatory response, which is a prerequisite for wound healing and scar formation (see [21] for a review).

In relation to this we observed that serum amyloid P-component precursor (SAP) was significantly increased in the cytosolic fraction after PI but not after IR. SAP is a precursor for serum amyloid $\mathrm{P}$ component which is an acute-phase reactant produced 
by the liver and able to activate the complement system [22]. SAP does not only exist in plasma but also in peripheral tissues where it is associated with extra-cellular matrix proteins [23-27]. To our knowledge, this study is the first to describe SAP as a potential specific marker for hypoxic cardiac tissue after PI.

Transoription and trawslation-related proteins

Prohibitin (membrane fraction) and histidine triad nucleotide binding protein 1 (cytosolic fraction) were both significantly reduced after PI but not after IR. Prohibitin is known to inhibit cell proliferation [28], to regulate transcriptional activity [29] and to stabilize mitochondrial proteins $[30]$. In addition, both proteins have been reported to function as tumour suppressers [31-33]. However at present, nothing is known about a functional tole of these proteins in relation to cardiovascular diseases. In our study, hetcrogeneous nuclear ribonucleoptotein $K$ (hnRNP $K$, cytosolic fraction) and in the study of Sakai et al. 19], elongation factor Tu showed increased expression after PI and IR. Both proteins are associated with serine/threonine protein kinase $C \varepsilon$, a protein complex with a critical role in protecting the myocardium against IR injury [34]. Elongation factor Tu promotes amino-acyl tRNA binding to the ribosome [35] and hnRNP is a nucleic acid binding protein involved in RNA processing [36], translocation [37], and translation [38]. The finding that proteins belonging to this functional group changed in expression level suggests possible extensive control over protein expression in part by regulation of $\mathrm{mRNA}$. This partially depends on the model, PI or IR.

\section{Heat shock proteins}

In accordance with the prewious studies by Schwertz et al. [8] and Sakai et al. [9], we observed a change in expression level of heat shock proteins (HSP) after myocardial infarction. These proteins are considered as "molecular chaperones", the expression of which increases by cellular stress [39]. HSP-27 (membrane fraction) and HSP-20 (cytosolic fraction) were increased both after PI and IR. Differential changes in HSP27 levels have been described in tat [40] and human [41, 42] cardiac tissues exhibiting heart failure. HSP-27 acts as a protective agent against hypoxic injury in cultured adult tat $|4.3|$ and canine cardiomyocytes [44]. However, this protective effect has not been shown in an in wivo animal model to date. Because of its increased expression level, our study suggests a possible role for HSP-27 in the cardioprotective mechanism after iz: wito PI and IR.

HSP-20 was identified at two spot locations after myocardial infarction. The spot at the lowest $\mathrm{pl}$ increased in expression level after IR and PI, while the spot at the highest $\mathrm{pl}$ decreased after PI alone. Phospho-isoforms for HSP-20 have been described in literarure [45] and additional research is necessary to investigate whether one or both of these spots in our models represents phospo-isoforms of HSP.20. Recently Chu at a [46] showed in mouse cardiomyocytes that HSP-20 increases in expression and phosphorylation after prolonged activation of the $\beta$-adrenergic signalling pathway, which has consequences for the regulation of cardiac contractility and $\mathrm{Ca}^{2+}$ handling. The same group also suggested that HSP-20 and its phosphoisoform may provide cardioprotection against $\beta$-agonist-induced apoptosis $[47]$. 
Extrapolation of these results to our study could mean that HSP-20 may have a role in cardiac myocyte function and cell death after myocardial infarction in which $\beta-$ adrenergic stimulation occurs to compensate for a reduced cardiac output.

Myocardial ischaemia is associated with a marked interstitial accumulation of catecholamines [48]. Under physiological conditions part of the catecholanines are broken down by catechol-O-methyltransferase (COMT) [49]. The finding that COMT levels were significantly decreased in the cytosolic fraction after PI and IR points to a myocardial adaptation of the metabolism of catecholamines or related substrates under these conditions $[49,50]$.

\section{Merabolism-related proteins}

Adenylate kinase 1. (AK1) in the membrane fraction and pyruwate dehydrogenase E1 component beta subunit (PDHE1- $\beta$ ) in the cytosolic fraction were both significantly. increased after IR and PI. AK1 reversibly catalyses (high-energy) phosphotransfer between ADP, ATP, AMP and serves as an integral component of phosphotransfer networks [51]. During metabolic challenges, AK1 has been reported to be an essential enzyme in maintaining myocardial energy homeostasis $[52,53]$ and in metabolic signal

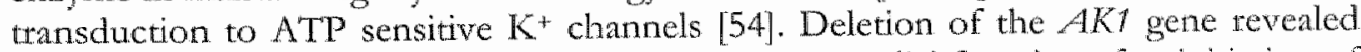
that adenylate kinase phosphotransfer supports myocardial function after initiation of ischaemic stress and safeguards intracellular nucleotide pools in post-ischaenic recovery [55]. Simultaneously PDHE1- $\beta$, which is a subunit of pynuvate dehydrogenase that largely controls the rate of entry of pyruvate into the Krebs cycle, was up-regulated. Both indicate a regulatory mechanism during IR and PI to achieve energy balance for the increased energy demands that occurs duting these stress periods and to achieve cellular energetic economy and metabolic signal transduction. In relation to this, the previous study of Sawicki et al. [10] showed after IR an increase in isocitrate dehydrogenase, a key enzyme in the Krebs cycle.

\section{Miscellaneaus}

At this moment it is not possible to fomulate a hypothesis about the relevance of a few proteins i.e. " $\alpha$-myosin heavy chain" (membrane fraction); "dual specificity phosphatase" (cytosolic fraction); and a protein "similar to Zn-alcohol dehydrogenase" (cytosolic fraction) which were differentially expressed after PL and/or IR.

\section{Conclusion}

This study demonstrates that mouse myocardial infarction models are suitable to study in wivo changes in the proteome early after induction of PI or IR. By analyzing selectively membrane and cytosolic fractions we were able to detect a substantial number of proteins that were differentially expressed in either compartment after PI, after IR or both. In addition, our approach allowed the identification of translocation of particular proteins such as annexins, from cytosolic to membrane compartments. Additional research is necessary to identify the functional relevance of these proteins in these pathologies and to detemine the character of possible pathology related post- 


\section{- Chapter 5}

translational modifications. The specific alterations in protein expression that took place after PI and IR may stimulate the search for new tools to diagnose myocardial infarction and to characterize specific pathology related changes in protein expression.

\section{References}

1. Cleutjens JP, Blankestein WM, at al. The infarcted myocardium: simply dead tissue, or a lively target for thetapeutic interventions. Cardiovasc Res. 1999; 44: 232 .

2. De Celle $T$, Heeringa $P$, el al. Sustained prorective effects of 7 -monohydroxyethylrutoside in an in viwo model of cardiac ischemia-reperfusion. Eur J Pharmacol. 2004; 494:205.

3. Flaherty JT, Weisfeldt ML Reperfusion injury. Free Radic Biol Med. 1988; 5: 409.

4. McDonough JL, Neverova l, et al. Proteomic analysis of human biopsy samples by single twodimensional electrophoresis: Coomassie, silver, mass spectrometry, and Western bloting. Proteonics. 2002; 2; 978.

5. McGregor E, Dunn MJ. Proteomics of heart disease. Hum Mol Genet. 2003; $12 \mathrm{spec}$ No 2: R135.

6. Lutgens $\mathrm{E}$, Dxemen MJ, et al. Chronic myocardial infarction in the mouse: cardiac structural and functional changes. Cardiovasc Res. 1999; 41:586.

7. De Celle T; Cleutiens J, et al. Long-Term Strucural and Functional Consequences of Cardiac Ischemia/Reperfusion Injury in vivo in Mice. Exp Physiol. 2004.

8. Schwertz $H_{\text {, Langin }} \mathrm{T}$, th al. Two-dimensional analysis of myocardial protein expression following myocardial ischemia and reperfusion in tabbits. Proteomics. 2002; 2: 988.

9. Sakai J, Ishikawa $H_{\text {, }}$ at. Proteomic analysis of tat heart in ischemia and ischemia-reperfusion using fluotescence two-dimensional difference gel electrophotesis. Proteomics. 2003; 3: 1,318.

10. Salwicki $G$, Jugdutt BI. Detection of regional changes in protein levels in the in vivo canine model of acure heart failure following ischemia-reperfusion injury: functional proteomics studies. Proteonics. 2004; 4: 2195.

11. Dumont EA, Hofstra $\mathrm{L}$, of al. Cardiomyocyte death induced by myocardial ischemia and reperfusion: measurement with recombinant human annexin $\mathrm{V}$ in a mouse model. Circulation. 2000; $102: 1564$.

12. Pasquali $\mathrm{C}$, Fialka $\mathrm{I}$, ot al. Preparative two-dimensional gel electrophoresis of membrane proteins. Flectrophoresis. 1997; 18:2573.

13. Sule $A$, Vanrobacys $F$, at at. Proteomic analysis of small heat shock protein isoforms in barley shoots. Phytochemistry. 2004; 65: 1853.

14. Perkins DN, Pappin DJ, at al. Probability-based protein identification by searching sequence databases using mass spectrometry data. Electrophoresis. 1999; 20: 3551.

15. Barron (j], Newman R[-H, at Amino acid secuence analysis of the annexin super-gene family of proteins. Eur J Biochem. 1991; 198: 749.

16. Gerke V, Moss SF. Amexins: from structure to function. Physiol Rev. 2002; 82: 331.

17. Dumont $\mathrm{NA}$, Reutelingsperget $\mathrm{CP}$, of at. Real-time imaging of apoptotic cell-membrane changes at the single-cell level in the beating murine heart. Nat Med. 2001; 7: 1352.

18. Bacchiochi $\mathrm{C}$, Lehrer $\mathrm{SS} . \mathrm{Ca}(2+)$-induced movement of tropomyosin in skeletal muscle thin Gilaments obserwed by multi-site FREET. Biophys J. 2002; 82: 1.524.

19. Metzlet $B$, Hammerer-Lercher $A$, et al. Plasma cardiac troponin " $T$ closely" correlates with infarce size in a nouse model of ncute myocardial infarction. Clin Chim Acta. 2002; 325: 87.

20. Remppis $A$, Ehlermann $P$, ot al. Cardiac troponin $T$ levels at 96 hours reflect myocardial infarct size: a pathoanatomical study. Cardiology. 2000; 93: 249.

21. Frangoginnis $\mathrm{NG}_{\mathrm{*}}$ Smith $\mathrm{CW}$, of al. The inflammatory response in myocardial infarction. Cardiovase Res. 2002; $53: 31$. 


\section{Cardiac protein expression after myocardial infarction.}

22. Steel DM, Whitehead AS. The major acute phase reactants: C-reactive protein, serum amyloid P component and serum amyloid A protein. Immunol Today. 1994; 15: 81.

23. Dyck RF, Exans DJ of amyloid P-component in human glomerular basenent menbmine. Abnomal patterns of immunofluorescent staining in glomerular disease. Lancet. $1980 ; 2: 606$.

24. Breathnach SM, Melrose $\mathrm{SM}_{s}$ a. Amyloid $\mathrm{P}$ component is located on elastic fibre mictofibrils in notmal human tissue. Nature. 1981; 293:652.

25. Breathnach SM, Melrose SM, at al Immunohistochemical studies of amyloid P component distribution in normal human skin. J Invest Dermatol. 1983; 80: 86.

26. Zahedi $\mathrm{K}$. Chatacterization of the binding of serum amyloid $\mathrm{P}$ to type IV collagen. J Biol Chem. 1996; 271: 14897.

27. Zahedi $K$. Characterization of the binding of serum anyloid $P$ to laminin. J Biol Chem. 1997; 272: 2143 .

28. Nuell M], Stewart DA, et al. Prohibirin, an evolutionarily conserved intracellular protein that blacks DNA synthesis in normal fibroblasts and Hel cells. Mol Cell Biol, 1991; 11: 1372.

29. Fusaro G, Dasgupta. $P$, et al. Prohibitin induces the transcriprional activity of $\mathrm{p}^{53}$ and is exported from the nucleus upon apoptotic signaling. I Biol Chem. 2003; 278: 47853.

30. Nijtmans LG, de Jong I, at. Prohibitins act as a metrbrane-bound chaperone for the stabilization of mitochondrial proteins. Embo ]. 2000; 19:2444.

31. Fong LY, Fidanza V, at avir-Torre-like syndrome in Fhit-deficient mice Proc Natl Acad Sci US A. 2000; $97: 4742$.

32. Zanesi N, Fidanza V, ot al. The tumor spectrum in FHIT-deficient mice. Proc Nad Acad Sci U SA. 2001; 98: 10250 .

33. Manjeshwar S, Branam DE, ef al. Tumor suppression by the prohibitin gene 3'untranslated region RNA in human breast cancer. Cancer Res. 2003; 63: 5251 .

34. Edmondson RD, Vondriska TM, ef al. Protein kinase C epsilon signaling complexes include metabolism- and transcription/translation-related proteins: complimentaty separation techniques with LC/MS/MS. Mol Cell Proteomics. 2002; 1: 421.

35. Cai YC, Bullard $\mathrm{JM}$, et al. Interaction of mitochondrial elongation factor 'Tu with aminoacyltRNA and elongation factor Ts. I Biol Chem. 2000; 275: 20308.

36. Shnyreva M, Schullery DS, et al Interaction of two multifunctional proteins. Heterogeneous nuclear ribonucleoprotein $K$ and $Y$-box-binding protein. J Biol Chem. 2000; 275: 15498.

37. Mataj IW, Englmeier L. Nucleocytoplasmic transport: the soluble phase. Annu Rev Biochem. $1098 ; 67: 265$.

38. Ostareck DH, Ostareck-Lederet A, at al. Lipoxygenase mRNA silencing in crythroid differentiation: The 3 UTR regulatory complex controls 605 ribosomal subunit joining. Cell. 2001; 104: 281.

39. Knowlton AA. The role of heat shock proteins in the heart. J Mol Cell Cardol. 1995; 27: 121.

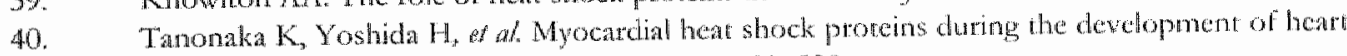
failure. Biochem Biophys Res Commun. 2001; 283 : 520.

41. Knowhton $A A_{\text {, }}$ Kapadia $S$, al. Differential expression of that shock protcins in nomal and failing human hearts. I Mol Cell Cardiol. 1998; 30: 811.

42. Scheler $\mathrm{C}, \mathrm{LI} \mathrm{XP}$, at Comparison of two dimensional electrophoresis patterns of heat shock protein Hep27 species in normal and cardiomyopathic hearts. Electrophotesis. 19\%; $20: 3623$.

43. Marrin JL, Mestril $R$, al small heat shock proteins and protection against ischemic injury in catdiac myocytes, Circulation. 1997; $96: 4343$.

44. Vander Heide RS. Increased expression of HSP27 protects canine myocytes from simulated ischemia-reperfusion injury. Am J Physiol Heart Circ Physiol. 2002; 282: H935.

45. Rembold CM, O'Connor $M$, of al. Selected contribution: HSP2O phosphorylation in nitroglycerin- and forskolin-induced sustained reductions in swine carotid medin trone. I Appl Physiol. 2001; $91: 1460$. 
Chapters

46. Chui $\mathrm{G}, \mathrm{Eg}$ ginaczy $\mathrm{GF}$, af ahosphoproteome analysis of cardiomyocytes subjected to betaadrenerge stimulation: identification and characterization of a cardiac heat shock protein 220 . Circ Res 2004; 5 : 184 .

47. Fan $G C, C h u, G$, et at. Small heat-shock protein Hsp20 phosphorylarion inhibits beta-agonistinduced cardiac apoptosis. Cire Res. 2004; 94: 1474.

48. Lameris TW, de Zeeuw $\mathrm{S}$, of at. Time course and mechanism of myocardial catecholamine release duing transient ischemia in vivo. Circulation. $2000 ; 101: 2645$.

49. Mannisto PT, Katkkola S. Carechol-O-nethyltransferase (COMT): biochemistry, molecular biology, pharmacology, and clinical efficacy of the new selective COMT inhibitors. Pharmacol Rev 1999; 51: 593.

50. Ball P, Knuppen R. Catecholoestrogens (2-and 4-hydroxyoestrogens): chemistry, biogenesis, metabolism, occurrence and physiological significance. Acta Endocrinol Suppl (Copenh). 1980; 232: 1

51. Dxela $P$, Kalvenas $A$, et al. The effect of aderylate kinase activity on the rate and efficiency of enetgy transport from mitochondria to hexokinase. Biochem Int. 1985; 10:259.

52. Dzeja PP, Pucar D, at al. Reduced activiry of enzymes coupling ATP-generating with ATPconsuming processes in the falling myocardium. Mol Cell Biochem. 1999; 201: 33 .

53. Puçar D, Janssen E, ef at. Compromised energetics in the adenylate kinase AK1 gene knockout heatt under metabolic stress. I Biol Chem. 2000; 275: 41424.

54. Carrasco AJ, Dzeja PP, ot al. Adenylate kinase phosphotransfer communicates cellular energetic signals to ATP-bensiuve potassium channels. Proc Natl Acad Sci U S A. 2001; 98: 7623.

55. Pucar D, Bast $\mathrm{P}$, of al. Adenylate kinase AK1 knockout heart: energetics and functional performance under ischemini-reperfusion. Am J Physiol Heart Circ Physiol. 2002; $283 ; \mathbb{H}_{776 .}$ 


\title{
Chapter 6
}

Lack of effect of 7-monohydroxyethylrutoside on cardiac protein expression in an in vivo mouse model of myocardial ischaemia-reperfusion as assessed by 2-D gel electrophoresis

\author{
Tijl De Celle ${ }^{1}$, Bart Devreese ${ }^{2}$, Jozef Van Beeumen ${ }^{2}$, \\ Aalt Bast ${ }^{1}$, Jos F. M. Smits', Ben J.A. Janssen ${ }^{1}$
}

Departments of Pharmacology \& Toxicology', Cardiovascular Research Institute Maastricht, Universiteit Maastricht, The Netherlands Laboratory of Protein Biochemistry and Protein Engineering ${ }^{2}$, Universiteit Gent, Belgium 
- Chapter 6

\begin{abstract}
Previously we showed that the antioxidant monoHER protects in an in wo mouse model of cardiac ischaemia-reperfusion when administered intraperitoneally (i.p.) one hour before ischaemia but it did not have a protective action when applied intravenously five min before reperfusion.

To explain this discrepancy we hypothesized that monoHER has an influence on a signal transduction pathway that might be associated to its protective mechanism of action.

Therefore we used a technique of 2-D gel electrophoresis combined with mass spectrometry in order to find related changes in protein expression or posttranslational modifications of proteins.

Ischaemia was maintained for $30 \mathrm{~min}$ by ligation of the left anterior descending coronary artery. MonoHER (500 $\mathrm{mg} / \mathrm{kg}$ ) or saline was administered i.p. one hour before ischaemia. Reperfusion was allowed for three hours and the area at risk of the left ventricle was processed for 2-D gel electrophoresis.

In total twelve protein spots changed significantly in expression level after IR. Pretteatment with monoHER did not alter this protein expression profile. Ten of the twelve protein spots could be identified by mass spectrometry. In both monoHERtreated and non-treated mice these were: heat shock protein-20 and heat shock protein-27, heterogeneous nuclear ribonucleoprotein $\mathrm{K}$, pyruvate dehydrogenase E1$\beta$, annexin A3 (at 2 spot locations), dual specificity phosphatase-3, catechol-Omethyltransferase, and adenylate kinase 1 (at 2 spot locations).

We conclude that the strong and sustained cardioprotective effects of monoHER as evidenced on a histological and functional level were not associated with detectable carly changes in the proteome. Whether the protective effects of monoHER during IR are related to alterations in expression level or post-translational modifications of low abundance proteins or proteins at specific subcellular locations needs further tesearch.
\end{abstract}


Eiffects of monolHR on cardiac protein expression -

\section{Introduction}

Current treatment of myocardial infarction is directed at the restoration of coronary blood flow to the ischaemic region. However, during revascularization, the heart undergoes further damage which, to a large extent, is due to the generation of reactive oxygen species (ROS) [1].

In a previous study we demonstrated that the antioxidant monoHER has sustained cardioprotective effects in an in wo mouse model of cardiac ischaemiareperfusion when administered i.p. one hour before ischaemia [2]. MonoHER significantly reduced myocardial neutrophil influx and infatct size and strongly attenuated IR induced deterioration of cardiac contractility [2]. In a subsequent study we demonstrated that monoHER does, however, not exhibit these cardioprotective effects when administered i.v. five min before reperfusion, a time point more relevant for extrapolation to a clinical situation (chapter 4).

This was however not expected, based on its pharmacokinetic properties.

Among the explanations for the lack of a clear pharmacodynamic effect of monoHER in this setting are the potential restriction in myocardial uptake in conditions of cardiac ischaemia-reperfusion or the necessity of formation of metabolites of monoHER (chapter 4).

In addition we hypothesized that cardioprotection is not related to the antioxidant effect only but also to an unknown side-effect of monoHER (or one of its metabolites) on proteins influencing ischaemia-reperfusion injury (chapter 4).

Specifically, monoHER might interfere with a characteristic signal transduction pathway, critically involved in the determination of cellular fate, injury, death or adaptation during ischaemia. In relation to this, the time point of monoHER administration, i.e. before ischaemia versus before reperfusion, might be very crucial.

Proteomic techniques allow the identification of proteins that undergo changes in. expression level, phosphorylation, oxidation-reduction or other post-translational modifications during in wivo cardiac ischaemia-reperfusion. For instance, Schwertz ef al. applied ptoteomics to search for protein changes induced by the synthetic serine protease inhibitor FUT 175, an inhibitor of the complement pathway, in an in wivo rabbit model of ischaemia-reperfusion [3]. Using $2-\mathrm{D}$ gel electrophoresis they found that treatment with FUT-175 resulted in preserved myocardial protein levels of superoxide dismutase and $\alpha B$-crystallin, which suggests that this agent does not only affect the complement system, but also affects the protein expression of other cardioprotective targets.

Similatly, by using this technicue, it might be possible to find alterations in the proteome that can be related to the mechanism of action of monoHER.

Furthermore, anti-oxidants might also interfere with the production of ROS during the period of ischaemia [4-7]. Specifically, when exposed to hypoxia, cardionyocytes have been shown to increase production of ROS derived from the mitochondrial electron transport chain [8]. The general physiological consequences of hypoxic mitochondrial. ROS production are not completely understood. Mitochondrial ROS may 1) promote the stabilization and activity of hypoxia inducible factor-1a (HIF-1a) transcription factor $[9-12]$; 2) alter cardiac myocyte contractilny 18 ; 3) modulate Nat. 
$\mathrm{K}^{+}$-ATPase activity [13]; or 4) influence mitochondrial depolarization [14] and 5) mitogen-activated protein kinases [15]. These studies reveal that ROS, besides their direct detrimental effects on cellular structures, influence a variety of cellular signal transduction cascades during ischaemia. This implies that monoHER, by reducing ROS during ischaemia, may have an influence on such pathways.

Thus we hypothesize that monoHER treatment may affect the proteome during ischaemia through 2 mechanisms. Firstly through an, at the moment, unknown sideeffect of monoHER or a metabolite or secondly through an indirect effect by reducing potential infuences of $R O S$ on a signal transcluction pathway.

Consequently the goal of this study was to examine the effects of monoHER on changes in the proteome, $3 \mathrm{~h}$ after reperfusion, by using a technique of 2-D gel electrophoresis combined with mass spectrometry. We chose this early time point because we were primarily interested to find the reason for the protective effects of monoHER. Moreover, previous studies showed that by using this technique it is possible to detect early alterations in the proteome induced by $\operatorname{IR}[3,16,17]$. This approach could provide more insight in the mechanism of action of monoHER in the setting of in wo cardiac ischaemia-teperfusion.

\section{Materials and methods}

\section{Animals}

Male Swiss mice (7-9 weeks old, weighting $35-40 \mathrm{~g}$ ) were used. The animals were purchased from Charles River (Maastricht, The Netherlands) and housed as described in detail in chapter 5 . "The experimental protocol was approved by the local animal ethics committee of the Universiteit Maastricht.

\section{In vivo cardiac ischaemia-reperfasion}

Mouse hearts were subjected to a $30 \mathrm{~min}$ ischaemia and $3 \mathrm{~h}$ teperfusion procedure as described in detail in chapter 5. Four experimental groups were compared; shamsaline, sham-monot:ER, IR-saline and IR-monoHER. Before injection, monoHER (7-monohydroxyethylrutoside, molecular weight 654.6) was dissolved in $36 \mathrm{mM}$ $\mathrm{NaOH}$ in sterile water, in a final concentration of $20 \mathrm{mg} / \mathrm{ml}$ ( $\mathrm{pH}=7.9-8.1$ ). MonoHER was given i.p. in a dose of $500 \mathrm{mg} / \mathrm{kg}$, one hour before induction of ischnemia $\mid 18$. In control mice $25 \mu / \mathrm{g}, 0.9 \% \mathrm{NaCl}$ solution (same $\mathrm{pH}$ ) was also injected i.p., one hour before ischaemia.

\section{Sample preparation}

For a description: see chapter 5

\section{Tho-dingusional get electropbromesis}

For a description: see chapter 5

\section{Spot detection and analysis}

Gel images were scanned and analyzed using PDQuest 7.1 software (BioRad). The gels were ordered in the appropriate matchset and protein spots were manually 
matched according to the manufacturer's guidelines. Two different matchsets were used to compare separately the IR groups (saline and monoHER) with their respective sham group (saline and monoHER) for both the cytosolic fraction as well as the membrane fraction.

For a detailed description readers are referted to chapter 5.

\section{Statistical analysis}

A statistical comparison of the relative abundance of each matched protein spot between the IR group (saline or monoHER, both $N=6$ ) and their respective sham group (saline or monoHER, both $N=6$ ) was accomplished using a two-tailed t-test (PDQuest). A qualitative between group difference means that a spot is only present in samples from one particular group and lacking in another. Quantitative and qualitative between group differences were considered statistically significant when changes in protein expression were $\geq 1.6$ times and a $P$-value $\leq 0.05$. All values are expressed as mean $\pm \mathrm{SD}$.

In-gel digestion

For a description: see chapter 5

Protein identification-mass spectrometry

For a description: see chapter 5

\section{Results}

\section{General}

The average amount of ventricular tissue from the AAR, collected per animal was $54.0 \pm 5.8 \mathrm{mg}$ and $51.0 \pm 9.5 \mathrm{mg}$ for the IR-saline group and the IR-monolHER group, respectively. The final protein fraction per amount of tissue was $4.5 \pm 0.8 \%$ and $4.7 \pm 2.9 \%$ for the cytosolic fractions and $8.6 \pm 1.9 \%$ and $7.1 \pm 2.8 \%$ for the membrane fractions of the IR-saline and the IR-monoHER group, respectively. Typical $2-D F$ spot patterns of both the cytosolic and membrane fraction, representative for a sham and IR group are shown in figure 1. The digtised master gel was composed of a total of 24 gels in which the IR-saline and IR-monoHER group were compared with theit respective sham groups. The mean number of spots in each gel that matched with the master gel was $512 \pm 119$ for the cytosolic Fraction and $127 \pm 24$ for the membrine fraction. The reproducibility of the 2-D gels was high. The mean correlation coefficient between all gels within the matchset of the IR group (and its respective sham group) was $0.82 \pm 0.05$ (cytosolic fraction) and $0.85 \pm 0.06$ (membranc fraction).

\section{Identification of protein spots ctanged in expression lotel}

Figure 1 indicates the protein spots on the 2-DF spot pattern that significantly clianged in expression level after IR. The spot numbers in this figure refer to the numbers in table $1(1 \mathrm{~A}-1 \mathrm{C})$ which lists these protein spots and their protein identification. 


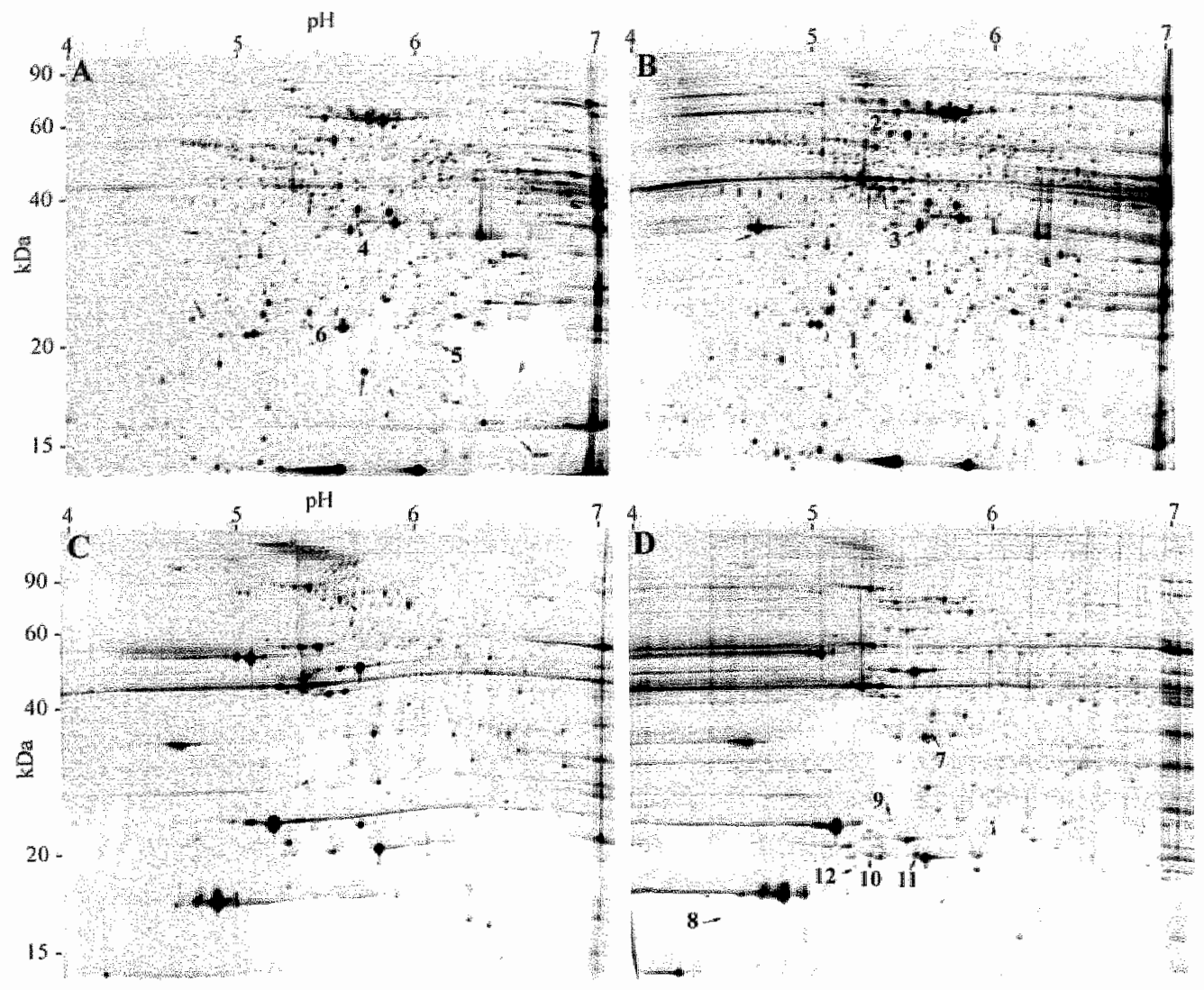

Figure 1: Sypro Rubly stained 2-DE, gels identical to the one shown in chapter 5. In this case only protein sposs displaying significant quantiative or qualitative changes in expression level ( $P \leq 0.05$ and densiry wito $\geq 1.6$ after $I R$ are depicted. These protein spots are the same in the IR, saline group and in the IR, monolHed group. Spot numbers refer to the numbers given in table l (1A-1D).

The experimental and theoretical mass and $\mathrm{pI}$ of the proteins and the density ratio (with $P$ value) of expression level after IR (saline and monoHER) compared with the respective sham group (saline and monoHER) are also listed in table 1.

After IR thete were significant changes in expression level in twelve protein spots. Ten of these protein spots $(83 \%)$ could be identified by mass spectrometry while 2 protein spots could not.

In table 1, the MASCOT score (chapter 5) of the identified peptides is given together with (parts of) the dedluced amino acid sequences. The two unidentified proteins were relatively low in abundance and probably fell, despite pooling, below the detection limit of the technique. 
Effects of monoHER on cardiac protein expressiton *

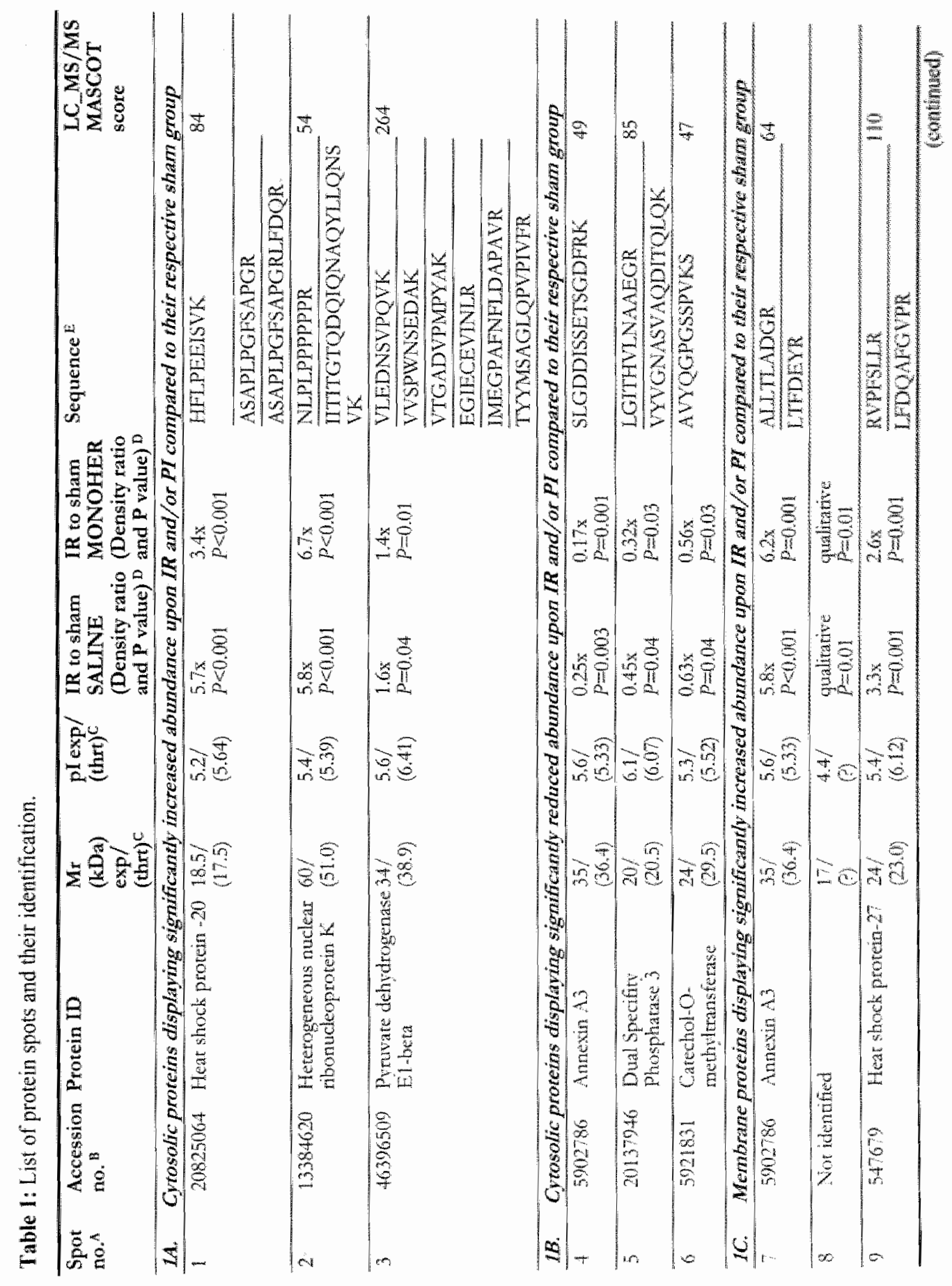


- Chapter 6

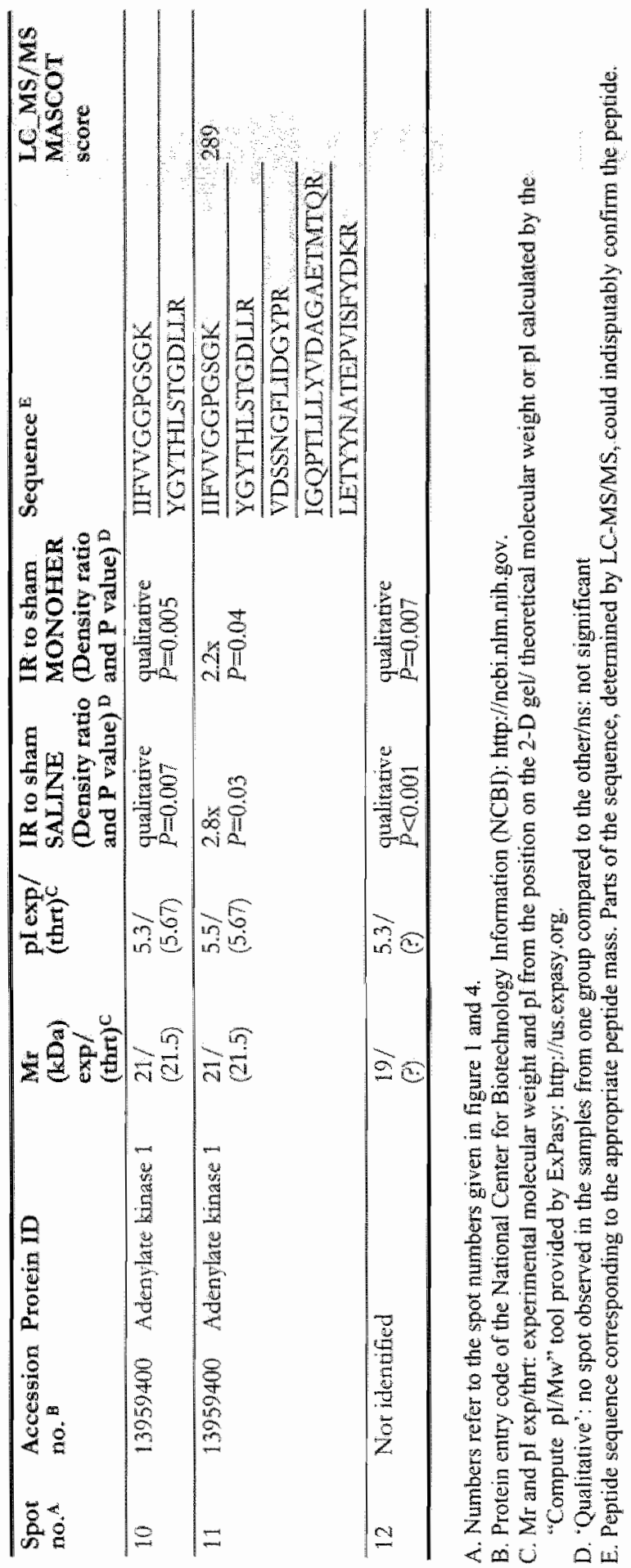


Identified proteins (or protein spots) that significanty changed in expression level after IR wete heat shock protein-20 (spot 1), heterogeneous nuclear ribonucleoprotein $\mathrm{K}$ (spot 2), pyruvate dehydrogenase E1- $\beta$ (spot 3), annexin A3 (spot 4 and spot 7), dual specificity phosphatase-3 (spot 5), catechol-O-methyltransferase (spot 6), heat shock protein-27 (spot 9) and adenylate kinase 1 (spot 10 and spot 11).

For both the cytosolic as well as the membrane fraction, protein spots that were significantly changed in expression level in the IR-saline group compared to the shamsaline group were also significantly changed in expression level in the IR-monoHER group compared to the sham-monoHER group and vice versa. In addition for both the cytosolic as well as the membrane fraction, none of the protein spots on the gels differed significantly in expression level between the IR-saline group and the IRmonoHER group.

\section{Translocation of annexin $A 3$}

Two-DE analysis showed that the quantity of annexin $A 3$ in the cytosolic fraction was 4 times lower $(P=0.003)$ in the IR-saline group than in the sham-saline group. In contrast, in the membrane fraction of the IR-saline group, the amount of annexin A3 was 5.8 times higher $(P=0.001)$ than in the sham-saline group.

The same phenomenon was observed in the monoHER groups. In the cytosolic fraction, the quantity of annexin A3 was around 6 times lower $(P=0.001)$ in the IRmonoHER group than in the sham-monoHER group. The quantity in the membrane fraction of the IR-monoHER group was around 6 times higher $(P=0.001)$ than in the sham-monoHER group.

\section{Post-translational modification of adenylate kinase-1}

Adenylate kinase-1 in the membrane fraction was significantly increased in expression level at two spot locations (spot 10 and spor 11) separated by a $\mathrm{pl}$ range of 0.27 . This phenomenon was observed in both the IR-saline and the IR-monoHER group.

\section{Discussion}

The goal of this study was to test if 7-monohydroxyethyltutoside (monoHLR) when administered i.p. one hour before ischaemia has an influence on changes in the cardiac proteome after ischaemia-reperfusion in an in wivo mouse model. In this way we hoped to gain insight into the molecular mechanism of action of monoHER during IR. However, we did not find significant differences in expression level of protein spots between the IR-saline and the IR-monoHER group. These results indicate that, contrary to expectations, the sustained protective effects of monoHLR visible on histological and functional level [2] were not detected on proteome level by using a technique of 2-D gel electrophoresis combined with mass spectrometry.

In our in wivo ischaemia-reperfusion model, twelve protein spots changed significantly in expression level. These proteins can be classified into functional groups being anticoagulant protein (annexin A3), translation- telated protein (hnRNP), heat shock proteins (HSP-20 and HSP-27), metabolism-related proteins 
(AK-1 and COMT) and miscellaneous (DSP-3). Their potential role in cardiac ischaemia-reperfusion is discussed in chapter 5 (discussion section).

Additionally, two unidentified proteins (spot 8 and spot 12) changed in expression level but could not be characterized by mass spectrometry, probably due to the fact that their abundance fell below the detection limit of the technique.

The significant decrease in abundance of annexin A3 in the cytosolic fraction and the significant increase in the membrane fraction were observed in both the IR-saline group and the IR-monoHER group. Furthermore adenylate kinase-1, a phosphotransfer catalyzing enzyme (chapter 5), was significantly increased at two spot locations in both the IR-saline and the IR-monoHER group. In addition, there were also no other protein spots on the gels specifically affected by monoHER treatment.

Possible explanations for the discrepancy between findings on histological/functional level (chapter 2) and proteome level are three-fold.

Firstly, it is possible that monoHER did not affect changes in protein expression after cardiac ischaemia-reperfusion. This is not very likely in view of the very strong protective effects of monoHER observed on histological and functional level. The proteins that were differentially expressed after catdiac ischaemia-reperfusion can be regarded as being functionally related to the imposed stimulus. Therefore it is surprising that they were not affected by the monoHER treatment, at least at the time point under investigation in the present study.

We chose to study the alterations in protein expression at 3 hours after initiation of reperfusion because we reasoned that this period was necessary for the development of significant altetations in the proteome (f.i. protein synthesis) which could give a clue on the cause of protection of monoHER. However, the present results indicate that this is obviously not the case. The study should be repeated either at an earlier time point (f.i. 20-30 min after IR) with a focus on postranslational modifications (see below) as well as at a later time point which may facilitate the identifications of other alterations in protein expression that might be influenced by monoHER.

Thirdly the technique we used in this study may not have been able to detect alterations in the proteome specifically triggered by monoHER. For example, we only analyzod proteins within a restricted isoelectric point (pI) range (between 4 and 7 ) and relatively low molecular weight (below $100 \mathrm{kDa}$. Additionally analyzing proteins within other pl and molecular weight ranges can resolve this possibility. Furthermore, despite the analyeic power of the approach we used in this study, systematic limitations of the approach at the present state of the technology must be taken into consideration. There are certain classes of proteins, such as integral transmembrane proteins, that are difficult to extract and consequently not easily visible on the gel. Other extraction procedures with agents that distupt membranes to separate these transmembrane proteins can possibly resolve this problem.

Furthermore, the analysis of post-translational modifications like protein phosphorylation and glycosylation [19,20], oxidation of proteins [21] or the detection of intermolecular protein disulfide formation [22], which might be important in signal transduction, requires a complex repertoire of additional analytical tools [23]. There are also limitations with respect to the dynamic range of proteins that can be displayed on a gel compared with the dymamic range of protein abundance within the cardiac 
cells which has been estimated to be as high as $10^{7}$ [24]. This problem increases with sample complexity because high abundant proteins muffle low abundant protem, like for example transcription factors, on the gel. Therefore the classical approach nay fail in the discovery of gene products that are major proteins of particular subcellular compartments, but are minor proteins of the whole crude homogenate.

Although we separately analyzed the cytosolic and membrane fraction, the enrichment of particular subcellular structures as for example mitochondria or nuclet and specifically analyzing their protein constituents provides the opportunity to deal with these problems.

We conclude that by using a technique of 2-D gel electrophoresis combined with mass spectrometry we did not find alterations in the proteome specitically triggered by monoHER after in viwo cardiac ischaemia-reperfusion in a mouse model. These results signify that the strong protective effects of monollER visible ar a later time point on histological and functional level were not detected on proteome level at an eatly time point by using the curtent techniques. Therefore additional sophisticated tools must be applied to search for such molecular mediators.

\section{References}

1. Flaherty JT, Weisfeldr ML. Reperfusion injury. Free Radic Biol Med. 1988; 5: 409.

2. De Celle $T$, Heeringa $P$, al sustained protective effects of 7-monohydroxyerhytutoside in an in vivo model of cardiac ischemia-reperfusion. Eur J Pharmacol. 2004; 494: 205.

3. Schwertz $H$, Jangin $T$, at. Two-dimensional analysis of myocaudial. protein expression following myocardial ischemia and reperfusion in tabbits. Proteomics. 2002; $2: 988$.

4. Vanden Hoek TL, Li C, et at. Significant levels of oxidants are generated by isolated cardiomyocytes during ischemia prior to reperfusion. J Mol Cell Cardiol. 1997, 29: 2571.

5. Becker LB. New concepts in reactive oxygen species and cardiowascular reperfusion physiology. Cardiovasc Res. 2004; $61: 461$.

6. Przyklenk $K$, Kloner RA. Effect of oxygen-deriwed free radical scavengers on infarct size following six hours of permanent coronary artery occlusions salvage of delay of myocyte necrosis? Basic Res Cardiol. 1987; 82: 146.

7. Kevin $L G$, Camara $A K$, ef al. Ischemic preconditioning alters real-time measure of $O 2$ radicals in intact hearts with ischeman and reperusion. Am I Physiol Heart Cire Physiol. 2003; 284: H566.

8. Duranteau \, Chandel NS, al al. Intracellular signaling by reactive oxygen species during hypoxia in cardiomyocytes. I Biol Chem. 1998; 273: 11619.

9. Schroedl C, McClintock DS, ef ax. Hypoxic but not anoxic stabilization of HIt alpha tequires mitochondrial reactive oxygen species. Am J Physiol lung Cell Mol Physiol. 2002, 283: 1.922.

10. Chande] NS, McClintock DS, et ad. Reactive oxygen species generated at mitrochondrat complex III stabilize hypoxia-inducible facrot-1alpha during hypoxiat a mechantsm of 02 sensing. J Biol Chem. 2000; 275: 25130 .

11. Chandel NS, Maltepe $\mathbb{E}$, of a. Mitochondrial renctive oxygen species trigger hypoxin-induced transcription. Proc Natil Acad Sci U S A. 1098; 95:11715.

12. Agani FH, Pichiule $\mathrm{P}$, ef al. The role of mitochondria in the regulation of hypoxia-inducible Factor I expression during hypoxia. I Biol Chem. 2000; 275: 35863.

13. Dada LA, Chandel NS, of al Hypoxia-induced endocytosis of Na,K-ATPase in alveolar epithelial cells is mediated by mirochondral reactive oxygen species and PKC-zeta. I Clin Irvest. 2003; 11: 1057 . 


\section{- Chapter 6}

14. Levratit J. Wwasc $H$, of all death during ischemia: relationship to mitochondriat depolatization and ROS generation. Am J Physiol Heart Curc Physiol. 2003; 284: H549.

15. Kuliz $A$, Chen $N$, at Mitochondrial ROS initiate phosphorylation of $\mathrm{p} 38$ MAP kinase during bypoxia in cardiomyocytes. Am J Physiol Lung Cell Mol Physiol. 2002; 282: L1324.

16. Sawichi $G$, Jugdure BI. Detection of regional changes in protein levels in the in wivo canine model of acute heart failure following ischemia-repertasion injury: functional proteomics studics. Proteonics. 2004; 4: 2195.

17. Sakaj J, Ishikawa $\mathrm{H}_{\text {, }}$ ef af. Proteomic analysis of rat heart in ischemia and ischemia-reperfusion using fluorescence two-dimensional difference gel electrophoresis. Proteomics. 2003; 3: 1318 .

18. van Acker $S A$, Kramer $\mathbb{K}$, af. Monohydroxyethylrutoside as protector against chronic doxorubicin-induced cardiotoxicity. Br J Pharmacol. 1995; 115: 1260.

19. Chu $G$, Egnaczyk GF, at Phosphoproteome analysis of cardiomyocytes subjected to betaadrenergic stimulation: identification and characterization of a cardiac heat shock protein $\mathrm{p}^{20}$. Circ Res. 2004; 94: 184.

20. Whelan SA, Hart GW. Proteomic approaches to analyze the dynamic relationships between aucleocytoplasmic protein glycosylation and phosphorylation. Circ Res. 2003; 93: 1047.

21. Ghezzi $P$, Bonetto V. Redox proteonics: identification of oxidatively modified proteins. Proteomics. 2003; 3: 1145 .

22. Brennan IP, Wait $R$, at at. Detection and mapping of widespread intermoleculat protein disulfide formation during catdiac oxidative stress using proteomics with diagonall electrophoresis. I Biol Chem. 2004; 279: 41352.

23. Mann $\mathrm{M}$; Ong $\mathrm{SE}$, at at. Analysis of protein phosphorylation using mass spectronetry: deciphering the phosphoproteome. Trends Biotechnol. 2002; 20: 261.

24. Gygi SP, Corthals GL, et at. Evaluation of two-dimensional gel electrophoresis-based proteome analysis technology. Proc Nat Acad Sci U S A. 2000; $97: 9390$. 
Summary and conchision.

Chapter 7

Summary and conclusions 
- Ehapter 7

\section{Summary}

The first goal of this thesis was to investigate the potential cardioprotective effects of the antioxidant 7-monohydroxyethylinutoside (monoHER) in an in jivo mouse model of cardiac ischaemia-reperfusion (IR). The second goal was to determine the early alterations in cardiac protein expression in this IR model in order to delineate the mechanisms of action of monolHER in this setting.

As the in wive mouse model of cardiac IR was the study object of this thesis we compared in chapter 2 the long-term structural and functional consequences of this myocardial infarction model to the ones induced by permanent ischaemia (PI).

The majority of studics on cardiac IR injury have focused on the short-term consequences of reperfusion. Using myocardial infarct size or neutrophil influx as parameters, the progression of cardiac tissue damage has been described in the time frame of a few hours up to one or a few days after the initiation of reperfusion. The Jong-term effects of IR injury, in terms of weeks or months, are less well examined in this in vivo mouse model. This is, however, a relevant aspect for extrapolation to the clinical setting as it may be that the outcome of interventions that are beneficial. shorty after initiation of reperfusion is different when the evaluation takes place at later stages.

In chapter 2 we showed that the long-term structural and functional consequences following cardiac IR are different from those observed after PI. Contractility of the heart was depressed for at least 2 weeks after IR, but was nearly restored after 8 weeks of IR. After cardiac IR, the gross architecture of the ventricular wall was preserved and the wound healing process was characterized by extensive calcification, minor hypertrophy and minor dilatation. In the PI model, the ischaemic area was not calcified, but completely replaced by connective tissue. In addition, the ventricular wall was severely dilated, the remaining myocardial muscle was strongly hypertrophied and loss of cardiac function was permanent.

The potential protective effects of exogenously administered antioxidants on cardiac reperfusion injury have been studied extensively. However, as described in detail in chapter 1 , the beneficial effects of antioxidant treatment in these models remain controversial and need further clarification. Moreover, most of these studies only investigated potential shott-term piotective effects after initiation of reperfusion and did not examine sustained protective effects.

In chapter 3, we evaluated the cardioprotective effects of the antioxidant flavonoid monoHER in the in wo mouse model of cardiac IR up till two weeks after IR, at time point when wound healing processes are completed. There were three indications that monoHER might act protective against injury in this model. These were: $1 /$ strong radical scavenging and iron chelating properties of monoHER; $2 /$ proven protective effects of monoHER against doxorubicin-induced cardiotoxicity in win in mice; $3 / \mathrm{in}$ wim anti-inflammatory effects of monoHER by reducing neutrophil adhesion.

We showed that monoHER exerted a sustained cardioprotective effect in this in wo mouse model of cardiac IR. This was demonstrated at two time points ( 24 hours and 
2 weeks after IR) by the fact that monoHER significantly teduced myocardial neutrophil influx, infarct size and maintenance of cardiac contractile responses when the heart was stressed with dobutamine and volume loading.

To our knowledge, this was the first time that sustained protective effects (in terms of weeks) of a flavonoid are demonstrated in this cardiac IR model.

The timing, toute and dose of monoHER administration in this study (chapter 3) were based on earlier in wivo mouse studies in which monoHER protected against doxorubicin-induced cardiotoxicity $[1,2]$. In these studies monoHER was administered intraperitoneally one hour before doxorubicin injection.

Obviously, to minimize myocardial damage evoked by chemotherapeutic agents such as doxorubicin it is logical to pre-treat patients with radical scavenging agents such as monoHER. However, when preventing "reperfusion injury", administering an antioxidant as a protective drug before the onset of ischaemia, has less clinical relevance. In addition, recent pharmacokinetic data in mice revealed that following intravenous injection of monoHER maximal myocardial tissue concentrations of the drug were reached almost immediately [3].

Therefore, in chapter 4 we set out a study to test if monoHER would also be effective when administered intravenously five minutes before reperfusion. Administration of monoHER at this time point neither affected the influx of meutrophils in the injured tissue nor improved stimulated cardiac contractility, 24 hours after reperfasion.

Thus monoHER protects in an in vino mouse model of cardiac IR when administered intraperitoneally one hour before ischaemia but lacks these properties when applied intravenously five minutes before reperfusion.

This discrepancy in results (between chapter 3 and 4 ) indicates that the time point of monoHER administration is very crucial to obtain cardioprotective effects.

Among the explanations for the lack of a clear pharmacodynamic effect of monoHER in the latter study (chapter 4) are: 1) the potential restriction in myocardial uptake of monoHER in conditions of cardiac $[R ; 2)$ the necessity of formation of active metabolites of monoHER; and 3) the possibility that cardioprotective effects are, directly or otherwise indirectly via antioxidant effects, due to interference of monoHER with specific signal transduction pathways during the ischaemic period. Such signal transduction pathways might be associated to the protective mechanism of action of monoHER. As signalling pathways consist of proteins, it is essential to study changes in protein expression or post-translational modifications of proteins to verify this hypothesis.

To search for those, two sets of proteomic studies were performed in which we used a technique of 2-DE combined with mass spectrometry (MS). We studied carly (210 $\mathrm{min}$ ) changes in protein expression because we were primarily interested in finding the reason for the protective effects of monoHER. In addition we were interested in identifying potential new targets for cardioprotection that are beneficial in the first few hours of myocardial infarction. Previous studies showed that by using this technique 
- Chapter 7

of $2 \mathrm{DE}$ and MS it is possible to detect early alterations in the proteome induced by cardiac IR $[4-6]$.

In chapter 5 we compared protein density changes in the area at risk of the mouse heart following in wiwo PI and IR. We analyzed cytosolic as well as membrane fractions and found a total of thirty-two protein spots (out of about 600 matched spots) that were differentially expressed. With this technique we were able to find twenty protein spots that were changed in expression level after PI alone, four protein spots that were changed in expression level after IR alone, and eight spots that changed commonly in both models. The results of this study are therefore a source for further studies in which the specific functional relevance of these proteins in models of myocardial infarction can be investigated.

Identified proteins (by MS) could be classified in seven functional groups being the $1 /$ anticoagulant proteins (Annexin A3 and Annexin A5), 2/ structural proteins (cardiac troponin $T, \alpha$-tropomyosin and $\alpha$-myosin heavy chain), $3 /$ inflammatory-related proteins (serum amyloid P-component precursor); 4 / transcription- and translationtrelated proteins (Prohibitin and Histidine Triad Nucleotide Binding Protein 1, Heterogeneous Nuclear Ribonucleoprotein $\mathbb{K}$ ), 5/ heat shock proteins (Heat Shock Protein 20\&27), 6/ metabolism-related proteins (Adenylate Kinase 1, Pyruvate Dehydrogenase E1 Component Beta Subunir, Catechol O-Methyltransferase) and 7/ miscellaneous (dual specificity phosphatase, similar to Zn-alcohol dehydrogenase).

A remarkable finding was the IR specific translocation of annexins (A3 and A5) from the cytosolic to the membrane compartment, a phenomenon that was verified by Western blotting. The fact that this phenomenon occurred after reperfusion only and not after permanent ischaemia suggests a specific related mechanism that triggers translocation of annexins to the membrane fraction during reperfusion. These findings may give new impetus for further studies in relation to annexins and early diagnosis of reperfusion injury in connection with earlier studies from our laboratory [7].

Four proteins were changed in expression level at multiple spot locations, characterized by a difference in isoelectric point. In the case of cardiac troponin $T$ and HSP 20 , these changes were also dependent on the model. In addition, one spot for the proteins adenylate kinase 1, cardiac troponin $T$ and HSP-20 was uniquely present in the IR and/or PI and not in the respective sham groups. Further research is necessary to detemine the character of possible pathology related post-translational modifications.

A total of twelve protein spots changed significantly in expression level after cardiac IR (chapter 6). Ten of these protein spots could be characterized by MS. These were: Heat Shock Protein-20 and Heat Shock Protein 27, Heterogeneous Nuclear Ribonucleoprotein K, Pyruvate Dehydrogenase E1- $\beta$, Annexin A3 at 2 spot locations), Dual Specificity Phosphatase-3, Catechol-O-Methyltransferase, and Adenylate Kinase 1 (at 2 spot locations).

Intraperitoneal administration of monoHER, one hour before ischaemin, did not alter this protein expression profile related to cardiac IR. This means that the proven cardioprotective effects of monoHER as evidenced at a later time point on 
histological and functional level were not detected on proteome level at an early time point by using the current techniques.

The disctepancy between these two studies in chapters 3 and 6 may be explained by the possibility: $1 /$ that monoHER did not affect changes in protein expression after cardiac IR; $2 /$ this time point was not relevant to detect alterations caused by monolHER; 3 / the technique we used in this study may not have been able to detect alterations in the proteome specifically triggered by monoHER.

\section{Conclusions and implications}

\section{The discreang in ontowe with antioxidant treatment related to ardiac IR}

As summarized in the general introduction to this thesis, numerous in witro and in wo studies have examined the role of antioxidant enzymes and less specific antioxidant interventions in reducing cardiac IR injury. The results of these studies are very conflicting since the number of studies in which protective effects were proven was comparable to the number that could not. Furthermore, it is reasonable to assume that numerous studies have been performed, that did not reach the stage of publication, because protective effects of the antioxidant under investigation was disputable or even could not be proven under certain conditions.

Although research on this topic started aiready in the early eighties, a clear explanation for this discrepancy is, up to now, not known. Among the experimental variables that have been postulated to explain these conflicting results are: 1/ animal species; $2 /$ general features of the experimental model (e.g. anaesthetized or awake model, openor closed-chest model); 3 / the presence or absence of critical stenosis; $4 /$ duration of ischaemia; 5/ duration of reperfusion; $6 /$ pharmacokinetic considerations; $7 /$ methodology to quantify infarct size; and 8/ inclusion or omission of measurements to control for baseline predictors of infarct size (e.g. collateral blood flow). However, up to now, there is no study available in literature that really proved that one of these factors or a combination of them is the cause for this discrepancy.

Studies in transgenic mice with altered levels of antioxidant enzymes consistently yield results in support of a detrimental tole for reactive oxygen species (ROS) in experimental myocardial IR injury (chapter 1). This means that the lack of effect of these exogenous antioxidants may be (in part) due to a restricted access to the sites of ROS generation. As the capacity of an antioxidant to gain entry to the target tissue and cells and the relevant ROS-producing intracellular compartments or sites is an important condition, this ability needs to be verified. It will not be surprising if therapies fail if they do not successfully enter these compartments.

\section{Pbarmacokinetin aspects (rime point of delinevy)}

In addition to this explanation, our study with monoHER revealed that the time point of administration of the antioxidant, to act protective, might be very crucial. MonofER exerted protective effects when it was administrated one hour before cardiac ischaemia. In contrast, no (protective) effect was found when it was applied intravenously right before reperfusion. This phenomenon has been observed also in. the doxorubicin mouse model. MonoHER protected against the cardiotoxicity of 
doxorubicin when it was administered one hour before doworubicin treatment but not when it was applied five minutes before doxorubicin treatment (unpublished observation, Prof. Aalt Bast). The data suggest that this time-dependency may be a specific characteristic of monoHER. Studies with superoxide dismutase [8] and a glutathione analogue [9] in dogs, as well as an $\alpha$-tocopherol analogue in rats [10] and melatonin in mice [11] demonstrated that the time point of antioxidant administration did not influence the protective capacity of these antioxidants in in wivo models of experimental cardiac IR. In addition, studies in which the time point of administration of the antioxidant was shown to be crucial for its protective effect are not available in literature. This means that the observation that the efficacy of antioxidant therapy is dependent on the time point of administration is not a general concept. Further research is thenefore necessary to determine this specific mechanism of action of monoHER.

The dominant concept of antioxidant therapy during cardiac IR is that the antioxidant agent reduces the detrimental effects of oxidative stress specifically during the initial phase of reperfusion by scavenging ROS [9, 12]. Recent pharmacokinetic studies with monoHER showed that the peak concentration of monoHER in heart tissue of mice was reached almost immediately after intravenous administration [3]. This implies that also in our current cardiac IR model the highest cardiac tissue levels of monoHER, when administered intravenously, right before reperfusion, are reached very early (within one minute) after the initiation of reperfusion.

Since this corresponds with the phase at which the production of ROS is the highest $[9,13]$, it was very unexpected that monoHER treatment lacked any beneficial effects when administered right before reperfusion. At the moment we do not have a clear explanation for this. Analyzing the pharmacokinetics of monoHER specifically in our cardiac IR model and determining the correlation between cardiac tissue levels of monoHIER and ROS during teperfusion gives the opportunity to test if the dominant concept (sec above) applies for monoHER tor. If this is not the case, a logic explanation may be that the antioxidant monoHER protects against detrimental effects during the period of ischaemia and not during the initial phase of reperfusion. In this case, it is also evident that there are doubts about the truth of this dominant concept that ROS act detrimental initially after reperfusion (see above).

Despite the dominant concept (ROS are produced primarily with the reintroduction of oxygen following reperfusion), several investigators have observed ROS generation during ischaemia [14]. In addition, the fact that our studies showed that monoHER acts protective when applied before ischaemia but not when applied right before reperfusion also indirectly indicate possible detrimental effects of ROS during the experimental ischaemic phase. In our view it is therefore essential to further determine to which extent and at which stage ROS act detrimental during cardiac IR injury in order to deliver the agents in a time-sensitive fashion.

\section{Clinitat insphations}

Severall clinical studies have evaluated the influence of antioxidants alone or in various combinations on IR injury in patients undergoing reperfusion therapy after myocardial infarction. Despite many reseatch efforts and a wide availability of antioxidant agents, 
there is at the moment no clinical evidence for the routine use of antroxidants in the clinical setting of cardiac IR. With respect to the clinical relevance it is evident that antioxidants ate administered right before reperfusion therapy. In relation to our findings with monoHER this pleads in favour of a more thorough and critical analysis of a specific antioxidant at several time points of administration in an experimental setting before specific clinical trials should be done. However, the fact that some antioxidants act protective in animal models when applied right before or during reperfusion and not in a clinical setting of cardiac IR makes an explanation even more complex. For example the free radical scavenger recombinant h-SOD when administered before [12] or at the moment of reperfusion [15] acted protective in an wivo dog model of cardiac IR but not in patients who underwent PTCA [16].

Myocardial infarction related to ischaemia-reperfusion is not a homogenous insult as shown by the patchy distribution of granulation and scar tissue. It is possible that some antioxidant compounds have failed because they protect the most affected regions of the area at risk but also contributed to additional injury in the adjoining tissue, as the border zones. This nearby tissue may loose preconditioning effects by the (non-specific) addition of antioxidants that scavenge ROS and these antioxidants are therefore interfering in adaptive natural cardioprotection.

\section{Pharmacodynamic aspects}

In our opinion it is necessary to define in mote detail the patho-mechanism specifically related to cardiac repefusion injury and to determine the influence of ROS and antioxidants on this mechanism. This underlines the need for studies in which the analysis of patho-mechanisms of permanent ischaemia and IR is compared next to each other in one study in order to determine targets specitically related to reperfusion injury.

The comparison of the effects of cardiac IR and permanent ischaemia (PI) on the proteome can provide a first view at this mechanism. Proteomic studies of human heart tissue are, however, complicated by factors such as small size of sample, availability, disease state, tissue heterogeneity, genetic variability, medical history, and therapeutic interventions [17].

Our proteomic study was set-up in order to resolve part of this mechanism of action of monoHER in an in wo mouse model of cardiac $I R$.

Our study demonstrates that in viwo mouse myocardial infarction models are suitable to study in wiwo changes in the proteome early after induction of PI or IR.

We were able to identify proteins that were changed in expression level specifically after IR or PI and proteins that were commonly changed in level in both models.

Three proteins, Annexin A3\&A5 and dual specificity phosphatase were significantly changed in expression level after cardiac IR but not after PI. This means that the changes in expression level of these proteins are specifically triggered by the process of cardiac $\mathbb{I R}$. Their functional significance needs to be investigated in ordet to determine their impact on IR injury or the contribution to its mechanism.

Twenty protein spots were significantly changed in expression level after Pl alone and are therefore potential targets for further study specifically on ischaemic injury. 
However, we showed that the infarct size is almost 4 times greater after cardiac PI compared to IR (chapter 2). This means that the affected area is possibly bigger after PI and alterations in proteome are consequently easier to intercept. To overcome this problem, more specific techniques, as for instance laser capture micro-dissection, will be necessary to select mote specifically the affected area for analysis. This is mainly true for the $\mathrm{IR}$ model as the infarct is patchy distributed in the area at risk.

In addition it is difficult to distinguish between detrimental effects triggered by the ischaemic period, the reperfusion period of the combination ischaemia and reperfusion. Studying the changes in protein expression specifically triggered by IR with different time-combinations of ischaemia and reperfusion can reduce part of this problem.

The protective effects of monoHER visible on histological and functional level were not detected on proteome level by using a technique of $2-\mathrm{DE}$ combined with mass spectrometry.

This implies that more specific tools as for example subcellular proteomics (chapter 1), the detection of oxidation of proteins [18] or of intermolecular protein disulfide formation [19] are necessary to determine changes in the proteome due to oxidative stress in order to determine parts of the mechanism of IR injury.

We conclude that the specific alterations in protein expression that take place after cardiac ischaemia-reperfusion and permanent ischaemia may stimulate the search for new tools to resolve specific mechanisms and to find specific targets for therapy for these pathologies.

\section{References}

1. van Acker FA, wan Acker SA, of al. 7 -monohydroxyethylfutoside protects against chronic doxorubicin-induced cardiotoxicity when administered only once per week. Clin Cancer Res. 2000; 6: 1337 .

2. van Acker SA, Kramer $K$, et at. Monohydroxyethylrutoside as protector against chronic doxormbicin-induced cardiotoxicity. Br J Phatmacol. 1995; 115: 1260.

3. Abou El Hassan MA, Kedde MA of al Bioavailability and pharmacokinetics of the cardioprotecting flavonoid 7-monohydroxyethylrutoside in mice. Cancer Chemother Pharmacol, 2003; $52: 371$.

4. Sakai J, Jshikawn $\mathrm{H}$, of a Proteomic analysis of tat heart in ischemin and ischemia-reperfusion using fluorescence two-dimensional difference gel electrophoresis. Proteomics. 2003; 3: 1318.

5. Sawicki 6 , Jugdute B1. Detection of regional changes in protein levels in the in vivo canine model of acute heart tailure following ischemia-reperfusion injury: functional proteomics studies. Proteomics. 2004: 4: 2195.

6. Sclawertz H, Langin 'T' af al. Two-dimensional analysis of myocardial protein expression following myocardial ischemia and reperfusion in rabbits. Proteomics. 2002; 2: 988.

7. Dumont $\mathrm{EA}$, Reutelingsperger $\mathrm{CP}$, ef at Real-time imaging of apoptotic cell-membrane changes at the single-cell level in the beating murine heart. Nat Med. 2001; 7:1352.

8. Tamma $Y$, Chi LG, ef al. Superoxide dismutase conjugated to polyethylene glycol provides sustained protection against myocardial ischemia/teperfusion injury in canine heart. Circ Res. $1988 ; 63: 944$. 
9. Bolli R, Jeroudi MO, a. Marked reduction of free radical generation and contractile dysfunction by antioxidant therapy begun at the time of reperfusion. Evidence that moendal "stunning" is a manifestation of reperfusion injury Circ Res, 1989,65:607.

10. Petty MA, Grisax JM, ot at. Protective effects of an alphyltacopherol analogue aganst myocardial reperfusion injury in rats. Fur J Phamncol 1992,210.85.

11. Chen $Z$, Chua $C C$, at al. Protective effect of melatonin on myocardial infarction Am I Plyysiol Heart Circ Physiol. 2003; 284: H1618.

12. Jolly $\mathrm{SR}$, Kane WJ, et al Canine myocardial teperfusion injury. Tts teduction by the combined administration of superoxide dismutase and catalase Circ Res. 1984; $54: 277$.

13. Mirsos SE, Fantone JC at a Canine myocardial reperfusion njury protection by a free thalical scavenger, $\mathrm{N}$-2-mercaptopropionyl glycine. J Cardiowasc Phamacol 1986; 8; 978.

14. Becker LB. New concepts in reactive oxygen species and cardiovascular reperfusion physiology. Cardiovasc Res. 2004; 61: 461 .

15. Ambrosio $G$, Becker $L C$, al Reduction in experimental infarct size by tecombinant human superoxide dismutase; insights into the pathophysiology of reperfusion injury Curculation. 1986; 74: 1424.

16. Flaherty JT, Pitt B, at al. Recombinant human superoxide dismatase (h-SOD) fails to improve recovery of ventricular function in pationts undergoing coronary angioplasty for acote myocatdial infarction. Circulation. 1994; 89: 1982.

17. McGregor E, Dunn MJ. Proteomics of heart disease. Hium Mol Genet. 2003; 12 Spec No 2: R135.

18. Ghezzi P, Bonetro V. Redox proteomics: identification of oxidatively modified proteins. Proteomics. 2003; 3: 1145.

19. Brennan JP, Wait $\mathrm{R}$, ef al. Detection and mapping of widespreat intermolecular protein disulfide formation during cardiac oxidative stress using proteomics with diagonal electrophoresis. J Biol Chem. 2004; 279: 41352. 


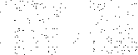

$-\quad$
$-\quad$ 
Chapter 7

\section{Samenvatting}


Het eerste doel van dit proefschrift was om in een in wivo muizenmodel van cardiale ischemie-teperfusie (IR) na te gaan of de antioxidante stof 7 monohydroxyethylrutoside (monoHER) een beschermende werking heeft op het muizenhart. On het werkingsmechanisme van monoHER in dit IR model te analyseren, was het tweede doel de vroege weranderingen in proteineëxpressie in het muizenhart te onderzoeken bij dit model.

Het in wo muixenmodel van cardiale IR is het studieobject van deze thesis. Daarom vergeleken wij in hoofdstuk 2 de structurele en functionele effecten van cardiale IR op het muizenhart, met deze geinduceerd door permanente ischemie (PI).

Het merendeel wan de studies met betrekking tot dit model hebben het accent gelegd op de kortetermijneffecten van reperfusie. Door gebruik te maken van parameters alls oppervlakte van het infarct en neutrofielinfiltratie werd de vooruitgang van weefselschade beschreven binnen een tijdsbestek wan een paar uren tot een paar dagen na de inductie van reperfusie. De langetermijneffecten van IR-schade, in termen van weken of masnden, werden slechts in beperkt mate onderzocht in dit in wo muizenmodel. Echter, voor extrapolatie naar een klinische situatie is het nagaan van de effecten op lange termijn zeer relevant, aangezien deze kunnen verschillen van de effecten op kotte termijn.

In hoofdstuk 2 toonden we aan dat de structurele en functionelle effecten van cardiale IR op lange termijn, verschillen van deze bij cardiale PI. De contractiliteit van het hart was anzienlijk verminderd gedurende minstens 2 weken na IR, maar was min of meer hersteld 8 weken na IR. Na cardiale IR was de algemene architectuur van de wand van het linker ventrikel intact gebleven en was het proces van wondheling gekatakteriseerd door uitgebreide callcificatie, beperkte hypertrofie en beperkte dilatatie.

In het PI model was de ischemische zone niet gecalcificeerd, maar volledig vervangen door bindweersel. Bijkomend was het linker" ventrikel, ten gevolge van PI, sterk gedilateerd, het resterende spierweetsel sterk gehypertrofteerd en het verlies van de hartfunctie permanent.

Het potentieel beschermend effect van exogeen toegediende antioxidanten op cardiale reperfusieschade zijn al uitgebreid bestudeetd. Echter, zoals in detail beschreven in hoofdstuk 1 , blijken de effecten van behandeling met antioxidanten in deze modellen controversieel en moeten deze verder uitgeklaverd worden. Bovendien, de meeste van deze studies hebben enkel kortetermijneffecten en geen langetermijneffecten van IR bestudeerd.

In hoofdstuk 3 hebben we de beschemende werking van de antioxidante stof monoHER op het hart, in het in wwo muzenmodel van cardiale $\mathbb{R R}$, geèvalueerd. Dit tot 2 weken na IR, het tijdstip warop het wondhelingsproces verwolledigd is.

Ex zijn drie tedenen waarom we voorop stelden dat monoHER mogelijk beschermend werkt in dit cardiaal IR model. Deze zijn: 1/ sterke radical opvangende en ijzerbindende eigenschappen van monoHER; 2 / de aangetoonde beschermende werking van monoHER tegen de cardiotoxiciteit geinduceerd door doxorubicine; 3 / in vim anti-inflammatoire effecten van monoHER doot een vermindering van de neutrofieladhesie. 
We toonden an dat monoHER blijrende beschemende effecten heeft in dit wh muizenmodel van cardiale IR. We hebben op 2 tijdstippen ( 24 wur en 2 weken aa IR) aangetoond dat een behandeling met monoHER de infiltratie van neutrofielem vermindert, de oppervlakte wan het infarct reduceert en bijkomend zorgt voor een behoud van de contractiele eigenschappen van het hart bij zowel stimulatie door dobutamine als door volumebelasting.

Voor zover we weten is deze studie de cerste die blyjende beschermende effecten aantoont van cen flavonoïd in dit muizenmodel van cardiale IR.

Het tijdstip, de route van toediening en de dosis van monolER wan in deze studie (hoofdstuk 3) voor gekozen werd, zijn gebaseerd op voorgaande studies in dewelke aangetoond werd dat monoHER een beschermend effect heeft in het model van doxorubicine geinduceerde cardiotoxiciteit [1, 2]. In deze studies werd monoHER intra-peritoneal, één uur voor doxorubicine injectie, toegediend.

Om de oxidatieve schade op het hart, veroorzakt door een chemotherapeutisch middel zoals doxorubicine, te verminderen, is het logisch om patiënten vooraf te behandelen met een antioxidante stof als monoHER. Echter, om "reperfusieschade" te verminderen is het toedienen van een antioxidante stof, voór de ischemische fase, vanuit klinisch oogpunt, niet relevant. Bovendien tonen recente farmacokinetische studies in muizen an dat de maximale weefselconcentratie van monoHER bijna onmiddellijk na intraveneuze toediening bereikt wordt [3].

In hoofdstuk 4 onderzochten we daarom of monoHER tevens effectief was wanneer het intraveneus, vijf minuten vór reperfusie, toegediend werd. Toediening van monoHER beinvloedde de infiltratie van neutrofielen in het hartweefsel, noch had het een beschermend effect op de cardiale contractiliteit, 24 uur na reperfusie.

MonoHER heeft dus een beschermende werking in het in wim muizenmodel van cardiale IR wanneer het intraperitoneal, één uur vóor ischemie toegediend wordt, manr niet wanneer het intraveneus, vijf minuten vóo reperfusie toegediend wordt.

Deze discrepantie in resultaten (tussen hoofdstuk 3 en 4) toont aan dat het tijdstip van monoHER toediening zeer cruciaal is om een zijn beschermend effect te realiseren.

Mogelijke verklaringen voor het ontbreken van een farmacodynamisch effect van monoHER in deze laatste studie (hoofdstuk 4) zijn: 1/ de mogelijke beperking in de opname van monoHER door het hatweefsel in het model van cardiale TR; $2 /$ de noodzaak voor de vorming van actieve metabolieten van monoHER; en 3/ de kans dat beschermende effecten, enerzijds direct of anderzijds indirect vila antioxidante effecten, te wijten zijn aan een wisselwerking van monoHIR mor specifieke signaaltransductiecascades gedurende de periode van ischemic. Deze signaaltransductiecascades zouden kunnen geassocieerd zijn aan de beschermende werking van monoHER.

Aangezien signaaltransductiecascades opgebouwd zijn uit proteinen is het essentied $\mathrm{om}$, ten einde deze hypothese te verifieren, veranderingen in proteinecxpressie of post-translationele modificaties van proteinen te bestuderen. 
- Chapter 7

Darom werden 2 reeksen 'proteomics' studies uitgevoerd dim.v. de techniek van 2-D gelelectroforese gecombineerd met massaspectrometrie (MS) voor de karakterisatie van de proteinin.

Aangezien we in eerste instantie geinteresseerd waren in de oorzaak van de beschermende werking van monoHER, bestudeerden we vroege (na 210 minuten) veranderingen in proteineëxpressie. Bijkomend waren we geinteresseerd in het iclentificeren var potentieel onbekende "protein targets" die een invloed hebben in de vroege fase na het ontstan van een hartinfarct. Voorgaande studies van andere laboratoria toonden aari dat deze techniek in staat is om vroege veranderingen in het proteoom, geinduceerd door cardiale IR, te detecteren [4-6].

In hoofdstuk 5 vergeleken we de veranderingen in proteïnedensiteit in de 'area at risls' van het muizenhart bij in wivo PI en IR. We analyseerden zowel cytosolische als. membraanfracties en vonden een totaal van 32 proteinespots (uit ongeveer 600 "matched' spots) die differentieel tot expressie kwamen.

Met cleze techniek waren we in staat om 20 proteinespots te bepalen die enkel na PI weranderden in densiteit, 4 proteinespots die enkel na IR veranderden in densiteit en tenslotte 8 proteinespots die gemeenschappelijk in beide modellen veranderden in densiteit. De resultaten van deze studie zijn daarom een basis voor verdere studies in dewelke de specifieke functionele relevantie van deze proteinen in modellen van hartinfarct onderzocht kunnen worden.

De geïdentificeerde proteinen (door MS) kunnen worden geclassificeerd in zeven functionele groepen, met name: 1/ anticoagulante proteinen (Annexin A3\&A5), 2/ structurele proteinen (cardiac troponin ' $T, \alpha$-tropomyosin and $\alpha$-myosin heavy chain), 3/ inflammatoir-gerelateerde proteinen (serum amyloid P-component precursor), 4/ transcriptie- en translatie- getelateerde proteinen (Prohibitin and Histidine Triad Nucleotide Binding Ptotein 1, Heterogeneous Nuclear Ribonucleoprotein $\mathbb{K}$ ), 5 / heat shock proteïnen (Heat Shock Protein 20 en Heat Shock Protein 27), 6/ metabolismegerelateerde proteinen (Adenylate Kinase 1, Pyruvate Dehydrogenase E1 Component: Beta Subunit, Catechol-O-Methyltransferase) en $7 /$ overige (dual specificity phosphatase, similar to Zn-alcohol dehydrogenase).

ben opmerkelike bevinding was de translocatie van annexines (A3 en A5) van het cytosolische naar het membranaire celcompartiment, tijdens cardiale IR. Een bevinding dic tevens bevestigd werd d.m.v. 'Western blotting'. Het feit dat dit fenomeen enkel optreedt na reperfusie en niet na permanente ischemie suggereert een specifiek mechanisme dat de translocatie van annexines induceert gedurende reperfusie. Deze bevindingen zijn een bijkomende stimulans voor verdere studies in relatie tot annexines en de vroege diagnose van reperfusieschade met betrekking tot voorgande studies in ons laboratorium [7].

Viet proteinen waren op meerdere spotlocaties veranderd in expressieniveau, gekarakteriseerd door een verschil in isoelectrisch punt. In het geval van troponine $T$ en HSP-20 waren deze veranderingen ook afhankelijk van het model. Bijkomend, éen spot voor de proteinen adenylate kinase 1, troponine $T$ en HSP-20 was uniek aanwezig in de IR en/of de PI groep en niet in de respectievelijke sham groepen. Voortgezet onderzoek is nodig voor het bepalen van pathologie gerelateerde posttranslationele modificaties. 
Een totaal van 12 proteinespots veranderde in expressieniveau na cardiale IR (hoofdstuk 6). Tien van deze proteinespots konden gekatakteriseerd worden met MS. Deze waren: Heat Shock Proteine 20 en Heat Shock Proteine 27, Heterogeneous Nuclear Ribonucleoprotein K, Pyruvate Dehydrogenase E1-B, Annexine A3 (op 2 spotlocaties), Dual Specificity Phosphatase-3, Catechol-O-Methyltransferase, and Adenylate Kinase 1 (op 2 spotocaties).

De intraperitoneale toediening van monoHER, één uur vóór ischemie, had geen invloed op het profiel van proteineèxpressie getelateerd an cardiale IR. Dit betekent dat de beschermende effecten van monoHER op lange-termijn, die angetoond werden op histologisch en functioneel niveau, niet geassocicerd waren met detecteerbare vroege veranderingen in het ptoteoom, nagegaan met 2-D gel electroforese. Mogelijke verklaringen voor de discrepantie in resultaten tussen beide studies in hoofdstuk 3 en 6 zijn: 1/ monoHER heeft geen invloed op de veranderingen in proteineexpressie na catdiale IR; $2 /$ het gekozen tijdstip is niet relevant voor het detecteren van veranderingen in het proteoom verootzaakt door monoHER; 3/ de techniels die we gebruikt hebben was niet in stat om veranderingen in het proteoom, specifick veroorzakt door monoHER, an te tonen.

We concluderen dat de specifieke veranderingen in proteineexpresssie die plaatsvinden na candiale ischemie-reperfusie en permanente ischemie de zoektocht stimuleren naar middelen voor het ontrafelen van specifieke mechanismen en het vinden van specifieke 'targets' die als therapie kunnen gebruikt worden.

\section{Referenties}

1. van Acker PA, van Acket SA, at a. 7-monohydroxyethylutoside protects against chronic doxorubicin-induced cardiotoxicity when adminiscered only orke per week. Clin Cancer Ros. $2000 ; 6: 1337$.

2. van Acker SA, Kramer $K$, a al. Monohydroxyethylrutoside as protector against chronic doxorubicin induced cardiotoxicity. Be J Phinacol. 1995; 115: 1260.

3. Abou El Hassan MA, Kedde MA, of al Broavalibility and phatracolunetics of the cardioproteceng flavotoid 7-monohydroxyethylutoside in mice. Cancer Chemothen Pharmacol. $2003 ; 52: 371$.

4. Sakd J. Ishikawa $\mathrm{H}$, of al. Proteonic analgsis of rat heart in ischemiand ischemia-peperfusion vising fuotescence wo-dimensional difference gel electrophoresis. Proteonics. 2003, 3: 1318.

5. Sawicki G, Jugdut BI. Detection of fegional changes in protein leyels in the in viwo canime model of acute hear failute following ischemia-roperfusion injury: funcrional protamics studies. Proteomics. 2004: 4: 2195.

6. Schwetz $\mathrm{H}$, Langin $\mathrm{T}$, a Twodimensional analysis of myocardial protein expression followng myocardial ischema and reperfusion in mbbits. Proteomics, 2002; 2 : 988.

7. Dumont EA, Reutelingsperger $C P$, at Real-tme inagng of apoptotic cell-membrane changes at the single-cell level in the beating murine hear. Nat Med. 2001; 7: 135 . 


\section{Dankwoord}

De charme van promoveren is volhouden, lopen op de lijn tussen pressie en passie, tussen doorzetten en toegeven, tussen de juiste en de verkeetde beslissingen, tussen succes en teleurstellingen en het feit dat e daarin niet alleen staat. Tegen iedereen die ik tijdens mijn doctoraat heb mogen ervaren als een steun en hulp zal ik wel eens één of meerdere malen een 'bedankt' hebben gezegd. Weet dan dat dit oprecht en welgemeend was, ook als je je naam in de rest van dit dankwootd niet tegenkomt.

Alleteerst wil ik natuurlijk mijn promotor Prof. Jos Smits en co-promotor dr. Ben Janssen bedaniken. Jos, ik kan mij nog herinneren dat ik u in mijn eerste werkweek op Farmacologie \& Toxicologie, als pas afgestudeerde student uit België, aansprak met Professor. Onmiddellijk wees u mij terecht dat voor mij de aanspreektitel niet Professor Smits was, maar wel Jos. Deze gezellige en vriendschappelijke sfeer met u en de andete collega's heb ik tot op het einde van mijn promotieschap mogen ervaren. Ik wil u bedanken voor het vertrouwen en de kans die u mij gaf om, in overleg, aan mijn eigen onderzoekswegen te bouwen. Jos, bedankt voor alle adviezen, boeiende discussies en hulp bij oa. het schrijven van de artikels en mijn proefschrift.

Ben, mijn directe en dagelijkse begeleider. Jou heb ik mogen ervaren als een enthousiast, betrokken en inspiratievol begeleider. Met jou had ik steeds een zeer open bespreking over oa. de keuze van de te volgen onderzoeksweg, de bepaling van de beste onderzoeksstrategie en het verwoorden van de discussies bij de artikels. In mijn enthousiasme, ambitie en overtuiging kon dit overleg er dan ook soms heftig aan toe gaan. Maar, ik ben er zeker van dat we samen de juiste beslissingen genomen hebben en dat je tevreden bent met het resultaat. Hartelijk bedanlkt voor alles!

Prof. Aalt Bast, Prof. Wim van der Vigh, Prof. Jo De Mey en Prof. Harry StruijckerBoudier wil ik tevens bedanken. Aalt, dankzij u kreeg ik de kans om monoHER te testen op het model van cardiale ischemie-reperfusie, wat de basis vormde van mijn eerste artikel. Prof. van der Vijgh, bedankt voor het kritisch nalezen van het monoHER artikel. Jo, spijtig dat het model van darm ischemie-reperfusie bij de muis niet consistent was, anders was ik ervan overtuigd dat, samenwerking met $u$, geleid had tot een gemeenschappelijk artikel. Uw adviezen waren waardevol. Harry, met $u$ had ik een interessant gesprek over de post-doc mogelijkheden na mijn AIO-schap.

De leden van de beoordelingscommissie onder leiding van Prof. dr. E. Mariman, die mijn proetschrift beoordeeld hebben, wil ik hartelijk bedanken voor cle tijd die ze geinvesteerd hebben in het lezen van mijn proefschrift.

Mijn oprechte dank gaat uit naar de mensen van het dierenlab. Jacques, Agnieszka, Peter Leenders, Helma en Nicole. Van jullie heb ik de techniek geleerd om muizen en ratten op de correcte manier te opereren. Bedankt hiervoor, voor de hulp en de prettige sfeer die er meestal op het lab heerste. Peter Lijnen, Gregorio, Ger en de andere (ex-)analisten wil ik bedanken voor de hulp, de tips en de gezelligheid.

De mensen van het CPV wil ik bedanken voor het goed verzorgen van de proefdieren.

Ik wil de U(H)D-ers van Farmaco/Toxico bedanken voor de adviezen en de discussies. Rob Hermans wil ik hierbij nogmaals bedanken voor zijn doordachte adviezen en steun bij onze vele gesprekiken (meestal in de late avonduurtjes op het 
lab). Alle AIOs en post-docs wil ik tevens bedanken voor de gezellige babbel en het meeleven. Verder nog veel succes!

Els, Mia en Marielle van het secretariat Famaco/Toxico wil ik bedanken voot de onmisbare en sympathieke assistentie bij alle administratieve activiteiten.

Peter Heeringa van het laboratorium voor Experimentele Immunologie en Bart de Vries van het laboratorium voor Experimentele Heelkunde wil ik hartelijk bedanken voor hun hulp en adviezen bij mijn eerste project met monoHER. Peter, jij bracht mij in contact met dr. J. Schanstra. Joost, met een beetje meer geluk was het Marie-Curie project aanvaard geworden. Toch bedankt voor de kans die je me bood.

De mensen op het laboratorium voor Pathologie wil ik hartelijk bedanken. Hier heb ik vele weken, weekeinden, avond en zelfs nachtelijke uurtjes gesleten bij het witwoeten van de proteomics experimenten. Ik wens Prof. dr. Mat Daemen te bedanken voor het mij ter beschikking stellen van het excellente materiaal voor het uitvoeren van deze experimenten. Marjo, Sylvia en Moniek jullie hebben mij op een efficiënte manier deze techniek aangeleerd en waren steeds bereid mij hierbij te helpen. Kitty, bedankt voor het verbeteren van de Engelse schrijfstijl van mijn publicaties. Jack, bedankt voot al jouw deskundige adviezen i.v.m histologie. De analisten wil ik bedanken voor de tips.

Het Mastrichts Proteomics platform wil ik bedanken voor het ter beschikking stellen van het materiaal en de adviezen.

Prof. dr. Bart Devreese, Prof dr. Jos Van Beeumen en Frank Vanrobaeys van de Universiteit Gent wil ik bedanken voor het witvoeren van de massaspectrometrische bepalingen. Jullie deskundige adviezen bij mijn proteomics experimenten, schrijven van het artilkel en beantwoorden van de wagen van de reviewers waren essentied. Kelly Tilleman, bedankt voor het mij wegwijs maken in PDQuest en andere proteomics tips.

Ik wil mijn collega's bij Pfizer bedanken voor de kansen die ze mij bieden, voor de gezellige sfeer en voor de financiële steun voot de drukkosten van dit boekje. Bruno, bedankt voor het advies bij de lay-out en het ontwerpen van de cover van dit boekje.

Mijn paranimfen, Tom en Henny, jullie ben ik alvast wat verschuldigd nu jullie in het "uur van de waarheid" naast mij willen staan. Tom, als broer leef jij steeds met mij mec. Ik ben fier op jou als bekwame kinesitherapeut en goede vader. Henny, it hebt de Bourgondische keuken in Mastricht geintroduceerd. Jouw spaghetusaus is nog steeds mijn stokpardje.

Ik wil de mensen bedanken die mij het nawwst aan het hart liggen en war ik steeds gehoor vind. Kaat, Siebe, Emma, mijn petekind Wout, mijn meter en de andere familieleden. Wim V, Wim VV, Steve en Els, Filip, Youri, Willem en Magali, Ieo en Josian. Jan zou fier zijn! Iinda bedankt voor de steun, het geduld, de leuke momenten en zoveel meer.

Mijn ouders bedank ik voor alle kansen die ze mij gaven en die steeds mijn grootste supporters zullen zipn. Jullie hebben mij in al mijn beslissingen gesteund en mij steeds met alle mogelijke middelen geholpen. Jullie weten dat ik dat nooit zal vergeten en dat ik jullie ontzettend dankbat ben voor alles. 


\section{Curriculum vitae}

The author of this thesis was born on May 16 1974 in Asse, Belgium. He attended high school, with natural science as main subject, at the Sint-Jozefsinstituut in Ternat, Belgium from 1986 to 1992. In October 1992 he started studying Master in Physical Therapy at the Faculty of Medicine at the Free University of Brussels, Belgium. The last yeat of this study he worked on a thesis entitled: "Comparative Study of the Registration of Spine Movements Measured with a Back Tracker System and an Inclinometer" unider the supervision of Prof. dr. P. Van Roy, at the Laboratory of Experimental Anatomy. He obtained his Master degree in Physical Therapy July $5^{\text {th }}$, 1996. In October 1996 he started studying Master in Biochemistry at the Faculty of Scierice at the University of Ghent. The last year of his biochemical training he worked on a thesis entitled "Gene Characterization and Overexpression Analysis of Cytochrome b-558 of the Purple Bacterium Ectothiorbodospira vactolata", under the supervision of Prof. dr. J. Van Beeumen at the Laboratory of Protein Biochemistry and Protein Engineering. He obtained his Master degree in Biochemistry on July $7^{\text {th }}$, 1999. In November 1999 he moved to Maastricht, The Netherlands where he was a PhD. student at the Laboratory of Pharmacology \& Toxicology (head Prof. dr. J. Smits) until November 2004. During this period the work that is contained in this thesis was accomplished under the supervision of $\mathrm{dr}$. Ben Janssen and Prof. dr. Jos Smits on a project entitled "Experimental Myocardial Infarction: A Proteomics Point of View". Since April 2005 he has been working at Pfizer (in Brussels) at the Medical Department as Medical Advisor/Medinfo.

\section{List of publications}

\section{Abstrats}

Ben JA Janssen, Tijl De Celle, UIf Gerhardt, Jos FM Smits; Control of Blood Pressure and Heart Rate after Myocardial Infarction in Mice; Hypertension, 2000; 36:4 655

Ben JA Janssen, Tijl De Celle, Jos FM Smits:

Impaired Pressor Response to L-NAME in Mice with Heart Failure is due to Sympathetic Hypo responsiveness; The Faseb Journal, 2001

Tijl De Celle, Peter Leenders, Jos Smits, Ben Janssen; Effects of Fluoxetine on Cardiac Function after Myocardial Infarction in Mice; The Faseb Journal, 2001

Tijl De Celle, Peter Heeringa, Aalt Bast, Jos Smits, Ben Janssen; Effects of the Antioxidant monoHER on the Neutrophil Influx after Myocardial IschemiaReperfusion in Mice; Nederlandse Farmacologiedagen, 2002 
Tijl De Celle, Peter Heeringa, W. Matthijs Blankestein, Aalt Bast, Jos Smits, Ben Janssen; 7-monohydtoxyethylrutoside, a Semisynthetic Flavonoid, Prevents Deterioration of Cardiac Function in a Mouse Model of Myocardial IschemiaReperfusion; The Fasel Journal, 2003 and Fypertension, 2002, Vol. 40 (No 4): p 575

\section{Book cluapter}

Ben Janssen, Tijl De Celle, Jos Paquay, Jos Smits and Matthijs Blankesteijn

Structural and Functional Adaptations of the Heart after Coronary Artery Ligation in the Mouse; The Physiological Genomics of the Critically Ill Mouse. Edited by Can Ince; Basic Science for the Cardiologist; Kluwer Academic Publishers Boston/Dordrecht/London; Chapter 16, page 211-224, 2003

Anticles

Tijl De Celle, Peter Heeringa, Agnieska Strzelecka, Aalt Bast, Jos Smits, Ben Janssen; Sustained Protective Effects of 7 - Monohydroxyethylrutoside in an in mo model of Cardiac Ischemia-Reperfusion; European Journal of Pharmacology* 2004, 494(2-3): 205-212

Tijl De Celle, Jack P. Cleurjens, W. Matthijs Blankesteijn, Jacques J. Debets, Jos F. Smits \& Ben J. Janssen; Long- term Structural and Functional Consequences of Cardiac Ischemia/Reperfusion Injury in wivo in Mice; Experimental Physiology; 2004, $89(5): 605-615$

Tij] De Celle, Frank Vanrobaeys, Peter Lijnen, Marthijs Blankesteijn, Jozef Van Beeumen, Bart Devreese, Jos Smits, Ben Janssen; Alterations in Mouse Myocardial; Proteome after in wivo Myocardial Infarction: Ischaemia versus Ischaemia-reperfusion; Experimental Physiology; 2005,

Ben J.A. Janssen, Tijl De Celle, Jacques J.M. Debets, Agnieszka E. Brouns, Michael F". Callahan and Thomas L. Smith; Effects of Anesthetics on Systemic Hemodynamics in Mice; Am. J. Physiol. Heart Circ. Physiol. 2004 Oct;287(4):H1618-24

Jos B.G. Paquay, Tijl De Celle, Gregorio E. Fazzi, Jack P.M. Cleutjens, Hans Duinel, Ben J.A. Janssen, Jo G.R. De Mey, Jos F.M. Smits and W. Mathijs Blankesteijn; Inverse Relation between Contractile Properties and Dilatation of Myocardial Infatct Tissue (in preparation) 